\author{
Lucas Nery Padilha
}

\title{
ANÁLISE COMPARATIVA DE ESTRATÉGIAS PARA REGULAÇÃO DE TENSÃO EM SISTEMAS DE DISTRIBUIÇÃO DE ENERGIA ELÉTRICA NA PRESENÇA DE GERADORES DISTRIBUÍDOS
}

Dissertação apresentada à Escola de Engenharia de São Carlos da Universidade de São Paulo, como parte dos requisitos para obtenção do título de Mestre em Ciências, Programa de Engenharia Elétrica

Área de Concentração: Sistemas Elétricos de Potência Orientador: Prof. Dr. José Carlos de Melo Vieira Júnior 
AUTORIZO A REPRODUÇĀO E DIVULGAÇĀO TOTAL OU PARCIAL DESTE TRABALHO, POR QUALQUER MEIO CONVENCIONAL OU ELETRÔNICO, PARA FINS DE ESTUDO E PESQUISA, DESDE QUE CITADA A FONTE.

Ficha catalográfica preparada pela Seção de Tratamento da Informaçāo do Serviço de Biblioteca - EESC/USP

P123a

Padilha, Lucas Nery

Análise comparativa de estratégias para regulação de tensāo em sistemas de distribuiçāo de energia elétrica na presença de geradores distribuidos / Lucas Nery Padilha ; orientador José Carlos de Melo Vieira Júnior. -- São Carlos, 2010.

Dissertaçāo (Mestrado-Programa de Pós-Graduaçāo em Engenharia Elétrica e Área de Concentraçāo em Sistemas Elétricos de Potência) -- Escola de Engenharia de Sāo Carlos da Universidade de São Paulo, 2010.

1. Redes de distribuiçāo de energia elétrica.

2. Cogeraçāo de energia elétrica. 3. Regulaçāo de tensāo. 4. Geração distribuída. 5. Dispositivos reguladores de tensāo. 6. Otimizaçāo nāo-linear. I. Título. 


\section{FOLHA DE JULGAMENTO}

Candidato: Engenheiro LUCAS NERY PADILHA.

Dissertação defendida e julgada em 02/07/2010 perante a Comissão Julgadora:

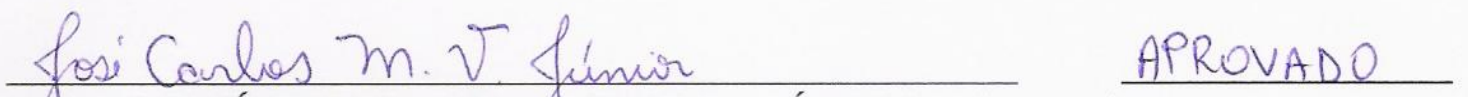
Prof. Dr. JOSÉ CARLOS DE MELO VIEIRA JÚNIOR - (Orientador) (Escola de Engenharia de São Carlos/USP)

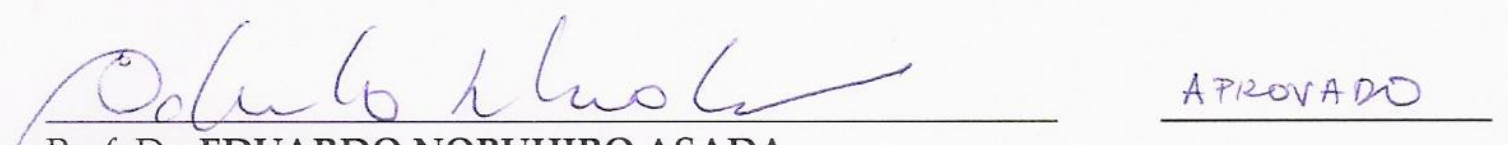

Prof. Dr. EDUARDO NOBUHIRO ASADA

(Escola de Engenharia de São Carlos/USP)

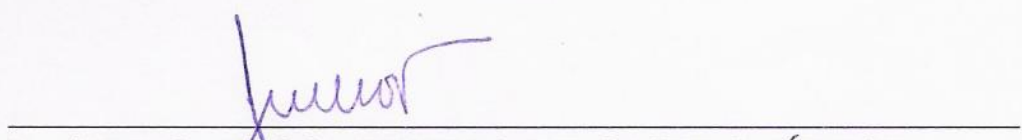

APROVADO

Prof. Dr. CARLOS ALBERTO DE CASTRO JÚNIOR

(Universidade Estadual de Campinas/UNICAMP)

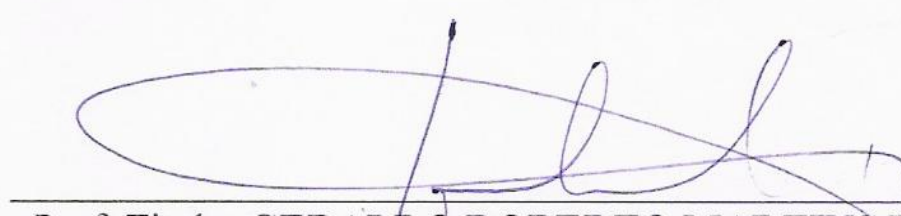

Prof. Titular GERALDO ROBERTO MARTINS DA COSTA

Coordenador do Prograna de Pós-Graduação em Engenharia Elétrica e Presidente da Comissão de Pós-Graduação 



\section{Agradecimentos}

Durante esta jornada, muitas pessoas me ajudaram a superar e sobrepor todas as dificuldades que surgiram, desde os momentos de fraqueza e incerteza do sucesso aos mais difíceis desafios técnicos, e das quais o apoio e incentivo me deram ânimo e coragem para continuar esta caminhada.

Agradeço primeiramente ao meu pai (Sérgio), minha mãe (Célia), e minha irmã (Juliana), pelo amor e apoio incondicional, não medindo esforços para que eu chegasse e concluísse mais esta etapa da minha vida.

À minha namorada (Daiane) que acompanhou de perto meus esforços e me deu conforto com seus gestos de amor e carinho.

Ao Prof. Dr. José Carlos de Melo Vieira Júnior, pelo apoio, atenção, disponibilidade, amizade e orientação durante todo o Mestrado.

Ao colega e Dr. Marcos J. Rider pela ajuda sincera no desvendar dos softwares necessários para a realização das simulações e conclusão deste trabalho.

Aos amigos do Laboratório de Sistemas de Energia Elétrica - LSEE (Breno, Daniel, Etienne, Gerson, Hermes, Janison, Marcelo, Monaro, Patrick, Sérgio, Ulisses, Vinicius, Wesley), dos quais jamais me esquecerei, pela amizade, apoio e incentivo.

Aos amigos dos demais laboratórios (Aldir, Alexandre, Chiesse, Eduardo, Gustavo, Helson e Valdemir).

Aos amigos da Bahia, que compartilharam de momentos de alegria e saudades durante minha estadia em São Carlos.

Ao Departamento de Engenharia Elétrica da Escola de Engenharia de São Carlos da Universidade de São Paulo, pela oportunidade de realização do curso de Mestrado.

Ao Conselho Nacional de Desenvolvimento Científico e Tecnológico - CNPq pela concessão da bolsa de Mestrado. 

"Tudo na vida acontece no momento certo, quando tem de ocorrer. Assim como a fruta sempre amadurece no seu devido tempo, na hora que tem de acontecer".

Maria Célia Nery Padilha 



\section{Sumário}

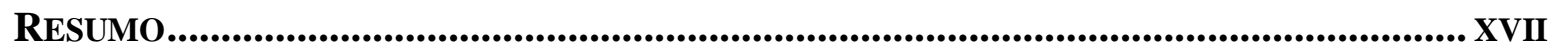

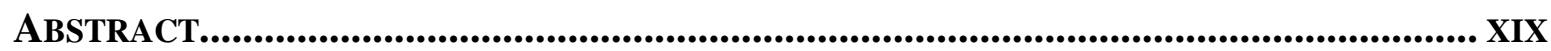

CAPÍTULO 1 .......................................................................................................................... 1

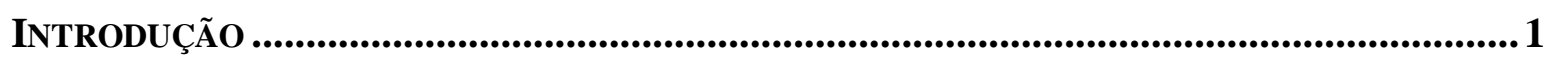

1.1 Objetivo do Trabalho ............................................................................. 4

1.2 Organização do Trabalho .................................................................................5

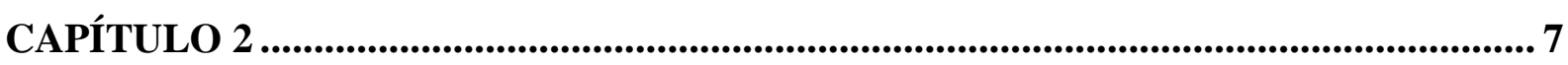

Regulação de Tensão em Sistemas de Distribuição de Energia Elétrica

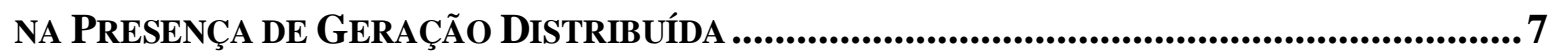

2.1 Dispositivos de Regulação de Tensão ...........................................................8

2.1.1 Banco de Capacitores ...................................................................... 8

2.1.2 Transformadores com Comutação de Tap .......................................... 10

2.1.3 Autotransformadores Reguladores de Tensão .................................... 14

2.2 Geradores Distribuídos................................................................................ 16

2.2.1 Impactos no Perfil de Tensão e Perdas Elétricas …………………...... 17

2.2.2 Operação dos Mecanismos de Controle de Tensão .............................. 21

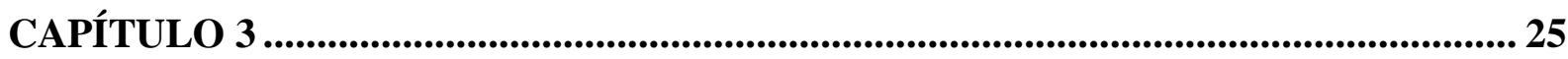

MÉTodo Computacional e Modelagem do Sistema Elétrico..................................25

3.1 Programação Matemática e Otimização ..................................................... 25

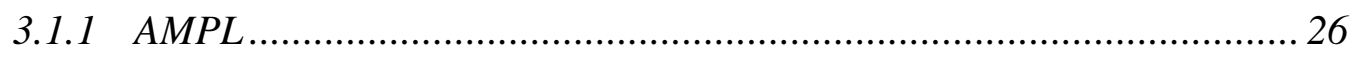

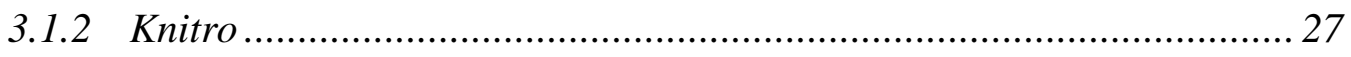

3.1.2.1 Visão Geral dos Problemas ................................................................. 28

3.1.2.2 Exemplo de Problema de Otimização Modelado no AMPL e Knitro....... 28

3.1.2.3 Solvers do Pacote Knitro......................................................................... 31

3.1.2.4 Branch and Bound ............................................................................... 32

3.2 Modelagem dos Componentes do Sistema Elétrico .................................. 38

3.2.1 Modelagem dos Elementos do Sistema Elétrico de Distribuição........... 40

3.2.1.1 Linhas de Distribuição ........................................................................... 40

3.2.1.2 Transformador da Subestação com Comutador de Taps sob Carga.......... 41

3.2.1.3 Transformador Regulador de Tensão................................................... 41

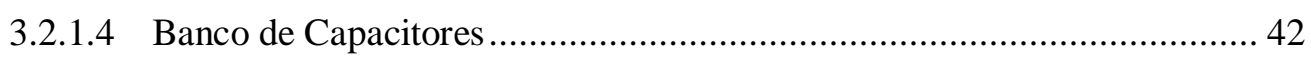


3.2.1.5 Geradores Síncronos Distribuídos ...................................................... 42

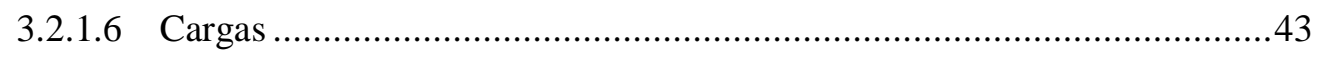

CAPÍTULO 4 ................................................................................................................. 47

ESTRATÉgIAS de OPERAÇÃo PARA OS DisPositivos REguladores de TENSÃo EM

SISTEMAS DE DISTRIBUIÇÃO COM GD ......................................................................... 47

4.1 Filosofia de Operação dos Geradores Distribuídos ................................. 47

4.1.1 Gerador Distribuído como Regulador de Tensão .............................. 48

4.1.2 Gerador Distribuído como Regulador de Potência Reativa................. 49

4.2 Formulação Matemática do Problema de Otimização ......................... 50

4.2.1 Minimização dos Desvios de Tensão ................................................ 51

4.2.2 Minimização das Perdas Elétricas ................................................. 55

4.3 Considerações Finais ............................................................................55

CAPÍTULO 5 .............................................................................................................. 57

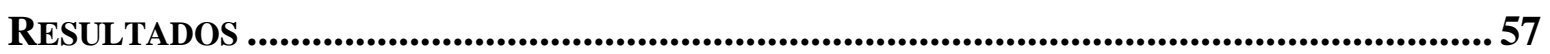

5.1 Sem Geradores Distribuídos ......................................................58

5.2 Geradores com Controle PV .........................................................6 64

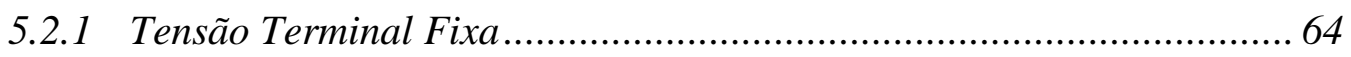

5.2.2 Tensão Terminal Variável ........................................................... 72

5.3 Geradores com Controle PQ .........................................................8 80

5.3.1 Potência Ativa Fixa .......................................................................... 80

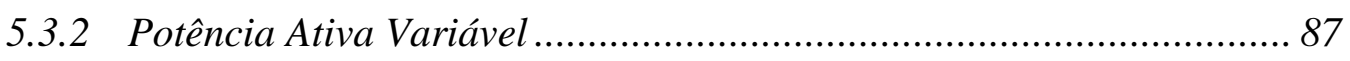

5.4 Considerações Finais .........................................................................96

CAPÍTULO 6 .................................................................................................................. 99

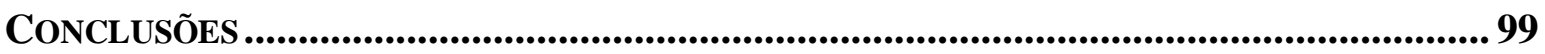

6.1 Considerações Finais ......................................................................99

6.2 Sugestões para Trabalhos Futuros..................................................... 100

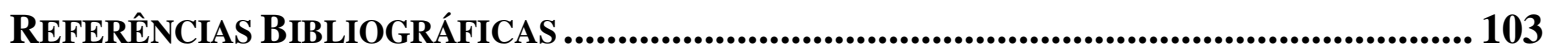

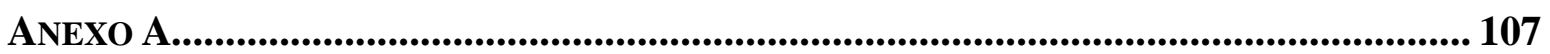

RESUltados dos Processos de OtimizaÇÃo ....................................................... 107

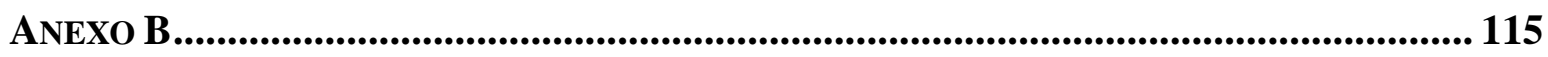




\section{Lista de Figuras}

Figura 2.1 - Capacitores instalados na barra da subestação e ao longo dos alimentadores (Fonte: [20]).

Figura 2.2 - Esquema do relé regulador automático de tensão......................................... 11

Figura 2.3 - Esquema do relé regulador de tensão com LDC (Fonte: [20])......................... 12

Figura 2.4 - Ajustes do relé regulador de tensão (Fonte: [20]).......................................... 13

Figura 2.5 - Reguladores de tensão instalados ao longo dos alimentadores (Fonte: [20])..... 15

Figura 2.6 - Regulador monofásico ANSI.................................................................. 15

Figura 2.7 - Conexões trifásicas para o autotransformador (Fonte: [20]). .......................... 16

Figura 2.8 - Fluxo de potência gerador-subestação......................................................... 18

Figura 3.1 - Exemplo de modelagem do arquivo "testproblem.mod"................................ 29

Figura 3.2 - Exemplo do arquivo de execução "testproblem.run". ...................................... 29

Figura 3.3 - Resolução do AMPL via CMD do arquivo "testproblem.run".......................... 30

Figura 3.4 - Exemplo de resolução de um problema utilizando o método de branch and

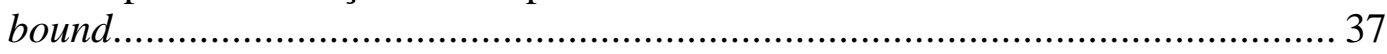

Figura 3.5 - Diagrama unifilar da rede de distribuição. .................................................. 39

Figura 3.6 - Modelo equivalente $\pi$ de uma linha de transmissão. ..................................... 40

Figura 3.7 - Modelo de transformador em fase......................................................... 41

Figura 3.8 - Circuito equivalente $\pi$ de um transformador em fase. ................................ 41

Figura 3.9 - Convenção de sinais para fluxos e injeções de potências................................... 42

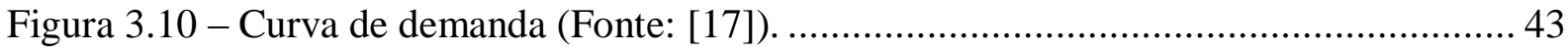

Figura 3.11 - Tipos de curvas de demanda (potência ativa e reativa).................................. 44

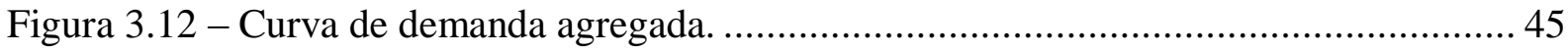

Figura 5.1 - Perfil de tensão para carregamento mínimo - SGD / min Tensão e min Perdas.

Figura 5.2 - Perfil de tensão para carregamento máximo - SGD / min Tensão e SGD / min Perdas.

Figura 5.3 - Perdas de totais energia sem geradores distribuídos: min Tensão e min Perdas.

Figura 5.4 - Perfil de tensão para carregamento mínimo - PV Fixo / min Tensão e min Perdas.

Figura 5.5 - Perfil de tensão para carregamento máximo - PV Fixo / min Tensão e min Perdas.

Figura 5.6 - Valores da função objetivo para o caso de minimização da variação da tensão - SGD e PV Fixo.

Figura 5.7 - Somatório dos desvios das tensões nodais - SGD e PV Fixo. 
Figura 5.8 - Perdas de Energia - min Tensão e min Perdas.

Figura 5.9 - Perfil de tensão dos geradores operando com controle PV Variável / min Tensão.

Figura 5.10 - Perfil de tensão dos geradores operando com controle PV Variável / min Perdas.

Figura 5.11 - Perfil de tensão para carregamento mínimo - PV Variável / min Tensão e min Perdas.

Figura 5.12 - Perfil de tensão para carregamento máximo - PV Variável / min Tensão e min Perdas.

Figura 5.13 - Valores da função objetivo para o caso de minimização da variação da tensão - SGD, PV Fixo e PV Variável.

Figura 5.14 - Somatório dos desvios das tensões nodais - SGD, PV Fixo e PV Variável. .... 75

Figura 5.15 - Perdas de Energia - min Tensão e min Perdas. .76

Figura 5.16 - Perfil de tensão para carregamento mínimo - PQ Fixo / min Tensão e min Perdas.

Figura 5.17 - Perfil de tensão para carregamento máximo - PQ Fixo / min Tensão e min Perdas.

Figura 5.18 - Valores da função objetivo para o caso de minimização da variação da tensão - SGD, PV Fixo, PV Variável e PQ Fixo.

Figura 5.19 - Somatório dos desvios das tensões nodais - SGD, PV Fixo, PV Variável e PQ Fixo.

Figura 5.20 - Perdas de Energia - min Tensão e min Perdas.

Figura 5.21 - Potência gerada pelos geradores operando com controle PQ Variável / min Tensão.

Figura 5.22 - Potência gerada pelos geradores operando com controle PQ Variável / min Perdas.

Figura 5.23 - Perfil de tensão para carregamento mínimo - PQ Variável / min Tensão e min Perdas.

Figura 5.24 - Perfil de tensão para carregamento máximo - PQ Variável / min Tensão e min Perdas.

Figura 5.25 - Valores da função objetivo para o caso da minimização da variação de tensão - SGD, PV Fixo, PV Variável, PQ Fixo e PQ Variável.

Figura 5.26 - Somatório dos desvios das tensões nodais - SGD, PV Fixo, PV Variável, PQ Fixo e PQ Variável.

Figura 5.27 - Perdas de Energia - min Tensão e min Perdas. 


\section{Lista de Tabelas}

Tabela 2.1 - Pontos de conexão em tensão nominal superior a $1 \mathrm{kV}$ e inferior a $69 \mathrm{kV}$ (regime permanente)........................................................................... 19

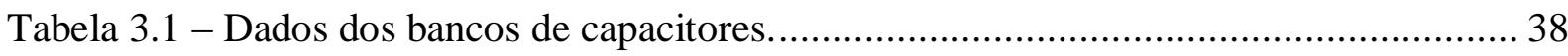

Tabela 3.2 - Dados dos transformadores de potência....................................................... 38

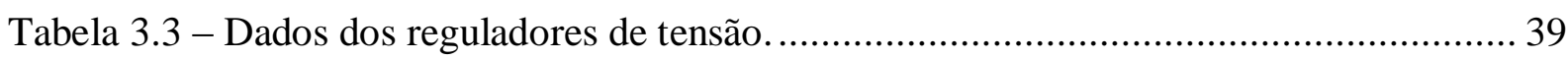

Tabela 3.4 - Tipos e valores de potência-base para as cargas........................................... 45

Tabela 5.1 - Configuração dos bancos de capacitores - SGD / min Tensão.......................... 60

Tabela 5.2 - Configuração dos bancos de capacitores - SGD / min Perdas.......................... 61

Tabela 5.3 - Configuração dos taps do transformador da subestação - SGD / min

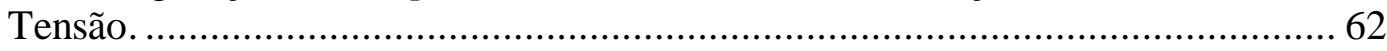

Tabela 5.4 - Configuração dos taps do transformador da subestação - SGD / min

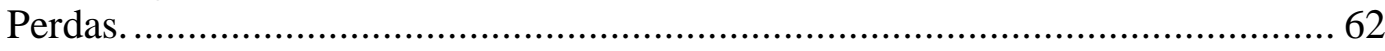

Tabela 5.5 - Configuração dos taps dos reguladores de tensão - SGD / min Tensão............. 63

Tabela 5.6 - Configuração dos taps dos reguladores de tensão - SGD / min Perdas. ............. 64

Tabela 5.7 - Resultados de fator de potência e carregamento dos geradores e configuração dos bancos de capacitores - PV Fixo / min Tensão.

Tabela 5.8 - Dados de fator de potência, carregamento e dos bancos de capacitores -

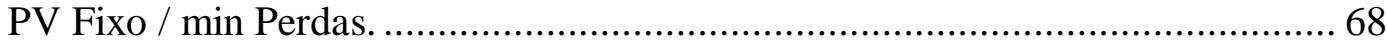

Tabela 5.9 - Configuração dos taps dos transformadores da subestação - PV Fixo / min Tensão.

Tabela 5.10 - Configuração dos taps do transformador da subestação - PV Fixo / min Perdas.

Tabela 5.11 - Configuração dos taps dos reguladores de tensão - PV Fixo / min $\Delta$ V .......... 71

Tabela 5.12 - Configuração dos taps dos reguladores de tensão - PV Fixo / min Perdas. ..... 71

Tabela 5.13 - Configuração dos bancos de capacitores - PV Variável / min Tensão............. 77

Tabela 5.14 - Configuração dos bancos de capacitores - PV Variável / min Perdas. ............ 77

Tabela 5.15 - Configuração dos taps dos transformadores da subestação - PV Variável / min Tensão.

Tabela 5.16 - Configuração dos taps dos transformadores da subestação - PV Variável / min Perdas.

Tabela 5.17 - Configuração dos taps dos reguladores de tensão - PV Variável / min Tensão.

Tabela 5.18 - Configuração dos taps dos reguladores de tensão - PV Variável / min Perdas.

Tabela 5.19 - Configuração dos bancos de capacitores - PQ Fixo / min Tensão. 84

Tabela 5.20 - Configuração dos bancos de capacitores - PQ Fixo / min Perdas...... 84 
Tabela 5.21 - Configuração dos taps dos transformadores da subestação - PQ Fixo / min Tensão.

Tabela 5.22 - Configuração dos taps dos transformadores da subestação - PQ Fixo / min Perdas.

Tabela 5.23 - Configuração dos taps dos reguladores de tensão - PQ Fixo / min Tensão..... 86

Tabela 5.24 - Configuração dos taps dos reguladores de tensão - PQ Fixo / min Perdas. ..... 87

Tabela 5.25 - Configuração dos bancos de capacitores - PQ Variável / min Tensão............. 92

Tabela 5.26 - Configuração dos bancos de capacitores - PQ Variável / min Perdas. ............ 93

Tabela 5.27 - Configuração dos taps dos transformadores da subestação - PQ Variável / min Tensão.

Tabela 5.28 - Configuração dos taps dos transformadores da subestação - PQ Variável / min Perdas.

Tabela 5.29 - Configuração dos tap dos reguladores de tensão - PQ Variável / min Tensão.

Tabela 5.30 - Configuração dos tap dos reguladores de tensão - PQ Variável / min Perdas. . 95

Tabela A.1 - Resultados para o caso SGD / min Tensão. 110

Tabela A. 2 - Resultados para o caso SGD / min Perdas. 110

Tabela A.3 - Resultados para a estratégia PV Fixo / min Tensão.

Tabela A.4 - Resultados para a estratégia PV Fixo / min Perdas.

Tabela A.5 - Resultados para a estratégia PV Variável / min Tensão.

Tabela A.6 - Resultados para a estratégia PV Variável / min Perdas.

Tabela A.7 - Resultados para a estratégia PQ Fixo / min Tensão.

Tabela A.8 - Resultados para a estratégia PQ Fixo / min Perdas.

Tabela A.9 - Resultados para a estratégia PQ Variável / min Tensão.

Tabela A.10 - Resultados para a estratégia PQ Variável / min Perdas. 114

Tabela B.1 - Dados das barras do sistema de 42 barras durante o período de 1 às 4 horas. .117

Tabela B. 2 - Dados das barras do sistema de 42 barras durante o período de 5 às 8 horas. .118

Tabela B.3 - Dados das barras do sistema de 42 barras durante o período de 9 às 10 horas.

Tabela B.4 - Dados das barras do sistema de 42 barras durante o período de 11 às 16 horas. 120

Tabela B.5 - Dados das barras do sistema de 42 barras durante o período de 17 às 20 horas. 121

Tabela B.6 - Dados das barras do sistema de 42 barras durante o período de 21 às 24 horas. 122

Tabela B.7 - Dados dos ramos do sistema de 42 barras. .123 


\section{Lista de Abreviaturas}

AMPL A Modeling Language for Mathematical Programming

ANEEL Agência Nacional de Energia Elétrica

ANSI American National Standards Institute

GD Geração Distribuída

IEEE Institute of Electrical and Electronics Engineers

LDC Line Drop Compensation

MME Ministério de Minas e Energia

NBR Norma da Associação Brasileira de Normas Técnicas

OLTC On-Load Tap Changer

PNT Perdas não-técnicas

PROINFA Programa de Incentivo às Fontes Alternativas de Energia Elétrica

PT Perdas técnicas 


\section{Resumo}

Padilha. L. N. Análise Comparativa de Estratégias para Regulação de Tensão em Sistemas de Distribuição de Energia Elétrica na Presença de Geradores Distribuídos, 2010. 143 f.. Dissertação (Mestrado em Engenharia Elétrica) - Escola de Engenharia de São Carlos da Universidade de São Paulo, São Carlos.

Para que a instalação de geração distribuída possa de fato beneficiar a operação das redes de distribuição e de subtransmissão de energia elétrica, seus impactos técnicos devem ser cuidadosamente estudados, sobretudo em redes de distribuição, as quais foram inicialmente planejadas para operar com fluxo de potência unidirecional. Dentre esses impactos, a influência da geração distribuída na regulação da tensão é um aspecto de suma importância, pois está diretamente relacionada à qualidade do fornecimento da energia elétrica aos consumidores. Neste contexto, é importante conhecer e dispor de meios para controlar a interação entre esses geradores e os dispositivos convencionais de regulação de tensão (transformadores com comutadores de tap sob carga, bancos de capacitores e reguladores de tensão) para que a tensão de suprimento permaneça dentro da faixa de valores admissíveis. Assim, este projeto de pesquisa propõe uma análise comparativa entre diferentes estratégias de operação de dispositivos reguladores de tensão em sistemas de distribuição com a presença de geradores distribuídos. Algumas das metodologias discutidas aqui são bastante consolidadas e usualmente aplicadas na operação de sistemas de distribuição de energia elétrica e em trabalhos acadêmicos, enquanto outras são sugeridas por este mesmo trabalho. Tais estratégias são propostas como problemas de otimização não linear inteira mista em que se consideram diferentes modos de operação dos geradores distribuídos e duas funçõesobjetivo distintas, tratadas de forma independente: minimização dos desvios de tensão nas barras e minimização das perdas elétricas. Os resultados da aplicação de cada estratégia de operação são apresentados e é realizada uma análise qualitativa das vantagens e desvantagens de cada uma. Tem-se até o momento um conjunto de informações que podem servir de suporte na configuração de características operativas e definição de parâmetros de controle para o sistema de regulação de tensão das redes de distribuição de energia elétrica.

Palavras-Chave: regulação de tensão, geração distribuída, dispositivos reguladores de tensão, otimização. 


\section{Abstract}

Padilha. L. N. Comparative Analysis of Voltage Regulation Strategies in Power Distribution Systems with Distributed Generators, 2010. 143 p.. Dissertation (Master Degree in Electrical Engineering) - Escola de Engenharia de São Carlos da Universidade de São Paulo, São Carlos.

In order to assure that the installation of distributed generation would improve the operation of distribution and subtransmission networks, its technical impacts should be carefully studied, especially in distribution networks, which were originally designed to operate with unidirectional power flow. Among these impacts, the influence of distributed generation on voltage regulation is a very important aspect because it is directly related to the quality of electricity supply to the consumers. In this context, it is important to know and employ means of controlling the interaction between these generators and conventional voltage regulation devices (transformers with on-load tap changers, shunt capacitor banks and voltage regulators) assuring that the voltage supply remains within the range of permissible values. Thus, this work proposes a comparative analysis among different operational strategies of voltage regulation devices in distribution systems in the presence of distributed generators. Some of the methodologies discussed here are fairly consolidated and usually applied in power industry and academic researches, while others are suggested by this work. Such strategies are proposed as mixed integer nonlinear programming problems considering different operation modes of distributed generators and two different objective functions, treated independently: minimization of voltage deviations and minimization of power losses. The results of each operation strategy application are presented and a qualitative analysis of the advantages and disadvantages of each one is performed. So far, a set of information that may provide support to configure operating characteristics and define control parameters of voltage regulation system in power distribution networks has been generated.

Keywords: voltage regulation, distributed (embedded) generation, voltage regulation devices, optimization. 


\section{Capítulo 1}

\section{Introdução}

Geração distribuída é um conceito relacionado à instalação e operação de pequenas e médias unidades de geradores elétricos conectados diretamente à rede de distribuição e subtransmissão de energia elétrica. Nos últimos anos, fatores como a reestruturação do setor de energia elétrica em diversos países, a necessidade de aproveitamento de diferentes fontes primárias de energia como forma de diversificação da matriz energética, avanços tecnológicos na área de geração de energia elétrica, a maior conscientização sobre conservação ambiental e a necessidade de suprir a crescente demanda por energia elétrica têm provocado o aumento considerável do interesse por geração distribuída (GD) ([1]-[4]). Além desses fatores, principalmente com relação à necessidade de suprir a demanda de energia futura, também outras várias razões são incentivos para o aumento no interesse por geração distribuída em um ambiente desregulado. Entre elas, destacam-se ([5]):

- Prover independência e flexibilidade para o consumidor autoprodutor de energia elétrica na questão de planejamento e desenvolvimento de suas instalações, particularmente importante no caso de cargas críticas e sensíveis em um ambiente sujeito a interrupções e cortes;

- O custo da energia elétrica produzida por geração distribuída também vem caindo, ao ponto em que chega a se tornar competitivo com a energia elétrica que é fornecida pela rede de distribuição. Companhias elétricas incentivam então a adição de geração em pontos críticos da rede elétrica, particularmente em pontos próximos da carga. Isto pode resultar em uma economia significante em investimentos de infra-estrutura do sistema de distribuição elétrica, particularmente em expansão;

- Permite que autoprodutores de energia elétrica utilizem sua geração interna em períodos em que a tarifa de energia elétrica seja elevada, economizando desse modo na fatura de energia elétrica. Além disso, o excesso de energia pode ser comercializado com a concessionária de energia elétrica, gerando lucro; 
- Com a queda de custos das tecnologias de geração distribuída, produtores independentes de energia podem instalar unidades de geração e integrá-las à rede, realizando lucro através da venda de energia;

- O potencial de prover ao sistema de distribuição de energia elétrica alguns serviços auxiliares, como por exemplo, auxiliar no controle de tensão, na estabilidade da rede de distribuição, entre outros. Produtores independentes ou consumidores autoprodutores podem prover esses serviços.

A instalação desse tipo de geração, cuja capacidade nominal dos geradores varia de centenas de $\mathrm{kW}$ a dezenas de MW, deve ser criteriosamente analisada, a fim de identificar eventuais impactos negativos aos sistemas de distribuição de energia elétrica. Portanto, integrar pontos de geração a sistemas que, costumeiramente, possuíam apenas uma direção de fluxo de potência, isto é, sistemas radiais unidirecionais, pode ser uma tarefa árdua. Neste contexto, diversas questões devem ser consideradas, sejam elas comerciais, gerenciais, regulatórias, técnicas e operativas ([1]). Entre os principais fatores técnicos a considerar, destacam-se ([1]): perfil de tensão em regime permanente, estabilidade de tensão, estabilidade de ângulo, filosofia do sistema de proteção, transitórios de tensão, correntes de curto-circuito, distorção harmônica, ferro-ressonância e confiabilidade. Sobre esses fatores, ressalta-se que seu comportamento dependerá enormemente da quantidade e modo de operação da geração a ser instalada, do tipo de gerador a ser empregado e das características da rede elétrica ([1]).

Dada a crescente instalação de geradores distribuídos em todo o mundo, a tecnologia de geração mais empregada compreende os geradores síncronos, sobretudo em unidades de cogeração e pequenas centrais hidrelétricas ([1]). Isto se deve ao fato de que a tecnologia empregada para instalar fontes de energia baseadas em geradores síncronos já está consolidada. No Brasil, a expansão de unidades de geração distribuída baseada em geradores síncronos é um fato, e entre os mecanismos promotores de tal expansão estão os incentivos governamentais para a construção de novas pequenas centrais termelétricas e hidrelétricas, no papel do PROINFA (Programa de Incentivo às Fontes Alternativas de Energia Elétrica) ([6]). Também, segundo [7], os geradores síncronos apresentam os melhores benefícios ao perfil e estabilidade de tensão dos sistemas de distribuição dentre outras fontes de geração distribuída. Por essas razões, os geradores síncronos são parte do objeto de estudo deste trabalho.

Neste cenário em que a inserção de geração distribuída aumenta a complexidade da operação e planejamento dos sistemas de distribuição de energia elétrica, as concessionárias devem continuar a garantir o fornecimento de energia elétrica dentro dos padrões de qualidade e confiabilidade estabelecidos pelos órgãos reguladores do setor elétrico. Portanto, 
novas metodologias de operação e de planejamento devem ser incorporadas às práticas vigentes dentro dessas empresas. Dentre tais práticas, este trabalho mantém o foco na regulação de tensão de sistemas de distribuição e nos métodos e mecanismos empregados para a manutenção do perfil de tensão de regime permanente dentro dos padrões de qualidade aceitáveis, e quais os impactos da integração de geradores distribuídos na regulação de tensão desses sistemas.

A regulação de tensão em sistemas de distribuição de energia elétrica é normalmente realizada com o emprego de comutadores automáticos dos taps nos transformadores localizados na subestação da concessionária, transformadores reguladores de tensão inseridos nos alimentadores e instalação de bancos de capacitores para provimento de potência reativa ([1], [8], [9]). Com a instalação de geradores distribuídos, os sistemas de distribuição podem perder sua característica de fluxo de potência unidirecional, além disso, acabam por resultar em uma elevação das tensões nodais, que pode causar a violação dos limites de sobretensão de regime permanente ([1], [8], [10]), ocasionando danos às instalações dos consumidores finais. Logo, em relação à regulação de tensão, é imprescindível a coordenação entre os dispositivos de controle de tensão já instalados nas redes elétricas mediante os geradores distribuídos inseridos nestes sistemas, para que os benefícios da geração distribuída possam ser aproveitados em sua plenitude ([8], [10]).

A estratégia mais adequada para realizar o controle de tensão de forma coordenada entre os equipamentos envolvidos deveria considerar a capacidade dos geradores distribuídos em prover os chamados serviços auxiliares, ou serviços ancilares ([11]). Esses serviços auxiliares são providos em adição à geração de potência ativa e podem ser definidos como todas aquelas atividades para apoiar a transmissão e distribuição de energia elétrica enquanto se mantém uma operação segura e confiável do sistema elétrico. São exemplos de serviços auxiliares: a regulação de freqüência, a garantia da estabilidade do sistema, manutenção das reservas de geração e transmissão, fornecimento/consumo de potência reativa para controle de tensão, e atenuação dos distúrbios gerando uma melhora da qualidade de energia.

Em relação à capacidade de controle de tensão por parte dos geradores distribuídos, há a seguinte dificuldade: o gerador distribuído, quando operado de forma a manter sua tensão terminal constante, pode contribuir significativamente para a manutenção do perfil de tensão dentro dos níveis aceitáveis ([12], [13]), no entanto, isso pode se dar às custas de um baixo fator de potência no ponto de conexão entre o gerador e a rede de distribuição. Assim, a geração distribuída, operando com baixo fator de potência, estaria sujeita à cobrança extra referente ao excesso de potência reativa em circulação. Tal possibilidade desencoraja os 
proprietários de geradores distribuídos a contribuírem com o controle de tensão, e os mesmos são estimulados a manter o fator de potência unitário no ponto de conexão com a rede elétrica ([1]). Atualmente, não há uma legislação ou consenso, e diferentes guias e práticas são empregados por concessionárias distintas sobre qual a melhor filosofia de controle a adotar para o sistema de excitação dos geradores síncronos distribuídos, seja este configurado como regulador de tensão (tensão terminal constante) ou como regulador de fator de potência (fator de potência constante) ([13]).

\subsection{Objetivo do Trabalho}

Diante da importância do tema, este trabalho tem como objetivo propor estratégias e analisar comparativamente as mesmas com outras já consolidadas para estabelecer condições de operação viáveis dos dispositivos convencionais de controle de tensão em redes de distribuição de energia elétrica mediante a presença de geradores síncronos distribuídos. Entre os dispositivos têm-se: o comutador de tap sob carga do transformador da subestação, transformadores reguladores de tensão nos alimentadores e bancos de capacitores. As estratégias de regulação de tensão considerarão diferentes configurações operativas dos geradores distribuídos e curvas de carga agregada típicas de conjuntos de consumidores.

O problema a ser analisado será formulado como um problema de otimização. São propostos dois estudos em paralelo, um em que a função objetivo é minimizar as variações de tensão nos barramentos da rede de distribuição e outro que propõe minimizar as perdas técnicas de energia nos alimentadores da rede elétrica sob estudo. A razão em efetuar os estudos considerando duas funções-objetivo distintas se baseia no fato de que tipicamente a totalidade das perdas elétricas nos sistemas de distribuição dificilmente ultrapassa $20 \%$ da carga instalada, segundo [14]. Logo, para diferentes cenários de operação da rede de distribuição, será avaliado se o fato de optar pela minimização das variações de tensão provocará um aumento substancial nas perdas elétricas, em relação à estratégia que visará a minimização das perdas.

As variáveis de controle empregadas neste trabalho são os taps dos transformadores reguladores de tensão (transformador da subestação e reguladores de tensão do alimentador), taps dos bancos de capacitores chaveáveis, e também a tensão terminal e potência ativa dos geradores distribuídos, dependendo do modo de controle do seu sistema de excitação.

Esse é um problema de programação não-linear com características de programação inteira mista devido à presença de variáveis discretas. Tanto a função objetivo quanto algumas 
das restrições são funções não-lineares. Por sua vez, cada uma das variáveis de tap (transformadores e bancos de capacitores) apenas pode assumir valores específicos prédeterminados na modelagem do sistema, enquanto que as outras variáveis, como por exemplo, as tensões nas barras, serão contínuas. As restrições desse problema são basicamente os limites de tensão do sistema elétrico, faixa de variação de taps, capacidade de compensação dos bancos de capacitores e geradores instalados, capacidades nominais dos geradores, e as equações do balanço de potência nos nós do sistema elétrico.

Uma característica marcante deste trabalho é expor a possibilidade, mediante estudos técnicos, do emprego da capacidade do gerador síncrono distribuído em controlar a tensão da barra em que se encontra conectado, buscando sempre maximizar os benefícios do mesmo para a operação da rede elétrica. Os resultados obtidos com as análises efetuadas nesta dissertação são úteis para que órgãos reguladores e/ou concessionárias de distribuição de energia elétrica entendam o impacto provocado pela instalação desses geradores na regulação de tensão em suas redes e com isso possam estabelecer um conjunto de recomendações técnicas para a operação dos mesmos. Além disso, serão apontadas as vantagens e desvantagens das estratégias de operação analisadas, as quais são baseadas na minimização das perdas elétricas e na minimização dos desvios de tensão.

\subsection{Organização do Trabalho}

A organização do trabalho é apresentada a seguir.

No Capítulo 2, uma breve introdução sobre os dispositivos de regulação de tensão é apresentada. Faz-se uma discussão sobre os impactos dos níveis de tensão na presença de geração distribuída e como o modo de controle da excitatriz dos geradores influencia na regulação de tensão em sistemas de distribuição. Apresenta-se uma revisão bibliográfica sobre o conceito e estratégias de controle de tensão em regime permanente.

No Capítulo 3, a ferramenta utilizada para realizar o cálculo de fluxo de potência ótimo é brevemente descrita. Também é apresentado o sistema de distribuição adotado para análise e os modelos de curvas de demanda.

No Capítulo 4 são descritas as metodologias e as estratégias de operação dos dispositivos reguladores de tensão e dos geradores distribuídos, bem como as formulações matemáticas empregadas.

No Capítulo 5, os resultados das simulações e as análises dos mesmos são apresentados. 
No Capítulo 6 são expostos os comentários e as conclusões deste trabalho, bem como são apresentadas algumas sugestões para trabalhos futuros.

Finalmente, os anexos A e B apresentam os resultados completos das simulações realizadas nesta dissertação, e os dados dos ramos do sistema elétrico, respectivamente. 


\section{Capítulo 2}

\section{Regulação de Tensão em Sistemas de Distribuição de Energia Elétrica na Presença de Geração Distribuída}

A integração de unidades de geração distribuída em redes de distribuição, até então conhecidas como redes passivas, acarreta diversos impactos técnicos, alguns podendo ser benéficos enquanto outros prejudiciais, afetando condições operacionais do sistema. Pode-se dizer que os então descritos sistemas passivos se transformam em sistemas elétricos ativos com a inclusão dos geradores distribuídos. Também as práticas e processos que incluem desde o planejamento da expansão futura e/ou recondicionamento das redes de distribuição, bem como sua operação segura e eficiente são afetados com a inserção de geração distribuída.

Segundo Salman ([15]), estudos mostram que a presença de geração distribuída pode (i) aumentar o nível de curto-circuito fazendo-se necessário a inclusão de reforços na proteção do sistema elétrico, (ii) requerer adaptação de novas práticas de proteção com a finalidade de prover adequada proteção aos geradores distribuídos e ao sistema associado contra condições anormais incluindo faltas e ilhamento, (iii) introduzir harmônicos na tensão ou na corrente, (iv) introduzir problemas relacionados à estabilidade e confiabilidade, (v) causar flutuações de tensão, (vi) alterar as perdas do sistema e (vii) interferir com os mecanismos de controle da magnitude de tensão de sistemas de distribuição. Dentre os impactos citados, os três últimos serão uma importante parte do estudo proposto. Busca-se, portanto, estratégias adequadas de operação dos dispositivos reguladores de tensão e geradores distribuídos visando eliminar ou abrandar possíveis efeitos indesejáveis desses impactos.

Com relação a esses impactos, os níveis de tensão em localidades de carga devem ser mantidos dentro de limites especificados por norma, os quais são obtidos principalmente por dispositivos de controle de tensão. O tópico a seguir apresenta uma discussão a respeito desses dispositivos. 


\subsection{Dispositivos de Regulação de Tensão}

A operação de dispositivos de regulação de tensão em sistemas sob influência de geradores distribuídos não é uma questão recente, como pode ser observado em [11] e [16]. Isso caracteriza não haver uma solução plenamente eficaz em relação ao assunto e que ainda há espaço para a proposição de novos guias, técnicas e/ou aperfeiçoamento daquelas já existentes.

São incluídos no processo de operação dos dispositivos de regulação de tensão frente à presença de geradores distribuídos, a posição dos taps do comutador automático de taps no transformador da subestação, dos taps dos bancos de capacitores e dos taps dos reguladores de tensão, e/ou o modo de controle da excitatriz do gerador síncrono (funcionando como regulador de tensão, regulador de fator de potência ou potência reativa constante). Durante a variação da carga ligada aos alimentadores de distribuição, de carga leve à carga pesada, esses taps devem variar, assim como os parâmetros de controle dos sistemas de excitação dos geradores, para que as tensões nodais de todos os consumidores permaneçam dentro dos limites admissíveis ([17]). Nos sub-tópicos seguintes são dispostas breves explanações sobre os dispositivos reguladores de tensão mais comumente encontrados nos sistemas de distribuição de energia elétrica.

\subsubsection{Banco de Capacitores}

Bancos de capacitores são mais comumente usados em sistemas de distribuição de energia elétrica para correção do fator de potência, podem ser parte integrante de filtros de harmônicos, provendo suporte de potência reativa e contribuindo na regulação de tensão. Esses são equipamentos de custos acessíveis, fáceis de instalar, requerem pouca manutenção, e ocasionam perdas muito baixas. Dentre estas, estão as razões pelas quais eles são demasiadamente usados em sistemas de distribuição. Bancos de capacitores são construídos com capacidade (kvar) relativamente baixas por motivos econômicos e de engenharia. Unidades individuais são então combinadas em conjuntos de bancos para obter um aumento das taxas de suprimento. Eles são adicionados em pequenos ou grandes conjuntos a fim de sanar demandas operacionais ([18]).

Esses componentes do sistema elétrico de potência podem ampliar a eficiência da rede de distribuição quando corretamente integrados ao sistema. Seus benefícios incluem desde a redução da queda de tensão nas linhas de distribuição a uma diminuição significativa das 
perdas de potência ativa. A fim de regular os níveis de tensão, bancos de capacitores são conectados em paralelo ou em série com as cargas. Capacitores em paralelo compensam correntes reativas, as quais reduzem a corrente total na linha. Correntes reduzidas causam menores quedas de tensão na linha o que resulta em um aumento das tensões nodais. Adicionalmente, correntes reduzidas aumentam a capacidade do sistema de potência, fazendo o mesmo suprir mais cargas, o que pode substituir futuros investimentos no aumento da capacidade do sistema elétrico ([18], [19]).

Outro benefício muito importante está ligado à correção do fator de potência das cargas do sistema, proporcionando que o mesmo fique dentro dos limites estabelecidos por lei, evitando pagamentos adicionais na fatura de energia elétrica. Porém, todos esses melhoramentos no sistema só são alcançados através de muitas análises e cautelosos estudos no dimensionamento e operação destes equipamentos, mas principalmente, na alocação destes dispositivos na rede de distribuição. Atribuições errôneas podem acarretar diversos problemas, entre estes, sobretensões e maiores índices de perdas nas linhas.

O emprego dos bancos de capacitores pode se dar tanto em sistemas de distribuição quanto de transmissão. Estes equipamentos podem ser fixos, fornecendo suporte constante, ou chaveados. Bancos fixos são mais fáceis de serem dimensionados e instalados, além de mais baratos ([20]).

Nos sistemas de distribuição, o emprego dos bancos de capacitores ocorre tanto na barra da subestação $\left(\mathrm{C}_{\text {shunt }}\right)$ quanto ao longo dos alimentadores $(\mathrm{C} 1)$, como pode ser visto na Figura 2.1.

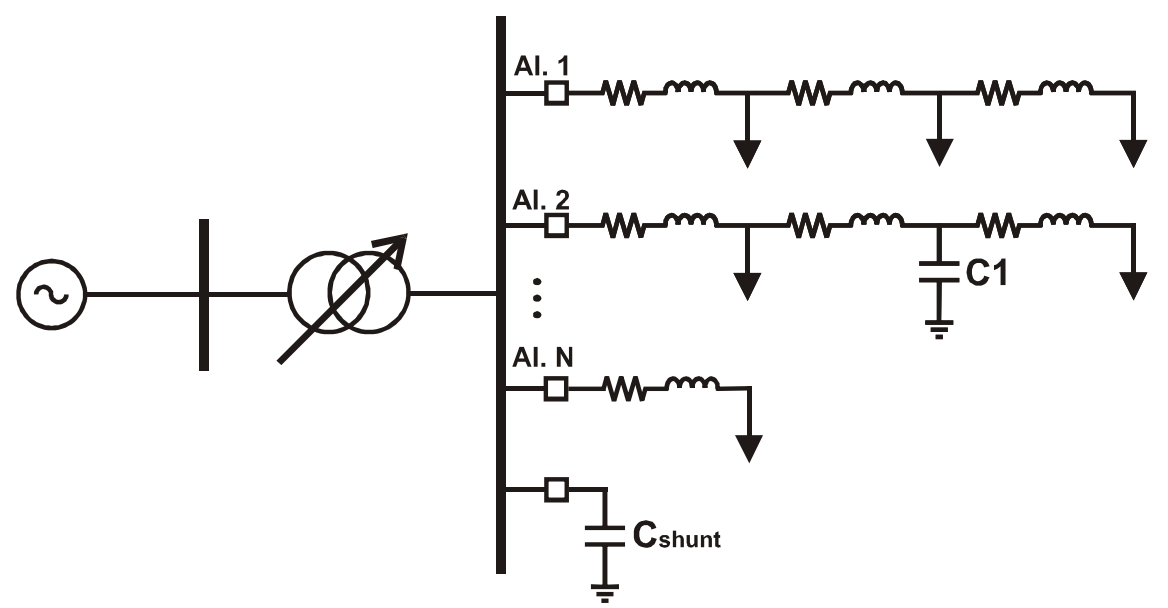

Figura 2.1 - Capacitores instalados na barra da subestação e ao longo dos alimentadores (Fonte: [20]).

A operação de bancos de capacitores é extremamente dependente da necessidade do sistema. Por isso, raramente eles são acionados juntos e/ou em sua totalidade em uma única 
operação. Com relação a sua instalação, como citado anteriormente, os bancos de capacitores podem ser instalados em paralelo ou em série. Quando instalados em paralelo, estes equipamentos compensam potência reativa elevando a tensão no alimentador. Em série, funcionam como um regulador de tensão comandado pela corrente e compensando a reatância da linha ([19]).

Em carga leve, a presença de bancos de capacitores fixos pode elevar a tensão acima dos limites, portanto faz-se necessário a presença de bancos de capacitores chaveados. As operações de chaveamento de bancos de capacitores em subestação são acompanhadas diariamente por sistemas supervisórios remotos ou por controladores locais. Com a diminuição dos custos das tecnologias, muitos sistemas utilizam bancos de capacitores com controle automatizado ([20]).

Com relação ao controle de capacitores chaveados, diversas são as estratégias. Estas incluem hora programada ou tempo de atraso (delay), temperatura ambiente, tensão (o controlador estabelece larguras de faixas e limites para diminuir a quantidade de operações de chaveamento, baseando-se na medição da tensão), medidas de potência reativa, fator de potência, corrente, e/ou uma combinação de todas essas estratégias ([18]). Porém, as principais estratégias usadas para o controle remoto de bancos de capacitores são: despacho realizado pelo operador, despacho diário programado, despacho mediante medições de potência reativa na subestação e despacho utilizando combinação entre medições de variáveis na subestação e ao longo do alimentador ([20]).

\subsubsection{Transformadores com Comutação de Tap}

Flutuações de tensão são principalmente originadas pela variação ao longo do dia no carregamento da rede de distribuição. Para contornar tal fato, os transformadores (principalmente aqueles instalados em subestações primárias) possuem um mecanismo comutador de tap sob carga - On-Load Tap Changer (OLTC). Eles promovem um pequeno ajuste, regulando tanto a magnitude de tensão, normalmente numa faixa de $\pm 10,0 \%$, e/ou alterando o ângulo de fase da tensão de linha ([17], [20]). Estes dispositivos são muito importantes no sistema de potência ajudando a prevenir sub/sobretensões inadmissíveis aos consumidores e aos agentes reguladores de energia elétrica.

A operação de comutação de tap pode ser entendida como segue: por meio de uma chave rotatória com um esquema de passo frente/reverso, o tap varia a relação entre o número de espiras dos enrolamentos do lado primário e secundário do transformador. O controle dessa 
chave é comandado por um relé regulador automático de tensão, também conhecido como "relé 90", que monitora e analisa a tensão do lado secundário do transformador e comanda as operações de comutação de tap mediante configurações previamente programadas, visando manter a mesma em um nível constante e mais próxima da referência ([20]). Essa comutação é automática e operada por motores que respondem ao comando desse relé para ajustar a tensão dentro de um nível especificado. O tempo morto de atuação (temporização) é inclusa para evitar o uso desnecessário devido à alta freqüência de comutações de tap ([19], [20]).

O mais simples arranjo de controle de tensão, como o apresentado na Figura 2.2, já se mostra bastante robusto. Não existe motivo para este arranjo ser afetado por mudanças relacionadas ao fator de potência ou mesmo uma reversão de potência reativa. Seu fator limitante inclui desconsideração da queda de tensão ao longo do alimentador e também a operação em paralelo de transformadores ([20]).

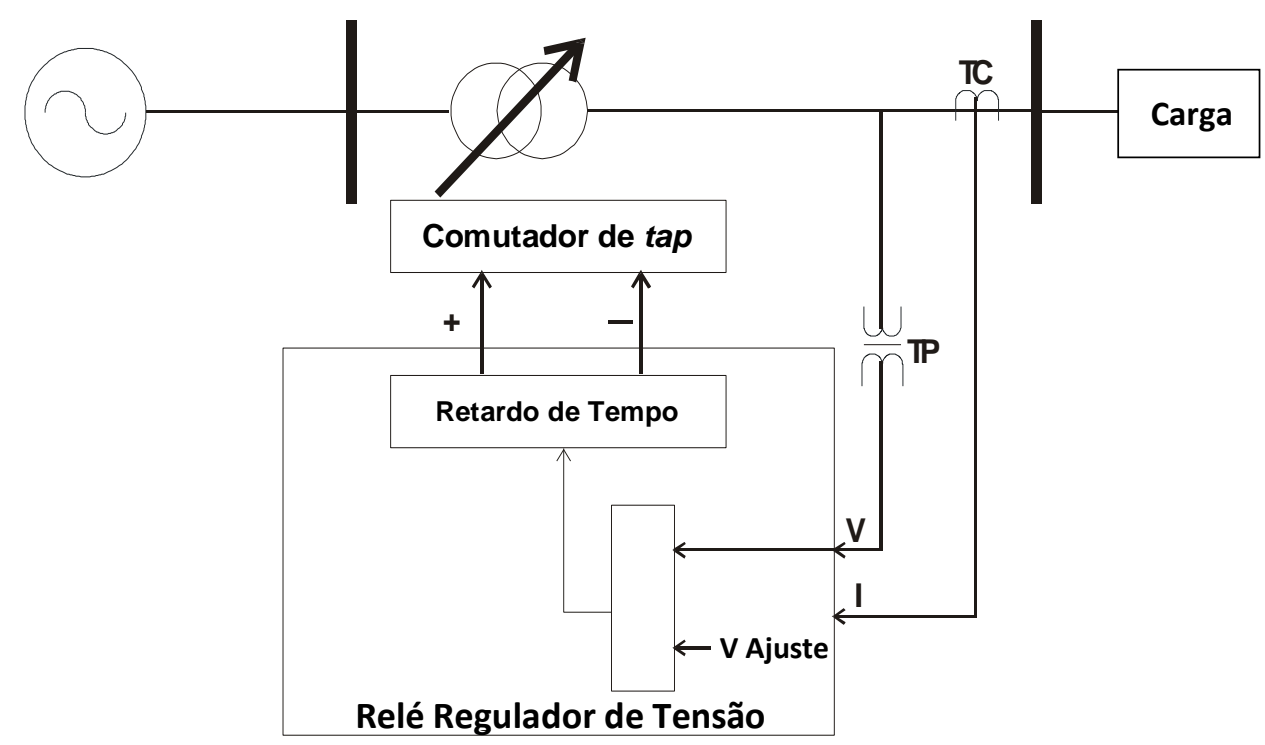

Figura 2.2 - Esquema do relé regulador automático de tensão.

Com relação ao fluxo de potência reverso é válido salientar que comutadores de tap são normalmente construídos para as operações do tipo step-down, isto é, sistemas de distribuição que usualmente fornecem energia da rede de alta tensão para as de baixa tensão. Porém, a inclusão de unidades de geração distribuída pode levar à operação de step-up, ou seja, uma operação inversa à mencionada anteriormente - os fluxos de energia bidirecionais devem agora ser incorporados na concepção hierárquica da rede assim como seus critérios de funcionamento. Portanto, alguns comutadores de tap podem não estar aptos a realizar operações com fluxo de potência reverso. Então, há casos em que as conexões de GD podem ser limitadas pelas diferentes capacidades direta e reversa do fluxo de potência desses componentes da rede de distribuição. Contudo, existem tipos de comutadores automáticos de 
tap que apresentam características simétricas e, portanto não oferecem problemas de fluxo de potência reverso ([21]). Um fato a se observar, é que a capacidade de fluxo reverso aumenta à medida que o fator de potência diminui tal que, o pior cenário de operação nessas condições é experimentado para fator de potência unitário ([21]).

Os controles de tensão empregados na prática são mais complexos do que o esquema anteriormente apresentado pela Figura 2.2. Uma dessas considerações práticas é justamente levar em conta a queda de tensão ao longo do alimentador, através de uma estratégia conhecida como Line Drop Compensation (LDC), que considera a localização do centro de carga. O objetivo da compensação de queda de linha é manter a tensão de consumidores mais distantes dentro de uma faixa aceitável.

A Figura 2.3 indica um esquema de regulador de tensão com LDC, o qual, no intuito de manter a magnitude de tensão da carga dentro da faixa de tensão aceitável, estima a queda de tensão, e os níveis de tensão são elevados também de acordo com a mesma. Isto pode ser realizado efetivamente por este mecanismo e para isso a corrente de linha precisa ser medida em adição à tensão, a qual é feita pelos transformadores de corrente (TC) do regulador de tensão. Então, baseado na corrente do secundário da subestação primária, os parâmetros de linha são configurados, valores de resistência $(\mathrm{R})$ e de reatância $(\mathrm{X})$, correspondendo à impedância equivalente $\left(Z_{e q}=R_{L}+j X_{L}\right)$ entre o componente regulador e o centro de carga. $\mathrm{O}$ controle calcula os componentes ativos e reativos da queda de tensão de linha e toma decisões para corrigir a magnitude de tensão da carga. Quando o centro de carga localiza-se no terminal de saída do regulador, a impedância $Z_{e q}$ recebe valor zero ([17]). Os valores de $\mathrm{R}$ e X dentro do relé são ajustados de forma a corresponder diretamente às impedâncias $R_{L}$ e $X_{L}$ da linha real.

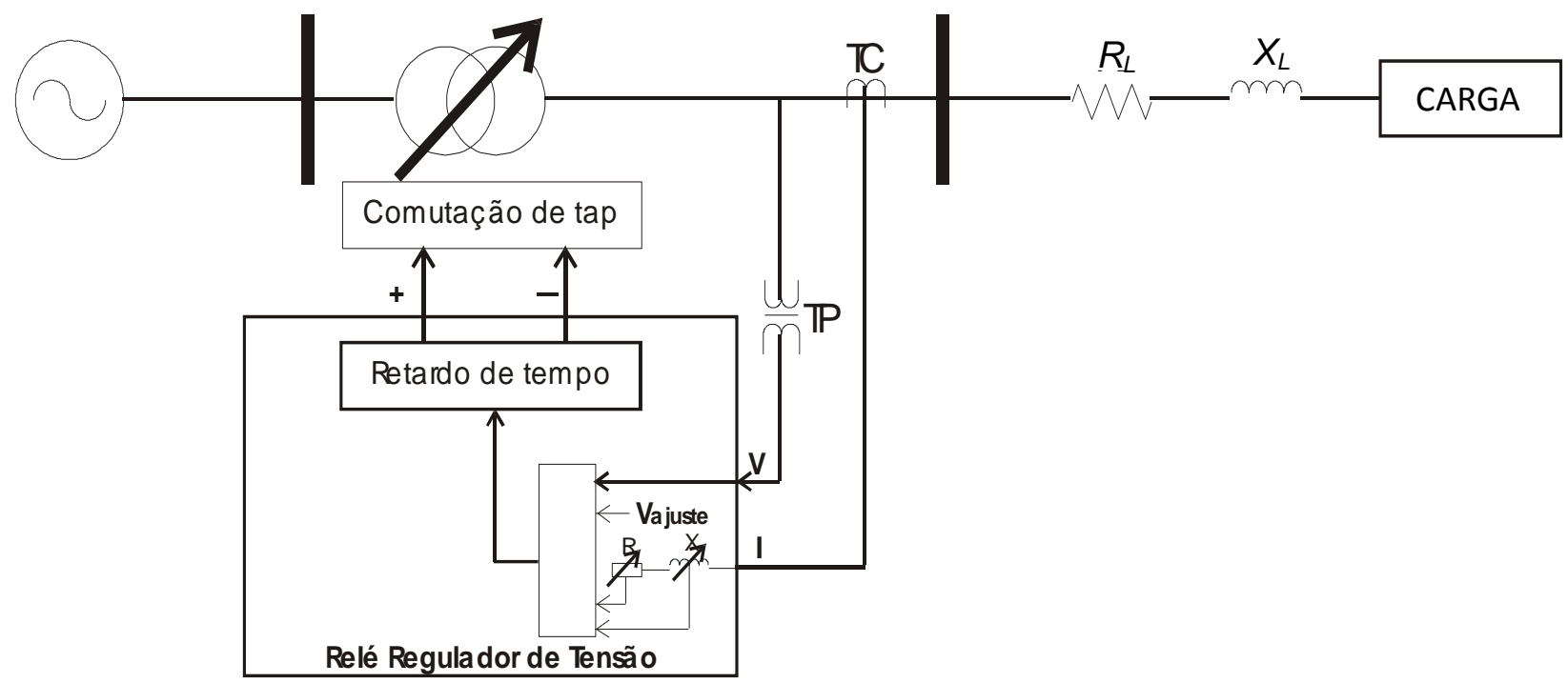

Figura 2.3 - Esquema do relé regulador de tensão com LDC (Fonte: [20]). 
Sobre as configurações necessárias ao relé regulador de tensão, cabe aqui, um resumo das principais características ([17]):

- Tensão de Referência: também chamada de ponto de ajuste ou centro de banda. É a tensão que é desejada no terminal do regulador ou em uma barra remota do alimentador. É a configuração chave do relé de controle e a tensão alvo a ser alcançada por este, possibilitando uma melhor condição operacional do equipamento;

- Largura de Faixa: a margem que define a tolerância aceitável para ambos os lados ( \pm ) da tensão de referência, isto é, a variação de tensão permitida entre a tensão de referência e a tensão provocada pela carga. Os níveis de tensão na carga poderão então variar cerca de metade dessa margem de variação. Por exemplo, se a tensão é especificada em $120 \mathrm{~V}$ e a margem é de $2 \mathrm{~V}$, no caso de uma sobre/sobtensão, o regulador vai comutar taps para que a tensão se enquadre entre 119 e $121 \mathrm{~V}$. Isto ajuda a evitar o excesso de acionamentos no comutador de taps;

- Temporização ou Tempo Morto: tempo de espera (delay) para iniciar uma execução do comando de passo, ou seja, comutação de tap, a partir do momento em que a tensão do regulador extrapola os limites estabelecidos. Esse ajuste permite evitar que o regulador atue para pequenas variações de tensão;

- E a compensação por queda de tensão na linha - Line Drop Compensation (LDC), que funciona compensando a queda de tensão da linha entre o regulador de tensão e um centro de carga determinado.

Esses ajustes estão graficamente representados na Figura 2.4.

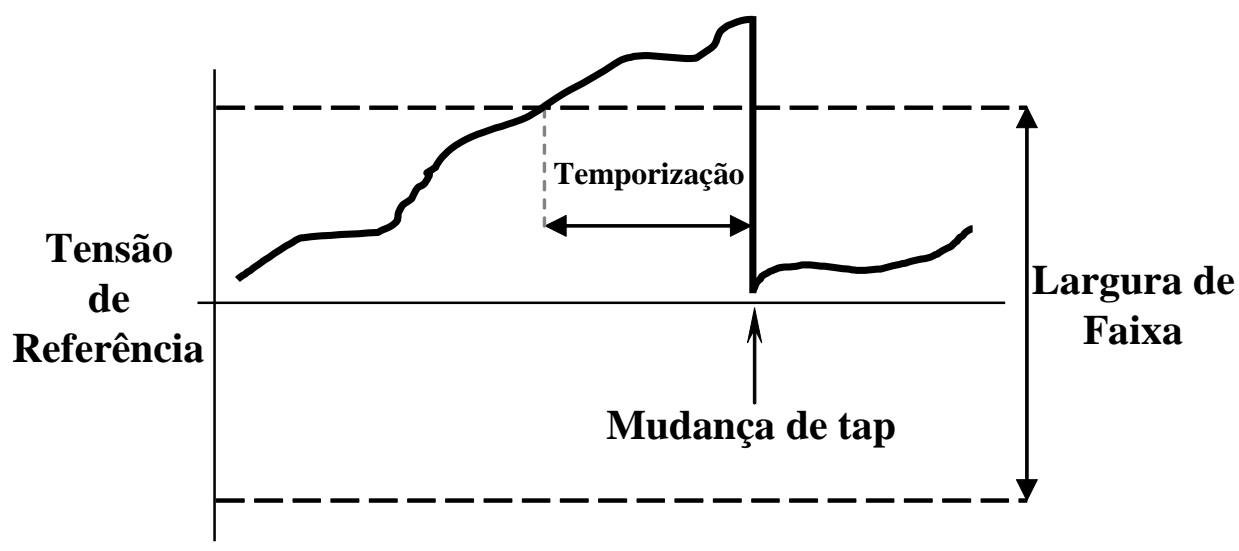

Figura 2.4 - Ajustes do relé regulador de tensão (Fonte: [20]). 
Uma temporização elevada ou uma grande largura de faixa diminuem o número de comutações, mas a regulação de tensão fica comprometida. Uma largura de faixa estreita ou uma baixa temporização melhoram o perfil de tensão, mas acarretam maiores comutações de tap e seu conseqüente desgaste.

Os comutadores de tap são desenvolvidos e construídos para realizar aproximadamente 1 milhão de operações em sua vida útil. Em condições normais eles realizam cerca de 70 comutações por dia, o que equivale a pouco mais de 25 mil por ano. Os relés reguladores de tensão possuem contadores de operações que auxiliam a equipe de manutenção a identificar o momento mais adequado para realizar a manutenção do dispositivo ou sua substituição. Assim, as operações de comutação de tap são contabilizadas diariamente através do contador de operações, e o excesso ou diminuição destas possibilita a constatação de problemas, seja uma situação indesejada na rede, como a ocorrência de flutuações de tensões no primário, ou mesmo na montagem e/ou configuração de algum parâmetro do transformador ([19], [20]).

\subsubsection{Autotransformadores Reguladores de Tensão}

Os reguladores de tensão são autotransformadores que possuem ajuste automático de tap, permitindo elevar ou reduzir a tensão no seu lado secundário, mantendo a mesma dentro de uma faixa de valores aceitáveis para os consumidores. Assim como no transformador da subestação, esse ajuste também é realizado por meio de uma chave rotatória. Os reguladores possuem várias entradas, permitindo a configuração da relação de transformação de acordo com a variação da tensão de entrada. Normalmente, possuem uma faixa de ajuste da magnitude de tensão que vai de $-10,0 \%$ a $+10,0 \%$, geralmente espaçadas em 32 posições, isto em condições como as descritas em [22]. Isto equivale dizer que cada passo provoca uma mudança de 5/8\% na magnitude de tensão ([17], [18]).

Esses equipamentos são comumente instalados em pontos entre os alimentadores em que a tensão não consegue ser regulada pela subestação, compensando as variações de tensão do lado primário e do secundário. A Figura 2.5 ilustra reguladores instalados ao longo dos alimentadores. Ressalta-se que tanto a comutação de tap como a alocação destes equipamentos influenciam enormemente na qualidade dos serviços de manutenção dos níveis de tensão dentro da rede de distribuição. 


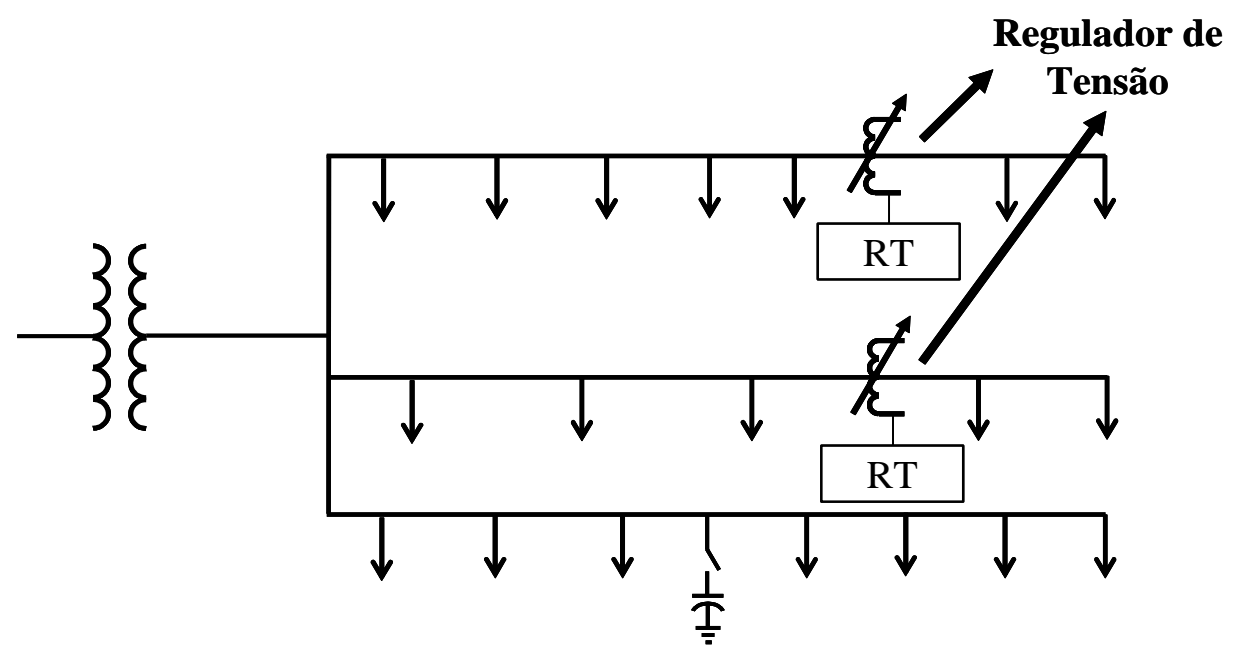

Figura 2.5 - Reguladores de tensão instalados ao longo dos alimentadores (Fonte: [20]).

O American National Standards Institute (ANSI) define os tipos de construção dos reguladores de tensão de passo. Estes possuem três terminais: Fonte, Carga e Fonte-Carga, conforme pode ser visto na Figura 2.6 ([17], [22]).

Elevação de tensão

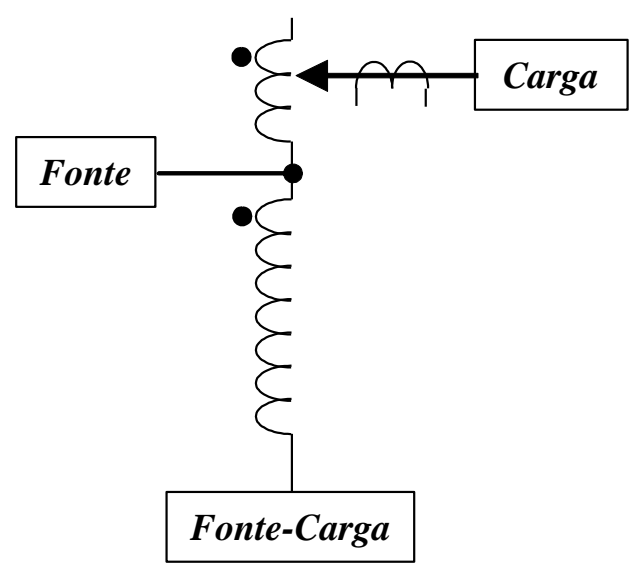

Diminuição de tensão

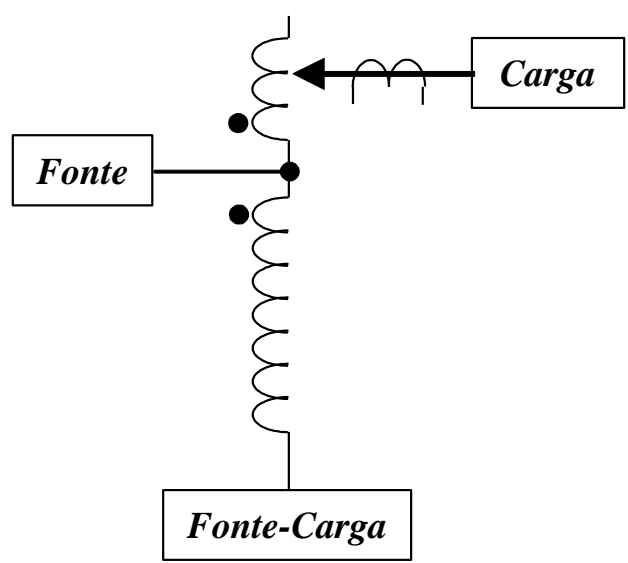

Figura 2.6 - Regulador monofásico ANSI.

O enrolamento série encontra-se entre a Fonte e a Carga, com o tap do lado da carga.

Os reguladores de tensão trifásicos controlam as três fases simultaneamente. Eles podem ter conexões Estrela com Terra, Triângulo Aberto e Triângulo Fechado, conforme pode ser visto na Figura 2.7 ([17], [20]). 


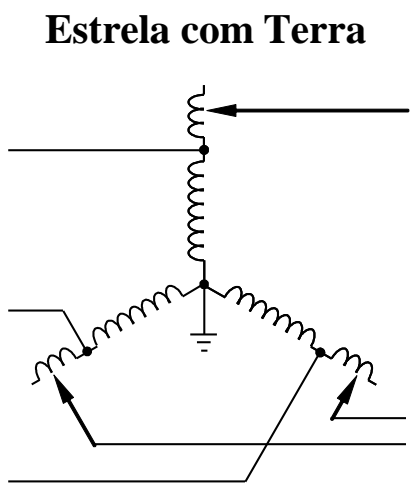

Triângulo Fechado

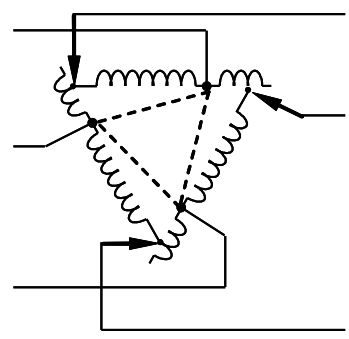

Triângulo Aberto

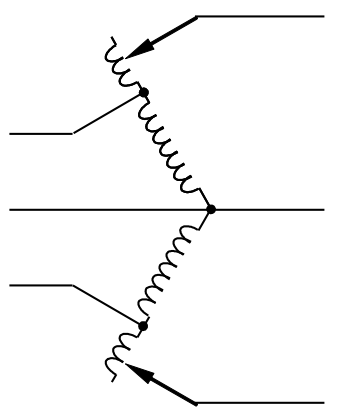

Figura 2.7 - Conexões trifásicas para o autotransformador (Fonte: [20]).

$\mathrm{Na}$ configuração Estrela com Terra a quatro condutores, geralmente utilizam-se três reguladores monofásicos, que conectam a linha ao neutro. Cada regulador controla independentemente a tensão, melhorando o controle do sistema desbalanceado. $\mathrm{Na}$ configuração Triângulo Fechado, três reguladores estão conectados fase a fase. Esse arranjo permite um acréscimo na faixa de regulação passando de $\pm 10 \%$ para $\pm 15 \%$. Já na configuração Triângulo Aberto, apenas dois reguladores monofásicos são necessários, conectando uma fase a outra ([20]).

Com relação ao controle dos reguladores de tensão, o acionamento do comutador de tap é controlado automaticamente por um relé de tensão, como descrito na seção anterior, o qual monitora continuamente o sistema, sendo responsável pelo ajuste e acionamento do mecanismo de comutação de taps. Basicamente o relé monitora a saída de tensão do transformador e, se esta ultrapassar limites pré-determinados, ele enviará o comando para acionamento e conseqüente operação do comutador.

Como comentado anteriormente, a inserção de unidades de geração distribuída pode influenciar enormemente na regulação de tensão. No tópico seguinte uma discussão sobre o assunto é abordada.

\subsection{Geradores Distribuídos}

Além de fornecer energia, geradores distribuídos podem ter uma importância crescente em um ambiente desregulado podendo prover alguns serviços auxiliares. Por exemplo, geradores síncronos distribuídos quando operam com o controle da excitatriz de forma a manter a tensão terminal constante, também contribuem para a regulação de tensão do sistema de distribuição (exceção de regiões mais isoladas). Isto acontece em razão da necessidade de o gerador compensar potência reativa, absorvendo ou injetando, para poder sustentar a tensão 
terminal constante, o que também atinge a rede de distribuição realizando a regulação de tensão ([1], [5], [11]). Em alguns países esta filosofia de operação é empregada com sucesso, apenas realizando um controle para que o fator de potência permaneça dentro de uma faixa aceitável para operação ([15]). Em outros, incluindo o Brasil, as premissas contratuais são predominantes, sustentando as decisões operacionais de modo a priorizar os interesses comerciais, ao invés, em alguns casos, do melhor interesse em suprir a estabilidade e segurança dos sistemas de distribuição ([16]).

Sobre a interferência de geradores distribuídos nos mecanismos de controle de tensão de redes de distribuição, alguns aspectos podem ser relacionados, entre eles ([15]):

- Geradores podem ser inseridos em sistemas de distribuição em áreas rurais muito distantes das subestações principais, o que torna o controle de tensão proveniente da subestação difícil e talvez impossível se o circuito entre a unidade de geração e a subestação possuir uma impedância elevada e uma baixa densidade de carga.

- Geradores conectados não tão distantes da subestação principal podem ser usados para ajudar o mecanismo automático de controle de tensão da subestação a regular as tensões de cargas locais.

- Caso a potência nominal de um gerador conectado em um alimentador seja maior que a carga total do alimentador, o fluxo de carga proveniente dos sistemas de subtransmissão até o transformador da subestação será reverso, pois o lado sensível que é normalmente o lado secundário do transformador, lado que alimenta a rede de distribuição, se torna o lado de suprimento.

No tópico a seguir apresenta-se uma breve revisão bibliográfica sobre os aspectos técnicos que influenciaram a elaboração deste trabalho, focando desde o impacto no perfil de tensão e perdas elétricas em uma análise em regime permanente, até a coordenação dos dispositivos de controle de tensão com os modos de operação dos geradores distribuídos.

\subsubsection{Impactos no Perfil de Tensão e Perdas Elétricas}

Em Masters ([10]) é apresentado um estudo sobre os impactos nos níveis de tensão quando geradores distribuídos são conectados no sistema de distribuição. Por meio de estudos de caso, o autor discute como a tensão em regime permanente se eleva quando esses geradores são inseridos no sistema sem a devida análise. O porquê deste aumento é explicado de forma simplificada devido à baixa relação reatância/resistência $(X / R)$ e da configuração 
radial comum nesses sistemas. Conectar um gerador ao sistema de distribuição afetará o fluxo de potência e o perfil de tensão dos alimentadores. Para injetar potência na rede elétrica, o gerador deve operar com uma tensão terminal mais elevada do que a da barra da subestação, a não ser que seja capaz de absorver grande quantidade de potência reativa. Isto pode ser explicado por meio da Figura 2.8 e da equação (2.1).

$$
\Delta \mathrm{V}=V_{G E N}-V_{S E}=(R P+X Q) / V_{G E N}
$$

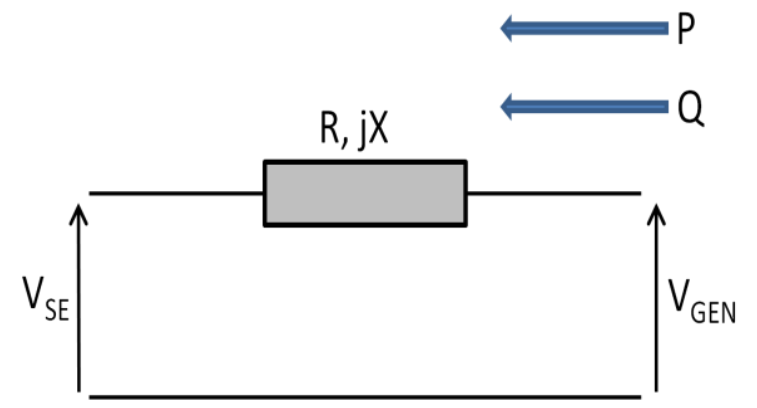

Sendo:

$V_{G E N}$ a tensão do gerador distribuído.

$V_{S E}$ a tensão da subestação primária do sistema de distribuição.

$R$ e $X$ são a resistência e reatância da linha.

$P$ e $Q$ são a potência ativa e reativa transmitidas do gerador para a linha.

Figura 2.8 - Fluxo de potência gerador-subestação.

O termo $X Q$ pode ser positivo ou negativo, estando sujeito à condição de trabalho do gerador, se este está injetando ou consumindo potência reativa, respectivamente. Todavia, como normalmente a magnitude da potência reativa é pequena comparada com a potência ativa (ao menos que alguma forma de compensação seja usada) e o valor de $R$ não é desprezível, o termo $R P+X Q$ tende a ser positivo. Portanto, o valor da tensão no ponto de conexão do gerador com o sistema de distribuição aumenta acima da tensão da subestação.

Em algumas partes do sistema, a tensão poderá aumentar, ou diminuir, além dos níveis de tensão permitidos ([10]). Para o caso brasileiro, esses níveis de tensão estão apresentados na Tabela 2.1, de acordo com a resolução $\mathrm{N}^{\mathrm{o}} 505$ de 26 de novembro de 2001 da Agência Nacional de Energia Elétrica (ANEEL) ([23]). O aumento dos níveis de tensão é mais preocupante quando o nível de carregamento do sistema elétrico é baixo, já que toda energia gerada não consumida poderá ser exportada de volta para a subestação, ratificando mais uma vez o fluxo reverso. Isto sugere que o aumento de tensão durante os períodos de mínima demanda é um dos fatores limitantes da quantidade e injeção de potência ativa dos geradores distribuídos ([13]). 
Tabela 2.1 - Pontos de conexão em tensão nominal superior a $1 \mathrm{kV}$ e inferior a $69 \mathrm{kV}$ (regime permanente).

\begin{tabular}{|c|c|}
\hline $\begin{array}{c}\text { Tensão de } \\
\text { Atendimento }(\text { TA) }\end{array}$ & $\begin{array}{c}\text { Faixa de Variação da Tensão de Leitura (TL) em } \\
\text { Relação à Tensão Contratada }(\text { TC) }\end{array}$ \\
\hline Adequada & $0,93 \mathrm{TC} \leq \mathrm{TL} \leq 1,05 \mathrm{TC}$ \\
\hline Precária & $0,90 \mathrm{TC} \leq \mathrm{TL}<0,93 \mathrm{TC}$ \\
\hline Crítica & $\mathrm{TL}<0,90 \mathrm{TC}$ ou TL $>1,05 \mathrm{TC}$ \\
\hline
\end{tabular}

Se a inserção de geradores causar uma elevação do perfil de tensão, também em Masters ([10]) são propostas diversas técnicas que podem ser empregadas para restabelecer os níveis de tensão dentro dos limites apropriados, objetivando maximizar a quantidade de potência injetada pelos geradores. Entre estas, têm-se:

- Redução da tensão no lado primário do transformador na subestação;

- Permitir que o gerador importe potência reativa (operação com fator de potência indutivo);

- Instalação de autotransformadores ou reguladores de tensão ao longo da linha (reajustando a tensão na linha);

- Incremento da bitola do condutor (redução da resistência);

- Restrição da geração quando o sistema opera com mínimo carregamento (redução da potência ativa transmitida);

- Uma combinação das recomendações acima mencionadas.

Outro importante impacto resultante da presença de geradores síncronos diz respeito às perdas elétricas. Este impacto é muito estudado, principalmente por sua importância econômica, e na prática seu aumento está diretamente ligado aos níveis de carregamento do sistema elétrico. De maneira simplificada essa relação é expressa da seguinte forma: uma maior carga implica em um maior valor de fluxo de potência, e como as perdas aumentam com o quadrado da corrente de carga, uma elevação do carregamento resultará em um aumento quadrático das perdas.

Em tempos passados, as concessionárias de energia costumavam usar o termo "redução de perdas" nos estudos para melhorias das redes de distribuição. Apesar da correta aplicação, atualmente é preferível usar termos como "otimizar" ou "minimizar" as perdas técnicas. Isto é adotado porque as perdas elétricas podem ser divididas em duas categorias, perdas técnicas (PT) - inerentes ao sistema - e perdas não-técnicas (PNT), conhecidas também por perdas comerciais (fraudes, furtos, erros de medição, etc.). Assim, visto que 
quase todas as ações para diminuir estas perdas envolvem investimentos e que, algumas vezes, estas reduções podem não compensar o investimento realizado, fica mais apropriado afirmar que se realizou um processo de minimização (otimização) e não redução de perdas (é possível reduzir as perdas, mas o custo não permite) ([24]). A minimização das perdas nos sistemas de distribuição, sendo elas técnicas, e a redução nas perdas não-técnicas são prioridades para um fornecimento com qualidade e maior rentabilidade, os quais são objetivos das distribuidoras de energia de todo o mundo.

Nos casos em que as perdas não-técnicas (ou comerciais) são insignificantes, a diferença entre as medições de energia adquirida (comprada) e vendida corresponde às perdas técnicas. As perdas não-técnicas ocorrem, em parte, em equipamentos das empresas, como: medidores com erros elevados, isoladores com fugas de correntes, etc., mas ocorrem também, por ações de outros, por furto ou fraude em medidores de energia elétrica. Na grande maioria das empresas distribuidoras de países desenvolvidos, as perdas não-técnicas não causam preocupações, pois representam valores insignificantes comparados com valores das perdas técnicas. Porém, em muitos países em desenvolvimento, a situação é oposta. Neste caso algumas empresas chegam a registrar números exagerados como, por exemplo, 20\% (para perdas técnicas na faixa de 5 a 10\%) ([24]).

Segundo registros de 2008, de toda a energia produzida no Brasil, as perdas elétricas chegam a $16 \%$, com média de $50 \%$ para cada uma de suas parcelas componentes: perdas técnicas e não técnicas. Alguns estados da federação apresentam perdas técnicas que variam de 3 a 20\%. As maiores perdas estão na Região Norte, da ordem de 19,7\%. Nas outras regiões do Brasil as perdas estão em torno de 13 e 14\% ([14]).

Estudos referentes ao comportamento de perdas elétricas na presença de unidades de geração distribuída já foram realizados. Em Salman ([15]), por exemplo, notou-se que o nível de perdas elétricas pode diminuir ou aumentar dependendo de onde é alocado o gerador, da quantidade de potência gerada e da topologia da rede.

Percebe-se que a eletricidade gerada localmente substitui a eletricidade que é gerada por uma fonte distante do centro de carga, o que significa que menos energia tem de ser transportada e, portanto, perdas mais baixas são produzidas nestes tipos de sistema. É também fato que o valor quantitativo desse benefício é maximizado se o total da produção local de geração corresponde mais ou menos ao consumo local. Se a produção local for superior ao consumo na mesma área, a direção da energia é revertida e as perdas aumentarão novamente.

Adicionalmente, as perdas elétricas são fortemente influenciadas pelo mecanismo de controle da excitação dos geradores síncronos, podendo este variar entre tensão constante e 
fator de potência constante, este último podendo ainda alternar entre capacitivo, indutivo ou unitário, como se pode observar em Gallardo ([25]).

Mesmo sendo de suma importância, obter o mínimo de perdas não necessariamente implica no melhor arranjo do sistema. Gallardo frisa este fato quando consegue menores valores de perdas elétricas por meio da operação do gerador com fator de potência capacitivo, limitando, em contrapartida, o nível de penetração de geração ao sistema de distribuição, ou seja, a quantidade de potência ativa que pode ser introduzida. Trabalho semelhante foi realizado por Freitas et. al. ([12]), que ainda acrescenta que o gerador operando com tensão constante pode aumentar o nível máximo de geradores síncronos a serem instalados nos sistemas de distribuição. Os resultados desses trabalhos apontam a viabilidade de se instalarem geradores operando com o sistema de controle de excitação funcionando como regulador de tensão, obtendo em muitos casos uma melhor faixa dos níveis de tensão.

\subsubsection{Operação dos Mecanismos de Controle de Tensão}

Em linhas gerais, todos os dispositivos de controle de tensão presentes no sistema de distribuição devem operar de forma a manter a tensão nas cargas dentro dos limites aceitáveis, diante da presença dos geradores distribuídos e para as diferentes condições de carregamento. Diversos trabalhos foram publicados discutindo algumas metodologias e propostas para a implementação desse processo. Alguns destes são discutidos a seguir.

Kojovic ([18]) realizou um estudo para determinar o impacto da geração distribuída na regulação de tensão quando esta é inserida em um sistema de distribuição típico. Simulações de fluxo de carga são realizadas avaliando a interação entre as unidades de geração distribuída e os dispositivos reguladores de tensão, que incluem bancos de capacitores e transformadores reguladores de tensão. Visando evitar manobras simultâneas de mais de um equipamento para a solução de um mesmo problema, uma coordenação apropriada entre a operação dos equipamentos de regulação de tensão para manutenção das tensões nodais dentro dos limites estabelecidos por normas técnicas é sugerida. Deste modo, primeiramente o autor recomenda encontrar a melhor configuração operativa desses dispositivos sem a presença dos geradores distribuídos, e então com a presença do mesmo realiza diversas simulações analisando como diferentes aspectos podem influenciar a manutenção dos níveis de tensão dentro da faixa adequada. Os principais aspectos analisados são a alocação tanto dos geradores como dos dispositivos reguladores, a quantidade de potência ativa e reativa geradas e o valor de tensão do gerador distribuído. Assim, consegue-se construir regras para o funcionamento e 
acionamento desses diferentes equipamentos. No entanto, o autor não chega a demonstrar um processo de otimização através dessas regras ou de qualquer outra forma, apenas deixando como contribuição conclusões extraídas do seu conhecimento técnico e da experiência adquirida com as simulações de fluxo de carga realizadas nesta pesquisa.

Outro trabalho [8] discute resultados sobre a elaboração de uma coordenação baseada em regras condicionantes à operação dos dispositivos reguladores de tensão. Nesse trabalho é investigado o controle de tensão e compensação de potência reativa em redes de distribuição, e como a inserção de unidades de geração distribuída baseada em máquinas síncronas afeta esse controle. Uma coordenação apropriada entre o transformador da subestação com comutador automático de tap sob carga e os bancos de capacitores chaveados presentes na subestação e nos alimentadores é proposta. Como em um caso mais comum de operação de sistemas de distribuição nos dias de hoje, é admitida a inexistência de comunicação, seja digital ou de outro tipo, entre o gerador e os dispositivos reguladores. Porém, diferente das metodologias utilizadas neste trabalho de Mestrado, a estratégia utilizada por [8] também se baseia no uso de regras semelhantes às sugeridas por [18], que condicionam a operação dos equipamentos reguladores de tensão. Por exemplo, uma queda de tensão excedendo o limite inferior da margem aceitável em um determinado alimentador, acionará o banco de capacitores mais próximo, este por sua vez diminuirá o fluxo de potência reativa através do transformador da subestação, o que pode acarretar na redução da tensão do lado secundário do transformador e conseqüentemente a operação do OLTC. O método proposto apresenta certa robustez, reduzindo perdas e flutuações de tensão no sistema de distribuição, além de diminuir o número de operações do OLTC, com e sem a presença de unidades de geração distribuída. Os autores também concluíram que desde que existam capacitores suficientes para suprir a demanda de potência reativa no sistema, o modo de operação do gerador distribuído não tem um efeito significante nas perdas da rede de distribuição. Entretanto, os mesmos recomendam que o modo de operação do gerador síncrono com tensão constante é benéfico, reduzindo significativamente operações do OLTC e diminuindo flutuações de tensão em toda a rede de distribuição. Apesar de eficiente, ainda assim o modelo de coordenação proposto por [8] não possibilita a obtenção de valores de tensão com máxima relevância qualitativa, algo próximo a que poderia chamar de valores otimizados de operação. Isto porque os resultados encontrados para os valores de tap dos transformadores são contínuos, e assim apresentam um relaxamento do resultado, indicando que sob situações variantes do dia a dia, principalmente em grandes sistemas com um elevado número de dispositivos, ficaria difícil prever o nível de variação de tensão com exatidão. 
Esse capítulo apresentou os principais aspectos no que tange à regulação de tensão em sistemas de distribuição de energia elétrica. Algumas contribuições que vêm ocorrendo nos últimos anos em termos de pesquisa do assunto também foram discutidas. O objetivo principal dessas estratégias é alcançar a melhoria na operação dos dispositivos de controle de tensão, ocasionando o atendimento às faixas de tensão estabelecidas pela legislação. 


\section{Capítulo 3}

\section{Método Computacional e Modelagem do Sistema Elétrico}

Neste capítulo, a metodologia computacional utilizada para realização dos estudos é descrita. Adicionalmente, os modelos empregados para representar e analisar os elementos do sistema de distribuição são apresentados.

\subsection{Programação Matemática e Otimização}

Cresce, cada vez mais, a importância do uso de técnicas de otimização para o planejamento e análise dos mais diversos sistemas industriais e sócio-econômicos. Contudo, modelar uma operação complexa de otimização não se faz simplesmente especificando restrições. Se pouquíssimas restrições são inseridas, muitas soluções qualitativamente inferiores poderiam satisfazê-las, se há restrições demais, soluções desejáveis são descartadas, ou na pior das hipóteses não aparecem soluções possíveis. Para obter sucesso neste tipo de otimização, é necessário fornecer uma maneira de contornar essas dificuldades. Além das restrições, adiciona-se um objetivo em função das variáveis, como custo ou lucro, que passa então a ser usado para decidir se uma solução é melhor do que outra. A partir daí, não importa que muitas soluções diferentes satisfaçam as restrições - é suficiente encontrar uma solução tal capaz de minimizar ou maximizar o objetivo.

A expressão "programação matemática" passou a ser utilizada para descrever a minimização ou maximização de uma função objetivo de muitas variáveis, sendo estas sujeitas a restrições. Práticas de programação matemática raramente são tão simples como executar algum método algorítmico em um computador e imprimir a solução ideal. $\mathrm{O}$ procedimento necessário para a elaboração destas práticas pode ser descrito, de forma geral, como segue:

- Formular um modelo, o resumo das variáveis do sistema, objetivos e restrições que representam a forma geral do problema a ser resolvido; 
- Coletar dados que permitam definir um problema específico;

- Gerar uma função objetivo específica e as equações de restrição do modelo e dos dados;

- Resolver o problema definido executando um programa computacional para solução de problemas (solver), para aplicar um algoritmo que encontre os valores ótimos das variáveis;

- Analisar os resultados;

- Refinar o modelo e os dados, conforme necessário, e repetir o processo.

Assim, para desenvolver a programação necessária à resolução do problema, neste trabalho, fez-se uso de um programa com um ambiente que oferece uma linguagem de programação de fácil manipulação e compatibilidade com um solver necessário para encontrar a solução do problema. As principais características desses programas são descritas nos itens seguintes.

\subsubsection{AMPL}

Embora algoritmos bem-sucedidos para programação matemática entraram em uso em meados 1950, o desenvolvimento e a distribuição de modelos de linguagem algébrica só começaram na década de 1970. Desde então, os avanços em informática e ciências da computação têm permitido que linguagens de programação se tornem cada vez mais eficientes e generalizadas.

A Modeling Language for Mathematical Programming (AMPL) ([26]) oferece um ambiente com linguagem de programação simples para configurar e solucionar problemas de programação matemática. A interface flexível e amigável permite a utilização dos mais diversos solvers, disponibilizando todos de uma vez, através de uma mesma programação, para que o usuário possa alternar entre eles e selecionar as opções que podem melhorar o desempenho do programa. Uma vez que a solução ótima seja encontrada, esta resposta pode ser convertida automaticamente de volta para a mesma linguagem em que o problema foi modelado, ou impressa em formato de arquivo de tal modo que os usuários possam analisálas. Todo o conjunto geral e expressões aritméticas do modelo de linguagem AMPL também podem ser utilizados para exibir os dados e resultados. Uma variedade de opções é disponibilizada para formatar ou alterar esses dados, imprimir relatórios, ou preparar estes resultados como entrada para outros programas. Para uma descrição mais aprofundada do AMPL deve-se consultar [27]. 


\subsection{2 $\underline{\text { Knitro }}$}

O Knitro ([28]) é uma biblioteca de programas (pacote de solucionadores - solvers) de otimização para encontrar soluções tanto para modelos de otimização contínua (com ou sem restrições), bem como modelos de otimização discreta com inteiros ou variáveis binárias (ou seja, programas de otimização inteira mista). Ele é projetado principalmente para encontrar soluções locais de grande escala em problemas não lineares contínuos. Embora concebido essencialmente para uso geral, otimização não-linear, o Knitro é eficiente para resolver todas as seguintes classes de problemas de otimização, desde:

- irrestrita;

- de limites restritos;

- sistemas de equações não lineares;

- alguns problemas quadrados, lineares e não lineares;

- problemas de programação linear;

- problemas de programação quadrática, convexos e não convexos;

- programas de matemática com restrições de complementaridade;

- problemas com restrições gerais não lineares, convexos e não convexos;

- programas lineares inteiros mistos de tamanho moderado ;

- programas não-lineares inteiros mistos de tamanho moderado.

Com todas suas aplicações, o pacote Knitro se apresenta como solver de característica robusta, e compilação rápida. Isto porque é composto por três algoritmos de otimização, que podem operar isoladamente ou em conjunto, através de um esquema de permuta, capazes de se revezar durante a resolução do problema, trocando um pelo outro, caso o algoritmo anterior não obtenha uma solução imediata. Estes são mais bem explanados mais adiante.

O Knitro oferece ainda os seguintes recursos:

- solução eficiente e robusta de problemas grandes ou pequenos;

- solucionadores (solvers) de problemas contínuos e discretos;

- derivados livres, opções de primeira e segunda derivada;

- algoritmos de ponto-interior (barreira) e conjunto-ativo (active-set);

- abordagem tanto iterativa como direta para as etapas de computação;

- interfaces de programação: C / C + +, Fortran, Java e Microsoft Excel;

- modelagem de interfaces de linguagem: AMPL, AIMMS, GAMS, Mathematica, MATLAB e MPL. 


\subsubsection{Visão Geral dos Problemas}

Os problemas resolvidos pelo Knitro se apresentam basicamente da seguinte forma:

Minimizar $f(x)$

sujeito a

$$
\begin{aligned}
& c^{\text {min }} \leq c(x) \leq c^{\text {máx }} \\
& b^{\text {min }} \leq x \leq b^{\text {máx }}
\end{aligned}
$$

em que $x \in R^{n}$ são as variáveis desconhecidas (que podem ser especificadas como contínuas, binárias ou inteiras), $c^{m i n}$ e $c^{\text {máx }}$ são os limites inferior e superior (possivelmente infinitos) das restrições gerais, e $b^{\text {mín }}$ e $b^{\text {máx }}$ são os limites inferior e superior simples (possivelmente infinitos) das variáveis. Esta formulação permite muitos tipos de restrições, incluindo igualdades $\left(\right.$ se $c^{\text {mín }}=c^{\text {máx }}$ ), variáveis fixas $\left(\right.$ se $\left.b^{\text {min }}=b^{\text {máx }}\right)$, e também restrições de desigualdade ou variáveis com limites. Restrições de complementaridade também podem ser incluídas. O Knitro assume que as funções $f(x)$ e $c(x)$, mesmo com problemas de descontinuidade, podem ser resolvidas com sucesso.

\subsubsection{Exemplo de Problema de Otimização Modelado no AMPL e Knitro}

Esta seção apresenta um exemplo de problema de otimização, demonstrando como se realiza a modelagem deste a partir da utilização do AMPL, incluindo o solver Knitro para efetuar a resolução do mesmo. O problema é definido tal como abaixo:

Minimizar

$$
1000-x_{1}^{2}-2 x_{2}^{2}-x_{3}^{2}-x_{1} x_{2}-x_{1} x_{3}
$$

sujeito a

$$
\begin{aligned}
& 8 x_{1}+14 x_{2}+7 x_{3}-56=0 \\
& x_{1}^{2}+x_{2}^{2}+x_{3}^{2}-25 \geq 0 \\
& x_{1}, x_{2}, x_{3} \geq 0
\end{aligned}
$$

e ponto inicial $x=\left[x_{1}, x_{2}, x_{3}\right]=[2,2,2]$.

O problema pode ser encontrado no pacote Knitro, sendo um dos exemplos fornecidos por este, e que é utilizado na aprendizagem do programa, por meio do arquivo "testproblem.mod", o qual é implementado na linguagem de programação AMPL e exposto a seguir. 


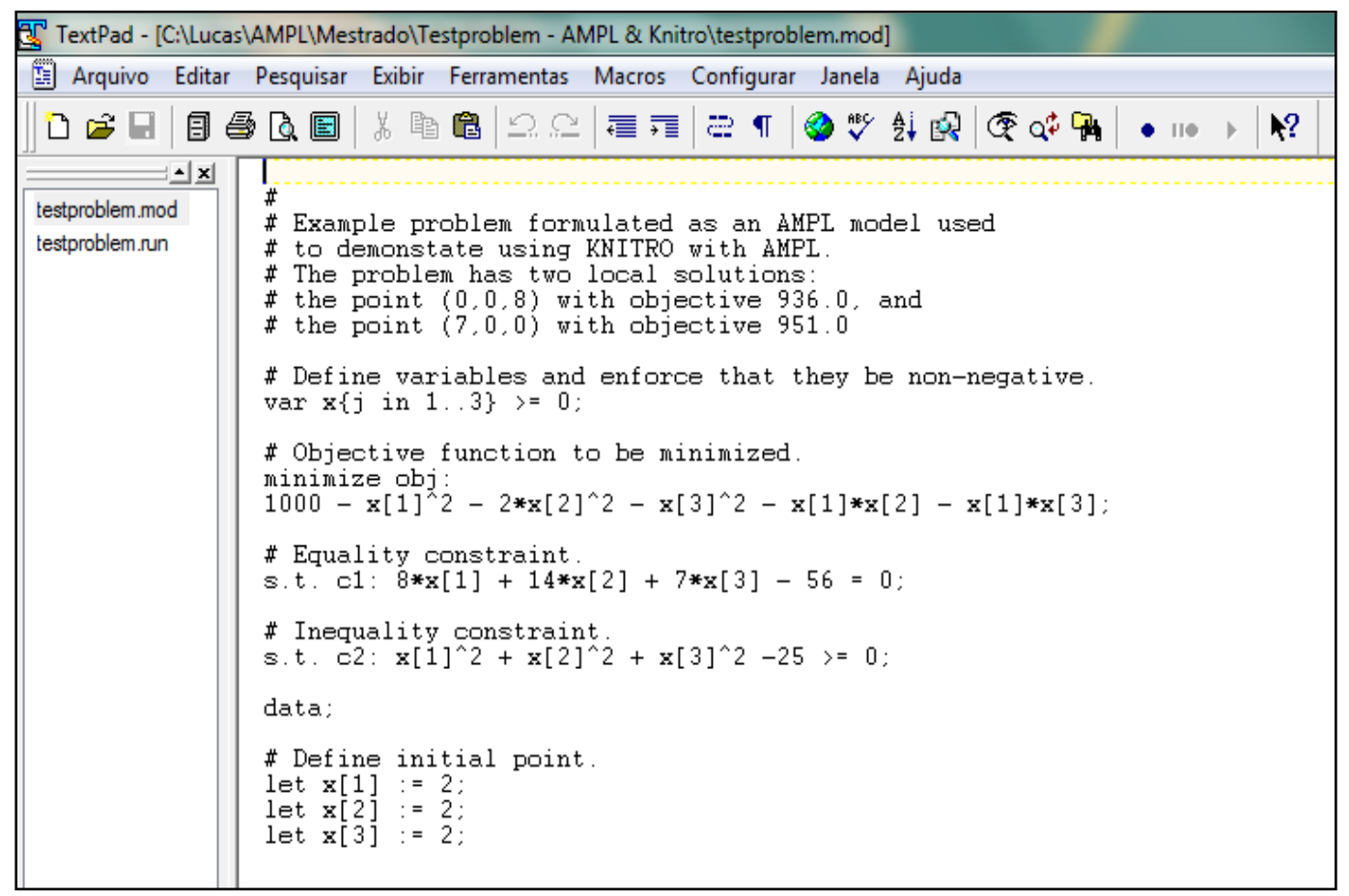

Figura 3.1 - Exemplo de modelagem do arquivo "testproblem.mod".

O exemplo anterior mostra a facilidade com que um problema de otimização pode ser expresso na linguagem de programação do AMPL. E, a seguir, apresenta-se o procedimento de execução do AMPL, utilizando o pacote de solver Knitro, para a resolução deste problema. Na Figura 3.2, configurou-se alg $=2$ (que determina um algoritmo específico dentre os três disponíveis dentro da biblioteca do Knitro para resolver o problema), maxcrossit $=2$ (para refinar a solução usando o algoritmo active set), e outlev = 1 (para limitar a saída do Knitro). Para mostrar a solução final, a variável $x$ e o valor da função objetivo pelo AMPL basta utilizar o comando "display" como segue.

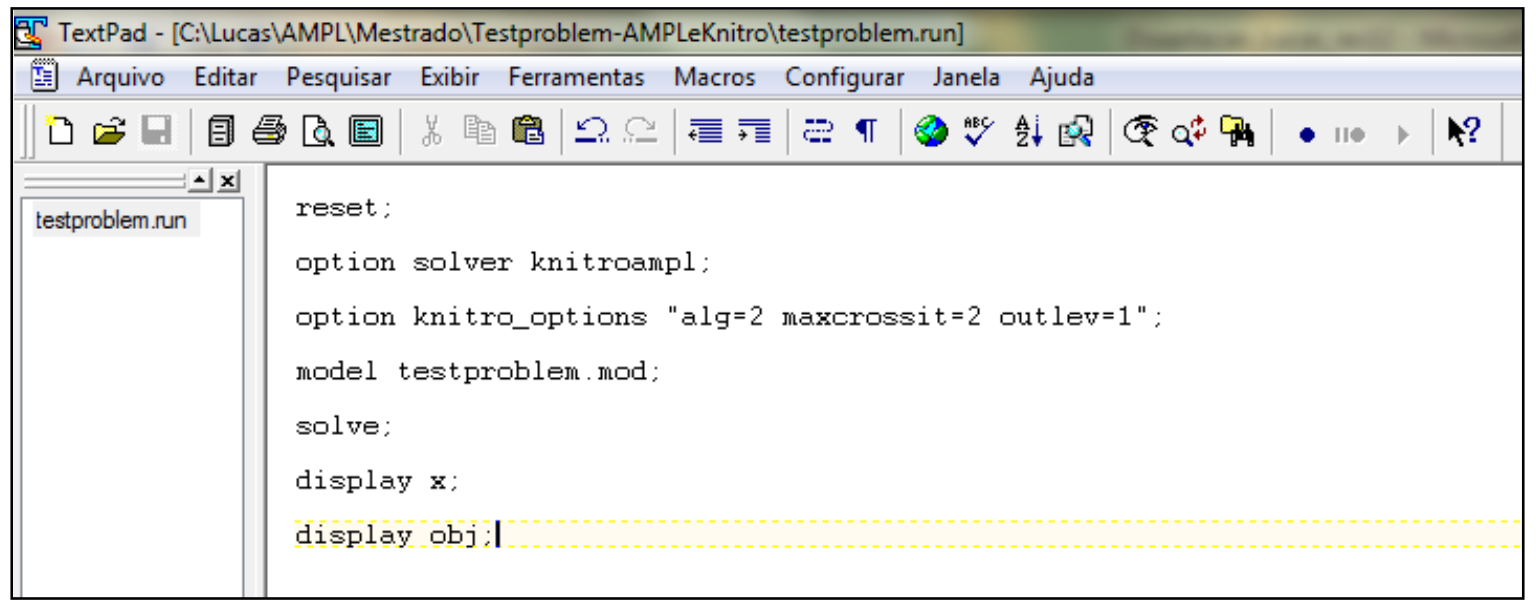

Figura 3.2 - Exemplo do arquivo de execução "testproblem.run". 
Por fim a resolução do problema é apresentada como na Figura 3.3.

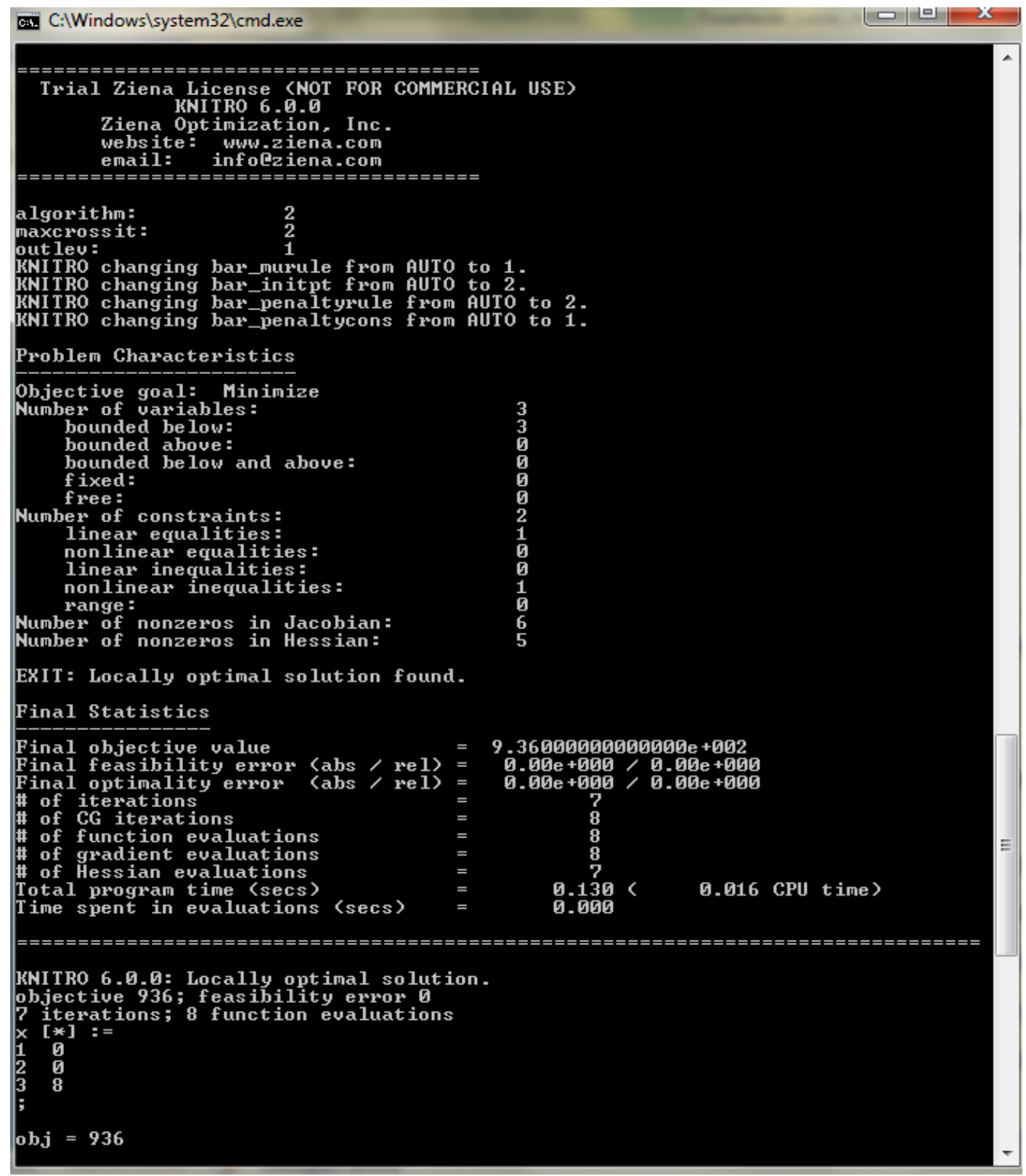

Figura 3.3 - Resolução do AMPL via CMD do arquivo "testproblem.run".

Após a conclusão, Knitro exibe uma mensagem e retorna um código de saída para o AMPL. De acordo com a Figura 3.3, foi possível encontrar uma solução, então a mensagem "Locally optimal solution found" - Solução ótima local encontrada, com código de saída zero (código de saída pode ser visto digitando "ampl: display solve exitcode;"). Se uma solução não for encontrada, então Knitro retorna um dos seguintes parâmetros:

- 0: Uma solução ótima local foi encontrada.

- $\quad-100$ até -199: Uma solução factível aproximada foi encontrada.

- -200 até -299: O código terminou em um ponto infactível. 
- 300: Aparentemente o problema não possui limites.

- -400 até -499: O código encerrou porque o programa alcançou um limite prédefinido.

- -500 até -599: O código encerrou por um erro de entrada ou algum problema fora do padrão.

Uma descrição mais detalhada dos códigos individuais de retorno e suas mensagens correspondentes é fornecida em [28].

\subsubsection{Solvers do Pacote Knitro}

A biblioteca Knitro possui implementados três métodos para resolver os problemas contínuos de otimização não-linear e dentre estes, dois são de pontos interiores e um de conjunto ativo (active-set). Cada algoritmo possui fortes propriedades de convergência e é codificado para obtenção da máxima eficiência e robustez. No entanto, os algoritmos têm diferenças fundamentais que levam a diferentes comportamentos em problemas de otimização não-linear. Juntos, os três métodos fornecem um conjunto de maneiras diferentes para atacar os problemas mais difíceis.

Métodos de pontos interiores (também conhecidos como métodos de barreira) substituem problemas de programação não-linear por uma série de subproblemas de barreira controlados por um parâmetro de barreira $\mu$. Regiões de confiança e uma função de mérito são usadas para promover a convergência. Eles realizam uma ou mais etapas de minimização em cada subproblema de barreira, em seguida diminuem o parâmetro de barreira e repetem o processo até que o problema original, por exemplo, composto pelas equações 3.1, 3.2 e 3.3, sejam resolvidos para a restrição desejada.

Métodos de conjunto ativo resolvem uma seqüência de subproblemas baseados em um modelo quadrático do problema original. Em contraste com os métodos de pontos interiores, esses algoritmos procuram desigualdades ativas e seguem um caminho mais exterior para a solução. O Knitro implementa um algoritmo de programação linear-quadrático seqüencial, de natureza semelhante a um método de programação quadrática seqüencial, mas utilizando subproblemas de programação linear para estimar o conjunto ativo. Este método pode ser preferível a algoritmos de pontos interiores quando um bom ponto inicial pode ser fornecido, por exemplo, resolvendo uma seqüência de problemas relacionados. Como citado anteriormente, Knitro também pode permutar de um algoritmo de pontos interiores e aplicar o método de conjunto-ativo para fornecer conjuntos ativos altamente precisos e informações importantes. 
Para uma descrição detalhada dos algoritmos de pontos de interiores, ver as referências [29] e [30], e para a teoria de convergência global ver [31]. O algoritmo conjuntoativo é descrito em [32] e a teoria da convergência global para este algoritmo em [33]. Um sumário das técnicas e algoritmos implementados no programa Knitro é dado em [34].

Para programas inteiros mistos, o Knitro oferece duas variantes do algoritmo Branch and Bound. A primeiro é uma implementação padrão, enquanto a segunda é voltada para problemas não-lineares convexos com programação inteira mista. $\mathrm{O}$ pacote não mostra detalhes dos algoritmos utilizados na busca da solução, o que impossibilita sua adaptação a casos especiais, dada a dificuldade de conhecer ou alterar o código de programação. Ainda assim, optou-se neste trabalho pela utilização deste solver com características Branch and Bound para determinar a melhor solução exata de menor valor da função objetivo.

\subsubsection{Branch and Bound}

Branch and Bound (BB) é um algoritmo utilizado para encontrar as melhores soluções de diversos problemas de otimização, especialmente quando esses envolvem variáveis discretas e otimização combinatória. É constituído por uma enumeração sistemática de todas as soluções candidatas, em que grandes subgrupos desses candidatos, considerados inadmissíveis ou "sem futuro" (acarretam valores contrários aos desejados pela função objetivo) são descartados em massa, fazendo-se uso de limites superiores e inferiores estimados a partir da quantidade que se pretende otimizar ([35]).

Por definição, supõe-se que o objetivo é encontrar o valor mínimo de uma função $f(x)$, em que $x$ varia sobre algum conjunto $S$ de soluções admissíveis ou candidatas (o espaço de busca ou região factível). Note-se que se pode descobrir o valor máximo de $f(x)$ encontrando o mínimo de $g(x)=-f(x)$.

Como citado anteriormente, o algoritmo branch-and-bound é um algoritmo enumerativo, cuja estrutura de resolução baseia-se na construção de uma árvore onde os nós representam os problemas candidatos e os ramos representam as novas restrições que devem ser consideradas. Por intermédio dessa árvore, todas as soluções inteiras da região factível do problema são enumeradas de modo implícito ou explícito o que garante que todas as soluções ótimas serão encontradas. A estrutura geral apresenta três elementos fundamentais, que serão detalhados a seguir: separação, relaxação e sondagem ([36]).

O processo de separação divide-se ainda em duas etapas, tal que, dado um conjunto $S$ de candidatos, ele retorna dois ou mais $(n)$ conjuntos menores $S_{1}, S_{2}, \ldots, S_{n}$, cuja união iguala a $S$. Observa-se que o mínimo de $f(x)$ sobre $S$ é $\min \left\{v_{1}, v_{2}, \ldots\right\}$, sendo cada $v_{i}$ um mínimo de 
$f(x)$ em $S_{i}$ ([37]). Esta etapa compreende a chamada ramificação (branching), uma vez que sua aplicação recursiva define a estrutura de árvore (a árvore de busca - the search tree) cujos nós são os subconjuntos de $S$.

$\checkmark$ Toda a solução factível de $S$ é uma solução de somente um dos subproblemas $S_{i}, i=1,2, \ldots, n$.

$\checkmark$ E uma solução factível de qualquer um dos subproblemas $S_{i}, i=1,2, \ldots, n$ é, também, uma solução viável de $S$.

Estas condições asseguram que o conjunto das soluções viáveis de cada um dos subproblemas $S_{i}, i=1,2, \ldots, n$ é uma partição do conjunto das soluções viáveis de $S$. Os subproblemas $S_{i}, i=1,2, \ldots, n$ são denominados descendentes de $S$ e podem, sucessivamente, gerar seus próprios descendentes ([36]).

O interesse na separação, é utilizar-se da estratégia "dividir para conquistar" para resolver o problema $S$. Sem entrar na questão de como se separa o problema de difícil solução, ou determina-se a variável, pode-se descrever, sumariamente, esta estratégia do seguinte modo. Enquanto a solução de $S$ não é possível, separa-se $S$ em dois ou mais subproblemas descendentes, gerando uma lista de problemas candidatos ( $S k$ ). Cada um dos subproblemas descendentes é mais fácil de resolver que o subproblema candidato de origem uma vez que foi acrescentada uma restrição (limite) na variável de separação. Cada nó se associa a um subproblema candidato e cada ramo indica o acréscimo de uma restrição relacionada com a variável empregada na separação. Portanto, à medida que se desce na árvore, a região viável dos descendentes gerados se torna cada vez mais restrita. Este procedimento que implica no acréscimo de novas restrições (limites superiores e inferiores) para o valor mínimo de $f(x)$ dentro de um subconjunto de $S$ dado, é chamado de delimitador (bounding). Esse limite é essencial para fazer o ranking, ou seja, ordenar a seqüência de solução dos subproblemas, e conseqüentemente, em localizar a solução ótima inteira mais rapidamente. O problema continua com a seleção de um dos candidatos dessa lista, tentando resolvê-lo. Se a solução não é possível, o problema é novamente separado e seus descendentes são adicionados à lista dos candidatos; caso contrário o problema é resolvido e uma nova solução é obtida. O valor da função objetivo dessa nova solução é, então, comparado com o valor da solução incumbente, que é a melhor solução viável conhecida até o momento. Caso a nova solução seja melhor do que a solução incumbente, ela se torna a nova incumbente. A seguir, retorna-se à lista e seleciona-se o próximo candidato. Isto é repetido até que a lista esteja vazia, quando se pode afirmar que a solução do problema é dada pela solução incumbente final. Assim, a recursão pára quando o candidato atual conjunto $S$ é reduzido a 
um único elemento, ou também quando o limite superior para o conjunto $S$ corresponde ao limite inferior. De qualquer maneira, qualquer elemento de $S$ será um mínimo da função dentro de $S$.

A forma usual de separação de um problema de programação inteira é realizada através de restrições contraditórias em uma única variável inteira (variável de separação ou de ramificação) ([36]).

A relaxação, etapa inicial, consiste em, temporariamente, ignorar algumas restrições do problema $S$ visando torná-lo mais fácil de resolver. A condição que deve ser satisfeita é que o conjunto de soluções viáveis do problema original $(S)$ esteja contido no conjunto de soluções viáveis do problema relaxado $\left(S_{R}\right)$. Isto implica que:

1. Se $S_{R}$ não tem solução factível, então o mesmo é verdadeiro para $S$.

2. O valor mínimo de $S$ não é menor que o valor mínimo de $S_{R}$.

3. Se uma solução ótima de $S_{R}$ é factível em $S$, então é uma solução ótima de $S$.

Dentre as formas possíveis de relaxação destaca-se a eliminação das restrições de integralidade das variáveis, o que transforma o problema misto em um problema padrão (linear ou não linear).

$\mathrm{Na}$ análise dos problemas candidatos existe a necessidade de determinar quais são promissores e, portanto, devem ser examinados, e quais podem ser sumariamente descartados. Isto é realizado na etapa de sondagem em que o problema candidato ( $S k$ ) é eliminado (descartado para análises futuras), juntamente com todos os seus descendentes, se satisfizer pelo menos um dos seguintes critérios ([36]):

$\checkmark \mathrm{O}$ problema candidato relaxado $\left(S k_{R}\right)$ não tem solução viável. Devido às implicações comentadas anteriormente, isto significa que o problema candidato (Sk) também não tem solução viável.

$\checkmark$ A solução ótima do problema candidato relaxado $\left(S k_{R}\right)$ é pior do que a melhor solução atualmente conhecida para $S$ (solução incumbente). Observar que a solução ótima do problema candidato relaxado é sempre melhor ou igual à solução do problema candidato e de seus descendentes.

$\checkmark$ Caso uma solução ótima do problema relaxado $\left(S k_{R}\right)$ seja factível, também é no problema candidato $(S k)$. Neste caso, como explanado anteriormente, ela é ótima em $S k$, e é também factível em $(S)$. Caso seja melhor que a incumbente atual, a solução deste problema candidato passa a ser a nova incumbente.

De forma resumida, a principal idéia do algoritmo BB é: se o limite inferior para algum nó da árvore $A$ (conjunto de candidatos) é maior que o limite superior de algum outro 
nó $B$, então A pode ser facilmente descartado da busca. Este procedimento de poda, geralmente, é implementada através da manutenção de uma variável global $m$ (compartilhada entre todos os nós da árvore), que registra o mínimo limite superior observado entre todas as sub-regiões analisadas até o momento. Qualquer nó cujo limite inferior é maior do que $m$ pode ser descartado.

$\mathrm{O}$ algoritmo de branch and bound é conceitualmente simples, mas a implementação computacional apresenta maior complexidade e podem aparecer problemas de esforço computacional e de memória na resolução de um problema de grande porte. Os principais parâmetros que determinam a qualidade de um algoritmo de BB estão relacionados com a determinação de uma boa solução incumbente inicial, a escolha da variável para separação e a escolha do próximo subproblema que deve ser analisado.

A seguir, será apresentado um exemplo simples para aplicar, de maneira prática e fácil, o método de programação inteira Branch and Bound. O problema caracteriza-se quando um pintor, ao se deparar com uma bela paisagem, na tentativa de replicá-la em um de seus quadros, tem de recriar a tonalidade do verde da grama desta paisagem. O desafio se constitui de tal forma que o pintor deve testar a coloração, verificando a tonalidade, antes de realizar a mistura, evitando assim o desperdício de seus produtos. Para isso, faz uso de um conta-gotas (equipamento para a mistura de suas tintas) para replicar a tonalidade da maneira mais próxima da que enxerga, criando esta cor a partir das cores básicas que compõem seu arsenal. A seguinte formulação é destinada ao problema:

Minimizar

$$
\left|V d-V_{\text {Grama }}\right|
$$

sujeito a

$$
\begin{aligned}
& 0,3 A m+0,4 A z+1,2 V m-V d=0 \\
& A m, A z, V m \geq 0 \text { e inteiro }
\end{aligned}
$$

sendo Am, Az e Vm as quantidades básicas de gotas das cores amarelo, azul e vermelho, respectivamente, que podem ser utilizadas na composição de suas pinturas, Vd é a tonalidade que se pretende alcançar e $V_{\text {Grama }}$ é a cor verde que o pintor enxerga, de valor de referência igual a 1. Vale salientar ainda, para o melhor entendimento do problema, que a equação (3.9) representa a fórmula para encontrar a tonalidade $\mathrm{Vd}$.

A Figura 3.4 ilustra os passos para aplicação do método BB. Entende-se que $\mathrm{Vd}^{0}$ é a tonalidade ideal e perfeitamente compatível com a cor $\mathrm{V}_{\mathrm{Grama}}$ que o pintor enxerga, porém $\mathrm{Vd}^{0}$ é formada de partes não inteiras de outras cores, em quantidades que o pintor não consegue manejar. Os valores das variáveis com as quais se obtém a resposta de $\mathrm{Vd}^{0}$ igual a 
1,000, compondo a solução do subproblema, foram obtidos através de programação não linear, sendo então, estes, uma solução contínua para o problema e declarados no exemplo como ponto inicial para execução do método.

Para resolver o problema, primeiramente é necessário fazer a expansão da árvore a partir do nó principal ' 0 ', ou seja, inicia-se com a divisão do problema principal em dois subproblemas. Assim, no primeiro passo (i) realiza-se a escolha de uma cor (variável de controle) a partir de uma condição pré-determinada, que no exemplo em questão, optou-se pela cor que estará presente em menor volume na mistura. Desta forma, aproxima-se esta variável para o inteiro próximo, isto é, a variável poderá assumir valores maiores que o inteiro próximo superior e valores menores para o inteiro próximo inferior. No exemplo, a variável Vm pode assumir os valores 0,000 e 1,000, e então se faz o processo de expansão, desta vez contudo, com a variável fixa nestes valores para se obter os nós ' 1 ' e '2'. Esta etapa simboliza o processo de branching. Pode-se observar que no nó ' 2 ', o valor de $\mathrm{Vd}^{2}$ (tonalidade) é muito superior ao valor de referência de $\mathrm{V}_{\mathrm{Grama}}$ (igual a 1), ou seja, a tonalidade de verde está muito longe da que se pretendia encontrar, indicando que a variação entre ambas é muito elevada e por isso este nó e suas derivações pode ser descartado, já que seria muito difícil ou até impossível que a expansão desse nó resultasse em um resultado melhor que o do outro nó (nó ' 1 '). O procedimento que acarreta no descarte de um nó ou ramo decorre da imposição de um limite específico ou cálculo para a obtenção do mesmo, que no exemplo pode ser sugerido como um valor fictício igual a 1,2, indicando que o valor obtido no subproblema se afasta ou supera em demasia a solução desejada, resumindo a etapa de bounding. Entretanto, a eliminação propriamente dita desse mesmo ramo simboliza o pruning. Dirige-se então, para o segundo passo (ii) e executa-se o mesmo procedimento, escolhe-se o nó mais promissor, no caso o nó ' 1 ', e realiza a aproximação de outra variável, dessa vez a variável Az, encontrando o nó '3' e o nó '4'. Mais uma vez percebe-se a existência de outro nó ('4') que também pode ser descartado, e então, no terceiro passo (iii) expande-se o nó ' 3 ' para encontrar os nós ' 5 ' e ‘ 6 '. Analisando o nó 5 , é possível perceber que este está muito distante ainda do valor de referência de $\mathrm{V}_{\mathrm{Grama}}$, indicando uma variação substancial, enquanto que a resposta $\left(\mathrm{Vd}^{6}\right)$ encontrada no nó ‘6’ resulta em uma variação mínima da tonalidade (função objetivo) entre as cores verdes $\mathrm{Vd}$ e $\mathrm{V}_{\mathrm{Grama}}$, e por isso é a solução escolhida.

Como este é um problema com tão poucas variáveis, fica simples verificar quais são as possíveis quantidades de tinta. Mas em problemas práticos, em que geralmente o número de variáveis é maior, faz-se necessária uma formulação matemática mais cuidadosa para que estes problemas possam ser resolvidos, já que os nós podem se expandir exponencialmente. 
i)

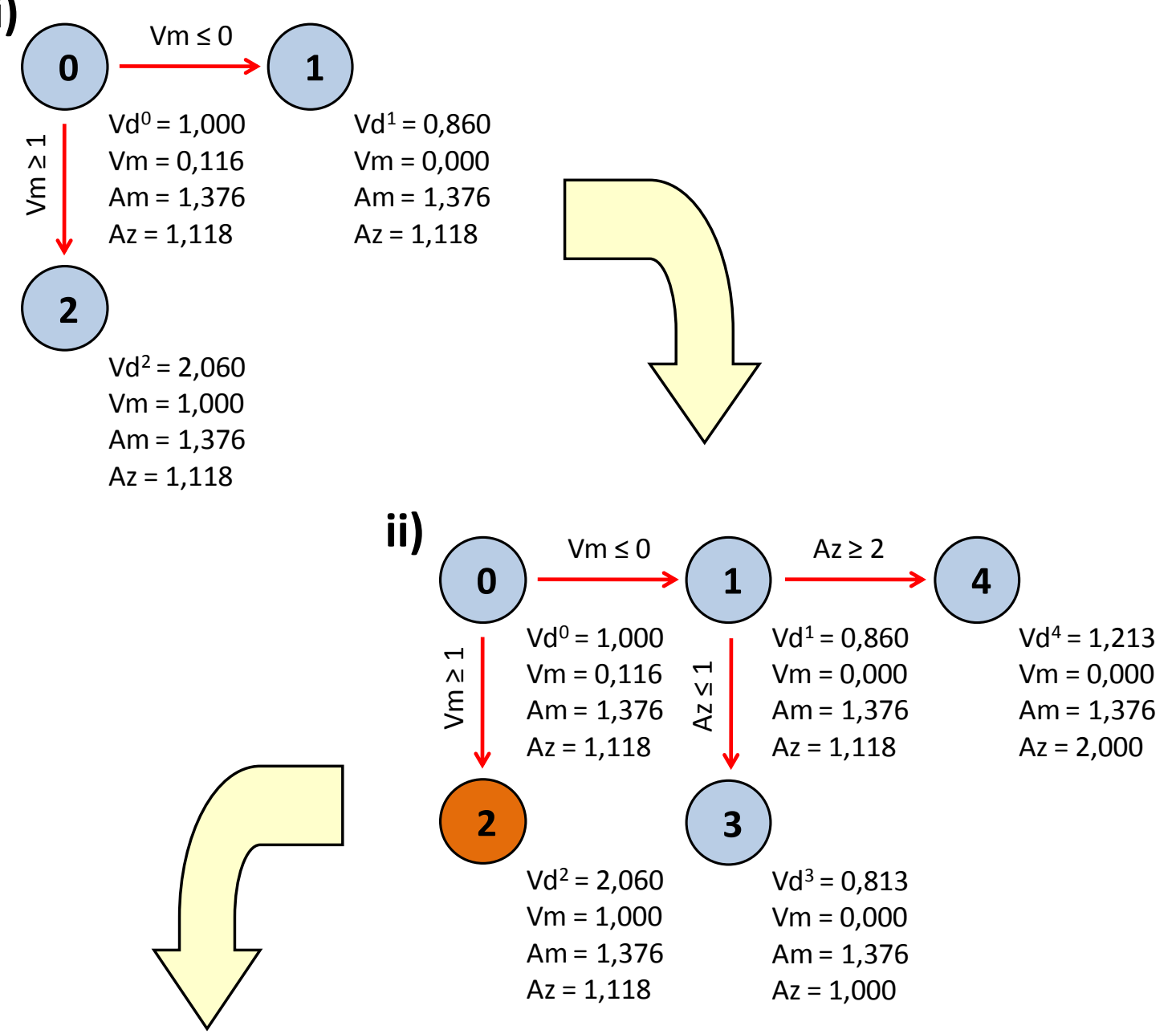

iii)

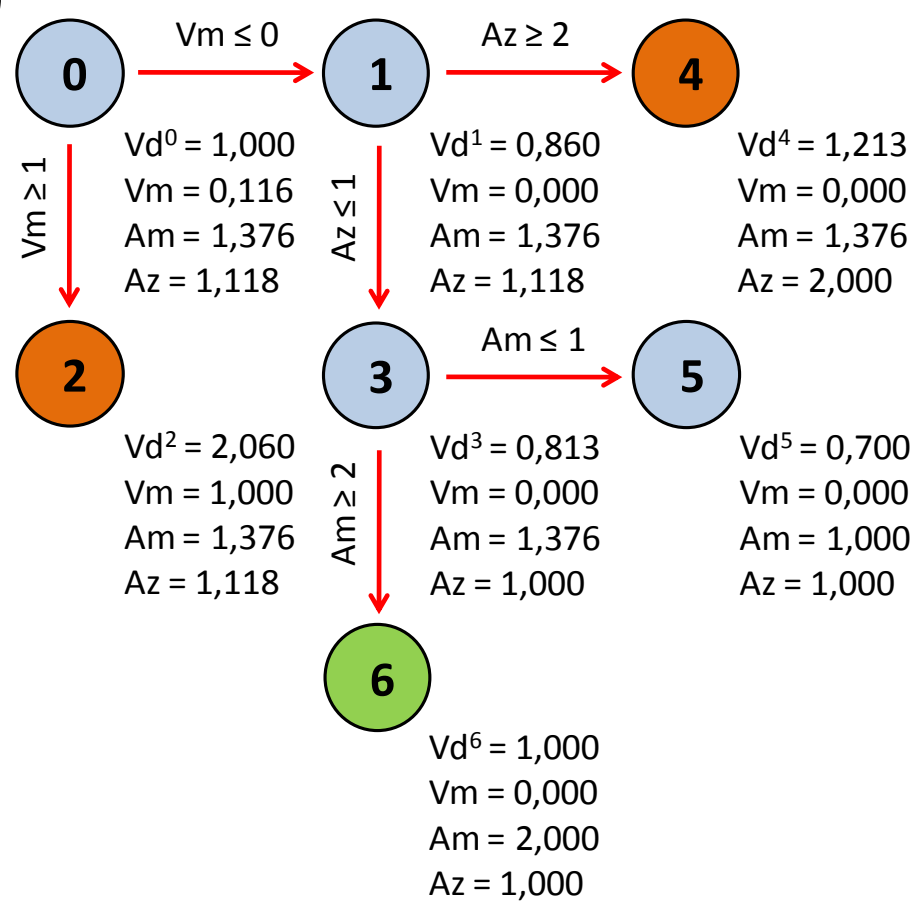

Figura 3.4 - Exemplo de resolução de um problema utilizando o método de branch and bound. 


\subsection{Modelagem dos Componentes do Sistema Elétrico}

O desenvolvimento deste trabalho foi realizado considerando uma rede de distribuição baseada em uma rede real composta por 42 barras, 5 bancos de capacitores, 2 reguladores de tensão e 2 geradores com 13,872 MVA de capacidade, cada um, representando uma central de cogeração movida a biomassa. A quase totalidade do sistema opera com tensão de $13,8 \mathrm{kV}$, com exceção dos alimentadores diretamente conectados na subestação $(84 \mathrm{kV})$ e os geradores $(0,48 \mathrm{kV})$. O diagrama unifilar ilustrado na Figura 3.5 representa a configuração do sistema descrito, enquanto que a Tabela 3.1, Tabela 3.2 e Tabela 3.3 apresentam de forma simplificada os dados dos equipamentos. Os bancos de capacitores são constituídos de módulos de 150 kvar como descritos na Tabela 3.1, e a porcentagem de módulos que serão acionados corresponde justamente ao número inteiro de módulos ativos. Na Tabela 3.2, a posição do tap igual a 0 indica 1 pu de tensão na saída do transformador; a posição +1 indica 1,025 pu de tensão, assim como a posição -1 indica 0,975 pu de tensão no secundário do transformador, assim por diante. Os dados que remetem aos transformadores reguladores de tensão estão na Tabela 3.3, um modelo padrão como descrito anteriormente no Capítulo 2.

Tabela 3.1 - Dados dos bancos de capacitores.

\begin{tabular}{|c|c|c|c|}
\hline $\begin{array}{c}\text { Banco de } \\
\text { Capacitor }\end{array}$ & $\begin{array}{c}\text { Módulos de } \\
\text { 150 kvar }\end{array}$ & $\begin{array}{c}\text { Módulos de } \\
\text { 300 kvar }\end{array}$ & $\begin{array}{c}\text { Potência } \\
\text { Total (kvar) }\end{array}$ \\
\hline BC-1 & 4 & - & 600 \\
\hline BC-2 & 4 & - & 600 \\
\hline BC-3 & - & 4 & 1200 \\
\hline BC-4 & - & 4 & 1200 \\
\hline BC-5 & - & 4 & 1200 \\
\hline
\end{tabular}

Tabela 3.2 - Dados dos transformadores de potência.

\begin{tabular}{|c|c|c|c|c|}
\hline \multirow{2}{*}{$\begin{array}{c}\text { Conexão } \\
\text { das barras }\end{array}$} & \multirow{2}{*}{$\begin{array}{c}\text { Relação de } \\
\text { transformação }\end{array}$} & \multirow{2}{*}{$\begin{array}{c}\text { Potência } \\
\text { (MVA) }\end{array}$} & $\begin{array}{c}\text { Tensão adicional } \\
\text { por tap }(\%)\end{array}$ & $\begin{array}{c}\text { Variação de } \\
\text { posições }\end{array}$ \\
\hline $1-4$ & $84 / 13,8 \mathrm{kV}$ & 15 & 2,5 & $-2 ;-1 ; 0 ;+1 ;+2$ \\
\hline $1-5$ & $84 / 13,8 \mathrm{kV}$ & 15 & 2,5 & $-2 ;-1 ; 0 ;+1 ;+2$ \\
\hline $2-6$ & $0,48 / 13,8 \mathrm{kV}$ & 15 & --- & ---- \\
\hline $3-7$ & $0,48 / 13,8 \mathrm{kV}$ & 15 & ---- & ---- \\
\hline
\end{tabular}




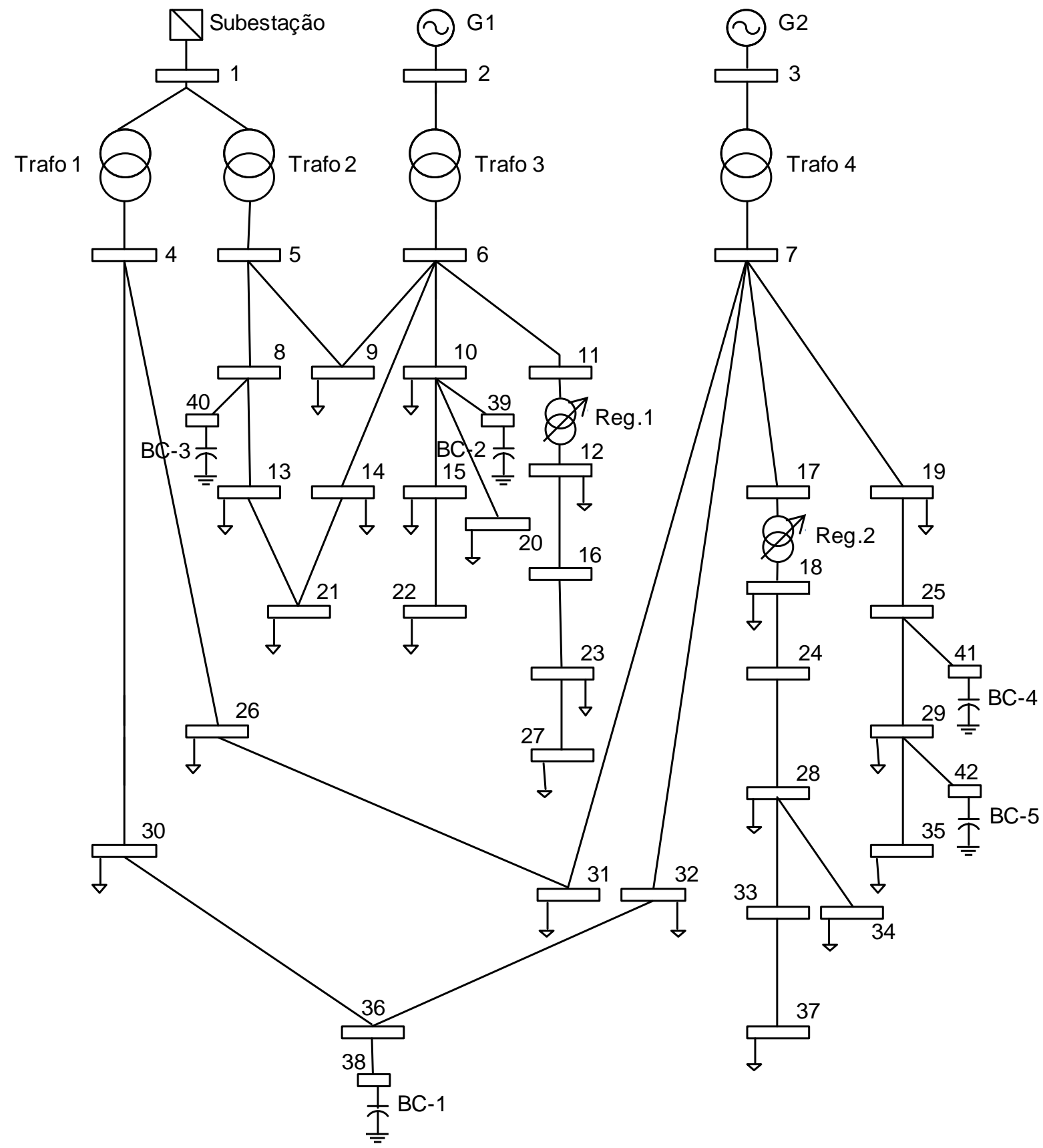

Figura 3.5 - Diagrama unifilar da rede de distribuição.

Tabela 3.3 - Dados dos reguladores de tensão.

\begin{tabular}{|c|c|c|c|c|}
\hline \multirow{2}{*}{$\begin{array}{c}\text { Conexão } \\
\text { das barras }\end{array}$} & \multirow{2}{*}{$\begin{array}{c}\text { Relação de } \\
\text { transformação }\end{array}$} & \multirow{2}{*}{$\begin{array}{c}\text { Potência } \\
\text { (MVA) }\end{array}$} & $\begin{array}{c}\text { Tensão adicional } \\
\text { por tap }(\%)\end{array}$ & Variação de posições \\
\hline $11-12$ & $13,8 / 13,8 \mathrm{kV}$ & 15 & $5 / 8$ & $\begin{array}{c}-16 ;-15 ;-14 ; \ldots 0 ;+1 ;+2 ; \ldots \\
+16\end{array}$ \\
\hline $17-18$ & $13,8 / 13,8 \mathrm{kV}$ & 15 & $5 / 8$ & $\begin{array}{c}-16 ;-15 ;-14 ; \ldots 0 ;+1 ;+2 ; \ldots \\
+16\end{array}$ \\
\hline
\end{tabular}




\subsubsection{Modelagem dos Elementos do Sistema Elétrico de Distribuiç̧ão}

Nesta seção, são apresentados os modelos utilizados na composição das linhas de distribuição, bancos de capacitores, transformadores com comutadores OLTC e reguladores de tensão, geradores distribuídos síncronos, e das cargas para o estudo do problema.

\subsubsection{Linhas de Distribuição}

As expressões que constituem os fluxos de potência ativa e reativa, e que são utilizadas nas linhas de distribuição em função das tensões terminais (magnitude e fase das tensões dos barramentos de saída e chegada da linha) deste trabalho, são elaboradas a partir do modelo $\pi$ das linhas de transmissão de energia elétrica. O modelo equivalente $\pi$ de uma linha de transmissão está representado na Figura 3.6, o qual é definido por três parâmetros: a resistência série $r_{k m}$; a reatância série $x_{k m}$; e a susceptância em derivação $b_{k m}^{s h}$ ([38]). Devido à natureza das linhas de distribuição, ou seja, classe de tensão inferior a $138 \mathrm{kV}$ e comprimentos inferiores a $60 \mathrm{~km}$, elas podem ser classificadas como linhas curtas. Portanto, o elemento em derivação $b_{k m}^{s h}$ pode ser desprezado ([7]).

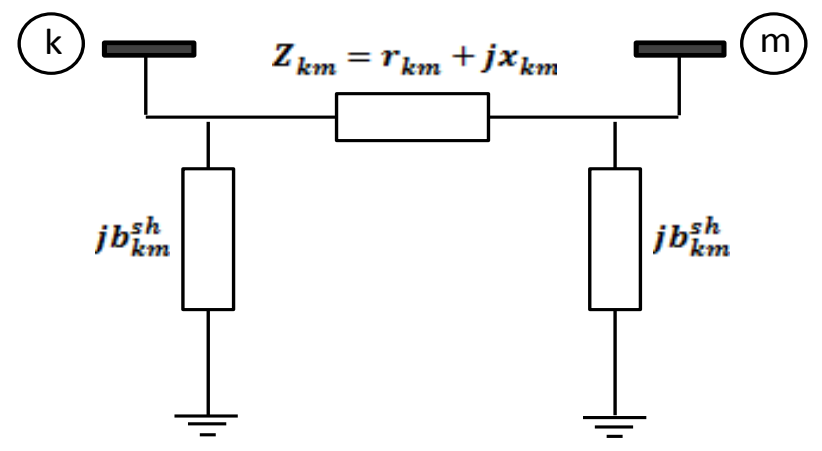

Figura 3.6 - Modelo equivalente $\pi$ de uma linha de transmissão.

Logo, a impedância do elemento série é:

$$
Z_{k m}=r_{k m}+j x_{k m}
$$

e a admitância série é dada pela expressão:

$$
y_{k m}=g_{k m}+j b_{k m}=Z_{k m}^{-1}=\frac{r_{k m}}{r_{k m}^{2}+x_{k m}^{2}}-j \frac{x_{k m}}{r_{k m}^{2}+x_{k m}^{2}}
$$

Ou seja, a condutância série $g_{k m}$ e a susceptância série $b_{k m}$ são dadas respectivamente, por:

$$
g_{k m}=\frac{r_{k m}}{r_{k m}^{2}+x_{k m}^{2}} ; b_{k m}=j \frac{-x_{k m}}{r_{k m}^{2}+x_{k m}^{2}}
$$




\subsubsection{Transformador da Subestação com Comutador de Taps sob Carga}

A representação geral do transformador da subestação com comutador automático de tap sob carga neste trabalho baseia-se em [38], um modelo de transformador em fase tal qual dado na Figura 3.7, que consiste basicamente de um autotransformador ideal com relação de transformação de 1:a e uma admitância série na barra receptora. É importante esclarecer que o mesmo não é padrão do Institute of Electrical and Electronics Engineers (IEEE), o qual usa uma relação de $a: 1$.

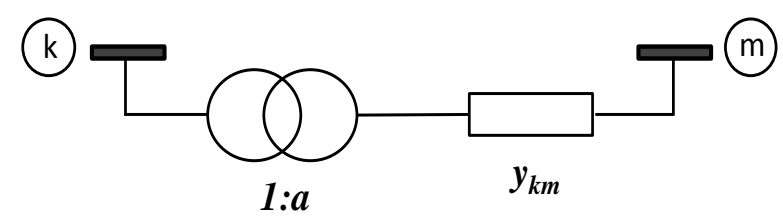

Figura 3.7 - Modelo de transformador em fase.

O modelo de transformador em fase pode ainda ser representado por um circuito equivalente $\pi$ de um transformador de dois enrolamentos, conforme ilustrado na Figura 3.8.

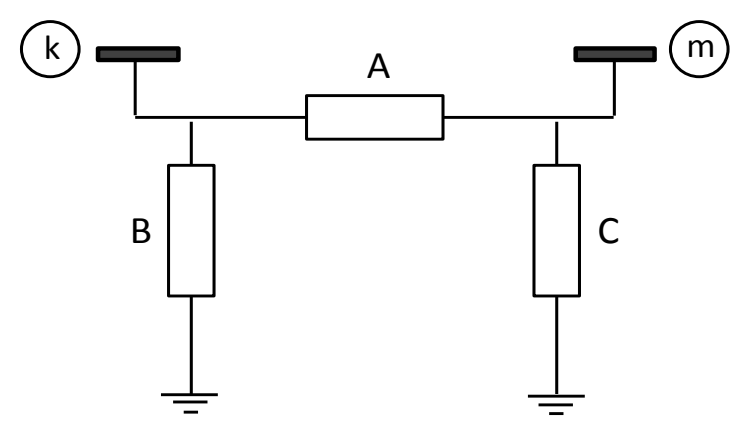

Figura 3.8 - Circuito equivalente $\pi$ de um transformador em fase.

A determinação das admitâncias $A, B$ e $C$ do circuito pode ser mais bem explicada em [38], cabendo apresentar aqui somente as expressões resultantes:

$$
\begin{aligned}
& A=a_{k m} y_{k m} \\
& B=a_{k m}\left(a_{k m}-1\right) y_{k m} \\
& C=\left(1-a_{k m}\right) y_{k m}
\end{aligned}
$$

sendo $a_{k m}$ a relação de transformação do transformador em fase conectado ao ramo $k-m$ (tap), admitindo o comutador de taps no lado secundário do equipamento, e $y_{k m}$ é a admitância série do transformador.

\subsubsection{Transformador Regulador de Tensão}

Neste trabalho, os reguladores de tensão também foram representados por um circuito equivalente $\pi$ de um transformador de dois enrolamentos, porém com algumas especificações 
que os diferenciam. Estas incluem a tensão adicionada por comutação de tap, fazendo com que os valores de mínimo e máximo alcancem $\pm 5,0 \%$ no lado secundário do transformador da subestação, e $\pm 10,0 \%$ no secundário dos transformadores reguladores de tensão.

Esta mesma modelagem de reguladores de tensão já havia sido utilizada anteriormente em diversos trabalhos, como em [39], [40] e [41].

\subsubsection{Banco de Capacitores}

A modelagem dos bancos de capacitores pode ser explicada através da inserção de um componente em derivação, representado pela admitância $j b_{k}^{s h}$, nas barras do sistema elétrico. Seguindo uma representação similar ao que acontece com as equações do problema de fluxo de carga, a injeção de potência reativa devida ao elemento shunt, adota a mesma convenção usada para as injeções de potências ativas e reativas, como indicadas na Figura 3.9.

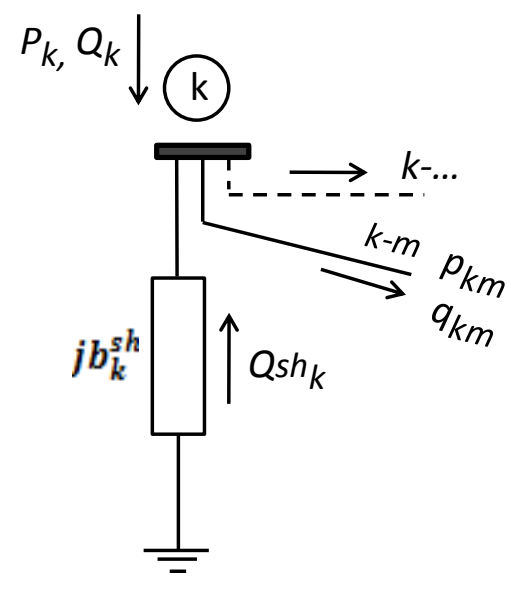

Figura 3.9 - Convenção de sinais para fluxos e injeções de potências.

Com relação à formulação da equação da potência reativa fornecida pelo banco de capacitores, o chaveamento de cada módulo é representado por uma variável de tap conforme a expressão (3.17):

$$
Q s h_{k}=\operatorname{tap}_{k} \times V_{k}^{2} b_{k}^{s h}
$$

em que:

$b_{k}^{s h}$ é a susceptância ligada à barra $k$.

$\operatorname{tap}_{k}$ indica a quantidade de módulos ativos do banco de capacitores $Q s h_{k}$ na barra $k$.

\subsubsection{Geradores Síncronos Distribuídos}

Os geradores distribuídos são aqui representados, de maneira aproximada, como dispositivos de carga com potência ativa positiva para o estudo de fluxo de carga em regime permanente ([7]). O modo de funcionamento dos geradores distribuídos depende do contrato 
de conexão, e neste trabalho serão consideradas operações em que o sistema de excitação funciona como regulador de tensão (controle PV) ou como regulador do fator de potência (controle PQ). Mais detalhes são apresentados no decorrer do trabalho.

\subsubsection{Cargas}

Sobre as cargas, destaca-se que estas apresentam uma variação que pode ser significativa com as horas do dia, dias da semana, estações do ano, etc. A atribuição de valores para as cargas pode ser uma tarefa complexa, dependendo da finalidade específica do estudo a ser realizado. A variação da carga dentro de algum período de tempo foi representado pela demanda, que é a média dos valores instantâneos da carga em um intervalo, geralmente igual a 15 minutos, tal como exemplificado na Figura 3.10. Quando estes valores de potências (ativa e/ou reativa) são registrados em um gráfico em função das horas do dia, obtém-se a chamada curva de carga diária (curva de demanda) ([17]). Estas curvas de carga apresentam-se bastante diferentes, dependendo do uso da energia elétrica realizado pelo consumidor. Assim, muitas vezes os consumidores são classificados em classes: industrial, comercial, residencial, rural, serviço público, iluminação pública e outros ([24]).

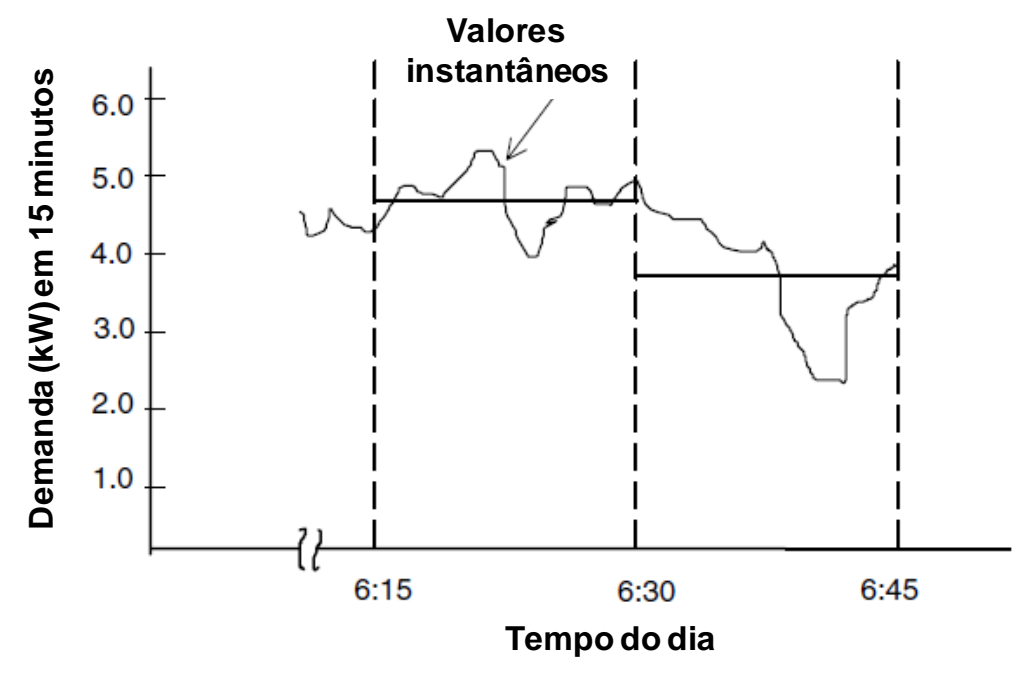

Figura 3.10 - Curva de demanda (Fonte: [17]).

As cargas ativa e reativa utilizadas no sistema em estudo foram consideradas como consumidores de energia ativa e reativa ligadas à rede de distribuição, e assim, modeladas como potência constante considerando os padrões de curva de demanda obtidos de [42]. Foram admitidos cinco padrões de curva de demanda: industrial01, industrial02, industrial03, comercial e residencial, conforme apresentados na Figura 3.11. Nesta figura, os valores estão em por unidade (pu) sendo que os valores de base para as potências são apresentados na Tabela 3.4. Ressalta-se que os mesmos padrões de consumo foram considerados para potência 
ativa e reativa. A Figura 3.12 apresenta a curva de demanda agregada de potência ativa, considerando todas as cargas do sistema elétrico da Figura 3.5.

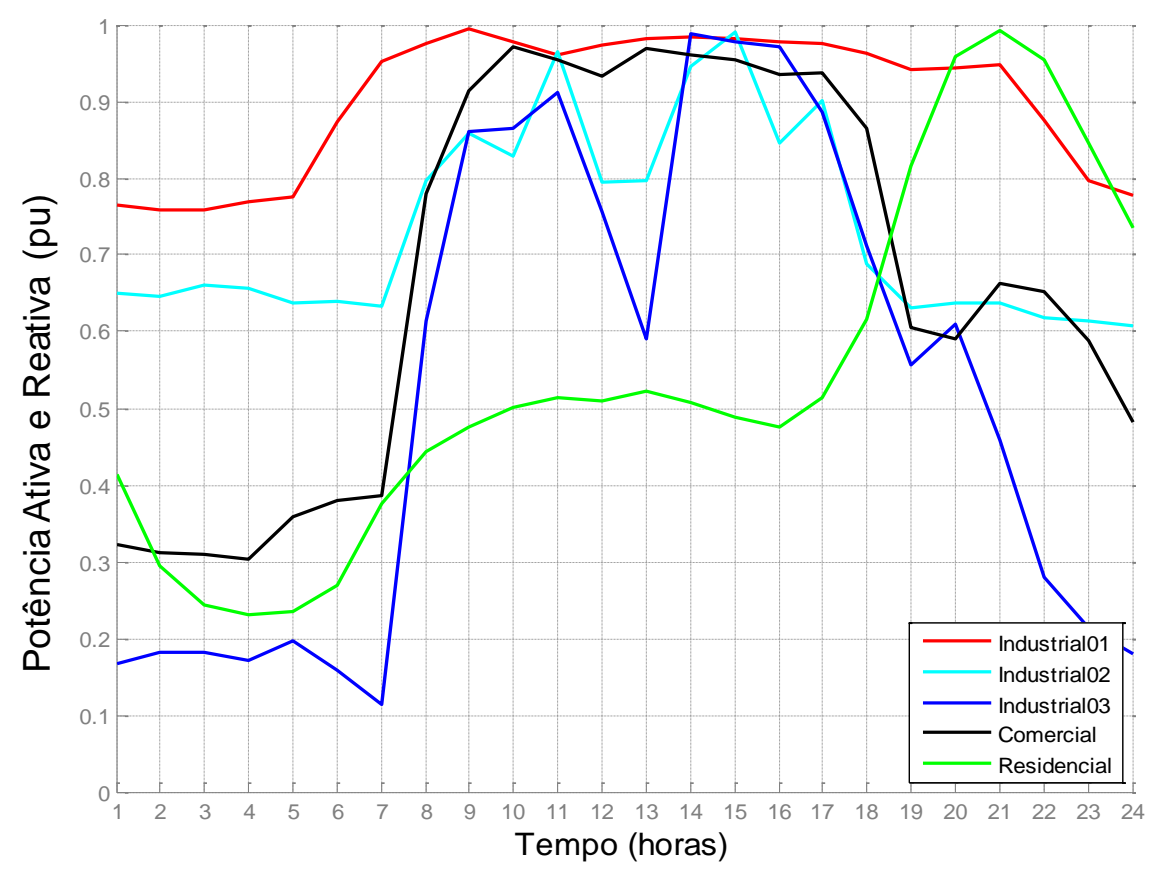

Figura 3.11 - Tipos de curvas de demanda (potência ativa e reativa). 
Tabela 3.4 - Tipos e valores de potência-base para as cargas.

\begin{tabular}{|c|c|c|c|}
\hline \multirow{2}{*}{ Barra } & \multicolumn{2}{|c|}{ Carga } & \multirow{2}{*}{ Tipo de Carga } \\
\cline { 2 - 3 } & (MW) & (Mvar) & \\
\hline 9 & 0,91 & 0,30 & Industrial01 \\
\hline 10 & 0,64 & 0,21 & Industrial02 \\
\hline 11 & 0,34 & 0,11 & Industrial03 \\
\hline 12 & 0,21 & 0,07 & Comercial \\
\hline 13 & 0,09 & 0,03 & Residencial \\
\hline 14 & 0,45 & 0,15 & Industrial03 \\
\hline 16 & 0,26 & 0,09 & Industrial02 \\
\hline 17 & 2,11 & 0,69 & Industrial01 \\
\hline 18 & 0,79 & 0,26 & Comercial \\
\hline 19 & 0,09 & 0,03 & Residencial \\
\hline 20 & 1,03 & 0,34 & Comercial \\
\hline 21 & 2,21 & 0,73 & Residencial \\
\hline 24 & 0,02 & 0,01 & Comercial \\
\hline 25 & 1,68 & 0,55 & Industrial01 \\
\hline 26 & 1,59 & 0,52 & Industrial02 \\
\hline 27 & 2,48 & 0,81 & Industrial03 \\
\hline 28 & 0,03 & 0,01 & Comercial \\
\hline 29 & 0,13 & 0,04 & Residencial \\
\hline 30 & 0,62 & 0,2 & Comercial \\
\hline 32 & 0,82 & 0,27 & Residencial \\
\hline 33 & 0,33 & 0,11 & Comercial \\
\hline 35 & 1,99 & 0,65 & Residencial \\
\hline
\end{tabular}

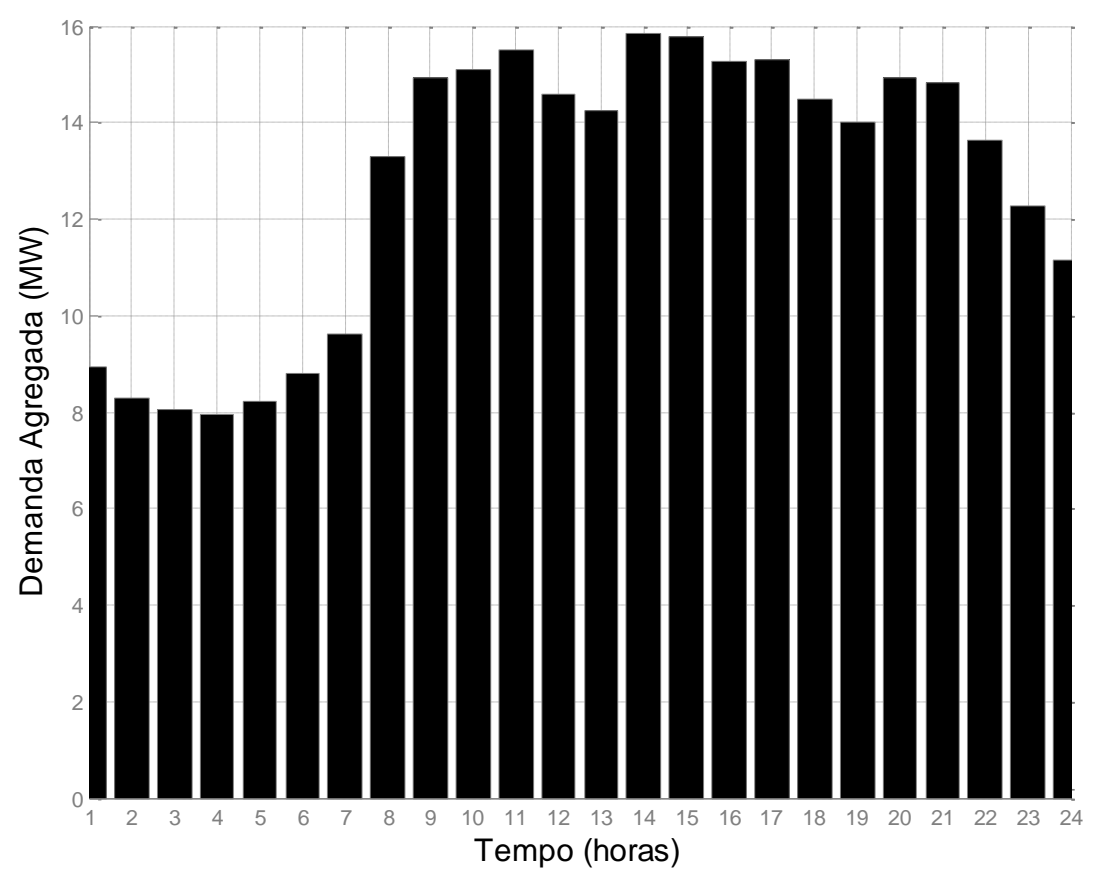

Figura 3.12 - Curva de demanda agregada. 


\section{Capítulo 4}

\section{Estratégias de Operação para os Dispositivos Reguladores de Tensão em Sistemas de Distribuição com GD}

Diversas podem ser as estratégias para atingir a operação adequada entre geradores distribuídos e os equipamentos de regulação de tensão. Estas estratégias podem incluir meios de comunicação, uma programação inteligente, manobras consequientes da medição dos valores elétricos trabalhados pelos equipamentos, ou mesmo uma combinação desses artifícios. Deve-se analisar primeiramente a interação dos dispositivos de controle de tensão dispostos no sistema de distribuição, e depois as conseqüências da inserção das unidades de geração, incluindo seus diversos tipos de sistemas de controle de excitação, para um melhor desempenho do sistema.

Neste capítulo, será abordado de maneira mais direta o principal objetivo do trabalho, que é propor a formulação de um problema de otimização que permita obter uma configuração otimizada de operação dos dispositivos reguladores de tensão em sistemas de distribuição diante da inserção de unidades de geração distribuída. Aqui serão apresentadas as filosofias de operação dos geradores, bem como as formulações matemáticas das estratégias consideradas no processo de otimização. O tópico a seguir discutirá as filosofias de controle da excitatriz de geradores distribuídos e o efeito destas na rede de distribuição.

\subsection{Filosofia de Operação dos Geradores Distribuídos}

É bem verdade que as redes de distribuição têm sido projetadas por muito tempo considerando a subestação da concessionária como a única fonte com capacidade de abastecimento de energia. Com os estudos e a inserção das unidades de geração distribuída, essa realidade se transformou, pois ocorreu o aparecimento de outras fontes de energia nos sistemas de distribuição ([1], [11], [43]). Assim, é altamente desejável que análises criteriosas 
sejam realizadas quando unidades de geração estão para ser integradas ao sistema de distribuição. Isso se faz necessário para estabelecer as condições de operação entre os geradores distribuídos e a rede elétrica para garantir o fornecimento de energia dentro dos padrões de qualidade exigidos pelas agências reguladores. Além disso, deve-se garantir que a rede de distribuição por si só seja capaz de fornecer energia elétrica aos consumidores, devido à possibilidade de que os geradores sejam desconectados em função da ocorrência de alguma contingência, ou mesmo em situações de desligamento programado ([10], [18]). Logo, é imprescindível um prévio conhecimento das manobras necessárias para a restauração e normalização imediata dos níveis de tensão. Portanto, este é o primeiro passo de um procedimento para melhor integrar as fontes de geração distribuída.

Uma vez definida a configuração operativa do sistema elétrico sem os geradores, são inseridas as unidades de geração. Estudar a viabilidade operacional do controle de excitação de unidades de geração é fundamental, pois os resultados provenientes deste procedimento podem significar menores perdas elétricas e conseqüentemente ganhos econômicos, além de prover uma melhoria dos níveis de tensão entregue aos consumidores.

Quando presentes no sistema, estas unidades podem operar com controle do tipo PV (potência ativa e tensão constantes), isto é, atuando como um regulador de tensão, e PQ (potência ativa e reativa constantes), atuando como um regulador de potência reativa ou de fator de potência.

\subsubsection{Gerador Distribuído como Regulador de Tensão}

Sob controle do tipo PV, o gerador poderá absorver ou prover potência reativa ao sistema a fim de manter a tensão no valor determinado. Essa possibilidade permite a melhoria do perfil de tensão da rede de distribuição ([1], [13], [25]). Este, porém, não é o único ganho. Também é ressaltado pelos trabalhos anteriormente citados que a atuação da excitatriz como um regulador de tensão possibilita uma maior penetração de geração no sistema elétrico de distribuição, sem prejudicar o seu desempenho.

A operação do gerador com o controle de excitação na condição de regulador de tensão pode acarretar um baixo fator de potência e conseqüentemente pagamentos extras devido à circulação de potência reativa em excesso, o que leva muitos proprietários desses geradores a não optar por este tipo de controle. Assim, para evitar tal cobrança, sob o modo de controle do tipo PV, devem ser analisadas a partir daí não só mais o perfil de tensão e as perdas de energia, mas também o fator de potência das unidades de geração e o carregamento 
dessas máquinas. Portanto, carregamentos superiores a $105 \%$ e fator de potência inferior a 0,92 devem ser consideradas condições proibitivas de operação. Estas considerações serão admitidas neste trabalho.

Sustentar a tensão terminal constante durante um período de operação (dias, meses etc), quando o gerador opera como um regulador de tensão, é a prática mais usual em sistemas em que esse tipo de operação é recomendado. Por outro lado, em determinadas situações, a tensão terminal das unidades de geração distribuída pode ser configurada para ser variável, dependendo do nível de carregamento do sistema. Quando isto ocorre, existe a possibilidade de que a alteração da tensão terminal dos geradores possa resolver problemas relacionados à extrapolação da faixa de tensão regulamentada por lei. Em momentos em que é necessário um grande número de manobras dos dispositivos reguladores, esta condição pode vir a ser bastante favorável, normalizando os níveis de tensão e diminuindo a quantidade de chaveamentos de comutadores de taps e unidades de bancos de capacitores.

Ressalta-se que considerar a tensão do gerador distribuído como variável é uma proposta deste trabalho ainda não discutida na literatura técnica que trata do assunto aqui abordado. Sendo assim, uma das contribuições desta dissertação é demonstrar que existem estratégias de controle em que a tensão controlada do gerador pode ser variada para acomodar diferentes níveis de carregamento do sistema elétrico, visando melhorar seu desempenho operativo, sobretudo em relação ao perfil de tensão e perdas elétricas.

\subsubsection{Gerador Distribuído como Regulador de Potência Reativa}

Em relação ao controle $\mathrm{PQ}$, a excitatriz do gerador atuando como regulador de potência reativa ou fator de potência é uma estratégia comumente adotada por proprietários dessas máquinas para evitar o pagamentos extras relativos à produção ou consumo excessivo de potência reativa. Logo, esse modo de controle garante que o fator de potência da máquina fique sempre acima de 0,92. Adicionalmente, operando de forma a manter o fator de potência capacitivo, geradores síncronos podem trazer outros benefícios como corrigir o fator de potência de cargas locais, principalmente no caso de autoprodutores industriais ([25]).

O gerador pode ser configurado para operar com potência reativa nula, garantindo sempre fator de potência unitário. Esta configuração tem sido recomendada pelas concessionárias de energia elétrica, muito embora se perca a capacidade de suporte de potência reativa dos geradores. Em contrapartida, essa prática pode provocar a elevação exagerada das tensões nodais especialmente em períodos de carga leve ([12]). Assim, uma 
redução na potência ativa gerada poderia ser uma medida eficaz para que o perfil de tensão permaneça dentro dos limites. No entanto, restringir o montante de potência ativa fornecida pelos geradores distribuídos não é uma prática comum abordada nos acordos contratuais que regem este mercado, nem tão pouco interessantes aos proprietários desses geradores. Os contratos de comercialização de energia estabelecidos entre produtor independente e concessionárias garantem que a energia contratada, seja esta parcial ou totalmente produzida por um produtor, dentro do período de tempo de contrato, deve ser entregue de forma regular, contínua e segura sob pena de multas por inadimplência para os casos em que a fiscalização da ANEEL constatar irregularidades ([23]). Entretanto, outra contribuição deste trabalho de mestrado é apresentar uma análise, quando as unidades de geração operam com controle PQ, em que a potência fornecida torna-se também uma variável de controle a fim de obter um melhor desempenho operativo do sistema sob os diferentes níveis de carregamento.

\subsection{Formulação Matemática do Problema de Otimização}

É proposta deste trabalho realizar a tarefa de obter condições operativas viáveis dos dispositivos reguladores de tensão em um sistema de distribuição de energia elétrica com a presença de unidades de geração distribuída, cujo método consiste em encontrar uma solução para o problema de otimização em que os resultados correspondam à melhor configuração possível para operação dos equipamentos de regulação de tensão. Como explanado no Capítulo 3, um problema de otimização deve possuir características bem definidas. Por meio da interpretação do problema que se deseja resolver, equações matemáticas são modeladas. Estas equações devem conter uma função objetivo na qual se espera maximizar ou minimizar alguma conseqüência, seja esta um efeito desejável ou inevitável, e equações de restrição, que representam os limites e a constituição do problema.

Como descrito no capítulo anterior, o problema foi modelado em interface AMPL. O mesmo converte os dados de programação e torna possível o problema ser solucionado através do método Branch and Bound. Um algoritmo que utiliza este método é capaz de resolver problemas de programação não linear inteira mista, e por isso faz-se necessário o pacote de solvers Knitro. Programação não linear, pois o problema contém funções não lineares (função objetivo, restrições de igualdade, etc.), e inteira porque o mesmo dispõe de variáveis tanto contínuas como discretas. As variáveis discretas compreendem os taps dos transformadores da subestação, dos reguladores de tensão, e do chaveamento de unidades de bancos de capacitores. 
Diversas filosofias de operação de geradores síncronos serão ponderadas, por isso diferentes restrições operacionais desses geradores serão consideradas para cada simulação, além das restrições do sistema elétrico e de seus componentes.

Neste trabalho, duas metodologias serão estudadas e analisadas em paralelo, com o objetivo de compará-las. Assim, tem-se um primeiro problema de otimização cuja função objetivo visa minimizar a variação dos níveis de tensão nos barramentos, e um segundo em que a função objetivo visa a redução das perdas elétricas nos alimentadores. Pode-se dizer que a formulação destas metodologias é resultado do estudo e da captação de informações das diversas referências comentadas no Capítulo 2, visando contribuir com a literatura técnica já existente na área. Entre as contribuições têm-se:

- Englobar todos os três dispositivos mais usuais na rede de distribuição e não só escolher alguns, como em [8], em que se utilizou somente o tap do transformador da subestação e bancos de capacitores, ou [18], que fez uso também dos bancos de capacitores em conjunto com os reguladores de tensão;

- Como em [25] fazer um estudo da consequiência de inserção de geradores distribuídos nos níveis de tensão entregue aos consumidores, assunto estudado a fundo por [10], e nas perdas elétricas, estudado primeiramente por [15], mas desta vez focando na coordenação de todos os dispositivos reguladores de tensão de um sistema de distribuição;

- Propor uma estratégia de operação dos dispositivos de regulação de tensão, quando estes sofrem influência de geradores distribuídos cuja tensão terminal é uma variável controlada, e quando a potência ativa pode variar visando uma melhor condição operativa do sistema;

O conjunto destas idéias torna este um trabalho inovador, diferenciando-o daqueles apresentados anteriormente.

\subsubsection{Minimização dos Desvios de Tensão}

Neste item é apresentada a formulação do problema de otimização, cuja função objetivo é minimizar os desvios das tensões nodais, tomando 1 pu como valor de referência. Optou-se por esse valor com o objetivo de manter as tensões nodais próximas aos seus valores nominais, evitando que as mesmas fiquem muito próximas aos limites recomendados por normas, por questões econômicas, de segurança e bom desempenho na operação dos equipamentos dos consumidores. Do ponto de vista do consumidor, uma elevação no valor de 
tensão em regime permanente pode provocar o aumento no consumo, refletindo na fatura de energia elétrica. A questão da segurança está relacionada ao risco de sobretensões momentâneas capazes de danificar equipamentos dos consumidores. Estando as tensões nodais próximas a 1,05 pu, as intensidades das sobretensões podem ser maiores. Essas sobretensões podem ser causadas por eventos na rede elétrica, tais como desligamentos de ramais, acionamento indevido de bancos de capacitores etc. Finalmente, operar com as tensões próximas ao limite inferior, ou seja, 0,93 pu, pode levar ao mau funcionamento de certos equipamentos nas instalações dos consumidores mediante condições de sobtensões. Esses fatos justificam, portanto, a recomendação de aproximar os valores das tensões nodais de $1 \mathrm{pu}$.

São considerados os modos de controle do sistema de excitação, limites de compensação de reativos e taps dos dispositivos reguladores de tensão. Assim, o problema pode ser formulado da seguinte maneira:

$$
\begin{aligned}
& \text { Min } f=\sum_{k=1}^{N B}\left(V_{s e t}-V_{k}\right)^{2} \\
& \text { s.a. } \\
& \qquad P=P_{k}^{e s p}-P_{k}=0 \\
& \Delta Q=Q_{k}^{e s p}-Q_{k}=0 \\
& \quad V_{k}^{\text {mín }}<V_{k}<V_{k}^{\text {máx }}
\end{aligned}
$$

a variável de comutação de taps dos transformadores é representada por tap $p_{k m}$, variando de 0,95 a 1,05 em passos de 0,25 para os transformadores da subestação, tal como na equação (4.5);

$$
\operatorname{tap}_{k m} \in\{0,950 ; 0,975 ; 1,000 ; 1,025 ; 1,050\}
$$

e varia de 0,90 a 1,10 em passos de 0,0625 para os autotransformadores reguladores de tensão, sendo apresentada na equação (4.6);

$$
\begin{aligned}
& \operatorname{tap}_{k m} \in\{0,90 ; 0,90625 ; 0,91250 ; \ldots ; 1,00 ; \ldots ; 1,08750 ; 1,09375 ; 1,10\} \\
& Q s h_{k}^{\text {mín }}<Q s h_{k}<Q s h_{k}^{\text {máx }} \\
& f p G_{k}^{\text {mín }}<\left|f p G_{k}\right|<f p G_{k}^{\text {máx }} \\
& 0<\text { Carreg }_{k}<\text { Carreg }_{k}^{\text {máx }}
\end{aligned}
$$

em que:

$k$ é igual a $1, \ldots$, até o número de barras do sistema elétrico sob estudo $(N B)$.

$V_{\text {set }}$ é a constante de tensão de referência (em pu).

$V_{k}$ a variável que representa a tensão nodal das barras. 
$P_{k}^{e s p}$ e $Q_{k}^{e s p}$ são os valores especificados de suprimento ou consumo (carga) de potência ativa e reativa na barra $k$ respectivamente (em pu).

$P_{k}$ e $Q_{k}$ são as variáveis nodais que representam as equações de injeção de potência ativa e reativa na barra $k$ respectivamente.

$V_{k}^{m i ́ n}$ e $V_{k}^{m a ́ x}$ são a margem inferior e superior dos limites da faixa de níveis aceitáveis de tensão da barra $k$ (em pu).

$\operatorname{tap}_{k m}$ representa neste trabalho o acréscimo ou decréscimo da tensão do secundário em relação à tensão do primário do transformador da subestação ou regulador de tensão. Por exemplo, um valor de 1,025 representa que a tensão do secundário é 1,025 vezes o valor da tensão do primário. Essa variável é tratada como uma variável discreta, representando a necessidade de uma programação inteira mista, e pode assumir somente os valores tal como apresentados nas Tabela 3.2 e Tabela 3.3.

$t a p_{k m}^{m i n}$ e $t a p_{k m}^{m a ́ x}$ são os alcances mínimo e máximo das manobras de comutação de tap do transformador da subestação e regulador de tensão no ramo $k-m$.

$Q s h_{k}^{m i n}$ e $Q s h_{k}^{m a ́ x}$ são o mínimo e máximo valor de potência reativa fornecida pelo banco de capacitor conectado na barra $k$ respectivamente.

$f p G_{k}^{m i ́ n}$ e $f p G_{k}^{m a ́ x}$ são os fatores de potência que limitam a operação dos geradores distribuídos síncronos na barra $k$, quando estas máquinas operam com controle PV.

Carreg $G_{k}^{\text {máx }}$ é o máximo carregamento que limita a operação dos geradores síncronos na barra $k$, quando estas máquinas operam com controle PV.

Como pode ser observado, a função objetivo da metodologia que propõe minimizar a os desvios de tensão é definida por apenas dois parâmetros. Eleva-se o somatório ao quadrado, com a finalidade de assegurar que a diferença entre as tensões resulte em um valor positivo, evitando a ocorrência de possíveis subtrações que distorceriam a solução do problema. Um operador matemático que garante o valor absoluto de operações como esta, o módulo (no caso, o comando de programação), não possui uma boa aceitação por parte do solver, sendo então essa uma idéia necessária para contornar dificuldades na modelagem. Já as restrições de igualdade que compõem este problema são definidas através das equações de variação de potência ativa e reativa, $\Delta P$ e $\Delta Q$ respectivamente. As variáveis $P_{k}$ da equação (4.2) e $Q_{k}$ da equação (4.3) podem ser substituídas pelas expressões dispostas a seguir:

$$
\begin{aligned}
& P_{k}=V_{k} \sum_{m \in k} V_{m}\left(G_{k m} \cos \left(\theta_{k}-\theta_{m}\right)+B_{k m} \operatorname{sen}\left(\theta_{k}-\theta_{m}\right)\right) \\
& Q_{k}=V_{k} \sum_{m \in k} V_{m}\left(G_{k m} \operatorname{sen}\left(\theta_{k}-\theta_{m}\right)-B_{k m} \cos \left(\theta_{k}-\theta_{m}\right)\right)
\end{aligned}
$$


sendo $V_{k}, V_{m}, \theta_{k}$ e $\theta_{m}$ os valores de módulo e ângulos das tensões das barras terminais do ramo $k-m$, e $G_{k m}$ e $B_{k m}$ são as partes real e imaginária dos elementos da matriz admitância nodal. Este conjunto de equações de fluxo de carga pode ser mais bem explicado em [38].

Com relação às restrições de desigualdade, estas incluem os limites de tensão regulamentados por lei, sendo o valor mínimo igual a 0,93 pu e o máximo igual a 1,05 pu, ou seja, em um sistema de 13,8 kV, tal como apresentado na Tabela 2.1. Entre as restrições de desigualdade, também estão os limites de comutação de tap do transformador da subestação e dos reguladores de tensão. Tal como apresentado na equação (3.14), o chaveamento dos bancos de capacitores possui uma variável de tap na expressão do componente de injeção de potência reativa, obtendo:

$$
Q s h_{k}=\operatorname{tap}_{k} \times V_{k}^{2} b_{k}^{s h}
$$

em que:

$b_{k}^{s h}$ é a susceptância ligada à barra $k$.

$\operatorname{tap}_{k}$ indica a quantidade de módulos ativos do banco de capacitores com potência total $Q s h_{k}$ na barra $k$. Neste trabalho, essa variável será representada também como variável discreta. Logo, nos resultados apresentados no próximo capítulo ela será mostrada como uma porcentagem da potência total do banco de capacitores. Estes possuem em sua totalidade 4 módulos, seja de 150 ou 300 kvar, tal como apresentados na Tabela 3.1, e assim seus valores podem assumir $0 \%$ em que nenhum módulo está ativo, ou 25, 50, 75, ou mesmo 100\% de módulos ativos.

Com relação aos limites de operação dos geradores distribuídos síncronos, estes compreendem o fator de potência e carregamento máximo permitido, de suma importância quando essas máquinas trabalham com controle PV. Sabe-se que o fator de potência dos geradores pode ser dado pela seguinte equação:

$$
f p G_{k}=\cos \left[\operatorname{arctg}\left(\frac{Q g_{k}}{P g_{k}}\right)\right]
$$

sendo $P g_{k}$ e $Q g_{k}$ potência ativa gerada e a potência reativa gerada ou consumida pelas unidades de geração. E, como explanado anteriormente, os valores permitidos devem estar entre 0,92 e 1 , sendo então $f p G_{k}^{\text {mín }}$ igual 0,92 e $f p G_{k}^{\text {máx }}$ o valor unitário, 1.

Foi admitido neste trabalho que o carregamento das máquinas síncronas não pode ultrapassar $105 \%$. Este limite pode ser dado pela equação:

$$
\text { Carreg } G_{k}=\frac{\sqrt{P g_{k}^{2}+Q g_{k}^{2}}}{S_{\text {Nominal }}} \times 100 \%
$$

em que $S_{\text {Nominal }}$ é a potência nominal das unidades de geração distribuída. 


\subsubsection{Minimização das Perdas Elétricas}

No processo de otimização em que o foco é minimizar as perdas elétricas, o problema é constituído pela função objetivo dada por:

$$
\operatorname{Min} f=\sum_{r=1}^{N R} g_{k m}\left(V_{k}^{2} a_{k m}^{2}+V_{m}^{2}-2 V_{k} V_{m} a_{k m} \cos \left(\theta_{k}-\theta_{m}\right)\right)
$$

em que $r$ é o ramo que compreende a linha de distribuição entre as barras $\mathrm{k}-\mathrm{m}$, e varia de 1 até número total de linhas $(N R)$, enquanto $g_{k m}$ é a condutância série desta mesma linha.

As restrições de igualdade e de desigualdade não diferem das apresentadas na metodologia anterior. Assim, com a implementação das metodologias propostas espera-se obter as condições operativas do gerador distribuído e dos dispositivos de regulação de tensão em sistemas de distribuição, de forma que estes últimos estejam coordenados para evitar violações dos limites estabelecidos por norma para as tensões nodais de regime permanente. Com relação à operação dos geradores distribuídos, pretende-se obter a solução que maximize os benefícios técnicos que os mesmos possam oferecer à operação de redes de distribuição, em termos de melhoria do perfil de tensão e redução das perdas de potência ativa.

\subsection{Considerações Finais}

Do que foi exposto anteriormente, estabelece-se que as seguintes estratégias de operação dos dispositivos de regulação de tensão e geradores distribuídos serão comparadas:

- Gerador distribuído operando com controle PV, com potência ativa e tensão fixas e minimização do desvio de tensão;

- Gerador distribuído operando com controle PV, com potência ativa e tensão fixas e minimização das perdas de potência ativa;

- Gerador distribuído operando com controle PV, com potência ativa fixa, tensão variável e minimização do desvio de tensão;

- Gerador distribuído operando com controle PV, com potência ativa fixa, tensão variável e minimização das perdas de potência ativa;

- Gerador distribuído operando com controle PQ, com potência ativa e reativa fixas e minimização do desvio de tensão;

- Gerador distribuído operando com controle PQ, com potência ativa e reativa fixas e minimização das perdas de potência ativa; 
- Gerador distribuído operando com controle PQ, com potência ativa variável, potência reativa fixa e minimização do desvio de tensão;

- Gerador distribuído operando com controle PQ, com potência ativa variável, potência reativa fixa e minimização das perdas de potência ativa.

No próximo capítulo, os resultados obtidos pelo processo de otimização em cada um dos cenários analisados serão comparados e discutidos. 


\section{Capítulo 5}

\section{Resultados}

Uma vez apresentados os dispositivos reguladores de tensão no Capítulo 2, o sistema elétrico estudado e seus componentes no Capítulo 3 e as estratégias para realizar a operação dos elementos do sistema de distribuição no Capítulo 4, este capítulo apresenta os resultados das simulações executadas para a apreciação e discussão dos modos operacionais dos geradores distribuídos juntamente com os dispositivos reguladores de tensão.

Os resultados da aplicação das estratégias servirão como subsídio para avaliar se existem condições favoráveis para a manutenção das características operativas do gerador durante o período analisado ou se a alteração das mesmas, em função da variação da carga, se apresenta como alternativa mais viável. Para tal análise, resultados como a variação das tensões nodais, o valor das perdas de potência ativa, as variações dos taps do transformador da subestação e dos reguladores de tensão, assim como dos capacitores, serão considerados.

As análises serão realizadas considerando as curvas de carga apresentadas no Capítulo 3. Para cada hora do dia e tomando o valor de potência ativa e reativa de cada consumidor nesse instante, são realizados, por meio de programação computacional, cálculos de fluxos de potência ótimos e armazenados os valores máximos e mínimos das tensões verificadas no sistema elétrico, como também as perdas de energia durante o período. Será feita uma discussão por meio da comparação entre as estratégias propostas para cada modo de operação das unidades de geração distribuída.

Devido ao grande número de informações geradas pelos resultados das simulações, as análises do perfil de tensão apresentadas neste capítulo considerarão apenas dois cenários de carregamento para as estratégias em discussão. Entretanto, os resultados completos são apresentados no Anexo A. Os dois cenários considerados são:

- Mínimo carregamento do sistema: corresponde ao instante de tempo em que a carga agregada é mínima. Isso ocorre às 4 horas.

- Máximo carregamento do sistema: corresponde ao instante de tempo em que a carga agregada é máxima. Isso ocorre às 14 horas. 
As análises referentes a alterações nos módulos de bancos de capacitores e mudanças de taps dos transformadores e reguladores de tensão são apresentadas considerando todo o período de 24 horas.

\subsection{Sem Geradores Distribuídos}

Inicialmente, estudos foram realizados a fim de encontrar a melhor configuração sem a presença de geradores (SGD), considerando os bancos de capacitores, o tap dos transformadores reguladores de tensão e comutadores da subestação. Os resultados dessa análise serão úteis para serem comparados com aqueles obtidos quando há geradores distribuídos na rede elétrica. A Figura 5.1, e Tabelas 5.1, 5.3 e 5.5 apresentam as configurações simuladas nas quais a função objetivo é a minimização da variação de tensão (min Tensão), enquanto que na Figura 5.2 e Tabelas 5.2, 5.4 e 5.6, mostram-se os resultados para a função objetivo de minimização das perdas de energia (min Perdas). As perdas de energia totais estão na Figura 5.3. Visando facilitar a análise dos resultados, pois estes compreendem enormes tabelas, as mesmas serão divididas e dispostas de modo que seja possível discutir cada uma destas seleções de resultados em função das estratégias consideradas. O mesmo procedimento será aplicado para os diversos modos estudados do controle de excitação das unidades de geração. É bom lembrar que o valor de base para as tensões é $13,8 \mathrm{kV}$.

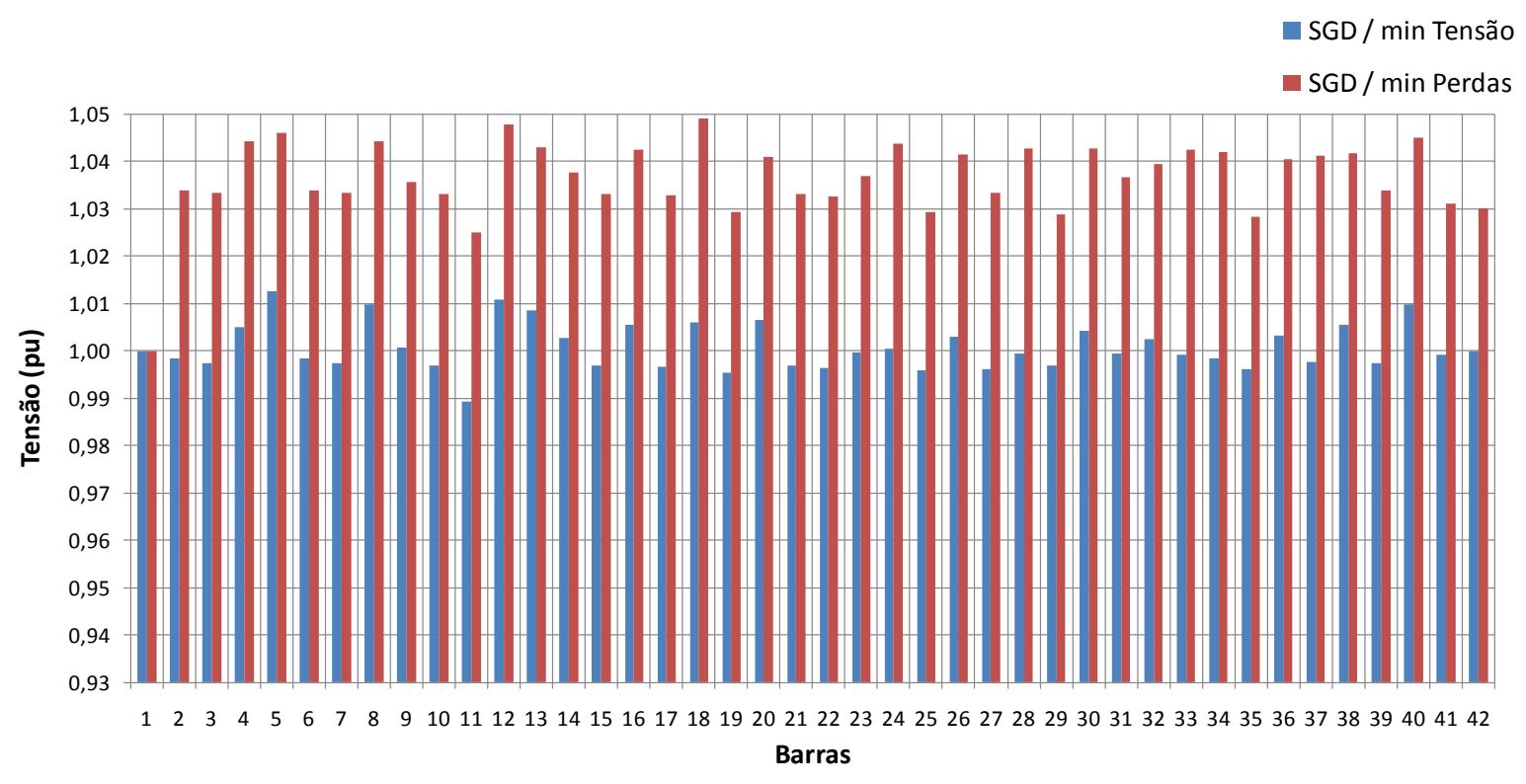

Figura 5.1 - Perfil de tensão para carregamento mínimo - SGD / min Tensão e min Perdas. 


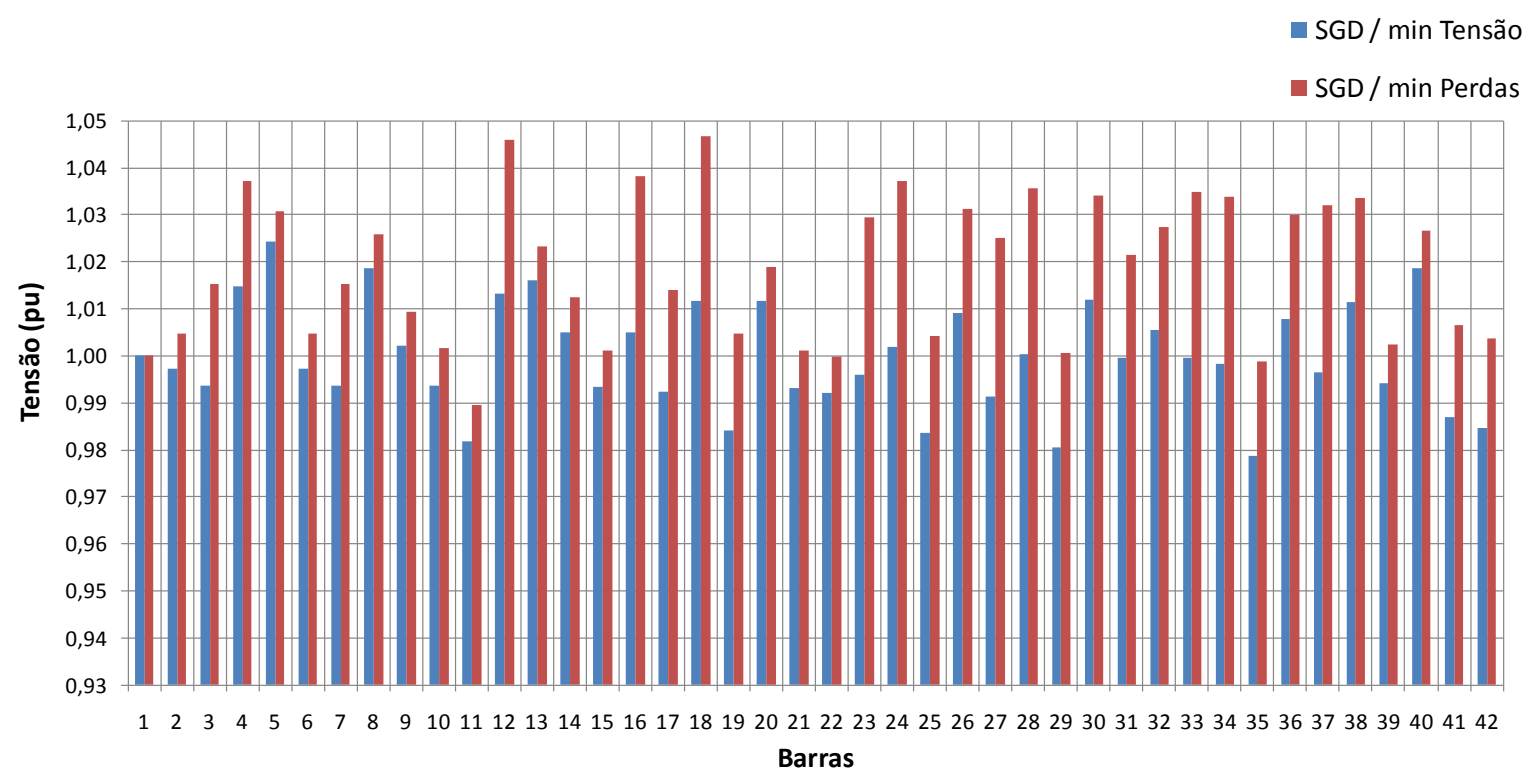

Figura 5.2 - Perfil de tensão para carregamento máximo - SGD / min Tensão e SGD / min Perdas.

Os resultados obtidos nas simulações cujo sistema se apresenta com a ausência de unidades de geração distribuída permitem inferir que a estratégia de minimização das perdas elétricas faz com que o sistema elétrico opere com elevados níveis de tensão, próximos ao limite máximo aceitável, visando com isso favorecer a redução dessas perdas, conforme pode ser observado na Figura 5.3. Esta figura apresenta as perdas totais de energia verificadas durante as 24 horas de operação do sistema elétrico, em que se percebe uma diferença nas perdas de energia de cerca de 5,8\% entre os resultados das diferentes estratégias propostas.

Analisando a Figura 5.2 observa-se que em situações de carregamento elevado, quando o objetivo é minimizar as perdas técnicas, fica difícil manter um perfil homogêneo das tensões nas barras. A estratégia que sugere a minimização dos desvios de tensão nivela os níveis de tensão aproximando os valores mínimos e máximos fazendo uso dos equipamentos de regulação, conforme se observa na Figura 5.1. 


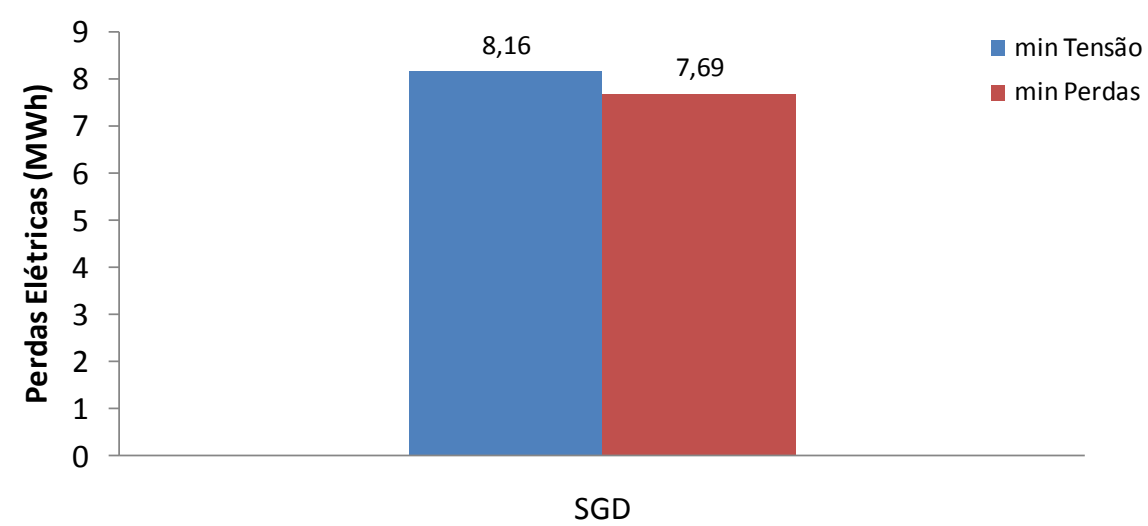

Figura 5.3 - Perdas de totais energia sem geradores distribuídos: min Tensão e min Perdas.

Com relação aos bancos de capacitores, a Tabela 5.1 e a Tabela 5.2 apresentam a configuração das unidades capacitivas em cada hora do dia, considerando a estratégia de minimização dos desvios de tensão e a de minimização das perdas, respectivamente. Comparando ambas as tabelas, nota-se um comportamento bastante diferente das configurações operativas dos bancos de capacitores para atender aos objetivos das estratégias de otimização. Por exemplo, na Tabela 5.1 o número de chaveamentos dos capacitores foi mais freqüente do que na Tabela 5.2.

Tabela 5.1 - Configuração dos bancos de capacitores - SGD / min Tensão.

\begin{tabular}{|c|c|c|c|c|c|}
\hline \multirow{2}{*}{$\begin{array}{c}\text { Tempo } \\
\text { (hora) }\end{array}$} & \multicolumn{4}{|c}{ Módulos de Bancos de Capacitores Ativos (\%) } \\
\cline { 2 - 6 } barra 38 & $\begin{array}{c}\text { BC-2 } \\
\text { barra 39 }\end{array}$ & $\begin{array}{c}\text { BC-3 } \\
\text { barra 40 }\end{array}$ & $\begin{array}{c}\text { BC-4 } \\
\text { barra 41 }\end{array}$ & $\begin{array}{c}\text { BC-5 } \\
\text { barra 42 }\end{array}$ \\
\hline 1 & $50,0 \%$ & $75,0 \%$ & $0,0 \%$ & $75,0 \%$ & $100,0 \%$ \\
\hline 2 & $50,0 \%$ & $25,0 \%$ & $0,0 \%$ & $50,0 \%$ & $100,0 \%$ \\
\hline 3 & $50,0 \%$ & $25,0 \%$ & $0,0 \%$ & $100,0 \%$ & $75,0 \%$ \\
\hline 4 & $50,0 \%$ & $25,0 \%$ & $0,0 \%$ & $100,0 \%$ & $75,0 \%$ \\
\hline 5 & $50,0 \%$ & $25,0 \%$ & $0,0 \%$ & $100,0 \%$ & $75,0 \%$ \\
\hline 6 & $25,0 \%$ & $75,0 \%$ & $0,0 \%$ & $100,0 \%$ & $100,0 \%$ \\
\hline 7 & $75,0 \%$ & $100,0 \%$ & $0,0 \%$ & $50,0 \%$ & $100,0 \%$ \\
\hline 8 & $0,0 \%$ & $100,0 \%$ & $75,0 \%$ & $100,0 \%$ & $100,0 \%$ \\
\hline 9 & $50,0 \%$ & $0,0 \%$ & $0,0 \%$ & $100,0 \%$ & $100,0 \%$ \\
\hline 10 & $75,0 \%$ & $25,0 \%$ & $0,0 \%$ & $100,0 \%$ & $100,0 \%$ \\
\hline 11 & $75,0 \%$ & $25,0 \%$ & $0,0 \%$ & $100,0 \%$ & $100,0 \%$ \\
\hline 12 & $50,0 \%$ & $0,0 \%$ & $0,0 \%$ & $100,0 \%$ & $100,0 \%$ \\
\hline 13 & $25,0 \%$ & $0,0 \%$ & $0,0 \%$ & $100,0 \%$ & $100,0 \%$ \\
\hline 14 & $75,0 \%$ & $50,0 \%$ & $0,0 \%$ & $100,0 \%$ & $100,0 \%$ \\
\hline 15 & $75,0 \%$ & $25,0 \%$ & $0,0 \%$ & $100,0 \%$ & $100,0 \%$ \\
\hline 16 & $75,0 \%$ & $25,0 \%$ & $0,0 \%$ & $100,0 \%$ & $100,0 \%$ \\
\hline 17 & $75,0 \%$ & $25,0 \%$ & $0,0 \%$ & $100,0 \%$ & $100,0 \%$ \\
\hline 18 & $50,0 \%$ & $0,0 \%$ & $0,0 \%$ & $100,0 \%$ & $100,0 \%$ \\
\hline 19 & $25,0 \%$ & $0,0 \%$ & $0,0 \%$ & $100,0 \%$ & $100,0 \%$ \\
\hline 20 & $50,0 \%$ & $25,0 \%$ & $0,0 \%$ & $100,0 \%$ & $100,0 \%$ \\
\hline 21 & $50,0 \%$ & $50,0 \%$ & $0,0 \%$ & $100,0 \%$ & $100,0 \%$ \\
\hline 22 & $0,0 \%$ & $0,0 \%$ & $0,0 \%$ & $100,0 \%$ & $100,0 \%$ \\
\hline 23 & $0,0 \%$ & $100,0 \%$ & $75,0 \%$ & $25,0 \%$ & $100,0 \%$ \\
\hline 24 & $0,0 \%$ & $100,0 \%$ & $75,0 \%$ & $50,0 \%$ & $75,0 \%$ \\
\hline
\end{tabular}


Tabela 5.2 - Configuração dos bancos de capacitores - SGD / min Perdas.

\begin{tabular}{|c|c|c|c|c|c|}
\hline \multirow[b]{2}{*}{$\begin{array}{l}\text { Tempo } \\
\text { (hora) }\end{array}$} & \multicolumn{5}{|c|}{ Módulos de Bancos de Capacitores Ativos (\%) } \\
\hline & $\begin{array}{c}\text { BC-1 } \\
\text { barra } 38\end{array}$ & $\begin{array}{c}\text { BC-2 } \\
\text { barra } 39\end{array}$ & $\begin{array}{c}\text { BC-3 } \\
\text { barra } 40\end{array}$ & $\begin{array}{c}\text { BC-4 } \\
\text { barra } 41\end{array}$ & $\begin{array}{c}\text { BC-5 } \\
\text { barra } 42\end{array}$ \\
\hline 1 & $25,0 \%$ & $75,0 \%$ & $75,0 \%$ & $75,0 \%$ & $25,0 \%$ \\
\hline 2 & $25,0 \%$ & $75,0 \%$ & $75,0 \%$ & $75,0 \%$ & $25,0 \%$ \\
\hline 3 & $25,0 \%$ & $75,0 \%$ & $75,0 \%$ & $50,0 \%$ & $25,0 \%$ \\
\hline 4 & $25,0 \%$ & $75,0 \%$ & $75,0 \%$ & $50,0 \%$ & $25,0 \%$ \\
\hline 5 & $25,0 \%$ & $75,0 \%$ & $75,0 \%$ & $75,0 \%$ & $25,0 \%$ \\
\hline 6 & $25,0 \%$ & $75,0 \%$ & $75,0 \%$ & $75,0 \%$ & $25,0 \%$ \\
\hline 7 & $25,0 \%$ & $75,0 \%$ & $75,0 \%$ & $50,0 \%$ & $50,0 \%$ \\
\hline 8 & $50,0 \%$ & $75,0 \%$ & $75,0 \%$ & $75,0 \%$ & $75,0 \%$ \\
\hline 9 & $75,0 \%$ & $75,0 \%$ & $75,0 \%$ & $75,0 \%$ & $75,0 \%$ \\
\hline 10 & $75,0 \%$ & $75,0 \%$ & $75,0 \%$ & $75,0 \%$ & $75,0 \%$ \\
\hline 11 & $75,0 \%$ & $75,0 \%$ & $75,0 \%$ & $75,0 \%$ & $75,0 \%$ \\
\hline 12 & $75,0 \%$ & $75,0 \%$ & $75,0 \%$ & $75,0 \%$ & $75,0 \%$ \\
\hline 13 & $50,0 \%$ & $75,0 \%$ & $75,0 \%$ & $75,0 \%$ & $75,0 \%$ \\
\hline 14 & $75,0 \%$ & $75,0 \%$ & $75,0 \%$ & $75,0 \%$ & $75,0 \%$ \\
\hline 15 & $75,0 \%$ & $75,0 \%$ & $75,0 \%$ & $75,0 \%$ & $75,0 \%$ \\
\hline 16 & $75,0 \%$ & $75,0 \%$ & $75,0 \%$ & $75,0 \%$ & $75,0 \%$ \\
\hline 17 & $75,0 \%$ & $75,0 \%$ & $75,0 \%$ & $75,0 \%$ & $75,0 \%$ \\
\hline 18 & $75,0 \%$ & $75,0 \%$ & $75,0 \%$ & $75,0 \%$ & $75,0 \%$ \\
\hline 19 & $50,0 \%$ & $75,0 \%$ & $75,0 \%$ & $75,0 \%$ & $75,0 \%$ \\
\hline 20 & $50,0 \%$ & $75,0 \%$ & $75,0 \%$ & $75,0 \%$ & $75,0 \%$ \\
\hline 21 & $50,0 \%$ & $75,0 \%$ & $75,0 \%$ & $75,0 \%$ & $75,0 \%$ \\
\hline 22 & $50,0 \%$ & $75,0 \%$ & $75,0 \%$ & $75,0 \%$ & $75,0 \%$ \\
\hline 23 & $25,0 \%$ & $75,0 \%$ & $75,0 \%$ & $75,0 \%$ & $50,0 \%$ \\
\hline 24 & $50,0 \%$ & $75,0 \%$ & $50,0 \%$ & $50,0 \%$ & $50,0 \%$ \\
\hline
\end{tabular}

Analisando as posições de tap obtidas da solução do problema para os transformadores da subestação com comutadores de taps sob carga, pode-se inferir que quando a estratégia foca na minimização de perdas de energia, estes equipamentos fazem uso de toda sua capacidade com o objetivo de elevar os níveis de tensão possibilitando a redução das perdas de potência ativa, tal como mostrado na Tabela 5.4. Já para o caso de minimização do desvio de tensão, observam-se alterações dos taps dos transformadores da subestação em função da variação da carga, conforme mostra a Tabela 5.3. 
Tabela 5.3 - Configuração dos taps do transformador da subestação - SGD / min Tensão.

\begin{tabular}{|c|c|c|}
\hline \multirow{2}{*}{ Tempo } & tap dos transformadores da subestação (pu) \\
\cline { 2 - 3 } (hora) & $\begin{array}{c}\text { Trafo 1 } \\
\text { ramo 1-4 }\end{array}$ & $\begin{array}{c}\text { Trafo } 2 \\
\text { ramo 1-5 }\end{array}$ \\
\hline 1 & 1,00000 & 1,02500 \\
\hline 2 & 1,00000 & 1,02500 \\
\hline 3 & 1,00000 & 1,02500 \\
\hline 4 & 1,00000 & 1,02500 \\
\hline 5 & 1,00000 & 1,02500 \\
\hline 6 & 1,00000 & 1,02500 \\
\hline 7 & 1,00000 & 1,02500 \\
\hline 8 & 1,02500 & 1,02500 \\
\hline 9 & 1,02500 & 1,05000 \\
\hline 10 & 1,02500 & 1,05000 \\
\hline 11 & 1,02500 & 1,05000 \\
\hline 12 & 1,02500 & 1,05000 \\
\hline 13 & 1,02500 & 1,05000 \\
\hline 14 & 1,02500 & 1,05000 \\
\hline 15 & 1,02500 & 1,05000 \\
\hline 16 & 1,02500 & 1,05000 \\
\hline 17 & 1,02500 & 1,05000 \\
\hline 18 & 1,02500 & 1,05000 \\
\hline 19 & 1,02500 & 1,05000 \\
\hline 20 & 1,02500 & 1,05000 \\
\hline 21 & 1,02500 & 1,05000 \\
\hline 22 & 1,02500 & 1,05000 \\
\hline 23 & 1,02500 & 1,02500 \\
\hline 24 & 1,02500 & 1,02500 \\
\hline & & \\
\hline
\end{tabular}

Tabela 5.4 - Configuração dos taps do transformador da subestação - SGD / min Perdas.

\begin{tabular}{|c|c|c|}
\hline \multirow{2}{*}{ Tempo } & tap dos transformadores da subestação (pu) \\
\cline { 2 - 3 } (hora) & $\begin{array}{c}\text { Trafo 1 } \\
\text { ramo 1-4 }\end{array}$ & $\begin{array}{c}\text { Trafo } 2 \\
\text { ramo 1-5 }\end{array}$ \\
\hline 1 & 1,05000 & 1,05000 \\
\hline 2 & 1,05000 & 1,05000 \\
\hline 3 & 1,05000 & 1,05000 \\
\hline 4 & 1,05000 & 1,05000 \\
\hline 5 & 1,05000 & 1,05000 \\
\hline 6 & 1,05000 & 1,05000 \\
\hline 7 & 1,05000 & 1,05000 \\
\hline 8 & 1,05000 & 1,05000 \\
\hline 9 & 1,05000 & 1,05000 \\
\hline 10 & 1,05000 & 1,05000 \\
\hline 11 & 1,05000 & 1,05000 \\
\hline 12 & 1,05000 & 1,05000 \\
\hline 13 & 1,05000 & 1,05000 \\
\hline 14 & 1,05000 & 1,05000 \\
\hline 15 & 1,05000 & 1,05000 \\
\hline 16 & 1,05000 & 1,05000 \\
\hline 17 & 1,05000 & 1,05000 \\
\hline 18 & 1,05000 & 1,05000 \\
\hline 19 & 1,05000 & 1,05000 \\
\hline 20 & 1,05000 & 1,05000 \\
\hline 21 & 1,05000 & 1,05000 \\
\hline 22 & 1,05000 & 1,05000 \\
\hline 23 & 1,05000 & 1,05000 \\
\hline 24 & 1,05000 & 1,05000 \\
\hline & & \\
\hline
\end{tabular}


Por último, os resultados dos taps dos reguladores de tensão, apresentados nas Tabelas 5.5 e 5.6, mostram uma evolução discreta do chaveamento destes equipamentos seguindo a linha de variação da demanda para ambas as metodologias.

Os resultados completos das tensões mínimas e máximas, e das perdas técnicas são apresentados no Anexo A, por meio da Tabela A.1 e Tabela A.2.

Tabela 5.5 - Configuração dos taps dos reguladores de tensão - SGD / min Tensão.

\begin{tabular}{|c|c|c|}
\hline \multirow{2}{*}{ Tempo } & \multicolumn{2}{|c|}{ tap dos reguladores de tensão $(\mathrm{pu})$} \\
\cline { 2 - 3 } (hora) & $\begin{array}{c}\text { Reg.1 } \\
\text { ramo 11-12 }\end{array}$ & $\begin{array}{c}\text { Reg.2 } \\
\text { ramo } 17-18\end{array}$ \\
\hline 1 & 1,02500 & 1,01875 \\
\hline 2 & 1,02500 & 1,01250 \\
\hline 3 & 1,02500 & 1,01250 \\
\hline 4 & 1,02500 & 1,01250 \\
\hline 5 & 1,02500 & 1,01250 \\
\hline 6 & 1,02500 & 1,01250 \\
\hline 7 & 1,03125 & 1,01875 \\
\hline 8 & 1,04375 & 1,01875 \\
\hline 9 & 1,03750 & 1,01875 \\
\hline 10 & 1,03750 & 1,01875 \\
\hline 11 & 1,03750 & 1,02500 \\
\hline 12 & 1,03750 & 1,01875 \\
\hline 13 & 1,03750 & 1,01875 \\
\hline 14 & 1,03750 & 1,02500 \\
\hline 15 & 1,03750 & 1,02500 \\
\hline 16 & 1,03750 & 1,02500 \\
\hline 17 & 1,03750 & 1,01875 \\
\hline 18 & 1,03750 & 1,01875 \\
\hline 19 & 1,04375 & 1,02500 \\
\hline 20 & 1,05000 & 1,02500 \\
\hline 21 & 1,05000 & 1,02500 \\
\hline 22 & 1,04375 & 1,02500 \\
\hline 23 & 1,05000 & 1,02500 \\
\hline 24 & 1,03750 & 1,01875 \\
\hline & & \\
\hline
\end{tabular}


Tabela 5.6 - Configuração dos taps dos reguladores de tensão - SGD / min Perdas.

\begin{tabular}{|c|c|c|}
\hline \multirow{2}{*}{ Tempo } & \multicolumn{2}{|c|}{ tap dos reguladores de tensão $(\mathrm{pu})$} \\
\cline { 2 - 3 } (hora) & $\begin{array}{c}\text { Reg.1 } \\
\text { ramo 11-12 }\end{array}$ & $\begin{array}{c}\text { Reg.2 } \\
\text { ramo 17-18 }\end{array}$ \\
\hline 1 & 1,03125 & 1,01875 \\
\hline 2 & 1,02500 & 1,01875 \\
\hline 3 & 1,02500 & 1,01875 \\
\hline 4 & 1,02500 & 1,01875 \\
\hline 5 & 1,02500 & 1,01250 \\
\hline 6 & 1,03125 & 1,01875 \\
\hline 7 & 1,03750 & 1,01875 \\
\hline 8 & 1,05000 & 1,02500 \\
\hline 9 & 1,06250 & 1,03125 \\
\hline 10 & 1,06250 & 1,03125 \\
\hline 11 & 1,06250 & 1,03750 \\
\hline 12 & 1,05625 & 1,03125 \\
\hline 13 & 1,05625 & 1,03125 \\
\hline 14 & 1,06250 & 1,03750 \\
\hline 15 & 1,06250 & 1,03750 \\
\hline 16 & 1,06250 & 1,03125 \\
\hline 17 & 1,06250 & 1,03125 \\
\hline 18 & 1,06250 & 1,03125 \\
\hline 19 & 1,06250 & 1,03125 \\
\hline 20 & 1,06875 & 1,03750 \\
\hline 21 & 1,06875 & 1,03750 \\
\hline 22 & 1,06250 & 1,03125 \\
\hline 23 & 1,05625 & 1,03125 \\
\hline 24 & 1,05000 & 1,02500 \\
\hline & & \\
\hline
\end{tabular}

\subsection{Geradores com Controle PV}

Nesta dissertação de mestrado, quando os geradores operam com o controle do tipo PV, a tensão terminal destes pode ser fixa ou variável, conforme explicado no Capítulo 4.

\subsubsection{Tensão Terminal Fixa}

Operando com tensão fixa, esta é especificada em 1 pu, isto é, $480 \mathrm{~V}$. Então, foram realizadas simulações em que cada um dos geradores fornece 10,5 MW, para cada estratégia proposta, a fim de verificar o impacto na rede elétrica, considerando cada condição de carregamento da rede. As Figuras 5.4 a 5.8 e Tabelas 5.7 a 5.12 apresentam os resultados desses testes. Nessas figuras e tabelas, o termo PV Fixo é empregado para representar o modo de controle da tensão dos geradores distribuídos.

Analisando os perfis de tensão de ambas as estratégias praticadas (Figura 5.4 e Figura 5.5), é visível a eficiência da metodologia que busca minimizar os desvios de tensão, apresentando um perfil de tensão mais plano em toda a rede, para ambos os carregamentos. A 
margem inferior não ultrapassou 0,986 pu e a superior 1,012 pu, enquanto que a estratégia de redução das perdas resultou em variações maiores: 0,975 pu e 1,05 pu.

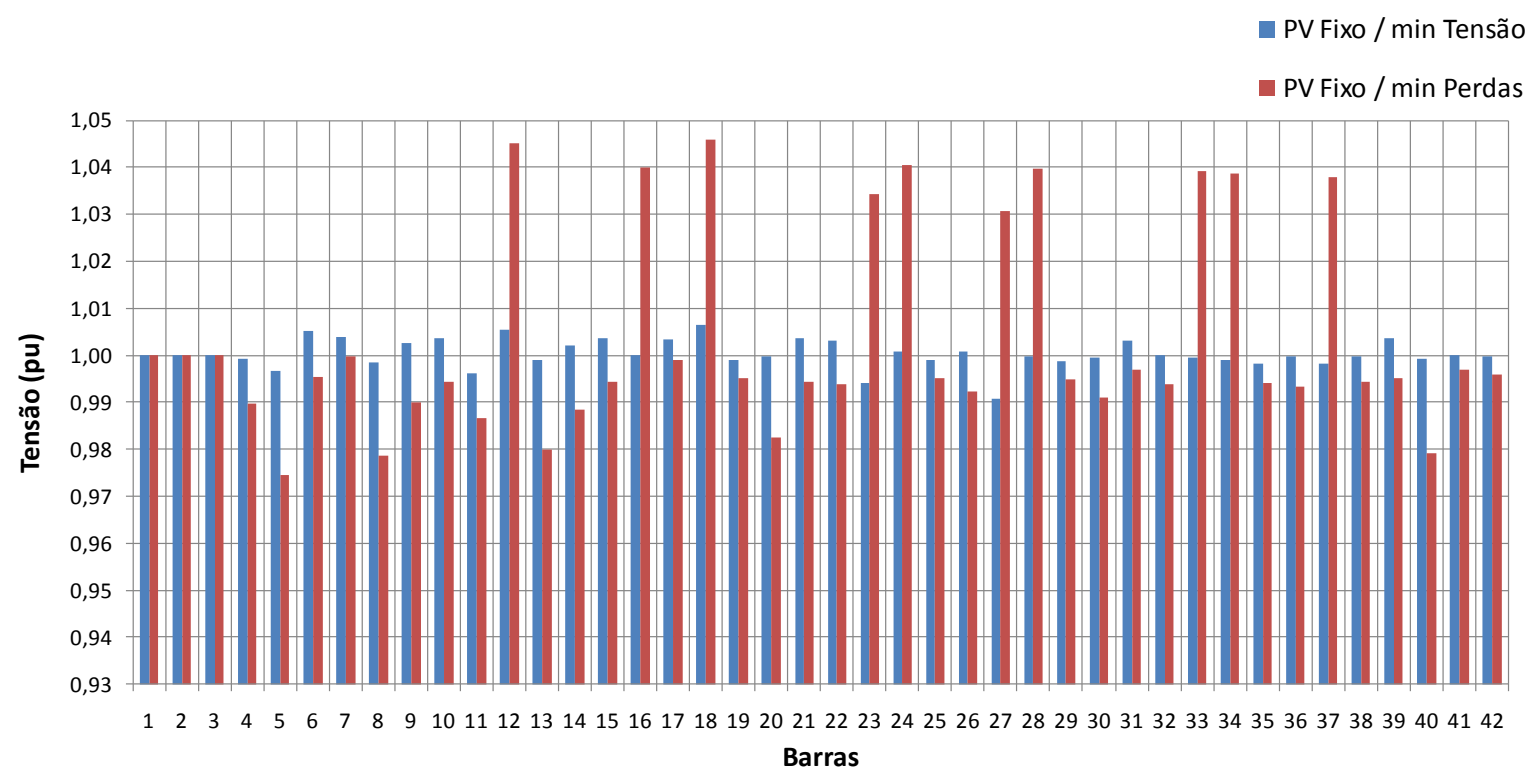

Figura 5.4 - Perfil de tensão para carregamento mínimo - PV Fixo / min Tensão e min Perdas.

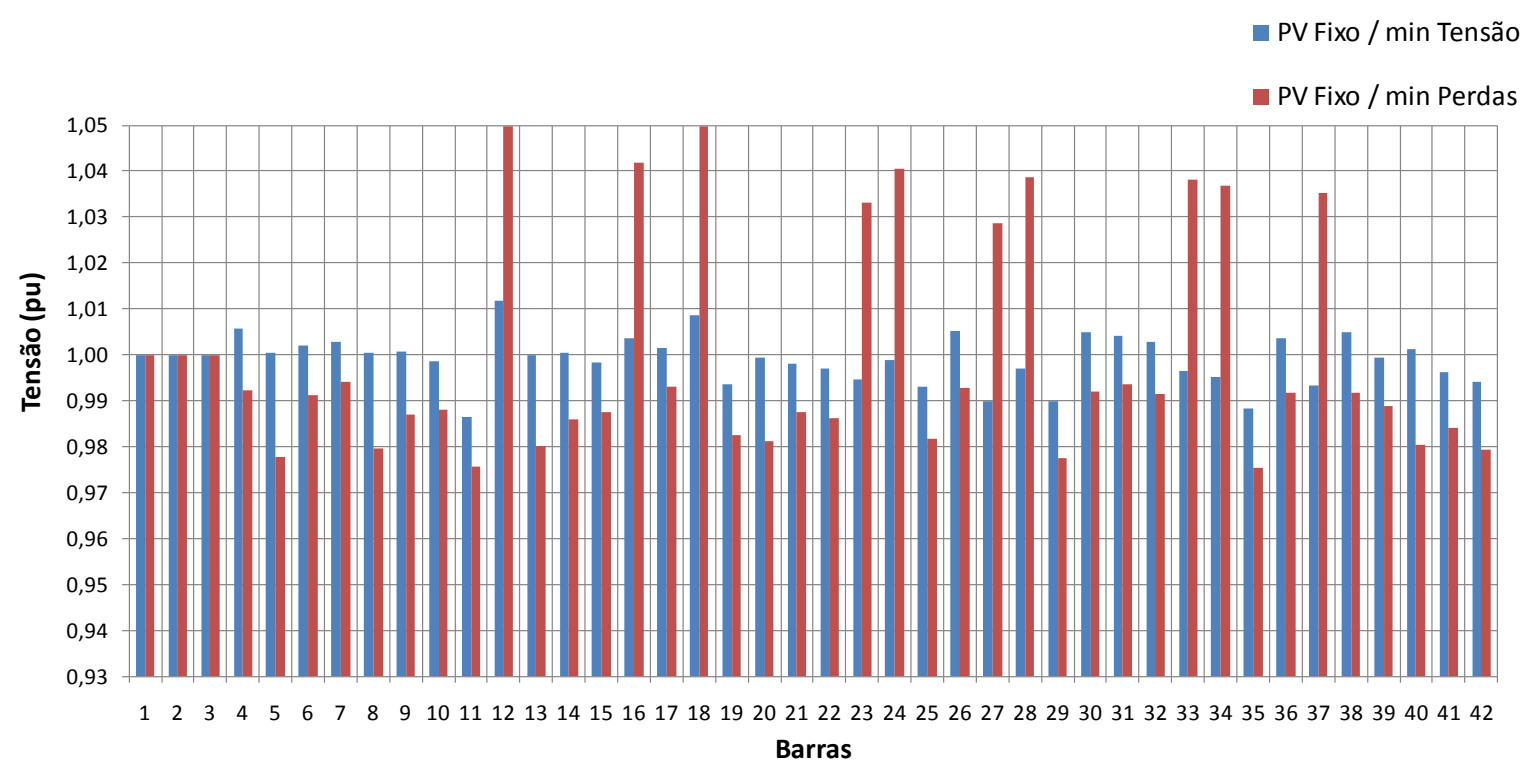

Figura 5.5 - Perfil de tensão para carregamento máximo - PV Fixo / min Tensão e min Perdas.

É importante enfatizar as melhorias no perfil de tensão obtidas com a inserção das unidades de geração distribuídas, principalmente quando a estratégia de operação dos dispositivos visa a minimização dos desvios de tensão. A Figura 5.6 apresenta o valor da função objetivo para cada hora do dia considerando o caso sem geradores e o PV Fixo. Nessa figura, percebe-se que as variações de tensão diante da ausência dos geradores síncronos se apresentam mais abruptas do que quando os mesmo estão presentes. 


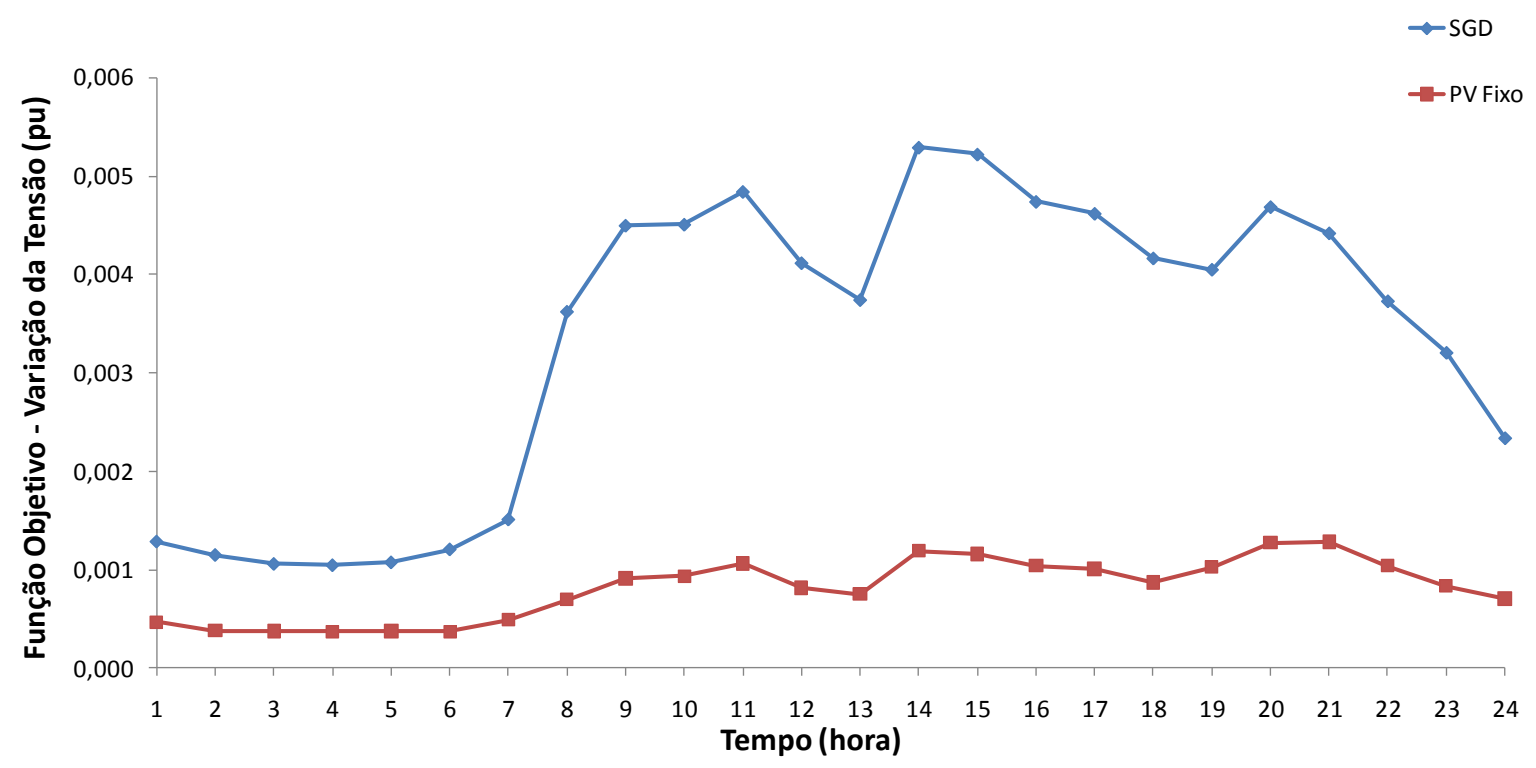

Figura 5.6 - Valores da função objetivo para o caso de minimização da variação da tensão - SGD e PV Fixo.

A Figura 5.7 apresenta o valor do somatório dos desvios das tensões nodais para as estratégias simuladas até então, ou seja, o caso sem geradores e PV Fixo, considerando ambas as funções objetivos. Ressalta-se que esse valor corresponde à função objetivo da expressão (4.1). É natural que a estratégia de minimização das perdas resulte em desvios de tensão muito maiores do que os obtidos com a estratégia de minimização da tensão, contudo, comparando esses resultados com o caso sem geradores (SGD) observa-se que a presença de geradores distribuídos contribuiu significativamente para a redução desses desvios, para ambas as funções objetivo.

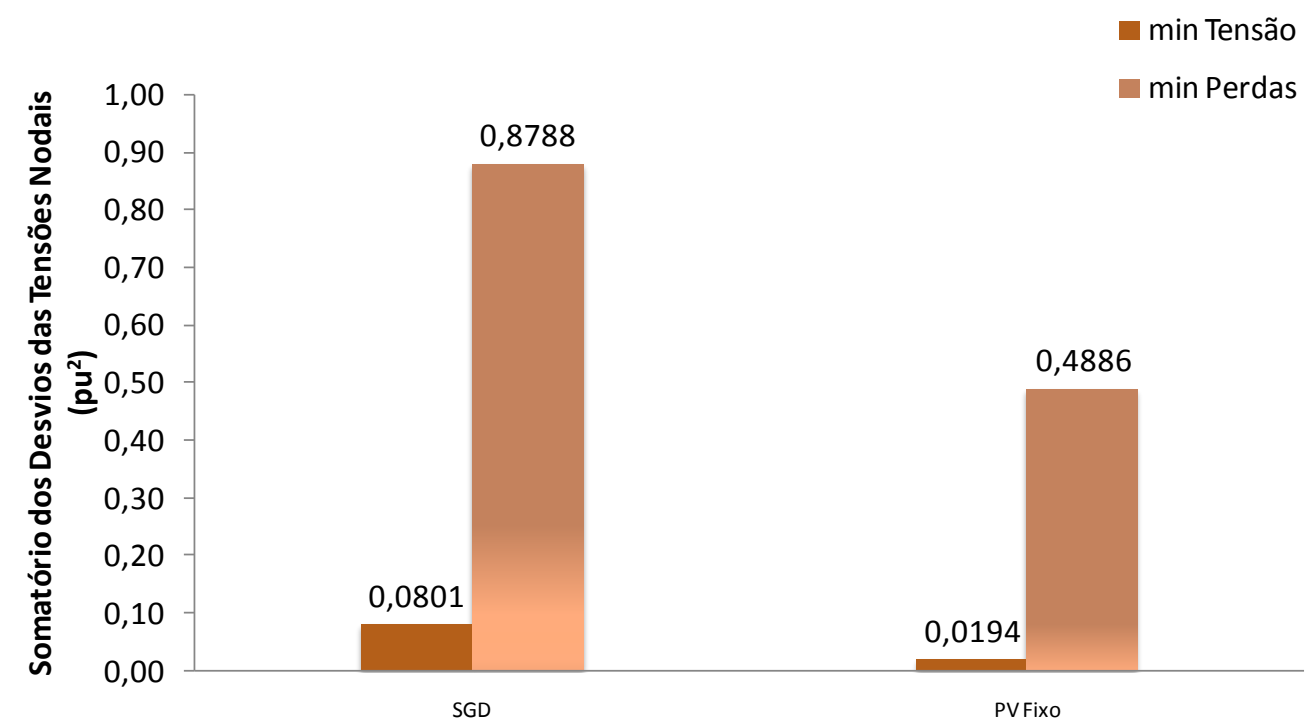

Figura 5.7 - Somatório dos desvios das tensões nodais - SGD e PV Fixo. 
Com os resultados apresentados na Figura 5.8, algumas observações podem ser feitas. Analisando as perdas elétricas de ambas as estratégias aplicadas para este modo de operação dos geradores, é possível verificar que houve uma diminuição bastante significativa das mesmas após a introdução dos geradores distribuídos. Além disso, observa-se que a diferença das perdas elétricas entre as estratégias analisadas não foi tão significativa. Portanto, com as características operativas simuladas, é possível manter um perfil de tensão mais plano e um nível baixo de perdas elétricas técnicas.

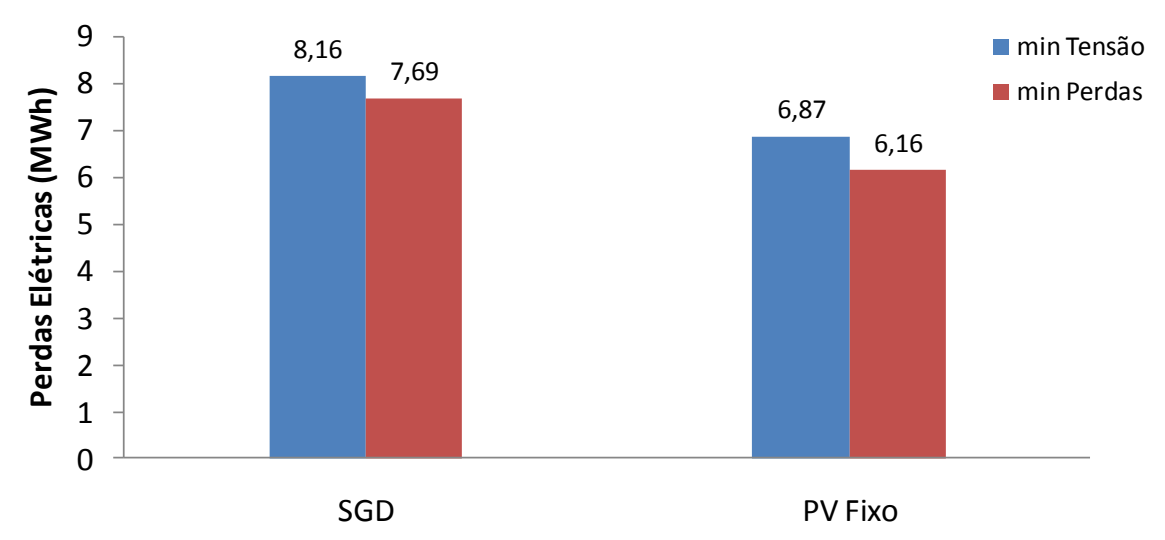

Figura 5.8 - Perdas de Energia - min Tensão e min Perdas.

Nos casos em que os geradores operam com controle PV, começam a ser discutidos os valores de fator de potência e carregamento destes geradores. Na Tabela 5.7 e Tabela 5.8 mostra-se que o fator de potência dos geradores em ambas as estratégias permaneceu próximo de unitário durante todo o período de análise (24 horas). Com relação ao carregamento dos geradores, estes também não oscilaram muito, ficando em torno de 75 e $76 \%$, dentro das condições aceitáveis de operação. Portanto, mostra-se aqui a viabilidade da operação do sistema elétrico mantendo os geradores com controle PV. Nessas mesmas tabelas pode-se observar uma evolução do chaveamento dos bancos de capacitores em função do carregamento da rede. No caso de minimização dos desvios de tensão, no geral observa-se, na Tabela 5.7, uma variação maior da potência exigida de cada banco de capacitor ao longo das 24 horas. Por exemplo, o banco de capacitores BC-4 fornece desde $0 \%$ a $100 \%$ de sua capacidade, mas permanece com 100\% durante boa parte do tempo. Já no caso de minimização das perdas (Tabela 5.8), esse mesmo banco de capacitores tem uma variação menor: de $25 \%$ a $75 \%$ de sua capacidade, com exceção da hora 23 em que o mesmo foi desligado $(0,0 \%)$. 
Tabela 5.7 - Resultados de fator de potência e carregamento dos geradores e configuração dos bancos de capacitores - PV Fixo / min Tensão.

\begin{tabular}{|c|c|c|c|c|c|c|c|c|c|}
\hline \multirow{2}{*}{ Tempo } & \multicolumn{2}{|c|}{$\begin{array}{c}\text { Fator de Potência } \\
\text { (hora) }\end{array}$} & \multicolumn{2}{|c|}{$\begin{array}{c}\text { Carregamento } \\
\text { dos Geradores }\end{array}$} & dos Geradores (\%) & \multicolumn{2}{|c|}{ Módulos de Bancos de Capacitores Ativos (\%) } \\
& G1 & G2 & G1 & BC-2 & BC-3 & BC-4 & BC-5 \\
barra 38 & barra 39 & barra 40 & barra 41 & barra 42 \\
\hline 1 & 0,996 & 0,997 & 76,011 & 75,898 & $0,0 \%$ & $0,0 \%$ & $75,0 \%$ & $0,0 \%$ & $50,0 \%$ \\
\hline 2 & 0,995 & 0,996 & 76,036 & 75,968 & $0,0 \%$ & $0,0 \%$ & $50,0 \%$ & $50,0 \%$ & $25,0 \%$ \\
\hline 3 & 0,994 & 0,997 & 76,131 & 75,921 & $0,0 \%$ & $0,0 \%$ & $75,0 \%$ & $25,0 \%$ & $25,0 \%$ \\
\hline 4 & 0,994 & 0,997 & 76,140 & 75,932 & $0,0 \%$ & $0,0 \%$ & $75,0 \%$ & $25,0 \%$ & $25,0 \%$ \\
\hline 5 & 0,995 & 0,997 & 76,106 & 75,915 & $0,0 \%$ & $0,0 \%$ & $75,0 \%$ & $25,0 \%$ & $25,0 \%$ \\
\hline 6 & 0,996 & 0,997 & 76,014 & 75,937 & $0,0 \%$ & $0,0 \%$ & $75,0 \%$ & $0,0 \%$ & $50,0 \%$ \\
\hline 7 & 0,997 & 0,997 & 75,910 & 75,934 & $0,0 \%$ & $0,0 \%$ & $75,0 \%$ & $25,0 \%$ & $50,0 \%$ \\
\hline 8 & 0,998 & 0,998 & 75,830 & 75,853 & $0,0 \%$ & $75,0 \%$ & $75,0 \%$ & $50,0 \%$ & $100,0 \%$ \\
\hline 9 & 0,999 & 0,999 & 75,748 & 75,796 & $0,0 \%$ & $75,0 \%$ & $75,0 \%$ & $100,0 \%$ & $100,0 \%$ \\
\hline 10 & 0,999 & 0,999 & 75,737 & 75,789 & $0,0 \%$ & $75,0 \%$ & $75,0 \%$ & $100,0 \%$ & $100,0 \%$ \\
\hline 11 & 0,999 & 0,998 & 75,730 & 75,812 & $25,0 \%$ & $75,0 \%$ & $75,0 \%$ & $100,0 \%$ & $100,0 \%$ \\
\hline 12 & 0,999 & 0,998 & 75,754 & 75,845 & $0,0 \%$ & $75,0 \%$ & $75,0 \%$ & $100,0 \%$ & $100,0 \%$ \\
\hline 13 & 0,999 & 0,998 & 75,756 & 75,849 & $0,0 \%$ & $75,0 \%$ & $75,0 \%$ & $75,0 \%$ & $100,0 \%$ \\
\hline 14 & 1,000 & 0,999 & 75,720 & 75,783 & $25,0 \%$ & $75,0 \%$ & $75,0 \%$ & $100,0 \%$ & $100,0 \%$ \\
\hline 15 & 1,000 & 0,999 & 75,725 & 75,784 & $25,0 \%$ & $75,0 \%$ & $75,0 \%$ & $100,0 \%$ & $100,0 \%$ \\
\hline 16 & 0,999 & 0,999 & 75,740 & 75,763 & $0,0 \%$ & $75,0 \%$ & $75,0 \%$ & $100,0 \%$ & $100,0 \%$ \\
\hline 17 & 0,999 & 0,999 & 75,733 & 75,763 & $0,0 \%$ & $75,0 \%$ & $75,0 \%$ & $100,0 \%$ & $100,0 \%$ \\
\hline 18 & 0,999 & 0,998 & 75,748 & 75,857 & $0,0 \%$ & $75,0 \%$ & $75,0 \%$ & $100,0 \%$ & $100,0 \%$ \\
\hline 19 & 0,999 & 1,000 & 75,756 & 75,696 & $75,0 \%$ & $75,0 \%$ & $75,0 \%$ & $100,0 \%$ & $100,0 \%$ \\
\hline 20 & 1,000 & 0,999 & 75,715 & 75,746 & $0,0 \%$ & $75,0 \%$ & $75,0 \%$ & $75,0 \%$ & $100,0 \%$ \\
\hline 21 & 1,000 & 0,999 & 75,708 & 75,735 & $0,0 \%$ & $75,0 \%$ & $75,0 \%$ & $100,0 \%$ & $75,0 \%$ \\
\hline 22 & 0,999 & 0,999 & 75,750 & 75,747 & $0,0 \%$ & $75,0 \%$ & $75,0 \%$ & $50,0 \%$ & $75,0 \%$ \\
\hline 23 & 0,998 & 0,999 & 75,851 & 75,755 & $0,0 \%$ & $75,0 \%$ & $75,0 \%$ & $50,0 \%$ & $50,0 \%$ \\
\hline 24 & 0,999 & 0,998 & 75,791 & 75,829 & $0,0 \%$ & $0,0 \%$ & $75,0 \%$ & $50,0 \%$ & $50,0 \%$ \\
\hline
\end{tabular}

Tabela 5.8 - Dados de fator de potência, carregamento e dos bancos de capacitores - PV Fixo / min Perdas.

\begin{tabular}{|c|c|c|c|c|c|c|c|c|c|}
\hline \multirow{2}{*}{ Tempo } & \multirow{2}{*}{$\begin{array}{c}\text { Fator de Potência } \\
\text { (hora) }\end{array}$} & Ges Geradores & Carregamento & \multicolumn{3}{|c|}{ Módulos de Bancos de Capacitores Ativos (\%) } \\
& G1 & G2 & G1 & GC-1 & BC-2 & BC-3 & BC-4 & BC-5 \\
barra 38 & barra 39 & barra 40 & barra 41 & barra 42 \\
\hline 1 & 0,988 & 0,997 & 76,622 & 75,899 & $0,0 \%$ & $50,0 \%$ & $50,0 \%$ & $25,0 \%$ & $25,0 \%$ \\
\hline 2 & 0,989 & 0,984 & 76,520 & 76,919 & $25,0 \%$ & $25,0 \%$ & $75,0 \%$ & $25,0 \%$ & $25,0 \%$ \\
\hline 3 & 0,987 & 0,998 & 76,661 & 75,823 & $0,0 \%$ & $25,0 \%$ & $25,0 \%$ & $25,0 \%$ & $25,0 \%$ \\
\hline 4 & 0,991 & 1,000 & 76,347 & 75,720 & $25,0 \%$ & $50,0 \%$ & $75,0 \%$ & $50,0 \%$ & $25,0 \%$ \\
\hline 5 & 0,988 & 1,000 & 76,602 & 75,726 & $25,0 \%$ & $25,0 \%$ & $50,0 \%$ & $50,0 \%$ & $25,0 \%$ \\
\hline 6 & 0,990 & 0,998 & 76,490 & 75,812 & $0,0 \%$ & $75,0 \%$ & $50,0 \%$ & $50,0 \%$ & $25,0 \%$ \\
\hline 7 & 0,980 & 0,997 & 77,208 & 75,929 & $0,0 \%$ & $25,0 \%$ & $0,0 \%$ & $25,0 \%$ & $25,0 \%$ \\
\hline 8 & 0,980 & 0,993 & 77,258 & 76,212 & $0,0 \%$ & $75,0 \%$ & $75,0 \%$ & $50,0 \%$ & $50,0 \%$ \\
\hline 9 & 0,969 & 0,990 & 78,104 & 76,448 & $0,0 \%$ & $50,0 \%$ & $25,0 \%$ & $75,0 \%$ & $50,0 \%$ \\
\hline 10 & 0,970 & 0,990 & 78,027 & 76,466 & $0,0 \%$ & $50,0 \%$ & $50,0 \%$ & $75,0 \%$ & $50,0 \%$ \\
\hline 11 & 0,971 & 0,988 & 77,930 & 76,617 & $0,0 \%$ & $50,0 \%$ & $75,0 \%$ & $75,0 \%$ & $50,0 \%$ \\
\hline 12 & 0,971 & 0,992 & 77,969 & 76,333 & $0,0 \%$ & $25,0 \%$ & $75,0 \%$ & $75,0 \%$ & $50,0 \%$ \\
\hline 13 & 0,969 & 0,992 & 78,108 & 76,324 & $0,0 \%$ & $25,0 \%$ & $50,0 \%$ & $50,0 \%$ & $50,0 \%$ \\
\hline 14 & 0,973 & 0,987 & 77,808 & 76,707 & $0,0 \%$ & $75,0 \%$ & $75,0 \%$ & $75,0 \%$ & $50,0 \%$ \\
\hline 15 & 0,971 & 0,987 & 77,971 & 76,701 & $0,0 \%$ & $50,0 \%$ & $75,0 \%$ & $75,0 \%$ & $50,0 \%$ \\
\hline 16 & 0,970 & 0,990 & 78,004 & 76,428 & $0,0 \%$ & $50,0 \%$ & $50,0 \%$ & $50,0 \%$ & $75,0 \%$ \\
\hline 17 & 0,972 & 0,989 & 77,903 & 76,548 & $0,0 \%$ & $50,0 \%$ & $75,0 \%$ & $75,0 \%$ & $50,0 \%$ \\
\hline 18 & 0,973 & 0,992 & 77,754 & 76,309 & $0,0 \%$ & $75,0 \%$ & $50,0 \%$ & $75,0 \%$ & $50,0 \%$ \\
\hline 19 & 0,973 & 0,990 & 77,758 & 76,491 & $0,0 \%$ & $50,0 \%$ & $75,0 \%$ & $25,0 \%$ & $50,0 \%$ \\
\hline 20 & 0,972 & 0,988 & 77,855 & 76,607 & $0,0 \%$ & $75,0 \%$ & $75,0 \%$ & $50,0 \%$ & $50,0 \%$ \\
\hline 21 & 0,971 & 0,989 & 77,927 & 76,523 & $0,0 \%$ & $75,0 \%$ & $75,0 \%$ & $50,0 \%$ & $50,0 \%$ \\
\hline 22 & 0,964 & 0,965 & 78,522 & 78,478 & $25,0 \%$ & $0,0 \%$ & $25,0 \%$ & $25,0 \%$ & $25,0 \%$ \\
\hline 23 & 0,978 & 0,990 & 77,359 & 76,438 & $0,0 \%$ & $50,0 \%$ & $75,0 \%$ & $0,0 \%$ & $25,0 \%$ \\
\hline 24 & 0,980 & 0,995 & 77,213 & 76,062 & $0,0 \%$ & $25,0 \%$ & $75,0 \%$ & $50,0 \%$ & $25,0 \%$ \\
\hline
\end{tabular}


Das tabelas 5.9 e 5.10 é interessante analisar que no caso da estratégia que visa minimizar as perdas de potência ativa, os taps foram chaveados para reduzir a tensão no lado secundário de um dos transformadores da subestação. Isso pode ser resultado da elevação do perfil de tensão causado pelos bancos de capacitores e dos transformadores reguladores de tensão, conforme pode ser visto na Tabela 5.12. As tabelas 5.9 e 5.10 também mostram que o número de chaveamento dos taps dos transformadores da subestação foi bastante reduzido, indicando um efeito positivo da presença dos geradores síncronos com controle PV Fixo.

Tabela 5.9 - Configuração dos taps dos transformadores da subestação - PV Fixo / min Tensão.

\begin{tabular}{|c|c|c|}
\hline \multirow{2}{*}{ Tempo } & tap dos transformadores da subestação (pu) \\
\cline { 2 - 3 } (hora) & $\begin{array}{c}\text { Trafo 1 } \\
\text { ramo 1-4 }\end{array}$ & $\begin{array}{c}\text { Trafo } 2 \\
\text { ramo 1-5 }\end{array}$ \\
\hline 1 & 1,02500 & 1,02500 \\
\hline 2 & 1,02500 & 1,02500 \\
\hline 3 & 1,02500 & 1,02500 \\
\hline 4 & 1,02500 & 1,02500 \\
\hline 5 & 1,02500 & 1,02500 \\
\hline 6 & 1,02500 & 1,02500 \\
\hline 7 & 1,02500 & 1,02500 \\
\hline 8 & 1,02500 & 1,02500 \\
\hline 9 & 1,02500 & 1,02500 \\
\hline 10 & 1,02500 & 1,02500 \\
\hline 11 & 1,02500 & 1,02500 \\
\hline 12 & 1,02500 & 1,02500 \\
\hline 13 & 1,02500 & 1,02500 \\
\hline 14 & 1,02500 & 1,02500 \\
\hline 15 & 1,02500 & 1,02500 \\
\hline 16 & 1,02500 & 1,02500 \\
\hline 17 & 1,02500 & 1,02500 \\
\hline 18 & 1,02500 & 1,02500 \\
\hline 19 & 1,00000 & 1,02500 \\
\hline 20 & 1,02500 & 1,02500 \\
\hline 21 & 1,02500 & 1,02500 \\
\hline 22 & 1,02500 & 1,02500 \\
\hline 23 & 1,02500 & 1,02500 \\
\hline 24 & 1,02500 & 1,02500 \\
\hline & & \\
\hline
\end{tabular}


Tabela 5.10 - Configuração dos taps do transformador da subestação - PV Fixo / min Perdas.

\begin{tabular}{|c|c|c|}
\hline \multirow{2}{*}{ Tempo } & \multicolumn{2}{|c|}{ tap dos transformadores da subestação $(\mathrm{pu})$} \\
\cline { 2 - 3 } & $\begin{array}{c}\text { Trafo } 1 \\
\text { ramo } 1-4\end{array}$ & $\begin{array}{c}\text { Trafo } 2 \\
\text { ramo 1-5 }\end{array}$ \\
\hline 1 & 1,00000 & 0,97500 \\
\hline 2 & 0,97500 & 0,97500 \\
\hline 3 & 1,00000 & 0,97500 \\
\hline 4 & 1,00000 & 0,97500 \\
\hline 5 & 1,00000 & 0,97500 \\
\hline 6 & 1,00000 & 0,97500 \\
\hline 7 & 1,00000 & 0,97500 \\
\hline 8 & 1,00000 & 0,97500 \\
\hline 9 & 1,00000 & 0,97500 \\
\hline 10 & 1,00000 & 0,97500 \\
\hline 11 & 1,00000 & 0,97500 \\
\hline 12 & 1,00000 & 0,97500 \\
\hline 13 & 1,00000 & 0,97500 \\
\hline 14 & 1,00000 & 0,97500 \\
\hline 15 & 1,00000 & 0,97500 \\
\hline 16 & 1,00000 & 0,97500 \\
\hline 17 & 1,00000 & 0,97500 \\
\hline 18 & 1,00000 & 0,97500 \\
\hline 19 & 1,00000 & 0,97500 \\
\hline 20 & 1,00000 & 0,97500 \\
\hline 21 & 1,00000 & 0,97500 \\
\hline 22 & 0,97500 & 0,97500 \\
\hline 23 & 1,00000 & 0,97500 \\
\hline 24 & 1,00000 & 0,97500 \\
\hline
\end{tabular}

Na Tabela 5.11 e Tabela 5.12 são mostradas as configurações dos taps dos transformadores reguladores de tensão em cada hora do dia. Observa-se uma diferença significativa entre os resultados das duas estratégias: na metodologia que objetiva minimizar as perdas elétricas, os taps dos reguladores de tensão foram mais elevados do que os resultados obtidos na metodologia de minimizar os desvios de tensão. Esse comportamento decorre do fato de que a manutenção das tensões nodais elevadas provoca a redução nas perdas elétricas. 
Tabela 5.11 - Configuração dos taps dos reguladores de tensão - PV Fixo / min $\Delta V$.

\begin{tabular}{|c|c|c|}
\hline \multirow{2}{*}{ Tempo } & \multicolumn{2}{|c|}{ tap dos reguladores de tensão $(\mathrm{pu})$} \\
\cline { 2 - 3 } (hora) & $\begin{array}{c}\text { Reg.1 } \\
\text { ramo 11-12 }\end{array}$ & $\begin{array}{c}\text { Reg.2 } \\
\text { ramo } 17-18\end{array}$ \\
\hline 1 & 1,01875 & 1,00625 \\
\hline 2 & 1,01875 & 1,00625 \\
\hline 3 & 1,01250 & 1,00625 \\
\hline 4 & 1,01250 & 1,00625 \\
\hline 5 & 1,01250 & 1,00625 \\
\hline 6 & 1,01875 & 1,00625 \\
\hline 7 & 1,02500 & 1,00625 \\
\hline 8 & 1,02500 & 1,01250 \\
\hline 9 & 1,03125 & 1,01250 \\
\hline 10 & 1,03125 & 1,01250 \\
\hline 11 & 1,03125 & 1,01250 \\
\hline 12 & 1,03125 & 1,01250 \\
\hline 13 & 1,03125 & 1,01250 \\
\hline 14 & 1,03125 & 1,01250 \\
\hline 15 & 1,03125 & 1,01250 \\
\hline 16 & 1,03125 & 1,01250 \\
\hline 17 & 1,03125 & 1,01250 \\
\hline 18 & 1,03125 & 1,01250 \\
\hline 19 & 1,03750 & 1,01875 \\
\hline 20 & 1,04375 & 1,01875 \\
\hline 21 & 1,04375 & 1,01875 \\
\hline 22 & 1,03750 & 1,01875 \\
\hline 23 & 1,03125 & 1,01875 \\
\hline 24 & 1,03125 & 1,01250 \\
\hline & & \\
\hline
\end{tabular}

Tabela 5.12 - Configuração dos taps dos reguladores de tensão - PV Fixo / min Perdas.

\begin{tabular}{|c|c|c|}
\hline \multirow{2}{*}{ Tempo } & \multicolumn{2}{|c|}{ tap dos reguladores de tensão (pu) } \\
\cline { 2 - 3 } (hora) & $\begin{array}{c}\text { Reg.1 } \\
\text { ramo 11-12 }\end{array}$ & $\begin{array}{c}\text { Reg. } 2 \\
\text { ramo } 17-18\end{array}$ \\
\hline 1 & 1,06875 & 1,05625 \\
\hline 2 & 1,06875 & 1,05625 \\
\hline 3 & 1,06875 & 1,05000 \\
\hline 4 & 1,06250 & 1,05000 \\
\hline 5 & 1,06875 & 1,05000 \\
\hline 6 & 1,06875 & 1,05000 \\
\hline 7 & 1,07500 & 1,05625 \\
\hline 8 & 1,07500 & 1,05625 \\
\hline 9 & 1,08125 & 1,05625 \\
\hline 10 & 1,08125 & 1,05625 \\
\hline 11 & 1,08125 & 1,06250 \\
\hline 12 & 1,08125 & 1,05625 \\
\hline 13 & 1,08125 & 1,05625 \\
\hline 14 & 1,08125 & 1,06250 \\
\hline 15 & 1,08125 & 1,06250 \\
\hline 16 & 1,08125 & 1,05625 \\
\hline 17 & 1,08125 & 1,05625 \\
\hline 18 & 1,08125 & 1,05625 \\
\hline 19 & 1,08125 & 1,06250 \\
\hline 20 & 1,08750 & 1,06250 \\
\hline 21 & 1,08750 & 1,06250 \\
\hline 22 & 1,08750 & 1,06875 \\
\hline 23 & 1,08125 & 1,06250 \\
\hline 24 & 1,07500 & 1,05625 \\
\hline & & \\
\hline
\end{tabular}




\subsubsection{Tensão Terminal Variável}

Quando a rede elétrica passa a operar com as unidades de geração sob controle PV, principalmente nos momentos de máxima demanda do sistema, elas proporcionam um grande auxílio na manutenção dos valores das tensões nodais dentro dos limites definidos por normas, resultando em um perfil de tensão mais uniforme. Com intuito de fazer com que os geradores distribuídos atuem como moduladores da tensão, minimizando alterações nas configurações dos dispositivos reguladores de tensão, a tensão de referência dos mesmos foi inserida como variável de controle do processo de otimização. Nesta seção, o termo PV Variável será empregado para representar esse modo de controle da tensão dos geradores distribuídos.

Para efeito de análise, o perfil de tensão dos geradores distribuídos em função do tempo, de ambas as estratégias, pode ser visualizado nas Figuras 5.9 e 5.10. Nota-se que a tensão de referência de ambos os geradores varia muito pouco, aproximadamente de 0,995 a 1,010 pu durante todo o período de análise, quando se minimizam os desvios de tensão (Figura 5.9). Esse resultado era esperado, visto que a tensão de referência escolhida na função objetivo desta técnica é 1 pu. No caso da Figura 5.10, em que os resultados da estratégia de minimização de perdas são mostrados, os geradores se comportaram de forma semelhante aos outros dispositivos reguladores de tensão, ou seja, a tensão de referência se elevou para o valor igual ao limite superior permissível nas barras, ou seja, 1,05 pu, durante a maior parte do período de análise. No caso analisado, as variações na tensão de referência dos geradores durante as 24 horas e para ambas as estratégias não foi significativa. Contudo, esta estratégia apresentou algumas vantagens em relação às outras, conforme será abordado no final deste capítulo.

Os efeitos provocados por esta estratégia de operação para máxima e mínima carga é que as tensões nodais ficaram em torno de 1 pu quando a função objetivo é minimização dos desvios de tensão, e em 1,04 pu quando se minimizam as perdas elétricas. Essas características são mostradas na Figura 5.11 e Figura 5.12, respectivamente. 


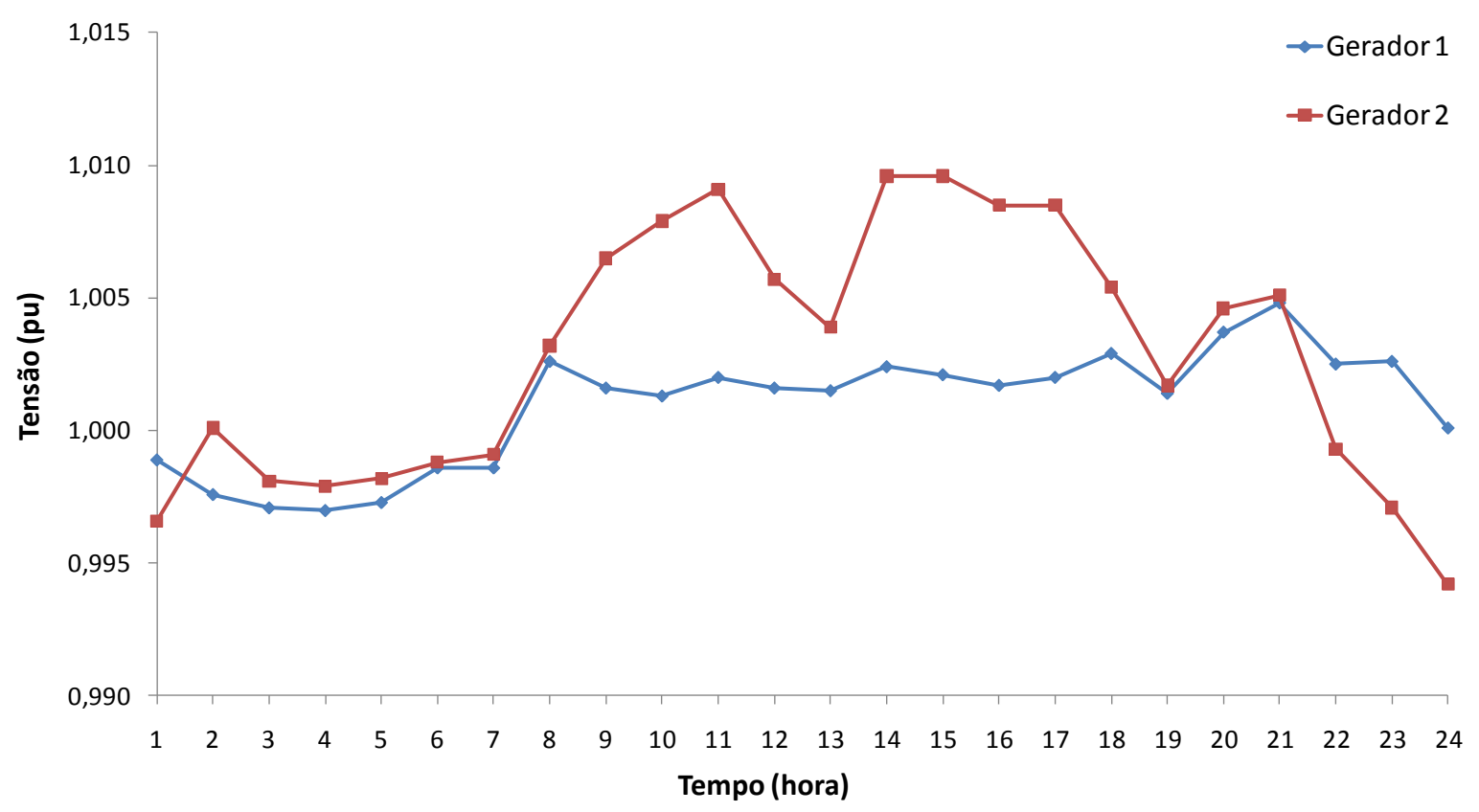

Figura 5.9 - Perfil de tensão dos geradores operando com controle PV Variável / min Tensão.

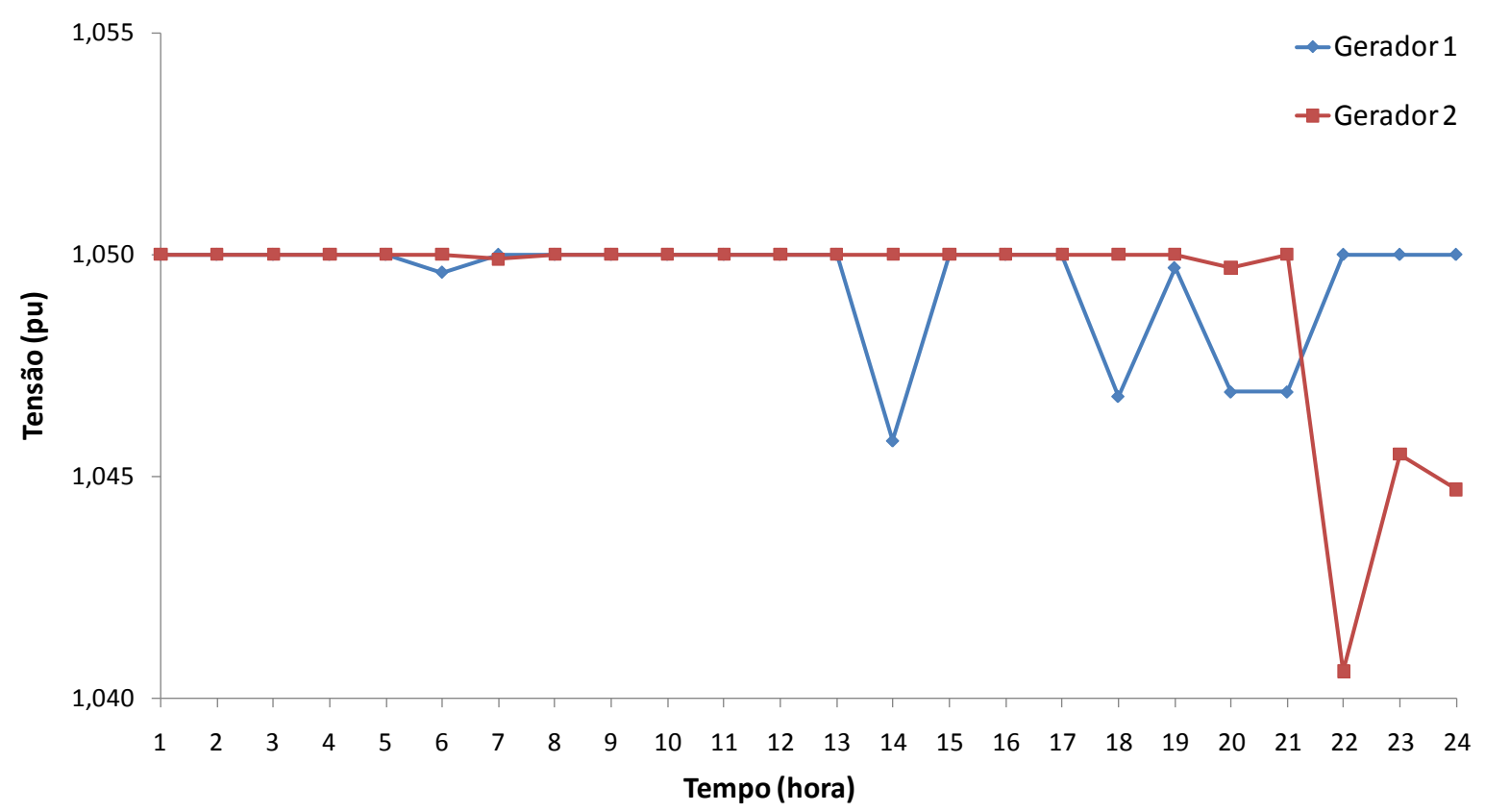

Figura 5.10 - Perfil de tensão dos geradores operando com controle PV Variável / min Perdas. 


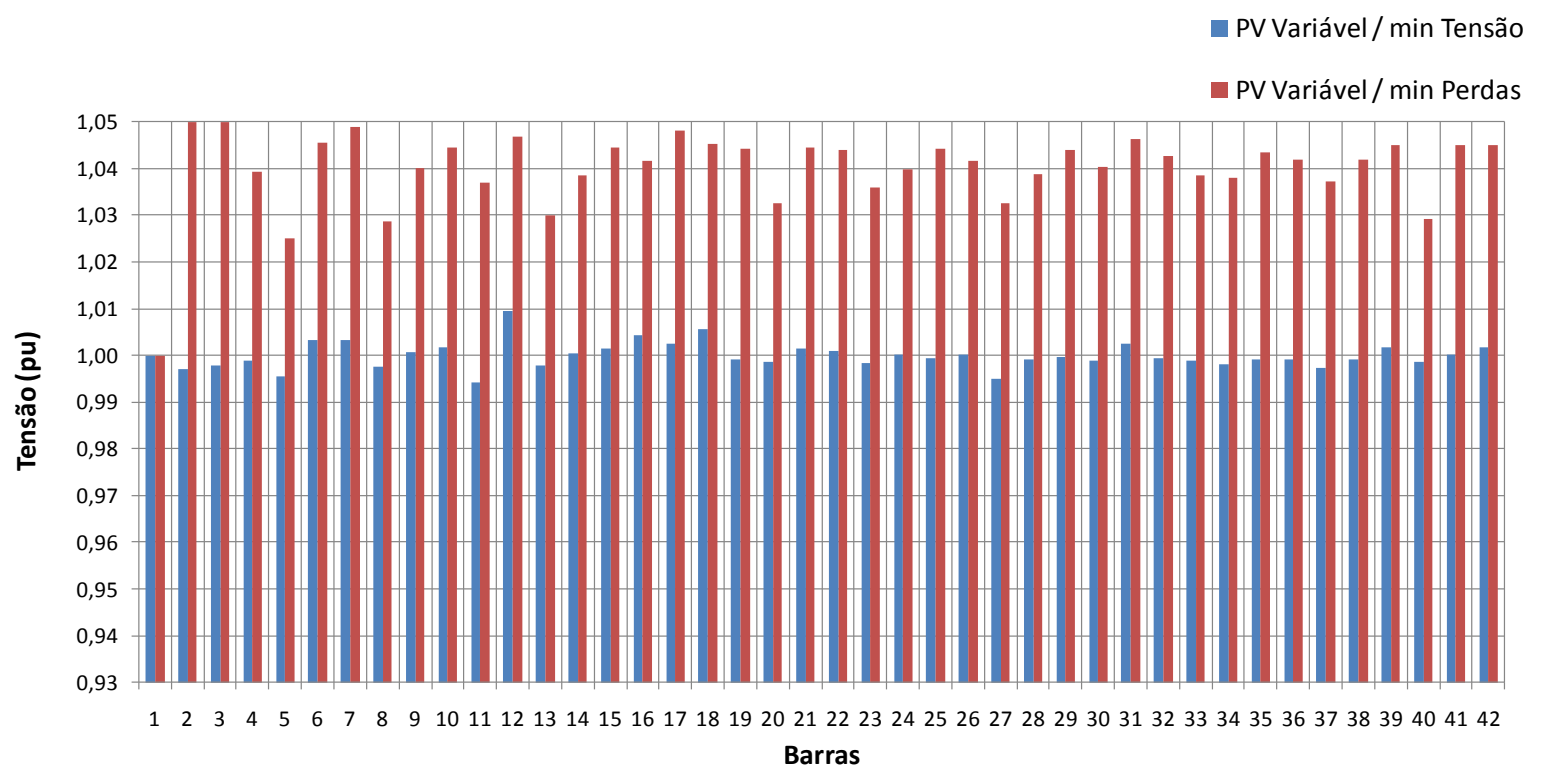

Figura 5.11 - Perfil de tensão para carregamento mínimo - PV Variável / min Tensão e min Perdas.

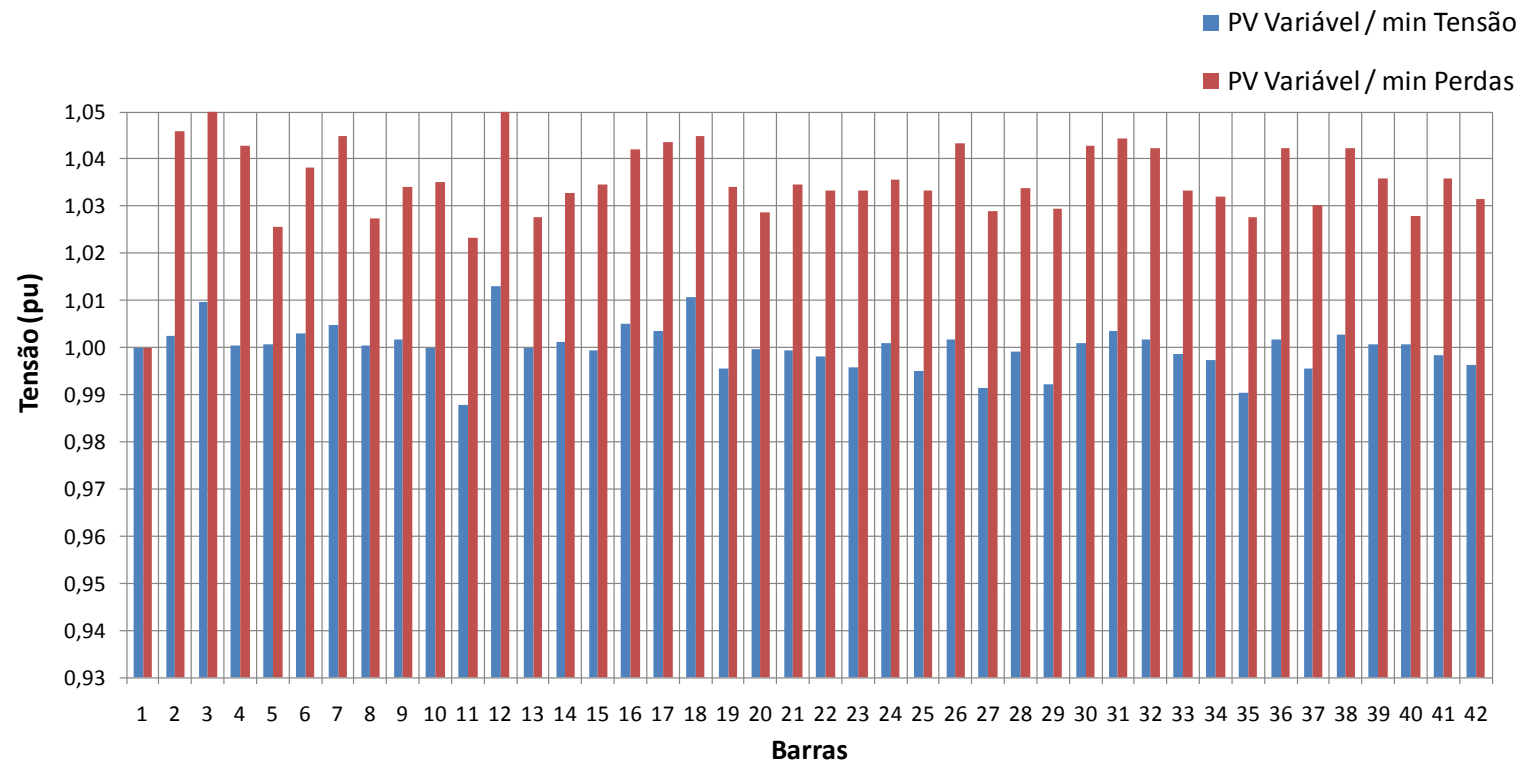

Figura 5.12 - Perfil de tensão para carregamento máximo - PV Variável / min Tensão e min Perdas.

Uma análise mais detalhada envolvendo a metodologia de minimização dos desvios de tensão mostra que utilizando a tensão de referência dos geradores como variável de controle consegue-se, de maneira geral, uma redução mais acentuada dos desvios de tensão quando comparada à manutenção da tensão fixa em 1 pu. Isso pode ser comprovado analisando a Figura 5.13, que apresenta o comportamento da função objetivo durante as 24 horas de operação. Este aspecto também é evidente analisando o somatório dos valores dos desvios de tensão das 24 horas de análise, apresentado na Figura 5.14. Observa-se neste caso, que a operação com PV Variável provocou uma degradação significativa nos desvios de tensão, 
quando se busca a minimização das perdas. Isso ocorreu porque as tensões dos geradores foram aumentadas até 1,05 ou em quase todo o período de operação do sistema elétrico, elevando o perfil das tensões nodais como um todo.

Em relação às perdas de energia, observa-se na Figura 5.15 uma ligeira redução para o caso PV Variável. Tal redução é mais acentuada na estratégia de minimização das perdas.

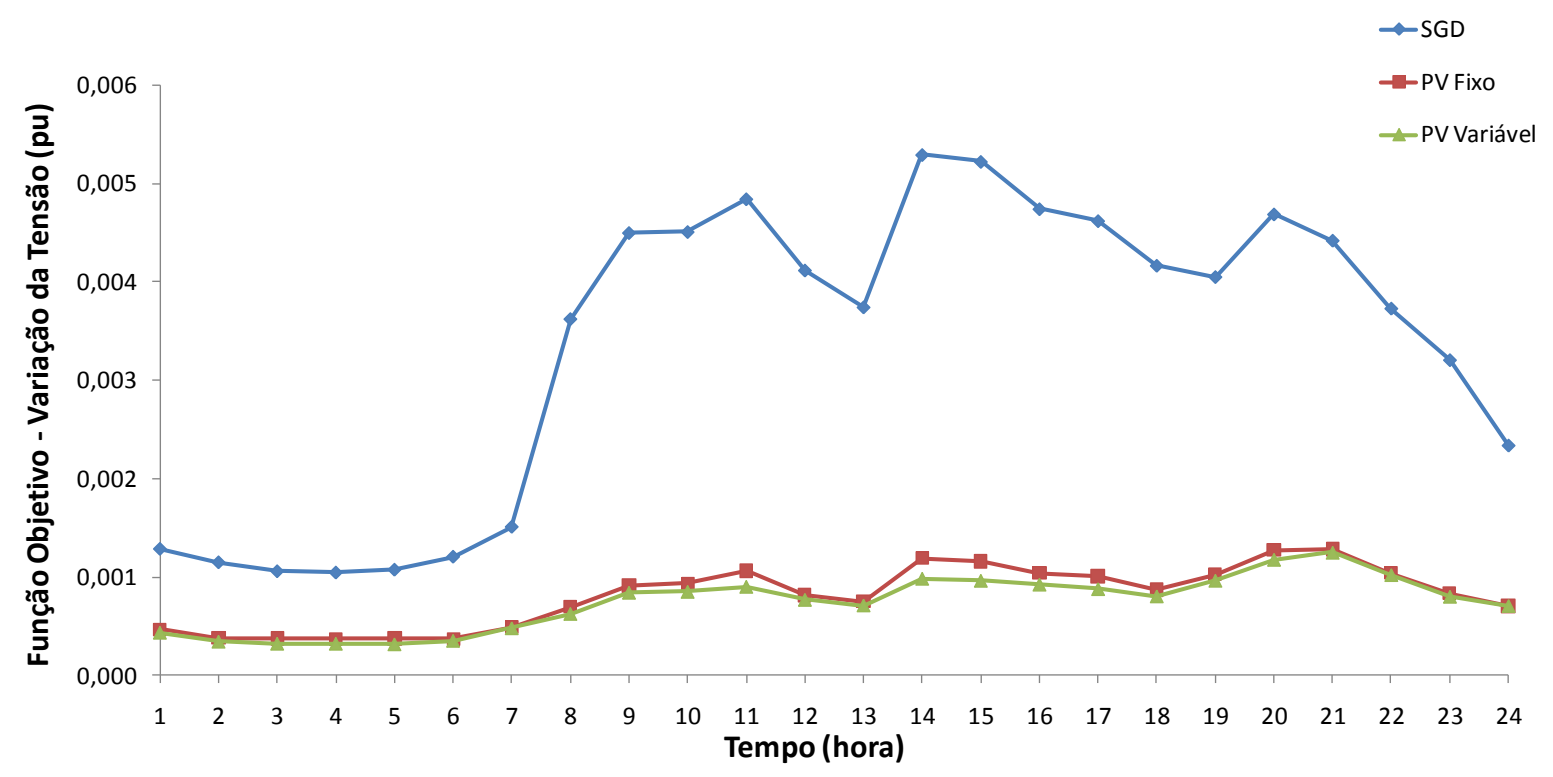

Figura 5.13 - Valores da função objetivo para o caso de minimização da variação da tensão - SGD, PV Fixo e PV Variável.

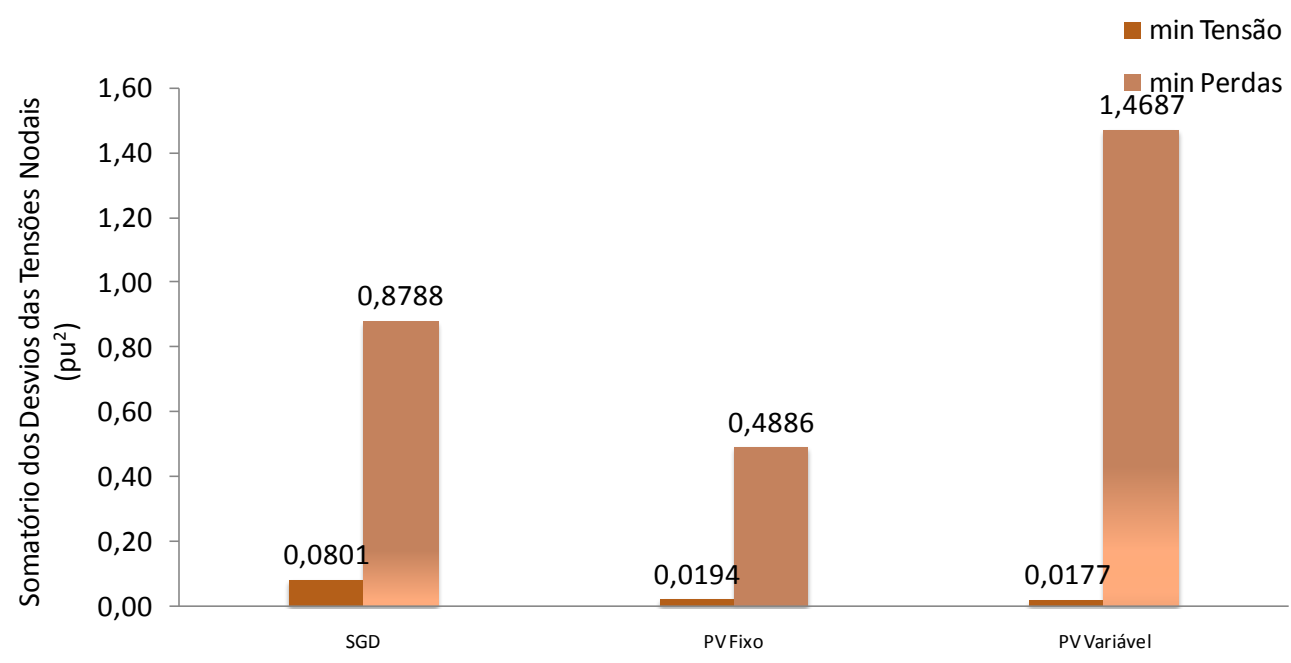

Figura 5.14 - Somatório dos desvios das tensões nodais - SGD, PV Fixo e PV Variável. 


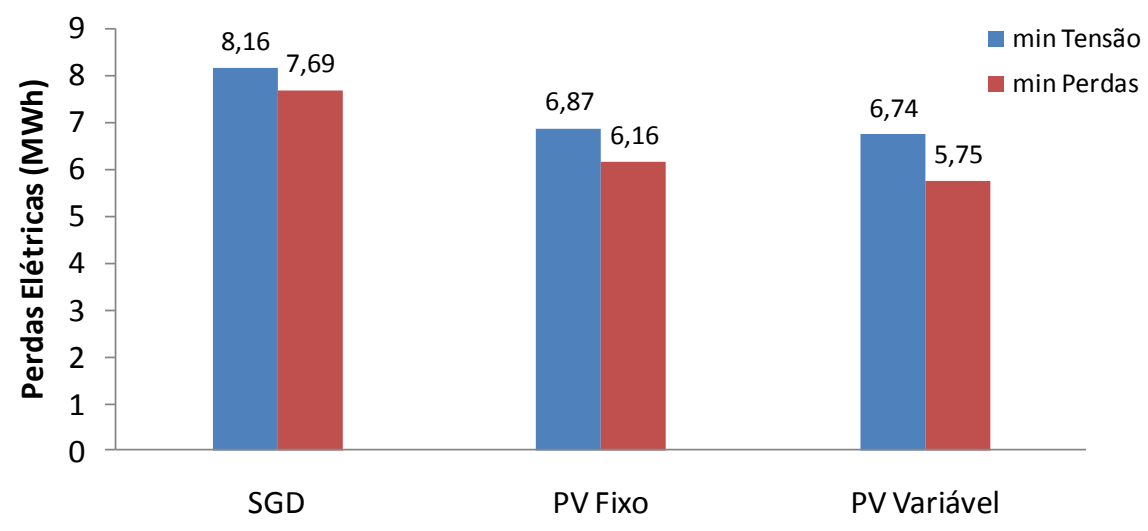

Figura 5.15 - Perdas de Energia - min Tensão e min Perdas.

A Tabela 5.13 e Tabela 5.14 apresentam as configurações dos bancos de capacitores, o fator de potência e carregamento dos geradores durante as 24 horas, para ambas as estratégias de controle de tensão, respectivamente. Em relação ao fator de potência e carregamento dos geradores, observa-se que foram mantidos dentro dos limites aceitáveis. Percebe-se ainda uma leve redução do fator de potência na estratégia que objetiva minimizar perdas, em contrapartida, um aumento do carregamento. Esta relação inversa se justifica em razão de o carregamento ter seu aumento resultado da elevação no fornecimento de potência reativa pelos geradores para manter a tensão controlada no nível determinado, causando a redução do fator de potência. 
Tabela 5.13 - Configuração dos bancos de capacitores - PV Variável / min Tensão.

\begin{tabular}{|c|c|c|c|c|c|c|c|c|c|}
\hline \multirow{3}{*}{$\begin{array}{l}\text { Tempo } \\
\text { (hora) }\end{array}$} & \multirow{2}{*}{\multicolumn{2}{|c|}{$\begin{array}{c}\text { Fator de Potência } \\
\text { dos Geradores }\end{array}$}} & \multirow{2}{*}{\multicolumn{2}{|c|}{$\begin{array}{c}\text { Carregamento } \\
\text { dos Geradores (\%) }\end{array}$}} & \multicolumn{5}{|c|}{ Módulos de Bancos de Capacitores Ativos (\%) } \\
\hline & & & & & \multirow{2}{*}{$\begin{array}{c}\text { BC-1 } \\
\text { barra } 38\end{array}$} & \multirow{2}{*}{$\begin{array}{c}\text { BC-2 } \\
\text { barra } 39\end{array}$} & \multirow{2}{*}{$\begin{array}{c}\text { BC-3 } \\
\text { barra } 40\end{array}$} & \multirow{2}{*}{$\begin{array}{c}\text { BC-4 } \\
\text { barra } 41\end{array}$} & \multirow{2}{*}{$\begin{array}{c}\text { BC-5 } \\
\text { barra } 42\end{array}$} \\
\hline & G1 & G2 & G1 & G2 & & & & & \\
\hline 1 & 0,994 & 0,994 & 76,114 & 76,181 & $0,0 \%$ & $0,0 \%$ & $100,0 \%$ & $50,0 \%$ & $50,0 \%$ \\
\hline 2 & 0,992 & 0,997 & 76,271 & 75,896 & $0,0 \%$ & $0,0 \%$ & $100,0 \%$ & $25,0 \%$ & $25,0 \%$ \\
\hline 3 & 0,992 & 0,994 & 76,334 & 76,148 & $0,0 \%$ & $0,0 \%$ & $100,0 \%$ & $25,0 \%$ & $50,0 \%$ \\
\hline 4 & 0,991 & 0,994 & 76,349 & 76,172 & $0,0 \%$ & $0,0 \%$ & $100,0 \%$ & $25,0 \%$ & $50,0 \%$ \\
\hline 5 & 0,992 & 0,994 & 76,295 & 76,137 & $0,0 \%$ & $0,0 \%$ & $100,0 \%$ & $25,0 \%$ & $50,0 \%$ \\
\hline 6 & 0,994 & 0,995 & 76,128 & 76,056 & $0,0 \%$ & $0,0 \%$ & $100,0 \%$ & $25,0 \%$ & $50,0 \%$ \\
\hline 7 & 0,996 & 0,995 & 76,006 & 76,040 & $0,0 \%$ & $0,0 \%$ & $100,0 \%$ & $50,0 \%$ & $50,0 \%$ \\
\hline 8 & 1,000 & 1,000 & 75,702 & 75,723 & $50,0 \%$ & $25,0 \%$ & $50,0 \%$ & $100,0 \%$ & $100,0 \%$ \\
\hline 9 & 1,000 & 0,997 & 75,696 & 75,944 & $50,0 \%$ & $50,0 \%$ & $50,0 \%$ & $100,0 \%$ & $100,0 \%$ \\
\hline 10 & 1,000 & 0,994 & 75,706 & 76,146 & $25,0 \%$ & $75,0 \%$ & $50,0 \%$ & $100,0 \%$ & $100,0 \%$ \\
\hline 11 & 1,000 & 0,992 & 75,693 & 76,325 & $25,0 \%$ & $75,0 \%$ & $25,0 \%$ & $100,0 \%$ & $100,0 \%$ \\
\hline 12 & 1,000 & 0,998 & 75,698 & 75,856 & $50,0 \%$ & $50,0 \%$ & $50,0 \%$ & $100,0 \%$ & $100,0 \%$ \\
\hline 13 & 1,000 & 0,999 & 75,703 & 75,766 & $50,0 \%$ & $75,0 \%$ & $25,0 \%$ & $100,0 \%$ & $100,0 \%$ \\
\hline 14 & 1,000 & 0,990 & 75,692 & 76,431 & $25,0 \%$ & $75,0 \%$ & $25,0 \%$ & $100,0 \%$ & $100,0 \%$ \\
\hline 15 & 1,000 & 0,990 & 75,692 & 76,423 & $25,0 \%$ & $75,0 \%$ & $25,0 \%$ & $100,0 \%$ & $100,0 \%$ \\
\hline 16 & 1,000 & 0,993 & 75,696 & 76,238 & $25,0 \%$ & $75,0 \%$ & $25,0 \%$ & $100,0 \%$ & $100,0 \%$ \\
\hline 17 & 1,000 & 0,993 & 75,693 & 76,241 & $25,0 \%$ & $75,0 \%$ & $25,0 \%$ & $100,0 \%$ & $100,0 \%$ \\
\hline 18 & 1,000 & 0,998 & 75,693 & 75,837 & $50,0 \%$ & $50,0 \%$ & $25,0 \%$ & $100,0 \%$ & $100,0 \%$ \\
\hline 19 & 1,000 & 1,000 & 75,700 & 75,705 & $75,0 \%$ & $50,0 \%$ & $50,0 \%$ & $100,0 \%$ & $100,0 \%$ \\
\hline 20 & 1,000 & 0,997 & 75,707 & 75,903 & $50,0 \%$ & $75,0 \%$ & $0,0 \%$ & $100,0 \%$ & $100,0 \%$ \\
\hline 21 & 0,999 & 0,996 & 75,754 & 76,018 & $50,0 \%$ & $50,0 \%$ & $0,0 \%$ & $100,0 \%$ & $75,0 \%$ \\
\hline 22 & 1,000 & 0,999 & 75,692 & 75,800 & $0,0 \%$ & $50,0 \%$ & $25,0 \%$ & $75,0 \%$ & $75,0 \%$ \\
\hline 23 & 1,000 & 0,996 & 75,695 & 75,996 & $0,0 \%$ & $0,0 \%$ & $50,0 \%$ & $75,0 \%$ & $75,0 \%$ \\
\hline 24 & 0,999 & 0,990 & 75,790 & 76,459 & $25,0 \%$ & $0,0 \%$ & $75,0 \%$ & $75,0 \%$ & $75,0 \%$ \\
\hline
\end{tabular}

Tabela 5.14 - Configuração dos bancos de capacitores - PV Variável / min Perdas.

\begin{tabular}{|c|c|c|c|c|c|c|c|c|c|}
\hline \multirow{3}{*}{$\begin{array}{l}\text { Tempo } \\
\text { (hora) }\end{array}$} & \multirow{2}{*}{\multicolumn{2}{|c|}{$\begin{array}{c}\text { Fator de Potência } \\
\text { dos Geradores }\end{array}$}} & \multirow{2}{*}{\multicolumn{2}{|c|}{$\begin{array}{c}\text { Carregamento } \\
\text { dos Geradores }(\%)\end{array}$}} & \multicolumn{5}{|c|}{ Módulos de Bancos de Capacitores Ativos (\%) } \\
\hline & & & & & \multirow{2}{*}{$\begin{array}{c}\text { BC-1 } \\
\text { barra } 38 \\
\end{array}$} & \multirow{2}{*}{$\begin{array}{c}\mathrm{BC}-2 \\
\text { barra } 39 \\
\end{array}$} & \multirow{2}{*}{$\begin{array}{r}\text { BC-3 } \\
\text { barra } 40 \\
\end{array}$} & \multirow{2}{*}{$\begin{array}{c}\mathrm{BC}-4 \\
\text { barra } 41 \\
\end{array}$} & \multirow{2}{*}{$\begin{array}{r}\text { BC-5 } \\
\text { barra } 42 \\
\end{array}$} \\
\hline & G1 & $\mathrm{G} 2$ & G1 & $\mathrm{G} 2$ & & & & & \\
\hline 1 & 0,988 & 0,998 & 76,583 & 75,854 & $0,0 \%$ & $50,0 \%$ & $50,0 \%$ & $25,0 \%$ & $25,0 \%$ \\
\hline 2 & 0,990 & 0,999 & 76,449 & 75,801 & $0,0 \%$ & $50,0 \%$ & $50,0 \%$ & $25,0 \%$ & $25,0 \%$ \\
\hline 3 & 0,991 & 0,999 & 76,405 & 75,786 & $0,0 \%$ & $50,0 \%$ & $50,0 \%$ & $25,0 \%$ & $25,0 \%$ \\
\hline 4 & 0,991 & 0,999 & 76,394 & 75,779 & $0,0 \%$ & $50,0 \%$ & $50,0 \%$ & $25,0 \%$ & $25,0 \%$ \\
\hline 5 & 0,990 & 0,999 & 76,439 & 75,791 & $0,0 \%$ & $50,0 \%$ & $50,0 \%$ & $25,0 \%$ & $25,0 \%$ \\
\hline 6 & 0,987 & 0,999 & 76,699 & 75,773 & $0,0 \%$ & $25,0 \%$ & $50,0 \%$ & $50,0 \%$ & $25,0 \%$ \\
\hline 7 & 0,984 & 0,998 & 76,947 & 75,877 & $0,0 \%$ & $25,0 \%$ & $50,0 \%$ & $25,0 \%$ & $25,0 \%$ \\
\hline 8 & 0,976 & 0,994 & 77,526 & 76,115 & $0,0 \%$ & $50,0 \%$ & $50,0 \%$ & $50,0 \%$ & $50,0 \%$ \\
\hline 9 & 0,974 & 0,992 & 77,750 & 76,319 & $0,0 \%$ & $50,0 \%$ & $75,0 \%$ & $75,0 \%$ & $50,0 \%$ \\
\hline 10 & 0,971 & 0,992 & 77,985 & 36 & $0,0 \%$ & $50,0 \%$ & $50,0 \%$ & $75,0 \%$ & $50,0 \%$ \\
\hline 11 & 0,972 & 0,990 & 77,874 & 76,476 & $0,0 \%$ & $50,0 \%$ & $75,0 \%$ & $75,0 \%$ & $50,0 \%$ \\
\hline 12 & 0,974 & 0,992 & 77,714 & 76,330 & $0,0 \%$ & $50,0 \%$ & $75,0 \%$ & $50,0 \%$ & $50,0 \%$ \\
\hline 13 & 0,974 & 0,993 & 77,702 & 76,218 & $0,0 \%$ & $50,0 \%$ & $75,0 \%$ & $50,0 \%$ & $50,0 \%$ \\
\hline 14 & 0,977 & 0,989 & 77,500 & 76,558 & $0,0 \%$ & $75,0 \%$ & $50,0 \%$ & $75,0 \%$ & $50,0 \%$ \\
\hline 15 & 0,974 & 0,989 & 77,698 & 76,552 & $0,0 \%$ & $75,0 \%$ & $75,0 \%$ & $75,0 \%$ & $50,0 \%$ \\
\hline 16 & 0,971 & 0,991 & 77,962 & 76,411 & $0,0 \%$ & $50,0 \%$ & $50,0 \%$ & $75,0 \%$ & $50,0 \%$ \\
\hline 17 & 0,972 & 0,991 & 77,847 & 76,411 & $0,0 \%$ & $50,0 \%$ & $75,0 \%$ & $75,0 \%$ & $50,0 \%$ \\
\hline 18 & 0,975 & 0,992 & 77,607 & 76,307 & $0,0 \%$ & $50,0 \%$ & $50,0 \%$ & $50,0 \%$ & $50,0 \%$ \\
\hline 19 & 0,973 & 0,992 & 77,831 & 76,265 & $0,0 \%$ & $50,0 \%$ & $50,0 \%$ & $50,0 \%$ & $50,0 \%$ \\
\hline 20 & 0,967 & 0,990 & 78,244 & 76,465 & $0,0 \%$ & $25,0 \%$ & $25,0 \%$ & $50,0 \%$ & $50,0 \%$ \\
\hline 21 & 0,968 & 0,989 & 78,156 & 76,534 & $0,0 \%$ & $25,0 \%$ & $50,0 \%$ & $75,0 \%$ & $25,0 \%$ \\
\hline 22 & 0,974 & 0,973 & 77,729 & 77,805 & $0,0 \%$ & $50,0 \%$ & $75,0 \%$ & $25,0 \%$ & $25,0 \%$ \\
\hline 23 & 0,979 & 0,977 & 77,305 & 77,498 & $25,0 \%$ & $50,0 \%$ & $75,0 \%$ & $25,0 \%$ & $25,0 \%$ \\
\hline 24 & 0,981 & 0,978 & 77,125 & 77,431 & $0,0 \%$ & $50,0 \%$ & $50,0 \%$ & $25,0 \%$ & $25,0 \%$ \\
\hline
\end{tabular}


Analisando o comportamento dos transformadores da subestação, a Tabela 5.15 e a Tabela 5.16 demonstram que seus taps foram ajustados mais próximos do limiar superior (1,05 pu) na estratégia de minimização de perdas, visando elevar as tensões nodais.

Finalmente, a variação nos taps dos reguladores de tensão está apresentada nas Tabelas 5.17 e 5.18, em que se percebe que os taps variaram de forma muito semelhante para as estratégias de minimizar desvio das tensões e minimizar as perdas elétricas. Comparando a Tabela 5.18 (PV Variável) com a Tabela 5.12 (PV Fixo) observa-se que com PV Variável houve uma menor excursão entre os taps dos reguladores. Neste caso, como os geradores contribuíram para manter as tensões nodais próximas de 1,05 pu, não foi necessário elevar em demasia os taps dos reguladores de tensão.

Tabela 5.15 - Configuração dos taps dos transformadores da subestação - PV Variável / min Tensão.

\begin{tabular}{|c|c|c|}
\hline \multirow{2}{*}{ Tempo } & \multicolumn{2}{|c|}{ tap dos transformadores da subestação $(\mathrm{pu})$} \\
\cline { 2 - 3 } (hora) & $\begin{array}{c}\text { Trafo } 1 \\
\text { ramo } 1-4\end{array}$ & $\begin{array}{c}\text { Trafo } 2 \\
\text { ramo } 1-5\end{array}$ \\
\hline 1 & 1,02500 & 1,02500 \\
\hline 2 & 1,02500 & 1,02500 \\
\hline 3 & 1,02500 & 1,02500 \\
\hline 4 & 1,02500 & 1,02500 \\
\hline 5 & 1,02500 & 1,02500 \\
\hline 6 & 1,02500 & 1,02500 \\
\hline 7 & 1,02500 & 1,02500 \\
\hline 8 & 1,00000 & 1,02500 \\
\hline 9 & 1,00000 & 1,02500 \\
\hline 10 & 1,00000 & 1,02500 \\
\hline 11 & 1,00000 & 1,02500 \\
\hline 12 & 1,00000 & 1,02500 \\
\hline 13 & 1,00000 & 1,02500 \\
\hline 14 & 1,00000 & 1,02500 \\
\hline 15 & 1,00000 & 1,02500 \\
\hline 16 & 1,00000 & 1,02500 \\
\hline 17 & 1,00000 & 1,02500 \\
\hline 18 & 1,00000 & 1,02500 \\
\hline 19 & 1,00000 & 1,02500 \\
\hline 20 & 1,00000 & 1,02500 \\
\hline 21 & 1,00000 & 1,02500 \\
\hline 22 & 1,02500 & 1,02500 \\
\hline 23 & 1,02500 & 1,02500 \\
\hline 24 & 1,02500 & 1,02500 \\
\hline & & \\
\hline
\end{tabular}


Tabela 5.16 - Configuração dos taps dos transformadores da subestação - PV Variável / min Perdas.

\begin{tabular}{|c|c|c|}
\hline \multirow{2}{*}{ Tempo } & tap dos transformadores da subestação $(\mathrm{pu})$ \\
\cline { 2 - 3 } (hora) & $\begin{array}{c}\text { Trafo 1 } \\
\text { ramo 1-4 }\end{array}$ & $\begin{array}{c}\text { Trafo } 2 \\
\text { ramo 1-5 }\end{array}$ \\
\hline 1 & 1,05000 & 1,02500 \\
\hline 2 & 1,05000 & 1,02500 \\
\hline 3 & 1,05000 & 1,02500 \\
\hline 4 & 1,05000 & 1,02500 \\
\hline 5 & 1,05000 & 1,02500 \\
\hline 6 & 1,05000 & 1,02500 \\
\hline 7 & 1,05000 & 1,02500 \\
\hline 8 & 1,05000 & 1,02500 \\
\hline 9 & 1,05000 & 1,02500 \\
\hline 10 & 1,05000 & 1,02500 \\
\hline 11 & 1,05000 & 1,02500 \\
\hline 12 & 1,05000 & 1,02500 \\
\hline 13 & 1,05000 & 1,02500 \\
\hline 14 & 1,05000 & 1,02500 \\
\hline 15 & 1,05000 & 1,02500 \\
\hline 16 & 1,05000 & 1,02500 \\
\hline 17 & 1,05000 & 1,02500 \\
\hline 18 & 1,05000 & 1,02500 \\
\hline 19 & 1,05000 & 1,02500 \\
\hline 20 & 1,05000 & 1,02500 \\
\hline 21 & 1,05000 & 1,02500 \\
\hline 22 & 1,02500 & 1,02500 \\
\hline 23 & 1,02500 & 1,02500 \\
\hline 24 & 1,02500 & 1,02500 \\
\hline & & \\
\hline
\end{tabular}

Tabela 5.17 - Configuração dos taps dos reguladores de tensão - PV Variável / min Tensão.

\begin{tabular}{|c|c|c|}
\hline \multirow{2}{*}{ Tempo } & \multicolumn{2}{|c|}{ tap dos reguladores de tensão (pu) } \\
\cline { 2 - 3 } (hora) & $\begin{array}{c}\text { Reg.1 } \\
\text { ramo 11-12 }\end{array}$ & $\begin{array}{c}\text { Reg.2 } \\
\text { ramo } 17-18\end{array}$ \\
\hline 1 & 1,01875 & 1,02500 \\
\hline 2 & 1,01875 & 1,00625 \\
\hline 3 & 1,01875 & 1,00625 \\
\hline 4 & 1,01875 & 1,00625 \\
\hline 5 & 1,01875 & 1,00625 \\
\hline 6 & 1,01875 & 1,00625 \\
\hline 7 & 1,02500 & 1,00625 \\
\hline 8 & 1,02500 & 1,01250 \\
\hline 9 & 1,03125 & 1,01250 \\
\hline 10 & 1,03125 & 1,01250 \\
\hline 11 & 1,03125 & 1,01250 \\
\hline 12 & 1,03125 & 1,01250 \\
\hline 13 & 1,03125 & 1,01250 \\
\hline 14 & 1,03125 & 1,01250 \\
\hline 15 & 1,03125 & 1,01250 \\
\hline 16 & 1,03125 & 1,01250 \\
\hline 17 & 1,03125 & 1,01250 \\
\hline 18 & 1,03125 & 1,01250 \\
\hline 19 & 1,03750 & 1,01875 \\
\hline 20 & 1,03750 & 1,01875 \\
\hline 21 & 1,03750 & 1,01875 \\
\hline 22 & 1,03750 & 1,01875 \\
\hline 23 & 1,03125 & 1,01875 \\
\hline 24 & 1,03125 & 1,01875 \\
\hline & & \\
\hline
\end{tabular}


Tabela 5.18 - Configuração dos taps dos reguladores de tensão - PV Variável / min Perdas.

\begin{tabular}{|c|c|c|}
\hline \multirow{2}{*}{$\begin{array}{c}\text { Tempo } \\
\text { (hora) }\end{array}$} & \begin{tabular}{c}
$|c|$ \\
\cline { 2 - 3 } \\
ramo $11-12$ dos reguladores de tensão (pu)
\end{tabular} & $\begin{array}{c}\text { Reg. } 2 \\
\text { ramo } 17-18\end{array}$ \\
\hline 1 & 1,01875 & 1,00625 \\
\hline 2 & 1,01250 & 1,00000 \\
\hline 3 & 1,01250 & 1,00000 \\
\hline 4 & 1,01250 & 1,00000 \\
\hline 5 & 1,01250 & 1,00000 \\
\hline 6 & 1,01875 & 1,00000 \\
\hline 7 & 1,01875 & 1,00625 \\
\hline 8 & 1,02500 & 1,00625 \\
\hline 9 & 1,02500 & 1,00625 \\
\hline 10 & 1,02500 & 1,00625 \\
\hline 11 & 1,02500 & 1,00625 \\
\hline 12 & 1,02500 & 1,00625 \\
\hline 13 & 1,02500 & 1,00625 \\
\hline 14 & 1,03125 & 1,00625 \\
\hline 15 & 1,02500 & 1,00625 \\
\hline 16 & 1,02500 & 1,00625 \\
\hline 17 & 1,02500 & 1,00625 \\
\hline 18 & 1,03125 & 1,00625 \\
\hline 19 & 1,03125 & 1,00625 \\
\hline 20 & 1,03750 & 1,01250 \\
\hline 21 & 1,03750 & 1,01250 \\
\hline 22 & 1,03125 & 1,02500 \\
\hline 23 & 1,02500 & 1,01875 \\
\hline 24 & 1,02500 & 1,01875 \\
\hline & & \\
\hline
\end{tabular}

\subsection{Geradores com Controle PQ}

Como sugerido no Capítulo 4, sob determinadas circunstâncias, seria favorável a possibilidade de que os geradores variem a potência ativa fornecida para o sistema de distribuição. Assim, neste trabalho, serão analisadas a operação do sistema elétrico com a presença de geradores com o controle do tipo PQ, sendo estes configurados tanto com potência ativa fixa (comumente empregada) como também variável.

\subsubsection{Potência Ativa Fixa}

Esta estratégia será identificada por PQ Fixo nesta dissertação. As unidades de geração distribuída foram configuradas para operar com potência reativa de 0 Mvar, ou seja, fator de potência unitário, mantendo o fornecimento de potência ativa em 10,5 MW cada um, isto é, um carregamento constante de 75,69\%. Os impactos da inserção destes geradores são apresentados nas Figuras 5.16 a 5.20, e Tabelas 5.19 a 5.24, considerando a minimização dos desvios de tensão e minimização das perdas. 
Analisando os resultados dos perfis de tensão da Figura 5.16 e da Figura 5.17, e comparando-os com os demais, observa-se que os desempenhos das duas estratégias foram semelhantes, variando apenas o valor das tensões, ou seja, no caso de minimização das perdas as tensões nodais se aproximam do limite superior, ao passo que no caso de minimização dos desvios de tensão, os valores ficam próximos de 1 pu.

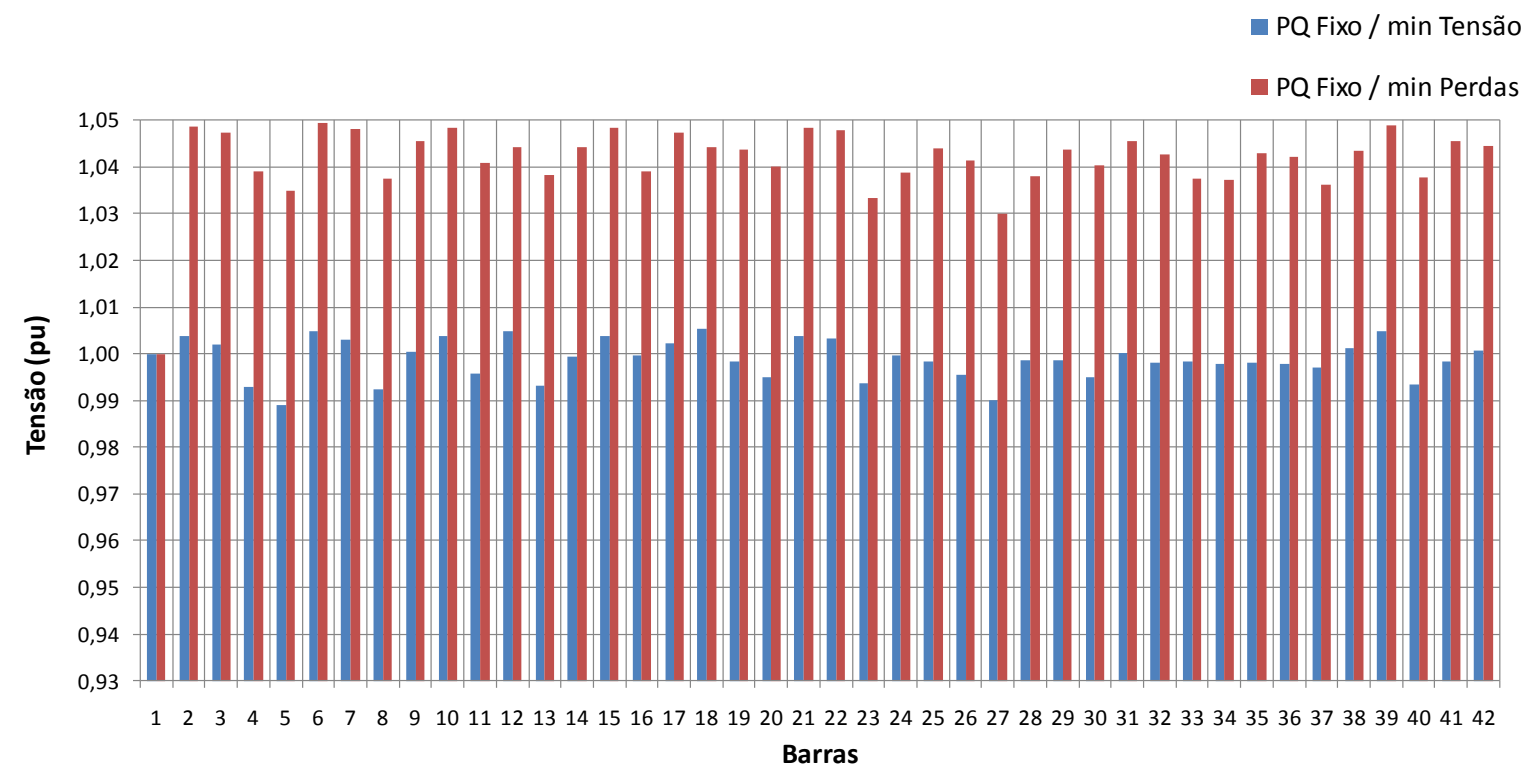

Figura 5.16 - Perfil de tensão para carregamento mínimo - PQ Fixo / min Tensão e min Perdas.

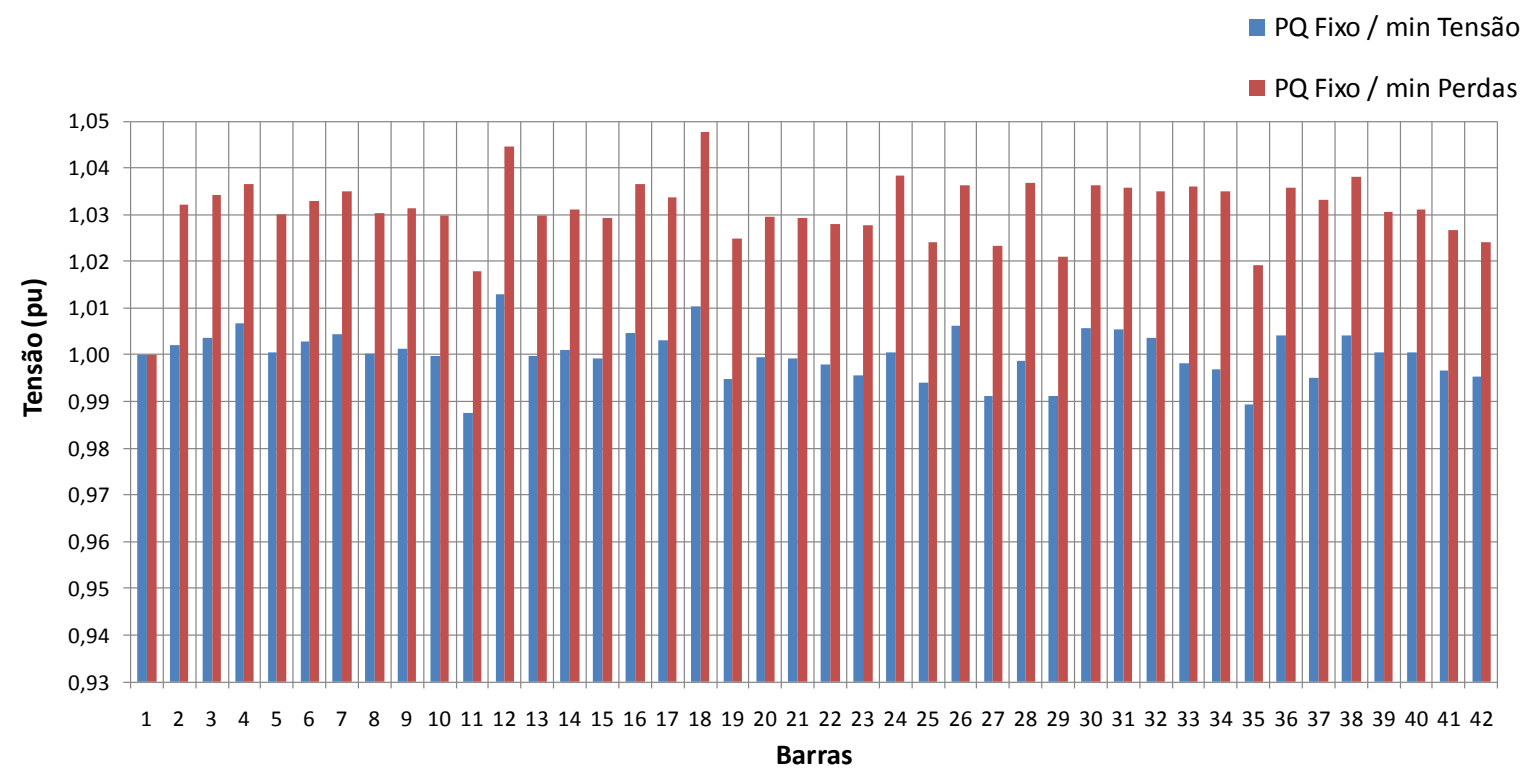

Figura 5.17 - Perfil de tensão para carregamento máximo - PQ Fixo / min Tensão e min Perdas.

A Figura 5.18 apresenta o comportamento do valor da função objetivo de minimização dos desvios de tensão considerando 24 horas de operação do sistema, para todos os casos analisados até esta seção. Observa-se que os valores da função objetivo para o caso PQ Fixo 
foram ligeiramente superiores aos valores das estratégias que consideram controle PV nos períodos de maior carregamento (após às 9:00). Isso também pode ser observado na Figura 5.19 , onde se conclui que as variações nos níveis de tensão são pequenas entre as estratégias que minimizam os desvios de tensão. Logo, este fato pode fortalecer o incentivo de concessionárias de energia elétrica sobre a atratividade da operação de geradores com controle PQ, em relação à metodologia que visa minimizar perdas elétricas. Destaca-se, na Figura 5.20, a redução nas perdas elétricas quando comparado aos casos anteriores em que se minimizavam os desvios de tensão. Isso ocorre porque não há fornecimento e nem consumo de potência reativa pelos geradores, quando estes operam sob modo de controle PQ.

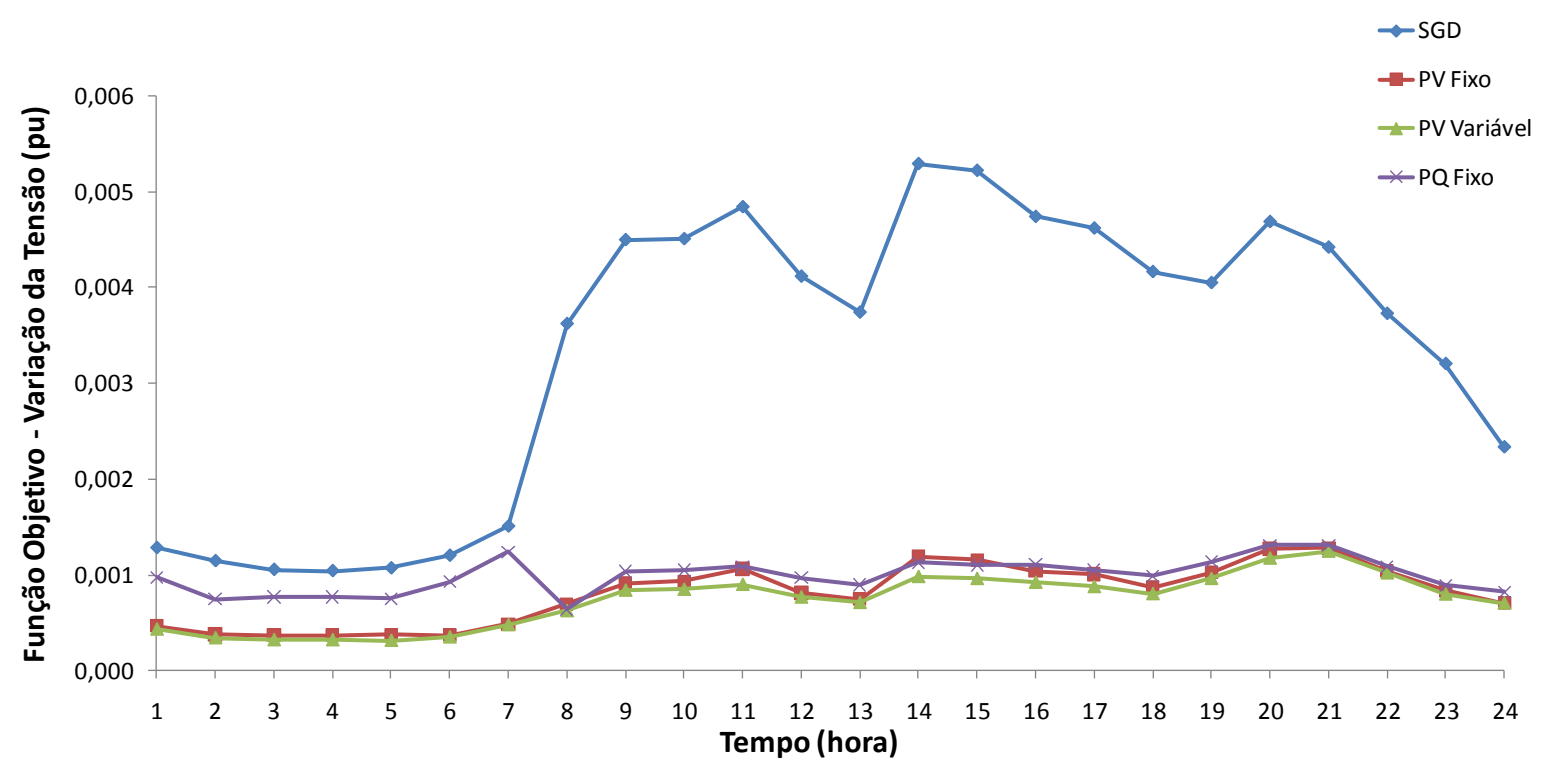

Figura 5.18 - Valores da função objetivo para o caso de minimização da variação da tensão - SGD, PV Fixo, PV Variável e PQ Fixo.

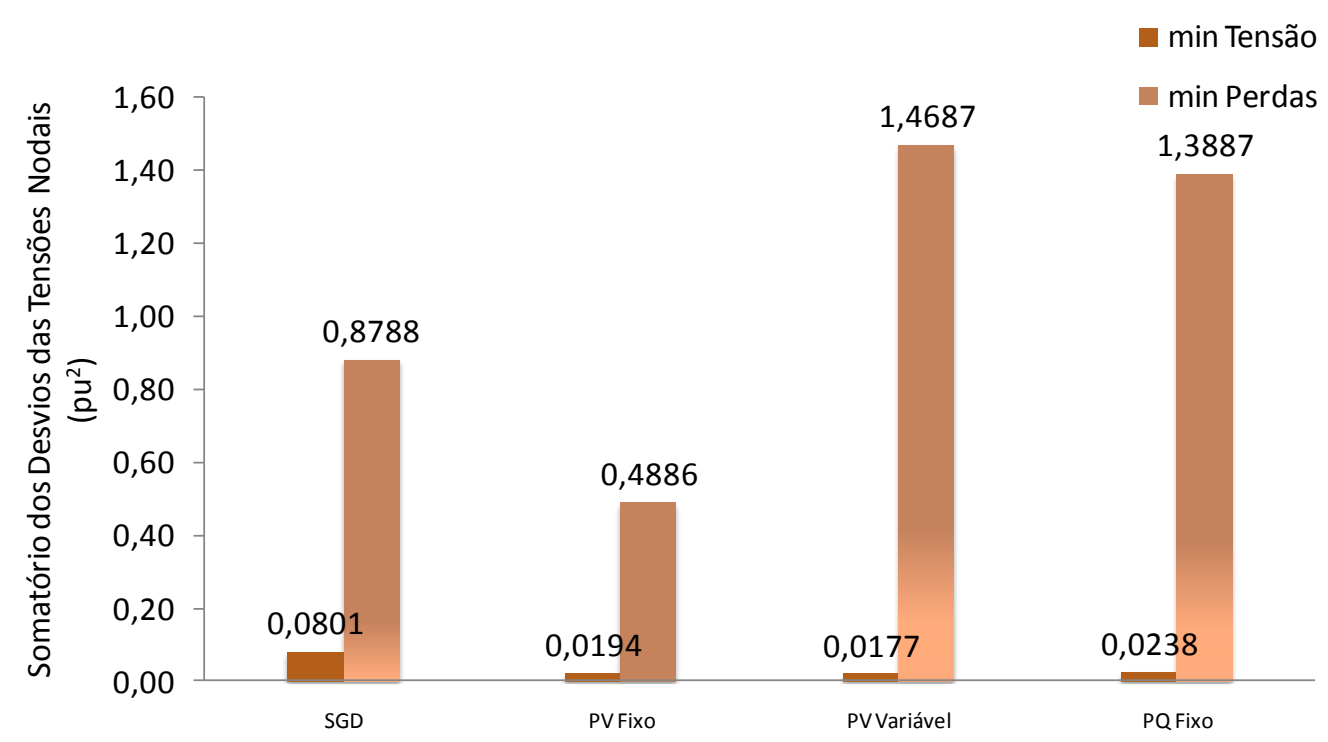


Figura 5.19 - Somatório dos desvios das tensões nodais - SGD, PV Fixo, PV Variável e PQ Fixo.

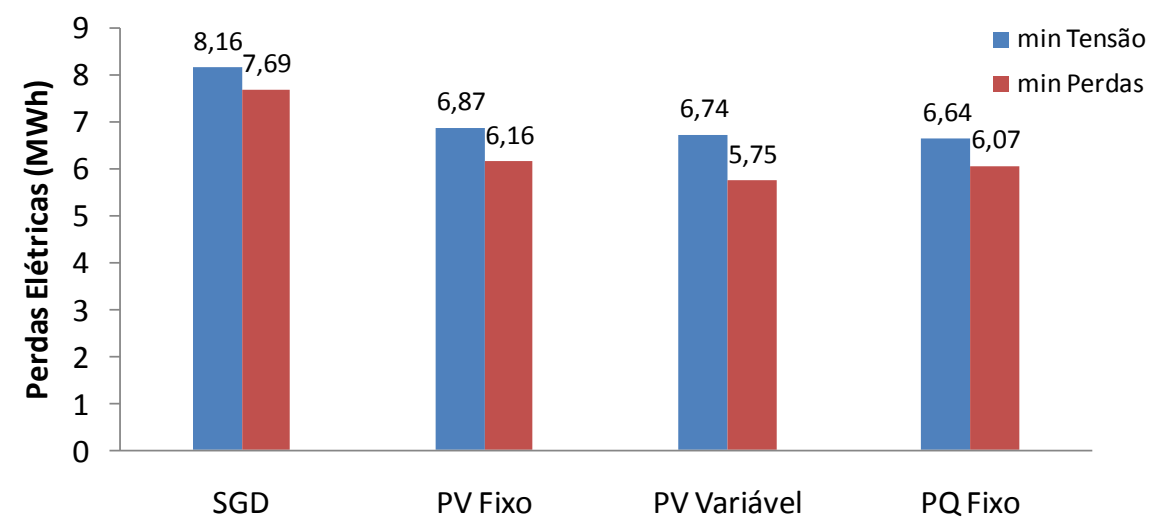

Figura 5.20 - Perdas de Energia - min Tensão e min Perdas.

Das configurações encontradas para os bancos de capacitores, presentes nas tabelas 5.19 e 5.20, observa-se prontamente que para o caso de minimização das perdas, no geral, foi necessária uma maior potência reativa fornecida pelos bancos de capacitores, mas houve redução do números de chaveamentos, quando comparado à minimização dos desvios de tensão.

Os taps dos transformadores da subestação não ultrapassam de 102,5\% (ou 1,025) na estratégia de minimização dos desvios de tensão conforme se observa na Tabela 5.21. Por outro lado para a minimização das perdas, os taps dos transformadores da subestação foram levados aos valores máximos, como pode ser observado na Tabela 5.22. Percebe-se que comportamento semelhante foi observado no caso sem geração distribuída (Tabela 5.2). 
Tabela 5.19 - Configuração dos bancos de capacitores - PQ Fixo / min Tensão.

\begin{tabular}{|c|c|c|c|c|c|}
\hline \multirow{2}{*}{$\begin{array}{c}\text { Tempo } \\
\text { (hora) }\end{array}$} & \multicolumn{4}{|c}{ Módulos de Bancos de Capacitores Ativos (\%) } \\
\cline { 2 - 6 } & $\begin{array}{c}\text { BC-1 } \\
\text { barra } 38\end{array}$ & $\begin{array}{c}\text { BC-2 } \\
\text { barra 39 }\end{array}$ & $\begin{array}{c}\text { BC-3 } \\
\text { barra 40 }\end{array}$ & $\begin{array}{c}\text { BC-4 } \\
\text { barra 41 }\end{array}$ & $\begin{array}{c}\text { BC-5 } \\
\text { barra 42 }\end{array}$ \\
\hline 1 & $75,0 \%$ & $75,0 \%$ & $100,0 \%$ & $50,0 \%$ & $50,0 \%$ \\
\hline 2 & $75,0 \%$ & $75,0 \%$ & $100,0 \%$ & $25,0 \%$ & $50,0 \%$ \\
\hline 3 & $75,0 \%$ & $75,0 \%$ & $100,0 \%$ & $25,0 \%$ & $50,0 \%$ \\
\hline 4 & $75,0 \%$ & $75,0 \%$ & $100,0 \%$ & $0,0 \%$ & $50,0 \%$ \\
\hline 5 & $75,0 \%$ & $75,0 \%$ & $100,0 \%$ & $25,0 \%$ & $50,0 \%$ \\
\hline 6 & $75,0 \%$ & $75,0 \%$ & $100,0 \%$ & $25,0 \%$ & $50,0 \%$ \\
\hline 7 & $75,0 \%$ & $0,0 \%$ & $0,0 \%$ & $50,0 \%$ & $50,0 \%$ \\
\hline 8 & $75,0 \%$ & $0,0 \%$ & $50,0 \%$ & $100,0 \%$ & $100,0 \%$ \\
\hline 9 & $0,0 \%$ & $50,0 \%$ & $25,0 \%$ & $25,0 \%$ & $100,0 \%$ \\
\hline 10 & $0,0 \%$ & $75,0 \%$ & $0,0 \%$ & $25,0 \%$ & $100,0 \%$ \\
\hline 11 & $0,0 \%$ & $50,0 \%$ & $50,0 \%$ & $50,0 \%$ & $100,0 \%$ \\
\hline 12 & $0,0 \%$ & $50,0 \%$ & $25,0 \%$ & $0,0 \%$ & $100,0 \%$ \\
\hline 13 & $0,0 \%$ & $25,0 \%$ & $50,0 \%$ & $25,0 \%$ & $75,0 \%$ \\
\hline 14 & $0,0 \%$ & $75,0 \%$ & $25,0 \%$ & $75,0 \%$ & $100,0 \%$ \\
\hline 15 & $0,0 \%$ & $75,0 \%$ & $25,0 \%$ & $75,0 \%$ & $100,0 \%$ \\
\hline 16 & $0,0 \%$ & $75,0 \%$ & $0,0 \%$ & $50,0 \%$ & $100,0 \%$ \\
\hline 17 & $0,0 \%$ & $50,0 \%$ & $50,0 \%$ & $50,0 \%$ & $100,0 \%$ \\
\hline 18 & $0,0 \%$ & $75,0 \%$ & $0,0 \%$ & $0,0 \%$ & $100,0 \%$ \\
\hline 19 & $0,0 \%$ & $25,0 \%$ & $50,0 \%$ & $25,0 \%$ & $75,0 \%$ \\
\hline 20 & $0,0 \%$ & $75,0 \%$ & $50,0 \%$ & $25,0 \%$ & $100,0 \%$ \\
\hline 21 & $0,0 \%$ & $75,0 \%$ & $50,0 \%$ & $50,0 \%$ & $75,0 \%$ \\
\hline 22 & $0,0 \%$ & $50,0 \%$ & $25,0 \%$ & $0,0 \%$ & $75,0 \%$ \\
\hline 23 & $0,0 \%$ & $0,0 \%$ & $25,0 \%$ & $25,0 \%$ & $25,0 \%$ \\
\hline 24 & $0,0 \%$ & $0,0 \%$ & $0,0 \%$ & $0,0 \%$ & $25,0 \%$ \\
\hline
\end{tabular}

Tabela 5.20 - Configuração dos bancos de capacitores - PQ Fixo / min Perdas.

\begin{tabular}{|c|c|c|c|c|c|}
\hline \multirow{2}{*}{$\begin{array}{c}\text { Tempo } \\
\text { (hora) }\end{array}$} & \multicolumn{4}{|c|}{ Módulos de Bancos de Capacitores Ativos (\%) } \\
\cline { 2 - 6 } barra 38 & $\begin{array}{c}\text { BC-2 } \\
\text { barra 39 }\end{array}$ & $\begin{array}{c}\text { BC-3 } \\
\text { barra 40 }\end{array}$ & $\begin{array}{c}\text { BC-4 } \\
\text { barra 41 }\end{array}$ & $\begin{array}{c}\text { BC-5 } \\
\text { barra 42 }\end{array}$ \\
\hline 1 & $25,0 \%$ & $75,0 \%$ & $25,0 \%$ & $50,0 \%$ & $50,0 \%$ \\
\hline 2 & $25,0 \%$ & $75,0 \%$ & $0,0 \%$ & $75,0 \%$ & $25,0 \%$ \\
\hline 3 & $25,0 \%$ & $75,0 \%$ & $0,0 \%$ & $75,0 \%$ & $25,0 \%$ \\
\hline 4 & $25,0 \%$ & $50,0 \%$ & $25,0 \%$ & $50,0 \%$ & $25,0 \%$ \\
\hline 5 & $25,0 \%$ & $75,0 \%$ & $0,0 \%$ & $75,0 \%$ & $25,0 \%$ \\
\hline 6 & $25,0 \%$ & $75,0 \%$ & $25,0 \%$ & $75,0 \%$ & $25,0 \%$ \\
\hline 7 & $25,0 \%$ & $75,0 \%$ & $75,0 \%$ & $50,0 \%$ & $50,0 \%$ \\
\hline 8 & $25,0 \%$ & $75,0 \%$ & $75,0 \%$ & $75,0 \%$ & $75,0 \%$ \\
\hline 9 & $50,0 \%$ & $75,0 \%$ & $75,0 \%$ & $75,0 \%$ & $75,0 \%$ \\
\hline 10 & $50,0 \%$ & $75,0 \%$ & $75,0 \%$ & $75,0 \%$ & $75,0 \%$ \\
\hline 11 & $50,0 \%$ & $75,0 \%$ & $75,0 \%$ & $75,0 \%$ & $75,0 \%$ \\
\hline 12 & $50,0 \%$ & $75,0 \%$ & $75,0 \%$ & $75,0 \%$ & $75,0 \%$ \\
\hline 13 & $25,0 \%$ & $75,0 \%$ & $75,0 \%$ & $75,0 \%$ & $75,0 \%$ \\
\hline 14 & $50,0 \%$ & $75,0 \%$ & $75,0 \%$ & $75,0 \%$ & $75,0 \%$ \\
\hline 15 & $50,0 \%$ & $75,0 \%$ & $75,0 \%$ & $75,0 \%$ & $75,0 \%$ \\
\hline 16 & $50,0 \%$ & $75,0 \%$ & $75,0 \%$ & $75,0 \%$ & $75,0 \%$ \\
\hline 17 & $50,0 \%$ & $75,0 \%$ & $75,0 \%$ & $75,0 \%$ & $75,0 \%$ \\
\hline 18 & $50,0 \%$ & $75,0 \%$ & $75,0 \%$ & $75,0 \%$ & $75,0 \%$ \\
\hline 19 & $50,0 \%$ & $75,0 \%$ & $75,0 \%$ & $75,0 \%$ & $75,0 \%$ \\
\hline 20 & $50,0 \%$ & $75,0 \%$ & $50,0 \%$ & $75,0 \%$ & $75,0 \%$ \\
\hline 21 & $25,0 \%$ & $75,0 \%$ & $75,0 \%$ & $75,0 \%$ & $75,0 \%$ \\
\hline 22 & $25,0 \%$ & $75,0 \%$ & $75,0 \%$ & $75,0 \%$ & $50,0 \%$ \\
\hline 23 & $25,0 \%$ & $75,0 \%$ & $50,0 \%$ & $75,0 \%$ & $50,0 \%$ \\
\hline 24 & $50,0 \%$ & $75,0 \%$ & $75,0 \%$ & $75,0 \%$ & $50,0 \%$ \\
\hline
\end{tabular}


Tabela 5.21 - Configuração dos taps dos transformadores da subestação - PQ Fixo / min Tensão.

\begin{tabular}{|c|c|c|}
\hline \multirow{2}{*}{ Tempo } & tap dos transformadores da subestação $(\mathrm{pu})$ \\
\cline { 2 - 3 } (hora) & $\begin{array}{c}\text { Trafo 1 } \\
\text { ramo 1-4 }\end{array}$ & $\begin{array}{c}\text { Trafo 2 } \\
\text { ramo 1-5 }\end{array}$ \\
\hline 1 & 1,00000 & 1,00000 \\
\hline 2 & 1,00000 & 1,00000 \\
\hline 3 & 1,00000 & 1,00000 \\
\hline 4 & 1,00000 & 1,00000 \\
\hline 5 & 1,00000 & 1,00000 \\
\hline 6 & 1,00000 & 1,00000 \\
\hline 7 & 1,00000 & 1,02500 \\
\hline 8 & 1,00000 & 1,02500 \\
\hline 9 & 1,02500 & 1,02500 \\
\hline 10 & 1,02500 & 1,02500 \\
\hline 11 & 1,02500 & 1,02500 \\
\hline 12 & 1,02500 & 1,02500 \\
\hline 13 & 1,02500 & 1,02500 \\
\hline 14 & 1,02500 & 1,02500 \\
\hline 15 & 1,02500 & 1,02500 \\
\hline 16 & 1,02500 & 1,02500 \\
\hline 17 & 1,02500 & 1,02500 \\
\hline 18 & 1,02500 & 1,02500 \\
\hline 19 & 1,02500 & 1,02500 \\
\hline 20 & 1,02500 & 1,02500 \\
\hline 21 & 1,02500 & 1,02500 \\
\hline 22 & 1,02500 & 1,02500 \\
\hline 23 & 1,02500 & 1,02500 \\
\hline 24 & 1,02500 & 1,02500 \\
\hline & & \\
\hline
\end{tabular}

Tabela 5.22 - Configuração dos taps dos transformadores da subestação - PQ Fixo / min Perdas.

\begin{tabular}{|c|c|c|}
\hline \multirow{2}{*}{ Tempo } & \multicolumn{2}{|c|}{ tap dos transformadores da subestação (pu) } \\
\cline { 2 - 3 } (hora) & $\begin{array}{c}\text { Trafo 1 } \\
\text { ramo 1-4 }\end{array}$ & $\begin{array}{c}\text { Trafo 2 } \\
\text { ramo 1-5 }\end{array}$ \\
\hline 1 & 1,05000 & 1,05000 \\
\hline 2 & 1,05000 & 1,05000 \\
\hline 3 & 1,05000 & 1,05000 \\
\hline 4 & 1,05000 & 1,05000 \\
\hline 5 & 1,05000 & 1,05000 \\
\hline 6 & 1,05000 & 1,05000 \\
\hline 7 & 1,05000 & 1,05000 \\
\hline 8 & 1,05000 & 1,05000 \\
\hline 9 & 1,05000 & 1,05000 \\
\hline 10 & 1,05000 & 1,05000 \\
\hline 11 & 1,05000 & 1,05000 \\
\hline 12 & 1,05000 & 1,05000 \\
\hline 13 & 1,05000 & 1,05000 \\
\hline 14 & 1,05000 & 1,05000 \\
\hline 15 & 1,05000 & 1,05000 \\
\hline 16 & 1,05000 & 1,05000 \\
\hline 17 & 1,05000 & 1,05000 \\
\hline 18 & 1,05000 & 1,05000 \\
\hline 19 & 1,05000 & 1,05000 \\
\hline 20 & 1,05000 & 1,05000 \\
\hline 21 & 1,05000 & 1,05000 \\
\hline 22 & 1,05000 & 1,05000 \\
\hline 23 & 1,05000 & 1,05000 \\
\hline 24 & 1,05000 & 1,05000 \\
\hline & & \\
\hline
\end{tabular}


As configurações dos taps dos reguladores de tensão, apresentadas na Tabela 5.23 e Tabela 5.24, resultaram em ajustes inferiores a 105\% (ou 1,05) nas 24 horas de operação do sistema elétrico para ambas as estratégias. Esse comportamento pode ser resultante do fato de que os taps dos transformadores da subestação e os módulos de bancos de capacitores ligados já estão elevados o suficiente para ocorrer atender às funções-objetivo. Logo, não há a necessidade de elevar as tensões nos nós conectados aos reguladores.

Tabela 5.23 - Configuração dos taps dos reguladores de tensão - PQ Fixo / min Tensão.

\begin{tabular}{|c|c|c|}
\hline \multirow{2}{*}{ Tempo } & \multicolumn{2}{|c|}{ tap dos reguladores de tensão $(\mathrm{pu})$} \\
\cline { 2 - 3 } (hora) & $\begin{array}{c}\text { Reg. } 1 \\
\text { ramo 11-12 }\end{array}$ & $\begin{array}{c}\text { Reg. } 2 \\
\text { ramo } 17-18\end{array}$ \\
\hline 1 & 1,02500 & 1,00625 \\
\hline 2 & 1,01875 & 1,00625 \\
\hline 3 & 1,01875 & 1,00625 \\
\hline 4 & 1,01250 & 1,00625 \\
\hline 5 & 1,01875 & 1,00625 \\
\hline 6 & 1,01875 & 1,00625 \\
\hline 7 & 1,01875 & 1,00625 \\
\hline 8 & 1,02500 & 1,01250 \\
\hline 9 & 1,03125 & 1,01250 \\
\hline 10 & 1,03125 & 1,01250 \\
\hline 11 & 1,03125 & 1,01250 \\
\hline 12 & 1,03125 & 1,01250 \\
\hline 13 & 1,03125 & 1,01250 \\
\hline 14 & 1,03125 & 1,01250 \\
\hline 15 & 1,03125 & 1,01250 \\
\hline 16 & 1,03125 & 1,01250 \\
\hline 17 & 1,03125 & 1,01250 \\
\hline 18 & 1,03125 & 1,01250 \\
\hline 19 & 1,03750 & 1,01875 \\
\hline 20 & 1,03750 & 1,01875 \\
\hline 21 & 1,03750 & 1,01875 \\
\hline 22 & 1,03750 & 1,01875 \\
\hline 23 & 1,03125 & 1,01875 \\
\hline 24 & 1,02500 & 1,01250 \\
\hline & & \\
\hline
\end{tabular}


Tabela 5.24 - Configuração dos taps dos reguladores de tensão - PQ Fixo / min Perdas.

\begin{tabular}{|c|c|c|}
\hline \multirow{2}{*}{ Tempo } & \multicolumn{2}{|c|}{ tap dos reguladores de tensão $(\mathrm{pu})$} \\
\cline { 2 - 3 } (hora) & $\begin{array}{c}\text { Reg.1 } \\
\text { ramo 11-12 }\end{array}$ & $\begin{array}{c}\text { Reg.2 } \\
\text { ramo } 17-18\end{array}$ \\
\hline 1 & 1,01250 & 1,00000 \\
\hline 2 & 1,01250 & 1,00000 \\
\hline 3 & 1,00625 & 1,00000 \\
\hline 4 & 1,00625 & 1,00000 \\
\hline 5 & 1,00625 & 1,00000 \\
\hline 6 & 1,01250 & 1,00000 \\
\hline 7 & 1,01250 & 1,00000 \\
\hline 8 & 1,02500 & 1,01250 \\
\hline 9 & 1,03125 & 1,01250 \\
\hline 10 & 1,03125 & 1,01250 \\
\hline 11 & 1,03125 & 1,01875 \\
\hline 12 & 1,03125 & 1,01250 \\
\hline 13 & 1,03125 & 1,01250 \\
\hline 14 & 1,03125 & 1,01875 \\
\hline 15 & 1,03125 & 1,01875 \\
\hline 16 & 1,03125 & 1,01250 \\
\hline 17 & 1,03125 & 1,01250 \\
\hline 18 & 1,03125 & 1,01250 \\
\hline 19 & 1,03125 & 1,01250 \\
\hline 20 & 1,04375 & 1,01875 \\
\hline 21 & 1,04375 & 1,01875 \\
\hline 22 & 1,03750 & 1,01875 \\
\hline 23 & 1,03125 & 1,01250 \\
\hline 24 & 1,01875 & 1,00625 \\
\hline & & \\
\hline
\end{tabular}

\subsubsection{Potência Ativa Variável}

A esta estratégia de controle será dado o nome de PQ Variável, sendo que a potência ativa do gerador será colocada como variável de controle no processo de otimização. Com essa alteração, espera-se obter um bom desempenho geral do sistema elétrico no que diz respeito à minimização dos desvios das tensões nodais. Em alguns casos, estando o gerador distribuído configurado para manter potência ativa e reativa fixas, pode-se obter níveis de tensões nodais elevados, culminando com a violação dos limites estabelecidos por normas técnicas ([10], [12], [13]). Logo, torna-se interessante criar condições em que a potência ativa do gerador possa ser controlada, ou mesmo despachada pelos centros de controle de sistemas de distribuição.

Com controle do tipo PQ Variável, as unidades de geração distribuída foram configuradas para operar com potência reativa constante de 0 var, ou seja, fator de potência igual a 1, entretanto, com a potência ativa atuando com mais uma variável de controle, por isso também será apresentado e discutido o carregamento destas máquinas. Os impactos da inserção destes geradores são apresentados nas Figuras 5.21 a 5.27, e Tabelas 5.19 a 5.30. 
Para um melhor esclarecimento, a potência dos geradores distribuídos em função do tempo em ambas as estratégias pode ser visualizada nas Figuras 5.21 e 5.22. Nota-se que as potências de ambos os geradores variam bastante em relação ao carregamento do sistema durante aproximadamente todo o período de análise, quando se minimizam os desvios de tensão (Figura 5.21). Neste caso, observa-se uma variação coerente em relação à variação da carga: os geradores fornecem menos potência ativa em períodos de baixa carga. Nos períodos de maior carregamento, a elevação das potências ativas dos geradores provoca o aumento das tensões nodais, culminando com um menor desvio das tensões e colaborando para a redução das perdas de potência ativa.

Em relação à Figura 5.22, ambos os geradores se comportaram de forma semelhante, e percebe-se que não aumentam o fornecimento de potência ativa próximo ao valor máximo $(13,872 \mathrm{MW})$. Neste caso, a redução das perdas teve uma contribuição significativa da redução da potência ativa fornecida pelos geradores. Pelo fato de ter havido uma redução na potência ativa fornecida pelos geradores, do ponto de vista econômico, não é interessante para os proprietários dos geradores distribuídos que os mesmos operem segundo as configurações resultantes dessa estratégia.

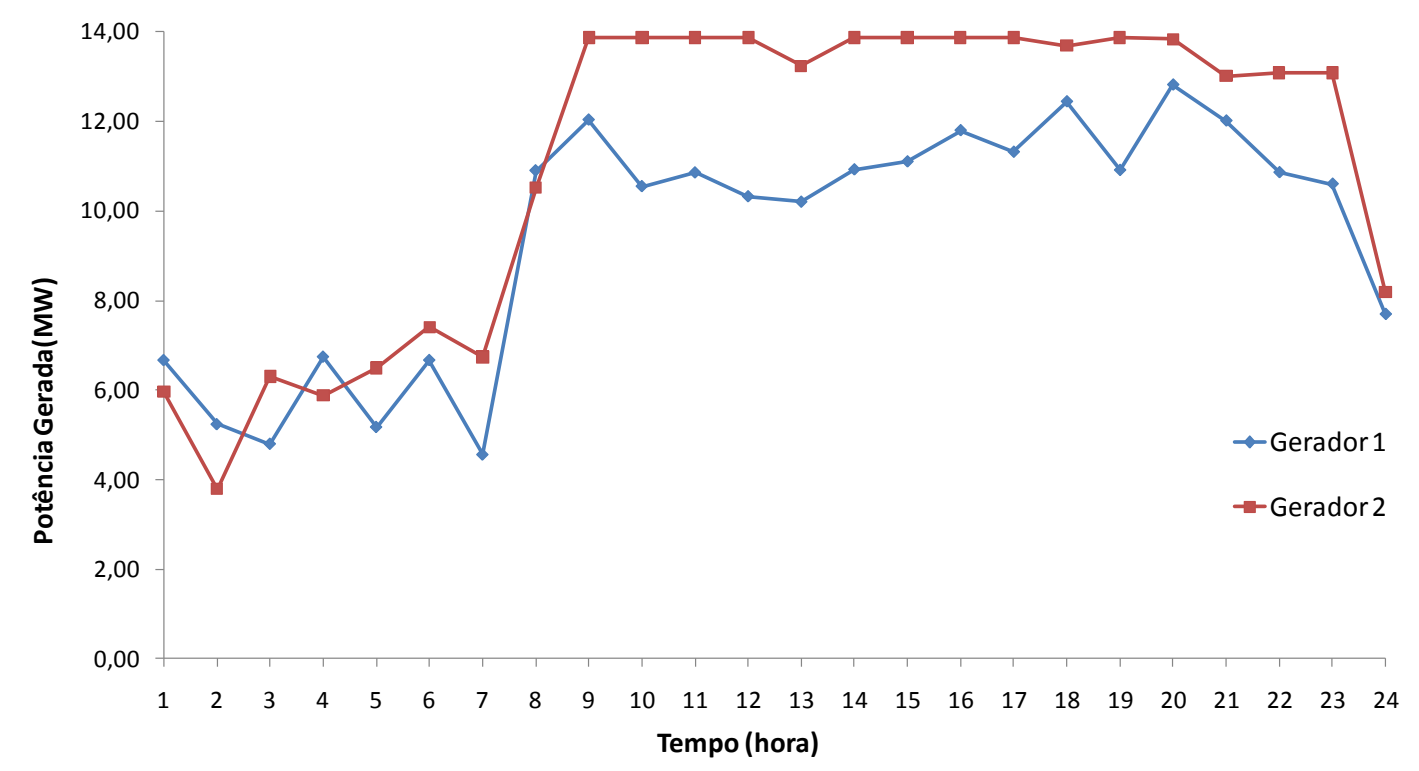

Figura 5.21 - Potência gerada pelos geradores operando com controle PQ Variável / min Tensão. 


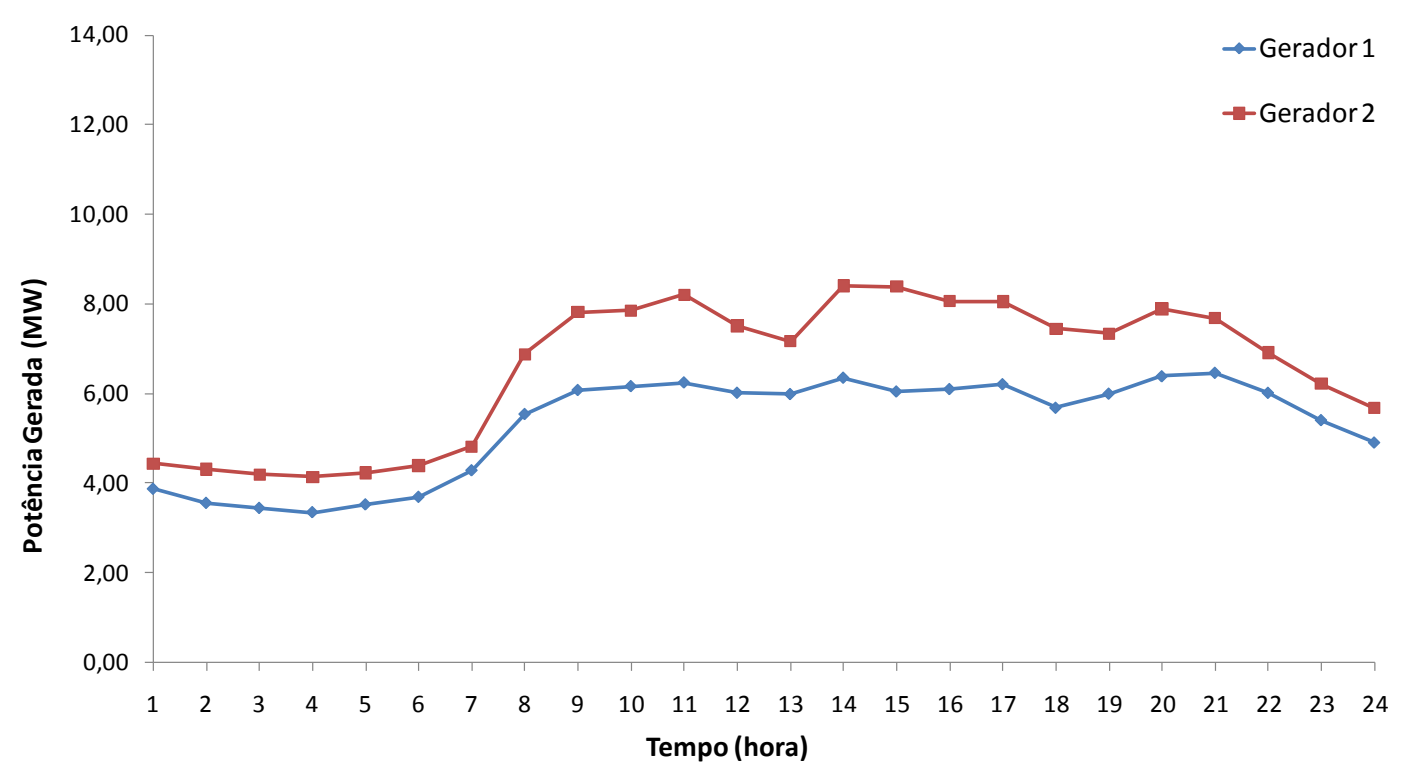

Figura 5.22 - Potência gerada pelos geradores operando com controle PQ Variável / min Perdas.

Os perfis de tensão apresentados nas Figuras 5.23 e 5.24 são similares aos obtidos quando o controle de operação dos geradores funcionava como regulador de fator de potência e o mesmo mantinha potência ativa fixa (PQ Fixo).

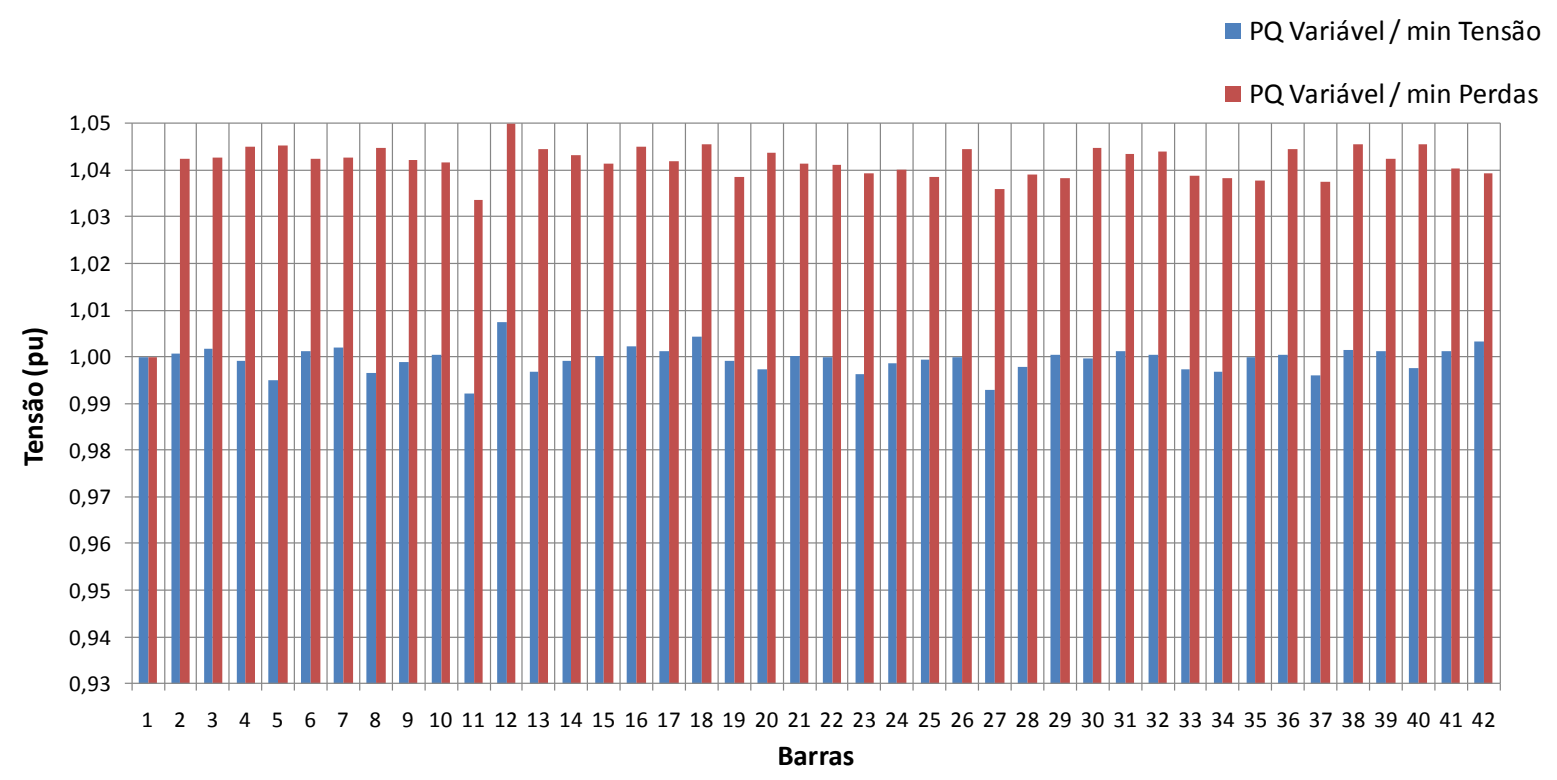

Figura 5.23 - Perfil de tensão para carregamento mínimo - PQ Variável / min Tensão e min Perdas. 


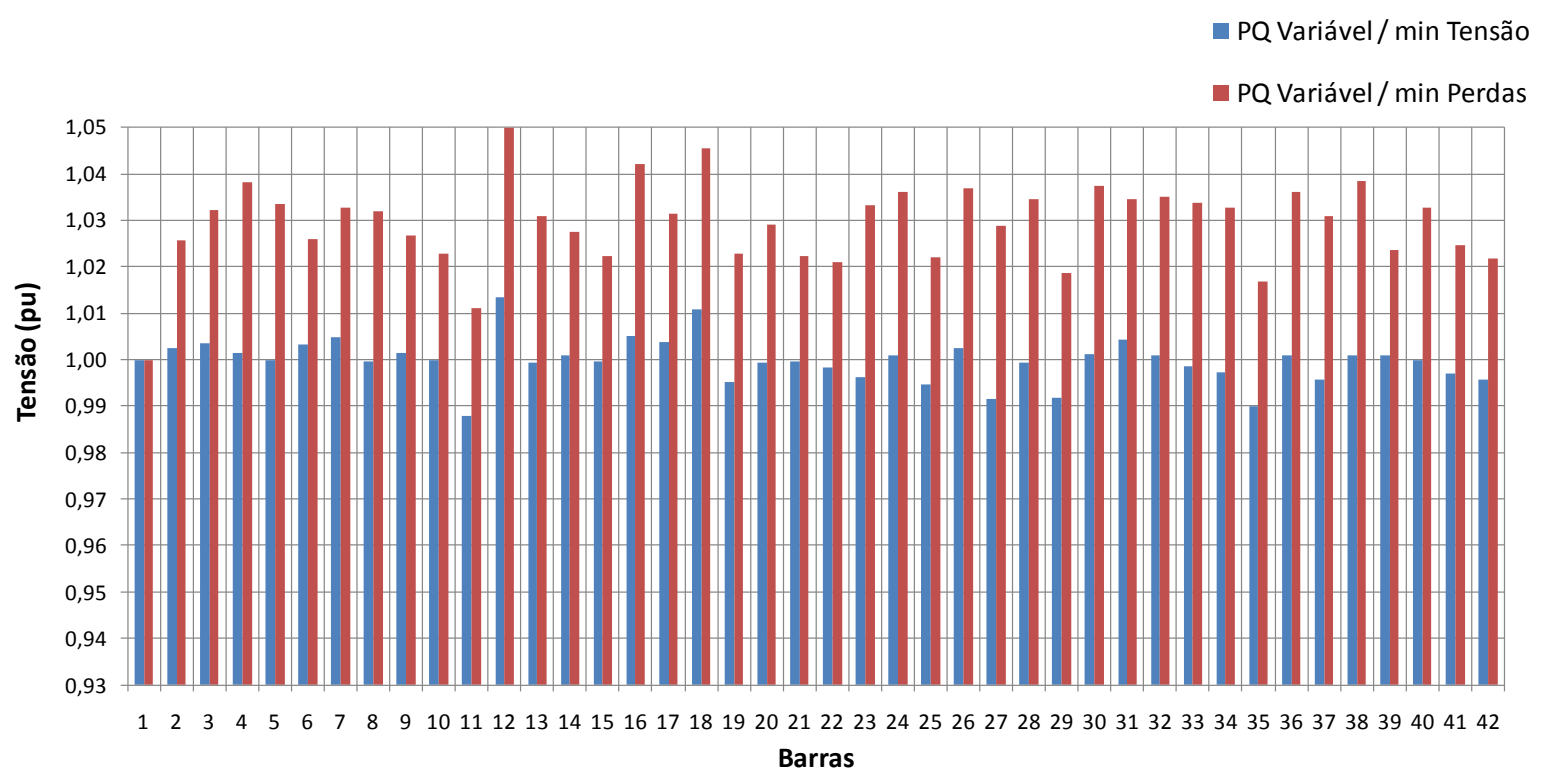

Figura 5.24 - Perfil de tensão para carregamento máximo - PQ Variável / min Tensão e min Perdas.

Ainda com relação aos níveis de tensão, na Figura 5.25, pode-se concluir que a estratégia que objetiva a minimização dos desvios de tensão para PQ Variável é bastante eficiente, mantendo o controle das tensões sob mínimos desvios, semelhante quando comparado aos modos de operação dos geradores distribuídos com controle PV (PV Fixo e PV Variável). A Figura 5.26 e a Figura 5.27 apresentam, de maneira direta, os benefícios adquiridos com esta estratégia de operação. Em relação à Figura 5.26, observa-se que o resultado desta estratégia para a função objetivo de minimização dos desvios de tensão foi menor do que o caso PV Fixo com a mesma função objetivo, demonstrando o seu bom desempenho. O bom desempenho em relação aos desvios de tensão também se revela para a função objetivo de minimização das perdas quando os resultados são comparados com o das estratégias PV Variável e PQ Fixo.

$\mathrm{Na}$ Figura 5.27, a redução nas perdas elétricas é evidente quando comparado aos casos anteriores. Para a estratégia de minimização dos desvios de tensão, a redução nas perdas elétricas é auxiliada pela redução da potência ativa fornecida pelos geradores, nos períodos de baixo carregamento do sistema. Para a estratégia de minimização das perdas elétricas, o controle da potência ativa possibilita uma redução significativa das perdas, no entanto isso pode não ser interessante financeiramente, conforme já discutido anteriormente. 


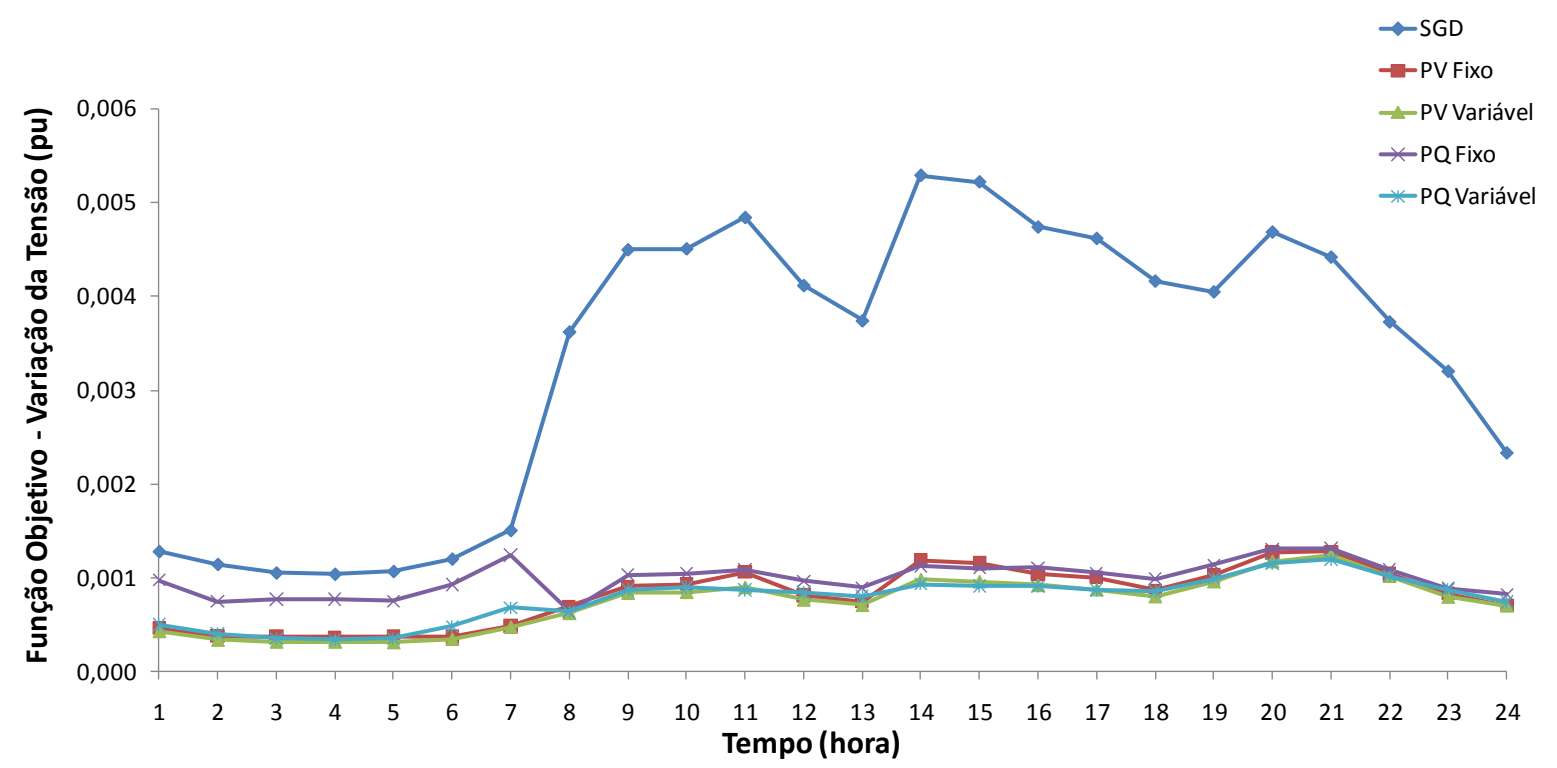

Figura 5.25 - Valores da função objetivo para o caso da minimização da variação de tensão - SGD, PV Fixo, PV Variável, PQ Fixo e PQ Variável.

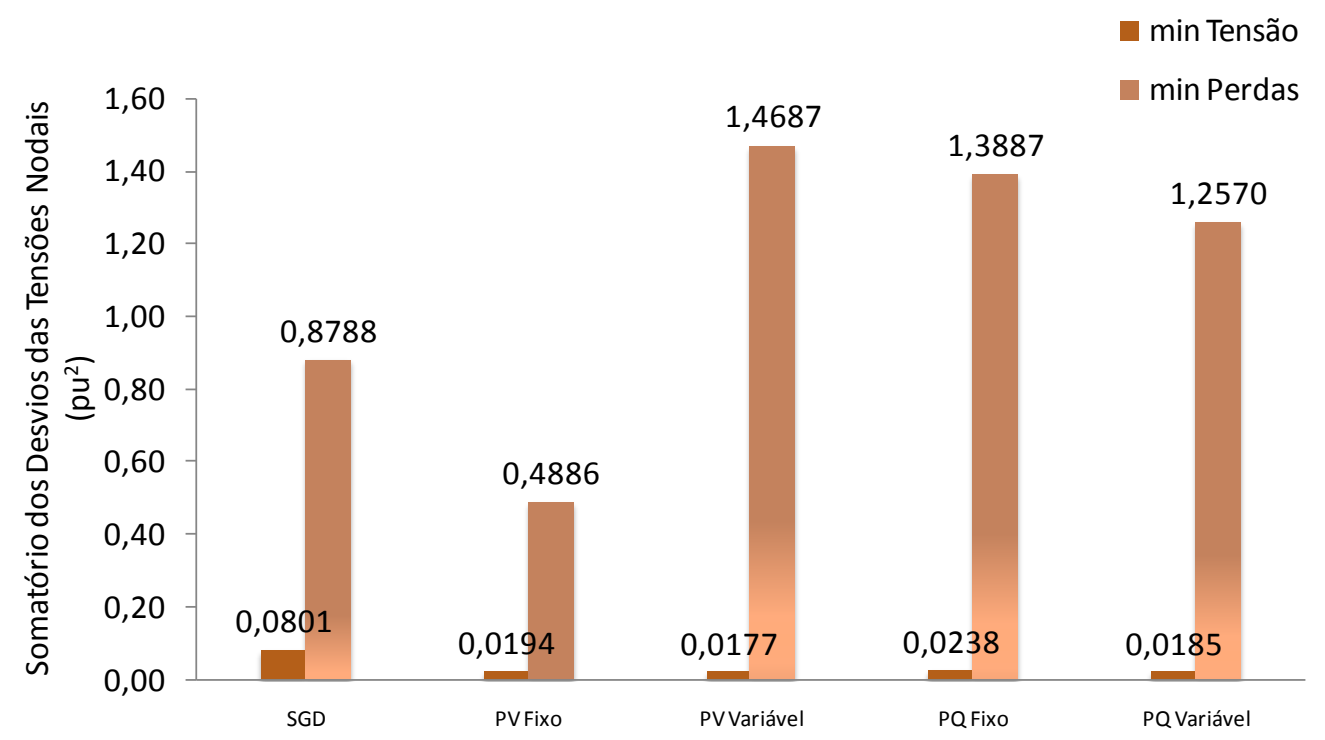

Figura 5.26 - Somatório dos desvios das tensões nodais - SGD, PV Fixo, PV Variável, PQ Fixo e PQ Variável. 


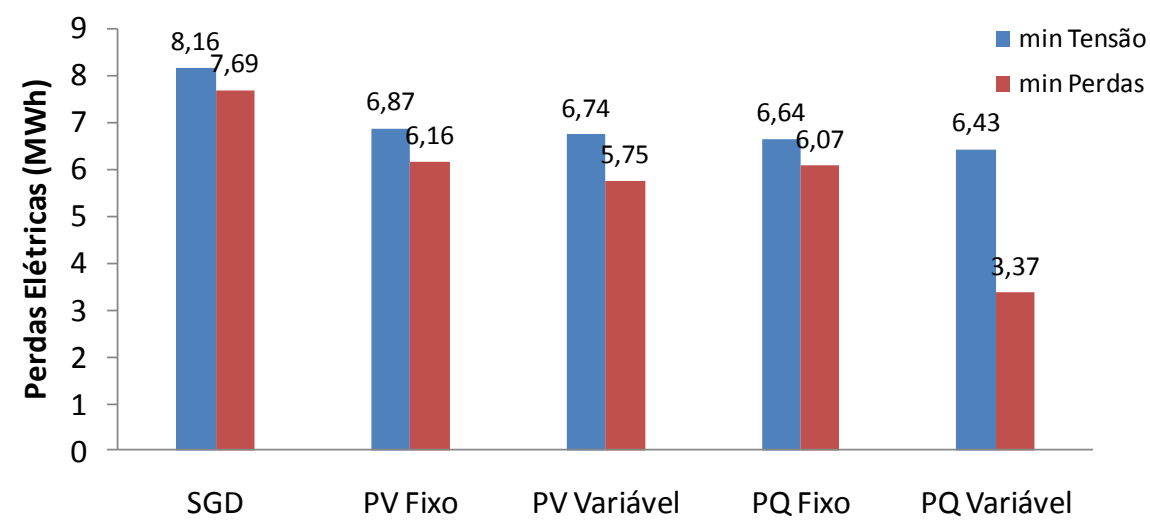

Figura 5.27 - Perdas de Energia - min Tensão e min Perdas.

Das configurações encontradas para os bancos de capacitores, apresentadas nas tabelas 5.25 e 5.26 para a minimização dos desvios de tensão e minimização das perdas, respectivamente, observa-se para esta última uma condição estacionária no chaveamento destes dispositivos, ou seja, o número de comutações é menor do que o registrado para a outra estratégia.

Tabela 5.25 - Configuração dos bancos de capacitores - PQ Variável / min Tensão.

\begin{tabular}{|c|c|c|c|c|c|c|c|}
\hline \multirow{2}{*}{ Tempo } & \multicolumn{2}{|c|}{$\begin{array}{c}\text { Carregamento } \\
\text { (hora) }\end{array}$} & \multicolumn{4}{|c|}{ Módulos de Bancos de Capacitores Ativos (\%) } \\
\cline { 6 - 8 } & G1 & BC-1 & BC-2 & BC-3 & BC-4 & BC-5 \\
barra 38 & barra 39 & barra 40 & barra 41 & barra 42 \\
\hline 1 & 48,064 & 42,962 & $25,0 \%$ & $100,0 \%$ & $100,0 \%$ & $75,0 \%$ & $75,0 \%$ \\
\hline 2 & 37,742 & 27,328 & $25,0 \%$ & $100,0 \%$ & $100,0 \%$ & $75,0 \%$ & $75,0 \%$ \\
\hline 3 & 34,594 & 45,475 & $25,0 \%$ & $100,0 \%$ & $100,0 \%$ & $50,0 \%$ & $75,0 \%$ \\
\hline 4 & 48,609 & 42,382 & $25,0 \%$ & $75,0 \%$ & $100,0 \%$ & $50,0 \%$ & $75,0 \%$ \\
\hline 5 & 37,296 & 46,847 & $25,0 \%$ & $100,0 \%$ & $100,0 \%$ & $50,0 \%$ & $75,0 \%$ \\
\hline 6 & 48,068 & 53,407 & $50,0 \%$ & $100,0 \%$ & $100,0 \%$ & $75,0 \%$ & $50,0 \%$ \\
\hline 7 & 32,862 & 48,582 & $25,0 \%$ & $0,0 \%$ & $0,0 \%$ & $75,0 \%$ & $75,0 \%$ \\
\hline 8 & 78,581 & 75,848 & $75,0 \%$ & $0,0 \%$ & $50,0 \%$ & $100,0 \%$ & $100,0 \%$ \\
\hline 9 & 86,749 & 100,000 & $0,0 \%$ & $25,0 \%$ & $75,0 \%$ & $50,0 \%$ & $100,0 \%$ \\
\hline 10 & 76,038 & 100,000 & $0,0 \%$ & $75,0 \%$ & $0,0 \%$ & $50,0 \%$ & $100,0 \%$ \\
\hline 11 & 78,246 & 100,000 & $0,0 \%$ & $50,0 \%$ & $50,0 \%$ & $75,0 \%$ & $100,0 \%$ \\
\hline 12 & 74,410 & 100,000 & $0,0 \%$ & $50,0 \%$ & $25,0 \%$ & $25,0 \%$ & $100,0 \%$ \\
\hline 13 & 73,537 & 95,465 & $0,0 \%$ & $50,0 \%$ & $25,0 \%$ & $25,0 \%$ & $75,0 \%$ \\
\hline 14 & 78,743 & 100,000 & $0,0 \%$ & $75,0 \%$ & $25,0 \%$ & $75,0 \%$ & $100,0 \%$ \\
\hline 15 & 80,023 & 100,000 & $0,0 \%$ & $50,0 \%$ & $50,0 \%$ & $75,0 \%$ & $100,0 \%$ \\
\hline 16 & 85,044 & 100,000 & $0,0 \%$ & $50,0 \%$ & $50,0 \%$ & $75,0 \%$ & $100,0 \%$ \\
\hline 17 & 81,573 & 100,000 & $0,0 \%$ & $25,0 \%$ & $75,0 \%$ & $50,0 \%$ & $100,0 \%$ \\
\hline 18 & 89,682 & 98,748 & $0,0 \%$ & $0,0 \%$ & $100,0 \%$ & $0,0 \%$ & $100,0 \%$ \\
\hline 19 & 78,651 & 99,998 & $0,0 \%$ & $25,0 \%$ & $50,0 \%$ & $50,0 \%$ & $75,0 \%$ \\
\hline 20 & 92,388 & 99,735 & $0,0 \%$ & $25,0 \%$ & $100,0 \%$ & $25,0 \%$ & $100,0 \%$ \\
\hline 21 & 86,598 & 93,860 & $0,0 \%$ & $75,0 \%$ & $50,0 \%$ & $50,0 \%$ & $75,0 \%$ \\
\hline 22 & 78,288 & 94,333 & $0,0 \%$ & $50,0 \%$ & $25,0 \%$ & $0,0 \%$ & $75,0 \%$ \\
\hline 23 & 76,435 & 94,320 & $0,0 \%$ & $0,0 \%$ & $25,0 \%$ & $0,0 \%$ & $50,0 \%$ \\
\hline 24 & 55,475 & 58,995 & $75,0 \%$ & $0,0 \%$ & $0,0 \%$ & $50,0 \%$ & $75,0 \%$ \\
\hline
\end{tabular}


Tabela 5.26 - Configuração dos bancos de capacitores - PQ Variável / min Perdas.

\begin{tabular}{|c|c|c|c|c|c|c|c|}
\hline \multirow{3}{*}{$\begin{array}{r}\text { Tempo } \\
\text { (hora) }\end{array}$} & \multirow{2}{*}{\multicolumn{2}{|c|}{\begin{tabular}{|c|} 
Carregamento \\
dos Geradores $(\%)$ \\
\end{tabular}}} & \multicolumn{5}{|c|}{ Módulos de Bancos de Capacitores Ativos (\%) } \\
\hline & & & \multirow{2}{*}{$\begin{array}{c}\text { BC-1 } \\
\text { barra } 38\end{array}$} & \multirow{2}{*}{$\begin{array}{c}\mathrm{BC}-2 \\
\text { barra } 39\end{array}$} & \multirow{2}{*}{$\begin{array}{c}\text { BC-3 } \\
\text { barra } 40\end{array}$} & \multirow{2}{*}{$\begin{array}{c}\mathrm{BC}-4 \\
\text { barra } 41\end{array}$} & \multirow{2}{*}{$\begin{array}{r}\text { BC-5 } \\
\text { barra } 42 \\
\end{array}$} \\
\hline & G1 & $\mathrm{G} 2$ & & & & & \\
\hline 1 & 27,864 & 32,002 & $25,0 \%$ & $75,0 \%$ & $25,0 \%$ & $75,0 \%$ & $25,0 \%$ \\
\hline 2 & 25,582 & 31,056 & $25,0 \%$ & $75,0 \%$ & $50,0 \%$ & $75,0 \%$ & $25,0 \%$ \\
\hline 3 & 24,771 & 30,205 & $25,0 \%$ & $75,0 \%$ & $50,0 \%$ & $50,0 \%$ & $25,0 \%$ \\
\hline 4 & 24,081 & 29,799 & $25,0 \%$ & $75,0 \%$ & $50,0 \%$ & $50,0 \%$ & $25,0 \%$ \\
\hline 5 & 25,338 & 30,457 & $25,0 \%$ & $75,0 \%$ & $50,0 \%$ & $75,0 \%$ & $25,0 \%$ \\
\hline 6 & 26,559 & 31,653 & $25,0 \%$ & $75,0 \%$ & $25,0 \%$ & $50,0 \%$ & $25,0 \%$ \\
\hline 7 & 30,845 & 34,724 & $25,0 \%$ & $75,0 \%$ & $75,0 \%$ & $75,0 \%$ & $25,0 \%$ \\
\hline 8 & 39,930 & 49,545 & $25,0 \%$ & $75,0 \%$ & $50,0 \%$ & $75,0 \%$ & $75,0 \%$ \\
\hline 9 & 43,809 & 56,366 & $50,0 \%$ & $75,0 \%$ & $75,0 \%$ & $75,0 \%$ & $75,0 \%$ \\
\hline 10 & 44,433 & 56,612 & $50,0 \%$ & $75,0 \%$ & $50,0 \%$ & $75,0 \%$ & $75,0 \%$ \\
\hline 11 & 45,032 & 59,147 & $50,0 \%$ & $75,0 \%$ & $50,0 \%$ & $75,0 \%$ & $75,0 \%$ \\
\hline 12 & 43,371 & 54,156 & $50,0 \%$ & $75,0 \%$ & $75,0 \%$ & $75,0 \%$ & $75,0 \%$ \\
\hline 13 & 43,154 & 51,671 & $25,0 \%$ & $75,0 \%$ & $75,0 \%$ & $75,0 \%$ & $75,0 \%$ \\
\hline 14 & 45,798 & & $50,0 \%$ & $75,0 \%$ & $75,0 \%$ & $75,0 \%$ & $75,0 \%$ \\
\hline 15 & 43,573 & 60,475 & $50,0 \%$ & $75,0 \%$ & $75,0 \%$ & $75,0 \%$ & $75,0 \%$ \\
\hline 16 & 43,961 & 58,088 & $50,0 \%$ & $75,0 \%$ & $50,0 \%$ & $75,0 \%$ & $75,0 \%$ \\
\hline 17 & 44,746 & 58,038 & $50,0 \%$ & $75,0 \%$ & $50,0 \%$ & $75,0 \%$ & $75,0 \%$ \\
\hline 18 & 40,938 & 53,663 & $25,0 \%$ & $75,0 \%$ & $75,0 \%$ & $75,0 \%$ & $75,0 \%$ \\
\hline 19 & 43,216 & 52,882 & $25,0 \%$ & $75,0 \%$ & $75,0 \%$ & $75,0 \%$ & $75,0 \%$ \\
\hline 20 & 46,021 & 56,899 & $25,0 \%$ & $75,0 \%$ & $75,0 \%$ & $75,0 \%$ & $75,0 \%$ \\
\hline 21 & 46,583 & 55,346 & $50,0 \%$ & $75,0 \%$ & $75,0 \%$ & $75,0 \%$ & $75,0 \%$ \\
\hline 22 & 43,357 & 49,852 & $50,0 \%$ & $75,0 \%$ & $75,0 \%$ & $75,0 \%$ & $50,0 \%$ \\
\hline 23 & 38,945 & 44,828 & $25,0 \%$ & $75,0 \%$ & $75,0 \%$ & $75,0 \%$ & $50,0 \%$ \\
\hline 24 & 35,325 & 40,917 & $25,0 \%$ & $75,0 \%$ & $75,0 \%$ & $75,0 \%$ & $25,0 \%$ \\
\hline
\end{tabular}

Com relação aos taps dos transformadores da subestação, apresentados na Tabela 5.27 e Tabela 5.28, para a estratégia de minimização de variação de tensão percebe-se um comportamento que indica uma relação direta com o carregamento da rede de distribuição estudada. Em períodos de menor carregamento não há atuação do comutador automático de taps, enquanto que em períodos de maior carregamento este atua de maneira branda. $\mathrm{Na}$ metodologia que busca minimização das perdas elétricas, observa-se um comportamento similar aos já encontrados nas Tabelas 5.2 e 5.22, ou seja, os taps são colocados em seus valores máximos.

As configurações dos taps dos reguladores de tensão, presentes na Tabela 5.29 e Tabela 5.30, resultaram em ajustes pouco diferenciados entre as estratégias simuladas. 
Tabela 5.27 - Configuração dos taps dos transformadores da subestação - PQ Variável / min Tensão.

\begin{tabular}{|c|c|c|}
\hline \multirow{2}{*}{$\begin{array}{c}\text { Tempo } \\
\text { (hora) }\end{array}$} & \begin{tabular}{c} 
tap dos transformadores da subestação $(\mathrm{pu})$ \\
\cline { 2 - 3 } ramo $1-4$
\end{tabular} & $\begin{array}{c}\text { Trafo } 2 \\
\text { ramo } 1-5\end{array}$ \\
\hline 1 & 1,00000 & 1,00000 \\
\hline 2 & 1,00000 & 1,00000 \\
\hline 3 & 1,00000 & 1,00000 \\
\hline 4 & 1,00000 & 1,00000 \\
\hline 5 & 1,00000 & 1,00000 \\
\hline 6 & 1,00000 & 1,00000 \\
\hline 7 & 1,00000 & 1,02500 \\
\hline 8 & 1,00000 & 1,02500 \\
\hline 9 & 1,02500 & 1,02500 \\
\hline 10 & 1,02500 & 1,02500 \\
\hline 11 & 1,02500 & 1,02500 \\
\hline 12 & 1,02500 & 1,02500 \\
\hline 13 & 1,02500 & 1,02500 \\
\hline 14 & 1,02500 & 1,02500 \\
\hline 15 & 1,02500 & 1,02500 \\
\hline 16 & 1,02500 & 1,02500 \\
\hline 17 & 1,02500 & 1,02500 \\
\hline 18 & 1,02500 & 1,02500 \\
\hline 19 & 1,02500 & 1,02500 \\
\hline 20 & 1,02500 & 1,02500 \\
\hline 21 & 1,02500 & 1,02500 \\
\hline 22 & 1,02500 & 1,02500 \\
\hline 23 & 1,02500 & 1,02500 \\
\hline 24 & 1,00000 & 1,02500 \\
\hline & & \\
\hline
\end{tabular}

Tabela 5.28 - Configuração dos taps dos transformadores da subestação - PQ Variável / min Perdas.

\begin{tabular}{|c|c|c|}
\hline \multirow{2}{*}{ Tempo } & \multicolumn{2}{|c|}{ tap dos transformadores da subestação $(\mathrm{pu})$} \\
\cline { 2 - 3 } (hora) & $\begin{array}{c}\text { Trafo } 1 \\
\text { ramo } 1-4\end{array}$ & $\begin{array}{c}\text { Trafo } 2 \\
\text { ramo 1-5 }\end{array}$ \\
\hline 1 & 1,05000 & 1,05000 \\
\hline 2 & 1,05000 & 1,05000 \\
\hline 3 & 1,05000 & 1,05000 \\
\hline 4 & 1,05000 & 1,05000 \\
\hline 5 & 1,05000 & 1,05000 \\
\hline 6 & 1,05000 & 1,05000 \\
\hline 7 & 1,05000 & 1,05000 \\
\hline 8 & 1,05000 & 1,05000 \\
\hline 9 & 1,05000 & 1,05000 \\
\hline 10 & 1,05000 & 1,05000 \\
\hline 11 & 1,05000 & 1,05000 \\
\hline 12 & 1,05000 & 1,05000 \\
\hline 13 & 1,05000 & 1,05000 \\
\hline 14 & 1,05000 & 1,05000 \\
\hline 15 & 1,05000 & 1,05000 \\
\hline 16 & 1,05000 & 1,05000 \\
\hline 17 & 1,05000 & 1,05000 \\
\hline 18 & 1,05000 & 1,05000 \\
\hline 19 & 1,05000 & 1,05000 \\
\hline 20 & 1,05000 & 1,05000 \\
\hline 21 & 1,05000 & 1,05000 \\
\hline 22 & 1,05000 & 1,05000 \\
\hline 23 & 1,05000 & 1,05000 \\
\hline 24 & 1,05000 & 1,05000 \\
\hline & & \\
\hline
\end{tabular}


Tabela 5.29 - Configuração dos tap dos reguladores de tensão - PQ Variável / min Tensão.

\begin{tabular}{|c|c|c|}
\hline \multirow{2}{*}{ Tempo } & \multicolumn{2}{|c|}{ tap dos reguladores de tensão $(\mathrm{pu})$} \\
\cline { 2 - 3 } (hora) & $\begin{array}{c}\text { Reg.1 } \\
\text { ramo 11-12 }\end{array}$ & $\begin{array}{c}\text { Reg. } 2 \\
\text { ramo } 17-18\end{array}$ \\
\hline 1 & 1,02500 & 1,01250 \\
\hline 2 & 1,02500 & 1,01250 \\
\hline 3 & 1,01875 & 1,00625 \\
\hline 4 & 1,01875 & 1,00625 \\
\hline 5 & 1,01875 & 1,00625 \\
\hline 6 & 1,02500 & 1,00625 \\
\hline 7 & 1,02500 & 1,01250 \\
\hline 8 & 1,02500 & 1,01250 \\
\hline 9 & 1,02500 & 1,00625 \\
\hline 10 & 1,03125 & 1,01250 \\
\hline 11 & 1,03125 & 1,01250 \\
\hline 12 & 1,03125 & 1,00625 \\
\hline 13 & 1,03125 & 1,01250 \\
\hline 14 & 1,03125 & 1,01250 \\
\hline 15 & 1,03125 & 1,01250 \\
\hline 16 & 1,02500 & 1,00625 \\
\hline 17 & 1,03125 & 1,01250 \\
\hline 18 & 1,03125 & 1,01250 \\
\hline 19 & 1,03750 & 1,01250 \\
\hline 20 & 1,03750 & 1,01875 \\
\hline 21 & 1,03750 & 1,01875 \\
\hline 22 & 1,03750 & 1,01875 \\
\hline 23 & 1,03125 & 1,01875 \\
\hline 24 & 1,03125 & 1,01875 \\
\hline & & \\
\hline
\end{tabular}

Tabela 5.30 - Configuração dos tap dos reguladores de tensão - PQ Variável / min Perdas.

\begin{tabular}{|c|c|c|}
\hline \multirow{2}{*}{ Tempo } & \multicolumn{2}{|c|}{ tap dos reguladores de tensão (pu) } \\
\cline { 2 - 3 } (hora) & $\begin{array}{c}\text { Reg.1 } \\
\text { ramo 11-12 }\end{array}$ & $\begin{array}{c}\text { Reg.2 } \\
\text { ramo 17-18 }\end{array}$ \\
\hline 1 & 1,02500 & 1,01250 \\
\hline 2 & 1,01875 & 1,00625 \\
\hline 3 & 1,01875 & 1,00625 \\
\hline 4 & 1,01875 & 1,00625 \\
\hline 5 & 1,01875 & 1,00625 \\
\hline 6 & 1,02500 & 1,01250 \\
\hline 7 & 1,02500 & 1,01250 \\
\hline 8 & 1,03750 & 1,01250 \\
\hline 9 & 1,03750 & 1,01875 \\
\hline 10 & 1,04375 & 1,01875 \\
\hline 11 & 1,04375 & 1,01875 \\
\hline 12 & 1,03750 & 1,01250 \\
\hline 13 & 1,03750 & 1,01875 \\
\hline 14 & 1,04375 & 1,01875 \\
\hline 15 & 1,04375 & 1,01875 \\
\hline 16 & 1,04375 & 1,01875 \\
\hline 17 & 1,04375 & 1,01875 \\
\hline 18 & 1,04375 & 1,01875 \\
\hline 19 & 1,04375 & 1,01875 \\
\hline 20 & 1,05000 & 1,02500 \\
\hline 21 & 1,05000 & 1,01875 \\
\hline 22 & 1,04375 & 1,01875 \\
\hline 23 & 1,03750 & 1,01875 \\
\hline 24 & 1,03125 & 1,01875 \\
\hline & & \\
\hline
\end{tabular}




\subsection{Considerações Finais}

Os resultados precedentes permitem uma análise comparativa qualitativa entre todas as estratégias simuladas, da qual se podem inferir algumas tendências que devem ser comprovadas mediante a análise de outros sistemas elétricos utilizando as mesmas estratégias.

Pelos resultados apresentados neste capítulo, observa-se que em todas as estratégias em que a geração distribuída esteve presente, utilizando qualquer uma das formulações do problema de otimização puderam-se encontrar configurações viáveis dos geradores distribuídos e dispositivos reguladores de tensão de forma a obter uma melhoria do desempenho de regime permanente da rede de distribuição em relação aos casos sem geração distribuída. As medidas dessa melhoria de desempenho são observadas principalmente analisando duas características. A primeira delas foi a redução nas perdas elétricas, mesmo nos casos em que a função objetivo foi a minimização dos desvios de tensão. A segunda se refere ao valor da função objetivo nos casos em que se minimizavam os desvios de tensão: verificou-se que o valor da função objetivo desprezando a geração distribuída é maior que todas as outras situações, confirmando que a inserção de geração distribuída contribuiu para a melhoria dessa característica.

A comparação entre as diversas estratégias analisadas mostrou que, em valores absolutos, a redução das perdas elétricas foi significativa apenas quando o gerador opera como regulador de fator de potência, tendo a potência ativa gerada como uma variável de controle. Como exemplo de análise, podem ser avaliados os casos que geraram a mínima e a máxima perda. O primeiro deles resultou em 3,37 MWh de perdas elétricas (considerando 24 horas de operação) e se refere à estratégia cuja função objetivo foi minimizar as perdas elétricas sendo colocada a potência ativa dos geradores como variável de controle no processo de otimização (PQ Variável / min Perdas). O segundo, resultou em 6,87 MWh e se refere à minimização dos desvios de tensão, sendo as tensões de referência dos geradores fixas durante o controle do processo de otimização (PV Fixo / min Tensão).

Um caso que produziu resultados interessantes foi o PQ Variável, cuja função objetivo do problema de otimização foi a minimização dos desvios de tensão. Para esta condição de operação, observou-se uma minimização dos desvios de tensão comparável aos obtidos com as estratégias PV Fixo e PV Variável. Além disso, as perdas elétricas também foram baixas, se comparadas àquelas estratégias. Finalmente, o despacho da potência ativa dos geradores variou conforme a carga do sistema elétrico, sendo que para os períodos de carga elevada os 
valores das potências geradas também foram elevados. Tal variação pode trazer benefícios técnicos à concessionária distribuidora de energia elétrica, pois nos períodos de carga baixa, a redução na potência gerada não provoca elevações excessivas das tensões nodais e reduz a possibilidade de fluxo de potência reverso na subestação da concessionária. Além disso, no período de carga alta, a potência gerada também foi elevada, culminando com a melhoria do perfil de tensão. Do ponto de vista econômico, a concessionária não precisa comprar o excesso de potência ativa produzida nos períodos de carga baixa se os geradores operassem fornecendo potência ativa fixa, e estes poderiam ser incentivados financeiramente a fornecerem mais potência nos horários de maior carregamento.

Em relação aos dispositivos de controle de tensão, com o desenvolvimento deste trabalho foi possível efetuar uma análise sobre o número de operações de chaveamento (sejam por alterações nos taps dos transformadores ou chaveamento de módulos de bancos de capacitores). Por exemplo, de forma geral, as estratégias que tinham como função objetivo a minimização das perdas elétricas resultaram em menores faixas de variação da quantidade de potência reativa fornecida pelos bancos de capacitores. Essa característica pode ser um indicativo de que serão necessários menos chaveamentos desses dispositivos para a rede elétrica estudada. Tal comportamento também foi observado para os taps dos transformadores da subestação. Entretanto, nestas situações observou-se a tendência de operar com tensões nodais próximas a 1,05 pu que, em situações reais, leva a um aumento do consumo de energia elétrica nas instalações dos consumidores. Além disso, operar com tensões próximas ao limite superior pode ser um problema, pois ele pode ser facilmente ultrapassado caso ocorram situações não contempladas nos estudos, como por exemplo, desligamento de ramais pela atuação do sistema de proteção, ligação indevida de bancos de capacitores etc. Sobre os reguladores de tensão, verificou-se a existência de uma relação direta entre a comutação, por parte destes equipamentos, e o desenvolvimento do carregamento do sistema elétrico.

Observa-se que a escolha da estratégia mais adequada para coordenar a operação dos dispositivos reguladores de tensão com os geradores distribuídos é uma solução de compromisso. O foco dessa operação pode ser a minimização dos desvios de tensão garantindo um perfil de tensão em torno de 1 pu no sistema elétrico às custas de um pequeno incremento nas perdas elétricas. Também poderia ser considerada a operação do gerador distribuído com fator de potência próximo ou abaixo de 0,92 sem a incidência de penalidades, se a qualidade geral do fornecimento de energia nessas condições contribuísse para a melhoria do desempenho da rede elétrica. Por outro lado, se o foco for a minimização das perdas elétricas, pode-se obter tensões nodais muito próximas ao limite superior, resultando nos 
riscos mencionados anteriormente. Uma proposta interessante então seria restringir um pouco o limite superior da faixa de tensão em contrapartida de um possível aumento das perdas técnicas. Em ambos os casos, a geração distribuída pode contribuir significativamente para atingir os dois objetivos. 


\section{Capítulo 6}

\section{Conclusões}

Neste capítulo são apresentadas e discutidas as conclusões referentes às estratégias empregadas, às simulações realizadas e aos resultados obtidos para a operação de sistemas de distribuição de energia elétrica com a presença de unidades de geração distribuída, considerando principalmente o desempenho dos perfis de tensão e perdas técnicas na rede elétrica. Também serão sugeridas algumas propostas para trabalhos futuros.

\subsection{Considerações Finais}

Este trabalho apresentou diferentes formulações matemáticas para um problema de otimização que consistiu em determinar a operação mais adequada de dispositivos reguladores de tensão instalados em sistemas de distribuição de energia elétrica na presença de geração distribuída. Tratar esta questão como um problema de otimização mostrou que se podem conseguir condições tecnicamente viáveis de operação dos elementos das redes de distribuição e geração distribuída em situações em que há diferentes variáveis a controlar, tais como taps de transformadores e de reguladores de tensão, potência ativa e reativa fornecida pelos bancos de capacitores e até mesmo a tensão de referência e potência ativa dos geradores distribuídos.

Os softwares (AMPL e Knitro) utilizados no desenvolvimento do trabalho demonstraram bastante eficiência e robustez, sendo o solver, capaz de resolver problemas de fluxo de potência ótimo das diversas modelagens propostas, atendendo satisfatoriamente às restrições, e mostrando em todos os casos as melhorias no perfil de tensão e nas perdas elétricas.

Das simulações realizadas e resultados discutidos, observou-se a viabilidade de operação dos geradores distribuídos atuando como regulador de tensão fornecendo potência ativa para a rede elétrica com elevado fator de potência, bem acima do limite de 0,92. Em muitos casos, esta filosofia de operação de geradores distribuídos é uma ação desestimulada 
pelo risco de operar com baixo fator de potência e pela carência de uma estratégia ou mesmo meios de comunicação para a coordenação entre os dispositivos de regulação de tensão. Logo, a demonstração da viabilidade das estratégias de operação propostas neste trabalho pode contribuir com as concessionárias de energia elétrica e proprietários de geradores distribuídos para definir regras de operação e controle dos diferentes dispositivos instalados nas redes de distribuição, e na elaboração de contratos específicos que visem o melhor desempenho do sistema de distribuição de energia elétrica como um todo.

Como uma importante contribuição deste trabalho, foi proposto que a tensão de referência dos geradores distribuídos fosse colocada como variável de controle no processo de otimização. Com isso, observou-se que a tensão terminal destas máquinas varia principalmente em função do carregamento da rede elétrica, garantindo os menores desvios de tensão entre as estratégias analisadas. Também foram elaboradas simulações e realizadas análises quanto à operação do gerador, atuando como regulador de fator de potência, fornecendo potência ativa variável à rede. Concluiu-se que este modo de operação em unidades de geração distribuída garante pequenas variações de tensão, e uma redução significativa das perdas técnicas, entre as outras filosofias estudadas.

Finalmente, analisando todas as situações simuladas observou-se que, com exceção da estratégia PQ Variável, as perdas de energia obtidas considerando a função objetivo de minimização dos desvios de tensão foram maiores, porém com valores muito próximos daqueles obtidos quando se desejava minimizar as perdas elétricas. Portanto, isso indica que os dispositivos reguladores de tensão e geradores distribuídos podem ser configurados visando minimizar os desvios das tensões nodais para se obter um melhor perfil de tensão da rede de distribuição.

\subsection{Sugestões para Trabalhos Futuros}

Assim como em qualquer tipo de trabalho, sempre existe a possibilidade de serem feitas melhorias, e durante o desenvolvimento desta dissertação de mestrado algumas questões foram levantadas e são sugeridas a seguir para dar continuidade ao desenvolvimento do tema aqui abordado:

- Adaptar a formulação do problema a partir de uma abordagem multi-objetivo, possibilitando a inserção de um sistema de pesos capaz de priorizar o acionamento (chaveamento) de dispositivos reguladores, além de considerar como funçõesobjetivo a minimização das perdas e/ou dos desvios de tensão; 
- Elevar o nível de detalhamento dos geradores distribuídos, inserindo variáveis dos controles de tensão e potência (regulador de tensão e de velocidade, e os limites de compensação de reativos) no processo de otimização. 


\section{Referências Bibliográficas}

[1] N. Jenkins, R. Allan, P. Crossley, D. Kischen e G. Strbac, Embedded Generation, London: The Institute of Electrical Engineers, 2000.

[2] Working Group 37.23, Impact of Increasing Contribution of Dispersed Generation on the Power System, CIGRÉ, Technical Report, 1999.

[3] CIRED Working Group 4, Dispersed Generation, CIRED, Technical Report, 1999.

[4] A-M. Borbely, and J. F. Kreider, Distributed Generation - The Power Paradigm for the New Millennium, Boca Raton: CRC Press, 2001.

[5] G. Jóos, B. T. Ooi, D. McGillis, F. D. Galiana, R. Marceau, The Potential of Distributed Generation to Provide Ancillary Services, In: IEEE Power Engineering Society General Meeting, Seattle, 2000, pp. 1762 - 1767.

[6] Ministério das Minas e Energia (MME). <http://www.mme.gov.br>. Acesso em 06/05/2008.

[7] Vu Van Thong, J. Driesen, R. Belmans, Power Quality and Voltage Stability of Distribution System with Distributed Energy Resources, International Journal of Distributed Energy Resources, vol. 1, no. 3, Apr. 2005, pp. 227 - 240.

[8] F. A. Viawan, D. Karlsson, Voltage and Reactive Power Control in Systems with Synchronous Machine-Based Distributed Generation, IEEE Trans. Power Delivery, vol. 23, no. 2, Apr. 2008, pp. $1079-1087$.

[9] P. Kundur, Power System Stability and Control, New York: McGraw-Hill, 1994.

[10] C. L. Masters, Voltage Rise: The Big Issue When Connecting Embedded Generation to Long $11 \mathrm{kV}$ Overhead Lines, Power Engineering Journal, vol. 16, no. 1, 2002, pp. 5 12.

[11] J. Morren, S. W. H. de Hann, and J. A. Ferreira, Distributed Generation Units Contributing to Voltage Control in Distribution Networks, $39^{\text {th }}$ International Universities Power Engineering Conference, vol. 2, 2004, pp. 789 - 793.

[12] W. Freitas, J. C. M. Vieira, A. Morelato, and W. Xu, Influence of Excitation Control Modes on the Allowable Penetration Level of Distributed Synchronous Generators, IEEE Trans. Energy Conversion, vol. 20, no. 2, 2005, pp. $474-480$.

[13] W. Freitas, J. C. M. Vieira, A. Morelato, L. C. P. Silva e V. Costa, Análise Comparativa entre Geradores Síncronos e Geradores de Indução com Rotor tipo Gaiola de Esquilo para Aplicação em Geração Distribuída, Revista Controle e Automação, vol. 16 , no. 3,2005 , pp. $332-344$. 
[14] Portal Eco Debate. <http://www.ecodebate.com.br>. Acesso em: maio de 2010.

[15] S. K. Salman, The Impact of Embedded Generation on Voltage Regulation and Losses of Distribution Networks, IEE Colloquium on The Impact of Embedded Generation on Distribution Networks, Oct. 1996, 4 p.

[16] W. J. S. Rogers, Impact of Embedded Generation on Design, Operation and Protection of Distribution Networks, IEE Colloquium on The Impact of Embedded Generation on Distribution Networks, Oct. 1996, 7 p.

[17] W. H. Kersting, Distribution System Modeling and Analysis, New York: CRC Press LLC, 2002.

[18] L. Kojovic, Impact of DG on Voltage Regulation, IEEE Power Engineering Society Summer Meeting, vol. 1, Jul. 2002, pp. 97 - 102.

[19] T. A. Short, Electric Power Distribution Handbook, Boca Raton: CRC Press LLC, 2004.

[20] W. F. Usida, Controle Fuzzy para Melhoria do Perfil de Tensão em Sistemas de Distribuição de Energia Elétrica. 2007. 121 f.. Dissertação (Mestrado em Engenharia Elétrica) - Escola de Engenharia de São Carlos da Universidade de São Paulo, São Carlos, 2007.

[21] Victor Levi, M. Kay, I. Povey, Reverse Power Flow Capability of Tap-Changers, $18^{\text {th }}$ International Conference on Electricity Distribution, Jun. 2005.

[22] ANSI/IEEE Std. C57.15-1986, IEEE Standard Requirements, Terminology, and Test Code for Step-voltage and Induction-voltage Regulators, Apr. 1988.

[23] Agência Nacional de Energia Elétrica (ANEEL). <http://www.aneel.gov.br>. Acesso em 18/10/2009.

[24] A. Padilha Feltrin, M. Escobar de Oliveira, Gestão das Perdas de Energia em Sistemas de Distribuição de Energia Elétrica, XVII Congresso Brasileiro de Automática, Tutoriais, 2008, $25 \mathrm{p}$.

[25] J. A. M. Gallardo, Impacto de Geradores Síncronos no Desempenho de Regime Permanente de Sistemas de Distribuição de Energia Elétrica. 2005. 121 f.. Dissertação (Mestrado em Engenharia Elétrica) - Universidade Estadual de Campinas, Faculdade de Engenharia Elétrica e de Computação, Campinas, 2005.

[26] AMPL. Disponível em <http://www.ampl.com>. Acesso em: junho de 2009.

[27] R. Fourer, D. M. Gay, and B. W. Kernighan. AMPL: A Modeling Language for Mathematical Programming, $2^{\text {nd }}$ Ed., Brooks/Cole - Thomson Learning, 2003.

[28] Knitro 6.0 User's Manual. <http://www.ziena.com/docs/Knitro60_UserManual.pdf $>$. Acesso em: julho de 2009. 
[29] R. A. Waltz, J. L. Morales, J. Nocedal, and D. Orban. An interior algorithm for nonlinear optimization that combines line search and trust region steps. Mathematical Programming, 2006, pp. $391-408$.

[30] R. H. Byrd, M. E. Hribar, and J. Nocedal. An interior point algorithm for large scale nonlinear programming. SIAM Journal on Optimization, 1999, pp. 877-900.

[31] R. H. Byrd, J.-Ch. Gilbert, and J. Nocedal, A trust region method based on interior point techniques for nonlinear programming. Mathematical Programming, 2000, pp. $149-185$.

[32] R. H. Byrd, N. I. M. Gould, J. Nocedal, and R. A.Waltz, An algorithm for nonlinear optimization using linear programming and equality constrained subproblems. Mathematical Programming, Series B, 2004, pp. 27 - 48.

[33] R. H. Byrd, N. I. M. Gould, J. Nocedal, and R. A. Waltz, On the convergence of successive linear-quadratic programming algorithms. SIAM Journal on Optimization, 2006, pp. 471-489.

[34] R. H. Byrd, J. Nocedal, and R.A. Waltz, KNITRO: An integrated package for nonlinear optimization. Editors: In G. di Pillo and M. Roma, Large-Scale Nonlinear Optimization, 2006, pp. $35-59$.

[35] M. C. Goldbarg, H. P. L. Luna, Otimização Combinatória e Programação Linear: Modelos e Algoritmos, Editora Campus, Rio de Janeiro, 2000.

[36] S. L. Haffner, Planejamento da Expansão dos Sistemas Elétricos no Contexto de um Ambiente Competitivo. 2000. 158f. Tese (Doutorado em Engenharia Elétrica) Universidade Estadual de Campinas, Faculdade de Engenharia Elétrica e de Computação, Campinas, 2000.

[37] D. C. S. Reis, Um algoritmo Branch and Bound para o Problema da Alocação Ótima de Monitores de Qualidade de Energia Elétrica em Redes de Transmissão. 2007. 110f. Dissertação (Mestrado em Engenharia Elétrica) - Programa de Pós-Graduação em Engenharia Elétrica, Universidade Federal de Juiz de Fora, Juiz de Fora, 2007.

[38] A. J. Monticelli, Fluxo de Carga em Redes de Energia Elétrica, Editora Edgard Blucher Ltda, 1983.

[39] T. Niknam, A.M. Ranjbar, Impact of Distributed Generation on Volt/Var Control in Distribution Networks, IEEE Bologna PowerTech Conference, Jun. 2003, 7 p.

[40] P. A. N. Garcia, J. L. R. Pereira, S. Carneiro Jr., Voltage Control Devices Models for Distribution Power Flow Analysis, IEEE Transactions on Power Systems, vol. 16, no. 4, Nov. 2001, pp. $586-594$.

[41] N. Vempati, R. R. Shoults, M. S. Chen, L. Schwobel, Simplified Feeder Modeling for Loadflow Calculations, IEEE Transactions on Power Systems, vol. PWRS-2, no. 1, Feb. 1987, pp. $168-174$. 
[42] J. A. Jardini, C. M. V. Tahan, M. R. Gouveia, S. U. Ahn, F. M. Figueiredo, Daily Load Profiles for Residential, Commercial and Industrial Low Voltage Consumers, IEEE Trans. on Power Delivery, vol. 15, no. 1, Jan. 2000, pp. 375 - 380.

[43] M. Thomson, Automatic Voltage Control Relays and Embedded Generation. I, Power Engineering Journal, vol. 14, Apr. 2000, pp. $71-76$. 


\section{Anexo A \\ Resultados dos Processos de \\ Otimização}


Neste anexo são apresentados os resultados dos valores mínimos e máximos do perfil de tensão de todo o sistema de distribuição juntamente com a barra correspondente, bem como os valores das perdas elétricas, considerando 24 horas de operação do sistema elétrico. Todos estes resultados são provenientes de simulações realizadas para cada hora do dia, referentes aos processos de otimização não-linear que visam o estudo de estratégias de operação de dispositivos reguladores de tensão em redes elétricas com fontes de geração distribuída para duas funções-objetivo distintas (minimização dos desvios de tensão e minimização de perdas) e diferentes modos de operação dos geradores distribuídos. Ressaltase que também se encontram os resultados das funções-objetivo.

Na Tabela A.1 encontram-se os resultados considerando o sistema de distribuição da Figura 3.5 e a estratégia de minimização de tensão. Cada linha da tabela corresponde a uma hora. Assim, inicia-se por ordem a coluna de tempo, depois seguem as colunas das injeções e/ou consumo de potência ativa das unidades de geração (G1 e G2) e da subestação, respectivamente. A coluna "mín" contém os valores da menor tensão nodal verificada para aquela hora, sendo que a coluna "barra" adjacente mostra a barra em que ocorre esta condição. A coluna "máx" apresenta o máximo valor de tensão, cuja barra correspondente é apresentada na coluna "barra", do seu lado direito. Finalmente, os resultados das perdas de energia e do valor da função objetivo em cada hora são apresentados, respectivamente, nas colunas seguintes. Todas as tabelas apresentadas posteriormente à Tabela A.1 podem ser interpretadas dessa forma.

As estratégias analisadas estão devidamente identificadas nas legendas das tabelas A.1 a A.10. 
Tabela A.1 - Resultados para o caso SGD / min Tensão.

\begin{tabular}{|c|c|c|c|c|c|c|c|}
\hline \multirow{2}{*}{$\begin{array}{l}\text { Tempo } \\
\text { (hora) }\end{array}$} & \multirow{2}{*}{$\begin{array}{l}\text { Potência Ativa } \\
\text { da Subestação } \\
(\mathrm{MW})\end{array}$} & \multicolumn{4}{|c|}{ Tensão da Rede (pu) } & \multirow{2}{*}{$\begin{array}{c}\text { Perdas de Energia } \\
\text { (MWh) }\end{array}$} & \multirow{2}{*}{$\begin{array}{c}\text { Valor Final } \\
\text { da } \\
\text { Funçao Objetivo } \\
\end{array}$} \\
\hline & & mín & barra & máx & barra & & \\
\hline 1 & 9,118 & 0,9873 & 11 & 1,0135 & 5 & 0,17 & 0,0012835455 \\
\hline 2 & 8,421 & 0,9874 & 11 & 1,0120 & 5 & 0,15 & 0,0011470185 \\
\hline 3 & 8,183 & 0,9890 & 11 & 1,0126 & 5 & 0,13 & 0,0010559922 \\
\hline 4 & 8,090 & 0,9893 & 11 & 1,0127 & 5 & 0,13 & 0,0010427106 \\
\hline 5 & 8,348 & 0,9881 & 11 & 1,0121 & 5 & 0,14 & 0,0010717679 \\
\hline 6 & 8,972 & 0,9881 & 11 & 1,0135 & 5 & 0,16 & 0,0012036915 \\
\hline 7 & 9,806 & 0,9842 & 11 & 1,0129 & 5 & 0,20 & 0,0015080762 \\
\hline 8 & 13,644 & 0,9744 & 11 & 1,0140 & 4 & 0,34 & 0,0036214885 \\
\hline 9 & 15,345 & 0,9807 & 11 & 1,0228 & 5 & 0,42 & 0,0044972293 \\
\hline 10 & 15,531 & 0,9818 & 11 & 1,0238 & 5 & 0,43 & 0,0045073448 \\
\hline 11 & 15,972 & 0,9810 & 11 & 1,0234 & 5 & 0,45 & 0,0048408490 \\
\hline 12 & 14,972 & 0,9812 & 11 & 1,0231 & 5 & 0,40 & 0,0041157341 \\
\hline 13 & 14,627 & 0,9815 & 11 & 1,0231 & 5 & 0,38 & 0,0037406017 \\
\hline 14 & 16,300 & 0,9788 & 35 & 1,0244 & 5 & 0,47 & 0,0052909135 \\
\hline 15 & 16,235 & 0,9791 & 35 & 1,0231 & 5 & 0,47 & 0,0052207591 \\
\hline 16 & 15,689 & 0,9822 & 11 & 1,0240 & 5 & 0,44 & 0,0047394372 \\
\hline 17 & 15,751 & 0,9812 & 11 & 1,0236 & 5 & 0,44 & 0,0046183428 \\
\hline 18 & 14,884 & 0,9797 & 11 & 1,0229 & 5 & 0,41 & 0,0041641745 \\
\hline 19 & 14,425 & 0,9786 & 11 & 1,0235 & 5 & 0,42 & 0,0040491106 \\
\hline 20 & 15,409 & 0,9748 & 11 & 1,0229 & 5 & 0,50 & 0,0046862152 \\
\hline 21 & 15,327 & 0,9759 & 11 & 1,0238 & 5 & 0,49 & 0,0044193931 \\
\hline 22 & 14,049 & 0,9776 & 11 & 1,0232 & 5 & 0,42 & 0,0037283980 \\
\hline 23 & 12,599 & 0,9733 & 11 & 1,0162 & 12 & 0,33 & 0,0032038547 \\
\hline 24 & 11,408 & 0,9803 & 11 & 1,0143 & 5 & 0,27 & 0,0023347022 \\
\hline & & & & & & 8,16 & 0,0800913507 \\
\hline
\end{tabular}

Tabela A.2 - Resultados para o caso SGD / min Perdas.

\begin{tabular}{|c|c|c|c|c|c|c|c|}
\hline \multirow{2}{*}{$\begin{array}{l}\text { Tempo } \\
\text { (hora) }\end{array}$} & \multirow{2}{*}{$\begin{array}{c}\text { Potência Ativa } \\
\text { da Subestação } \\
(\mathrm{MW})\end{array}$} & \multicolumn{4}{|c|}{ Tensão da Rede (pu) } & \multirow{2}{*}{$\begin{array}{c}\text { Perdas de Energia } \\
\text { (MWh) }\end{array}$} & \multirow{2}{*}{$\begin{array}{c}\text { Valor Final } \\
\text { da } \\
\text { Funçao Objetivo }\end{array}$} \\
\hline & & mín & barra & máx & barra & & \\
\hline 1 & 9,100 & 1,0000 & 1 & 1,0471 & 12 & 0,16 & 0,1562955349 \\
\hline 2 & 8,404 & 1,0000 & 1 & 1,0497 & 18 & 0,13 & 0,1283708159 \\
\hline 3 & 8,168 & 1,0000 & 1 & 1,0486 & 18 & 0,12 & 0,1193014215 \\
\hline 4 & 8,075 & 1,0000 & 1 & 1,0492 & 18 & 0,12 & 0,1167185196 \\
\hline 5 & 8,332 & 1,0000 & 1 & 1,0464 & 12 & 0,12 & 0,1221923967 \\
\hline 6 & 8,953 & 1,0000 & 1 & 1,0486 & 18 & 0,14 & 0,1443323173 \\
\hline 7 & 9,787 & 1,0000 & 1 & 1,0478 & 12 & 0,18 & 0,1806207128 \\
\hline 8 & 13,625 & 0,9995 & 11 & 1,0456 & 18 & 0,32 & 0,3168558350 \\
\hline 9 & 15,321 & 0,9930 & 11 & 1,0499 & 12 & 0,40 & 0,3971317164 \\
\hline 10 & 15,510 & 0,9918 & 11 & 1,0486 & 12 & 0,41 & 0,4051531662 \\
\hline 11 & 15,950 & 0,9909 & 11 & 1,0485 & 18 & 0,43 & 0,4293289369 \\
\hline 12 & 14,950 & 0,9934 & 11 & 1,0496 & 18 & 0,38 & 0,3781985208 \\
\hline 13 & 14,604 & 0,9937 & 11 & 1,0485 & 18 & 0,36 & 0,3586720681 \\
\hline 14 & 16,281 & 0,9895 & 11 & 1,0467 & 18 & 0,45 & 0,4498853483 \\
\hline 15 & 16,212 & 0,9903 & 11 & 1,0471 & 12 & 0,44 & 0,4441096221 \\
\hline 16 & 15,668 & 0,9922 & 11 & 1,0491 & 12 & 0,42 & 0,4160843471 \\
\hline 17 & 15,730 & 0,9912 & 11 & 1,0480 & 12 & 0,42 & 0,4196591266 \\
\hline 18 & 14,860 & 0,9919 & 11 & 1,0500 & 18 & 0,39 & 0,3863386034 \\
\hline 19 & 14,400 & 0,9909 & 11 & 1,0467 & 12 & 0,40 & 0,3993577532 \\
\hline 20 & 15,384 & 0,9849 & 11 & 1,0462 & 18 & 0,47 & 0,4703899400 \\
\hline 21 & 15,305 & 0,9837 & 11 & 1,0479 & 18 & 0,47 & 0,4667494198 \\
\hline 22 & 14,022 & 0,9899 & 11 & 1,0487 & 18 & 0,39 & 0,3938917357 \\
\hline 23 & 12,579 & 0,9985 & 11 & 1,0491 & 12 & 0,31 & 0,3138119863 \\
\hline 24 & 11,392 & 1,0000 & 1 & 1,0485 & 12 & 0,26 & 0,2579053279 \\
\hline & & & & & & 7,69 & 7,6713551726 \\
\hline
\end{tabular}


Tabela A.3 - Resultados para a estratégia PV Fixo / min Tensão.

\begin{tabular}{|c|c|c|c|c|c|c|c|c|}
\hline \multirow{2}{*}{$\begin{array}{l}\text { Tempo } \\
\text { (hora) } \\
\end{array}$} & \multirow{2}{*}{$\begin{array}{l}\text { Pot. Ativa } \\
\text { (MW) }\end{array}$} & \multirow{2}{*}{$\begin{array}{c}\text { Potência Ativa } \\
\text { da Subestação } \\
\text { (MW) }\end{array}$} & \multicolumn{4}{|c|}{ Tensão da Rede (pu) } & \multirow{2}{*}{$\begin{array}{c}\text { Perdas de Energia } \\
\text { (MWh) }\end{array}$} & \multirow{2}{*}{$\begin{array}{c}\text { Valor Final } \\
\text { da } \\
\text { Funçao Objetivo }\end{array}$} \\
\hline & & & mín & barra & máx & barra & & \\
\hline 1 & \multirow{24}{*}{10,5} & $-11,752$ & 0,9910 & 27 & 1,0082 & 12 & 0,30 & 0,0004665915 \\
\hline 2 & & $-12,417$ & 0,9949 & 27 & 1,0103 & 12 & 0,31 & 0,0003798328 \\
\hline 3 & & $-12,639$ & 0,9905 & 27 & 1,0063 & 18 & 0,31 & 0,0003732511 \\
\hline 4 & & $-12,729$ & 0,9907 & 27 & 1,0064 & 18 & 0,31 & 0,0003702143 \\
\hline 5 & & $-12,482$ & 0,9902 & 27 & 1,0064 & 18 & 0,31 & 0,0003759895 \\
\hline 6 & & $-11,890$ & 0,9923 & 27 & 1,0092 & 12 & 0,30 & 0,0003718314 \\
\hline 7 & & $-11,098$ & 0,9917 & 11 & 1,0122 & 12 & 0,30 & 0,0004888983 \\
\hline 8 & & $-7,431$ & 0,9881 & 27 & 1,0102 & 18 & 0,26 & 0,0006949497 \\
\hline 9 & & $-5,813$ & 0,9875 & 11 & 1,0130 & 12 & 0,26 & 0,0009119320 \\
\hline 10 & & $-5,633$ & 0,9872 & 11 & 1,0126 & 12 & 0,26 & 0,0009347445 \\
\hline 11 & & $-5,215$ & 0,9870 & 11 & 1,0124 & 12 & 0,27 & 0,0010630662 \\
\hline 12 & & $-6,167$ & 0,9875 & 11 & 1,0131 & 12 & 0,26 & 0,0008141552 \\
\hline 13 & & $-6,495$ & 0,9876 & 11 & 1,0132 & 12 & 0,26 & 0,0007487953 \\
\hline 14 & & $-4,901$ & 0,9865 & 11 & 1,0119 & 12 & 0,27 & 0,0011902291 \\
\hline 15 & & $-4,965$ & 0,9869 & 11 & 1,0123 & 12 & 0,27 & 0,0011582272 \\
\hline 16 & & $-5,484$ & 0,9873 & 11 & 1,0129 & 12 & 0,26 & 0,0010398895 \\
\hline 17 & & $-5,425$ & 0,9869 & 11 & 1,0123 & 12 & 0,26 & 0,0010064396 \\
\hline 18 & & $-6,255$ & 0,9864 & 11 & 1,0115 & 12 & 0,27 & 0,0008678927 \\
\hline 19 & & $-6,707$ & 0,9846 & 11 & 1,0151 & 12 & 0,29 & 0,0010268149 \\
\hline 20 & & $-5,772$ & 0,9821 & 11 & 1,0180 & 12 & 0,31 & 0,0012717451 \\
\hline 21 & & $-5,846$ & 0,9817 & 11 & 1,0175 & 12 & 0,32 & 0,0012819159 \\
\hline 22 & & $-7,065$ & 0,9839 & 11 & 1,0142 & 12 & 0,31 & 0,0010416711 \\
\hline 23 & & $-8,438$ & 0,9871 & 11 & 1,0137 & 18 & 0,30 & 0,0008339090 \\
\hline 24 & & $-9,568$ & 0,9881 & 11 & 1,0136 & 12 & 0,30 & 0,0007064779 \\
\hline & & & & & & & 6,87 & 0,0194194640 \\
\hline
\end{tabular}

Tabela A.4 - Resultados para a estratégia PV Fixo / min Perdas.

\begin{tabular}{|c|c|c|c|c|c|c|c|c|}
\hline \multirow{2}{*}{$\begin{array}{l}\text { Tempo } \\
\text { (hora) } \\
\end{array}$} & \multirow{2}{*}{$\begin{array}{r}\text { Pot. Ativa } \\
\text { (MW) }\end{array}$} & \multirow{2}{*}{$\begin{array}{c}\text { Potência Ativa } \\
\text { da Subestação } \\
\text { (MW) }\end{array}$} & \multicolumn{4}{|c|}{ Tensão da Rede (pu) } & \multirow{2}{*}{$\begin{array}{c}\text { Perdas de Energia } \\
(\mathrm{MWh})\end{array}$} & \multirow{2}{*}{$\begin{array}{c}\text { Valor Final } \\
\text { da } \\
\text { Funçao Objetivo }\end{array}$} \\
\hline & & & mín & barra & máx & barra & & \\
\hline 1 & \multirow{24}{*}{10,5} & $-11,782$ & 0,9744 & 5 & 1,0491 & 18 & 0,27 & 0,2746081118 \\
\hline 2 & & $-12,443$ & 0,9743 & 5 & 1,0496 & 12 & 0,28 & 0,2819895895 \\
\hline 3 & & $-12,667$ & 0,973 & 5 & 1,0499 & 12 & 0,28 & 0,2843006246 \\
\hline 4 & & $-12,756$ & 0,9745 & 5 & 1,0459 & 18 & 0,29 & 0,2863142953 \\
\hline 5 & & $-12,509$ & 0,9737 & 5 & 1,0500 & 12 & 0,28 & 0,2812075149 \\
\hline 6 & & $-11,918$ & 0,9747 & 5 & 1,0487 & 12 & 0,27 & 0,2726412899 \\
\hline 7 & & $-11,127$ & 0,9733 & 5 & 1,0499 & 12 & 0,27 & 0,2667038837 \\
\hline 8 & & $-7,460$ & 0,977 & 5 & 1,0471 & 12 & 0,23 & 0,2318508768 \\
\hline 9 & & $-5,842$ & 0,9756 & 11 & 1,0497 & 12 & 0,23 & 0,2340505619 \\
\hline 10 & & $-5,661$ & 0,9756 & 11 & 1,0497 & 12 & 0,23 & 0,2341641568 \\
\hline 11 & & $-5,244$ & 0,9757 & 11 & 1,0500 & 18 & 0,24 & 0,2355338442 \\
\hline 12 & & $-6,196$ & 0,9758 & 11 & 1,0500 & 12 & 0,23 & 0,2327872557 \\
\hline 13 & & $-6,524$ & 0,9756 & 11 & 1,0498 & 12 & 0,23 & 0,2302413809 \\
\hline 14 & & $-4,930$ & 0,9755 & 35 & 1,0498 & 18 & 0,24 & 0,2395770932 \\
\hline 15 & & $-4,994$ & 0,9756 & 11 & 1,0497 & 18 & 0,24 & 0,2374800232 \\
\hline 16 & & $-5,512$ & 0,9757 & 11 & 1,0499 & 12 & 0,24 & 0,2369486427 \\
\hline 17 & & $-5,454$ & 0,9757 & 11 & 1,0497 & 12 & 0,24 & 0,2361184218 \\
\hline 18 & & $-6,285$ & 0,9752 & 11 & 1,0490 & 12 & 0,24 & 0,2413111399 \\
\hline 19 & & $-6,736$ & 0,9733 & 11 & 1,0499 & 18 & 0,26 & 0,2633052952 \\
\hline 20 & & $-5,805$ & 0,9712 & 11 & 1,0495 & 12 & 0,28 & 0,2811813010 \\
\hline 21 & & $-5,880$ & 0,9709 & 11 & 1,0490 & 12 & 0,28 & 0,2822910448 \\
\hline 22 & & $-7,098$ & 0,9711 & 11 & 1,0498 & 18 & 0,27 & 0,2741666888 \\
\hline 23 & & $-8,469$ & 0,9759 & 11 & 1,0500 & 18 & 0,27 & 0,2661236660 \\
\hline 24 & & $-9,599$ & 0,9758 & 5 & 1,0463 & 18 & 0,27 & 0,2663247998 \\
\hline & & & & & & & 6,16 & 6,1712215024 \\
\hline
\end{tabular}


Tabela A.5 - Resultados para a estratégia PV Variável / min Tensão.

\begin{tabular}{|c|c|c|c|c|c|c|c|c|}
\hline \multirow{2}{*}{$\begin{array}{r}\text { Tempo } \\
\text { (hora) } \\
\end{array}$} & \multirow{2}{*}{$\begin{array}{c}\text { Pot. Ativa } \\
\text { (MW) }\end{array}$} & \multirow{2}{*}{$\begin{array}{c}\text { Potência Ativa } \\
\text { da Subestação } \\
\text { (MW) }\end{array}$} & \multicolumn{4}{|c|}{ Tensão da Rede (pu) } & \multirow{2}{*}{$\begin{array}{c}\text { Perdas de Energia } \\
\qquad(\mathrm{MWh})\end{array}$} & \multirow{2}{*}{$\begin{array}{c}\text { Valor Final } \\
\text { da } \\
\text { Funçao Objetivo }\end{array}$} \\
\hline & & & mín & barra & máx & barra & & \\
\hline 1 & \multirow{24}{*}{10,5} & $-11,748$ & 0,9905 & 27 & 1,0096 & 18 & 0,31 & 0,0004328143 \\
\hline 2 & & $-12,412$ & 0,9936 & 27 & 1,0090 & 12 & 0,32 & 0,0003416631 \\
\hline 3 & & $-12,634$ & 0,9941 & 11 & 1,0095 & 12 & 0,32 & 0,0003208097 \\
\hline 4 & & $-12,723$ & 0,9942 & 11 & 1,0096 & 12 & 0,32 & 0,0003206129 \\
\hline 5 & & $-12,476$ & 0,9941 & 11 & 1,0095 & 12 & 0,31 & 0,0003149485 \\
\hline 6 & & $-11,887$ & 0,9915 & 27 & 1,0084 & 12 & 0,30 & 0,0003503531 \\
\hline 7 & & $-11,095$ & 0,9910 & 11 & 1,0114 & 12 & 0,30 & 0,0004783945 \\
\hline 8 & & $-7,438$ & 0,9890 & 27 & 1,0099 & 12 & 0,25 & 0,0006248846 \\
\hline 9 & & $-5,822$ & 0,9880 & 11 & 1,0136 & 12 & 0,25 & 0,0008402273 \\
\hline 10 & & $-5,643$ & 0,9879 & 11 & 1,0134 & 12 & 0,25 & 0,0008495103 \\
\hline 11 & & $-5,227$ & 0,9879 & 11 & 1,0134 & 12 & 0,25 & 0,0009008428 \\
\hline 12 & & $-6,175$ & 0,9880 & 11 & 1,0136 & 12 & 0,25 & 0,0007677765 \\
\hline 13 & & $-6,504$ & 0,9882 & 11 & 1,0137 & 12 & 0,25 & 0,0007114184 \\
\hline 14 & & $-4,913$ & 0,9878 & 11 & 1,0131 & 12 & 0,26 & 0,0009830642 \\
\hline 15 & & $-4,978$ & 0,9879 & 11 & 1,0134 & 12 & 0,25 & 0,0009622769 \\
\hline 16 & & $-5,495$ & 0,9880 & 11 & 1,0136 & 12 & 0,25 & 0,0009230806 \\
\hline 17 & & $-5,437$ & 0,9879 & 11 & 1,0133 & 12 & 0,25 & 0,0008773312 \\
\hline 18 & & $-6,266$ & 0,9875 & 11 & 1,0127 & 12 & 0,26 & 0,0008033811 \\
\hline 19 & & $-6,709$ & 0,9849 & 11 & 1,0154 & 12 & 0,29 & 0,0009627911 \\
\hline 20 & & $-5,783$ & 0,9840 & 11 & 1,0139 & 12 & 0,30 & 0,0011760436 \\
\hline 21 & & $-5,859$ & 0,9841 & 11 & 1,0138 & 12 & 0,30 & 0,0012482080 \\
\hline 22 & & $-7,068$ & 0,9848 & 11 & 1,0151 & 12 & 0,30 & 0,0010205786 \\
\hline 23 & & $-8,436$ & 0,9874 & 11 & 1,0128 & 18 & 0,30 & 0,0007994199 \\
\hline 24 & & $-9,562$ & 0,9881 & 11 & 1,0137 & 12 & 0,30 & 0,0007054236 \\
\hline & & & & & & & 6,74 & 0,0177158545 \\
\hline
\end{tabular}

Tabela A.6 - Resultados para a estratégia PV Variável / min Perdas.

\begin{tabular}{|c|c|c|c|c|c|c|c|c|}
\hline \multirow{2}{*}{$\begin{array}{l}\text { Tempo } \\
\text { (hora) }\end{array}$} & \multirow{2}{*}{$\begin{array}{c}\text { Pot. Ativa } \\
\text { (MW) }\end{array}$} & \multirow{2}{*}{$\begin{array}{l}\text { Potência Ativa } \\
\text { da Subestação } \\
\text { (MW) }\end{array}$} & \multicolumn{4}{|c|}{ Tensão da Rede (pu) } & \multirow{2}{*}{$\begin{array}{c}\text { Perdas de Energia } \\
\text { (MWh) }\end{array}$} & \multirow{2}{*}{$\begin{array}{c}\text { Valor Final } \\
\text { da } \\
\text { Funçao Objetivo }\end{array}$} \\
\hline & & & mín & barra & máx & barra & & \\
\hline 1 & \multirow{24}{*}{10,5} & $-11,804$ & 1,00 & 1 & 1,05 & 18 & 0,25 & 0,2524728197 \\
\hline 2 & & $-12,467$ & 1,00 & 1 & 1,05 & 3 & 0,26 & 0,2580733437 \\
\hline 3 & & $-12,691$ & 1,00 & 1 & 1,05 & 3 & 0,26 & 0,2601898320 \\
\hline 4 & & $-12,780$ & 1,00 & 1 & 1,05 & 3 & 0,26 & 0,2616478532 \\
\hline 5 & & $-12,533$ & 1,00 & 1 & 1,05 & 3 & 0,26 & 0,2571573301 \\
\hline 6 & & $-11,941$ & 1,00 & 1 & 1,05 & 12 & 0,25 & 0,2501411116 \\
\hline 7 & & $-11,148$ & 1,00 & 1 & 1,05 & 18 & 0,25 & 0,2457013809 \\
\hline 8 & & $-7,477$ & 1,00 & 1 & 1,05 & 2 & 0,21 & 0,2149722304 \\
\hline 9 & & $-5,858$ & 1,00 & 1 & 1,05 & 3 & 0,22 & 0,2174954489 \\
\hline 10 & & $-5,677$ & 1,00 & 1 & 1,05 & 2 & 0,22 & 0,2178920342 \\
\hline 11 & & $-5,260$ & 1,00 & 1 & 1,05 & 3 & 0,22 & 0,2197479261 \\
\hline 12 & & $-6,212$ & 1,00 & 1 & 1,05 & 3 & 0,22 & 0,2165525059 \\
\hline 13 & & $-6,540$ & 1,00 & 1 & 1,05 & 3 & 0,21 & 0,2144289320 \\
\hline 14 & & $-4,946$ & 1,00 & 1 & 1,05 & 3 & 0,22 & 0,2233558554 \\
\hline 15 & & $-5,010$ & 1,00 & 1 & 1,05 & 3 & 0,22 & 0,2213182165 \\
\hline 16 & & $-5,528$ & 1,00 & 1 & 1,05 & 2 & 0,22 & 0,2201132046 \\
\hline 17 & & $-5,470$ & 1,00 & 1 & 1,05 & 3 & 0,22 & 0,2199371794 \\
\hline 18 & & $-6,302$ & 1,00 & 1 & 1,05 & 3 & 0,23 & 0,2250980239 \\
\hline 19 & & $-6,752$ & 1,00 & 1 & 1,05 & 3 & 0,25 & 0,2470291969 \\
\hline 20 & & $-5,821$ & 1,00 & 1 & 1,05 & 18 & 0,27 & 0,2653718700 \\
\hline 21 & & $-5,895$ & 1,00 & 1 & 1,05 & 3 & 0,27 & 0,2667866925 \\
\hline 22 & & $-7,114$ & 1,00 & 1 & 1,05 & 2 & 0,26 & 0,2580258285 \\
\hline 23 & & $-8,485$ & 1,00 & 1 & 1,05 & 18 & 0,25 & 0,2492313733 \\
\hline 24 & & $-9,618$ & 1,00 & 1 & 1,05 & 2 & 0,25 & 0,2476863845 \\
\hline & & & & & & & 5,75 & 5,7304265741 \\
\hline
\end{tabular}


Tabela A.7 - Resultados para a estratégia PQ Fixo / min Tensão.

\begin{tabular}{|c|c|c|c|c|c|c|c|c|}
\hline \multirow{2}{*}{$\begin{array}{l}\text { Tempo } \\
\text { (hora) } \\
\end{array}$} & \multirow{2}{*}{$\begin{array}{c}\text { Pot. Ativa } \\
(\mathrm{MW}) \\
\end{array}$} & \multirow{2}{*}{$\begin{array}{c}\text { Potência Ativa } \\
\text { da Subestação } \\
\text { (MW) }\end{array}$} & \multicolumn{4}{|c|}{ Tensão da Rede (pu) } & \multirow{2}{*}{$\begin{array}{c}\text { Perdas de Energia } \\
\text { (MWh) }\end{array}$} & \multirow{2}{*}{$\begin{array}{c}\text { Valor Final } \\
\text { da } \\
\text { Funçao Objetivo }\end{array}$} \\
\hline & & & mín & barra & máx & barra & & \\
\hline 1 & \multirow{24}{*}{10,5} & $-11,773$ & 0,9876 & 5 & 1,0111 & 12 & 0,28 & 0,0009762228 \\
\hline 2 & & $-12,437$ & 0,9886 & 5 & 1,0092 & 12 & 0,29 & 0,0007485841 \\
\hline 3 & & $-12,662$ & 0,9889 & 5 & 1,0108 & 12 & 0,29 & 0,0007714563 \\
\hline 4 & & $-12,751$ & 0,9890 & 5 & 1,0053 & 18 & 0,29 & 0,0007713355 \\
\hline 5 & & $-12,504$ & 0,9886 & 5 & 1,0101 & 12 & 0,29 & 0,0007519665 \\
\hline 6 & & $-11,910$ & 0,9876 & 5 & 1,0059 & 12 & 0,28 & 0,0009279809 \\
\hline 7 & & $-11,115$ & 0,9937 & 27 & 1,0132 & 12 & 0,28 & 0,0012420153 \\
\hline 8 & & $-7,436$ & 0,9893 & 27 & 1,0102 & 12 & 0,26 & 0,0006416994 \\
\hline 9 & & $-5,819$ & 0,9880 & 11 & 1,0136 & 12 & 0,26 & 0,0010337695 \\
\hline 10 & & $-5,639$ & 0,9876 & 11 & 1,0131 & 12 & 0,26 & 0,0010476733 \\
\hline 11 & & $-5,220$ & 0,9881 & 11 & 1,0136 & 12 & 0,26 & 0,0010861669 \\
\hline 12 & & $-6,173$ & 0,9884 & 11 & 1,0139 & 12 & 0,26 & 0,0009695467 \\
\hline 13 & & $-6,501$ & 0,9880 & 11 & 1,0136 & 12 & 0,25 & 0,0008970802 \\
\hline 14 & & $-4,908$ & 0,9875 & 11 & 1,0129 & 12 & 0,26 & 0,0011267915 \\
\hline 15 & & $-4,973$ & 0,9882 & 11 & 1,0137 & 12 & 0,26 & 0,0011055694 \\
\hline 16 & & $-5,491$ & 0,9880 & 11 & 1,0135 & 12 & 0,26 & 0,0011084207 \\
\hline 17 & & $-5,431$ & 0,9883 & 11 & 1,0137 & 12 & 0,26 & 0,0010503145 \\
\hline 18 & & $-6,263$ & 0,9874 & 11 & 1,0126 & 12 & 0,26 & 0,0009912273 \\
\hline 19 & & $-6,709$ & 0,9849 & 11 & 1,0154 & 12 & 0,29 & 0,0011390021 \\
\hline 20 & & $-5,777$ & 0,9843 & 11 & 1,0142 & 18 & 0,31 & 0,0013110058 \\
\hline 21 & & $-5,851$ & 0,9833 & 11 & 1,0132 & 18 & 0,31 & 0,0013113737 \\
\hline 22 & & $-7,070$ & 0,9845 & 11 & 1,0148 & 12 & 0,30 & 0,0010881654 \\
\hline 23 & & $-8,442$ & 0,9872 & 11 & 1,0134 & 18 & 0,29 & 0,0008934845 \\
\hline 24 & & $-9,577$ & 0,9888 & 27 & 1,0106 & 12 & 0,29 & 0,0008227570 \\
\hline & & & & & & & 6,64 & 0,0238136094 \\
\hline
\end{tabular}

Tabela A.8 - Resultados para a estratégia PQ Fixo / min Perdas.

\begin{tabular}{|c|c|c|c|c|c|c|c|c|}
\hline \multirow{2}{*}{$\begin{array}{l}\text { Tempo } \\
\text { (hora) }\end{array}$} & \multirow{2}{*}{$\begin{array}{c}\text { Pot. Ativa } \\
\text { (MW) }\end{array}$} & \multirow{2}{*}{$\begin{array}{c}\text { Potência Ativa } \\
\text { da Subestação } \\
\text { (MW) }\end{array}$} & \multicolumn{4}{|c|}{ Tensão da Rede (pu) } & \multirow{2}{*}{$\begin{array}{c}\text { Perdas de Energia } \\
\text { (MWh) }\end{array}$} & \multirow{2}{*}{$\begin{array}{c}\text { Valor Final } \\
\text { da } \\
\text { Funçao Objetivo }\end{array}$} \\
\hline & & & mín & barra & máx & barra & & \\
\hline 1 & \multirow{24}{*}{10,5} & $-11,799$ & 1,00 & 1 & 1,0493 & 7 & 0,26 & 0,2574465797 \\
\hline 2 & & $-12,463$ & 1,00 & 1 & 1,0496 & 12 & 0,26 & 0,2615048984 \\
\hline 3 & & $-12,688$ & 1,00 & 1 & 1,0499 & 39 & 0,26 & 0,2631378779 \\
\hline 4 & & $-12,776$ & 1,00 & 1 & 1,0494 & 6 & 0,27 & 0,2656806386 \\
\hline 5 & & $-12,530$ & 1,00 & 1 & 1,0497 & 7 & 0,26 & 0,2604635617 \\
\hline 6 & & $-11,937$ & 1,00 & 1 & 1,0486 & 39 & 0,25 & 0,2545210145 \\
\hline 7 & & $-11,142$ & 1,00 & 1 & 1,0489 & 39 & 0,25 & 0,2515051571 \\
\hline 8 & & $-7,463$ & 1,00 & 1 & 1,0494 & 18 & 0,23 & 0,2285977687 \\
\hline 9 & & $-5,840$ & 1,00 & 1 & 1,0475 & 12 & 0,24 & 0,2352845134 \\
\hline 10 & & $-5,659$ & 1,00 & 1 & 1,0465 & 12 & 0,24 & 0,2362638719 \\
\hline 11 & & $-5,240$ & 1,00 & 1 & 1,0491 & 18 & 0,24 & 0,2394049133 \\
\hline 12 & & $-6,195$ & 1,00 & 1 & 1,0484 & 18 & 0,23 & 0,2333684951 \\
\hline 13 & & $-6,524$ & 1,00 & 1 & 1,0481 & 12 & 0,23 & 0,2308849551 \\
\hline 14 & & $-4,925$ & 1,00 & 1 & 1,0478 & 18 & 0,24 & 0,2442917044 \\
\hline 15 & & $-4,990$ & 1,00 & 1 & 1,0478 & 18 & 0,24 & 0,2418878665 \\
\hline 16 & & $-5,510$ & 1,00 & 1 & 1,0469 & 12 & 0,24 & 0,2388903625 \\
\hline 17 & & $-5,451$ & 1,00 & 1 & 1,0459 & 12 & 0,24 & 0,2392564293 \\
\hline 18 & & $-6,284$ & 1,00 & 1 & 1,0486 & 18 & 0,24 & 0,2424616644 \\
\hline 19 & & $-6,734$ & 1,00 & 1 & 1,0484 & 18 & 0,27 & 0,2652252184 \\
\hline 20 & & $-5,799$ & 1,00 & 1 & 1,0500 & 18 & 0,29 & 0,2873512329 \\
\hline 21 & & $-5,873$ & 1,00 & 1 & 1,0499 & 12 & 0,29 & 0,2888600583 \\
\hline 22 & & $-7,095$ & 1,00 & 1 & 1,0493 & 12 & 0,28 & 0,2767203212 \\
\hline 23 & & $-8,471$ & 1,00 & 1 & 1,0491 & 12 & 0,26 & 0,2633288569 \\
\hline 24 & & $-9,607$ & 1,00 & 1 & 1,0488 & 18 & 0,26 & 0,2582032669 \\
\hline & & & & & & & 6,07 & 6,0645412271 \\
\hline
\end{tabular}


Tabela A.9 - Resultados para a estratégia PQ Variável / min Tensão.

\begin{tabular}{|c|c|c|c|c|c|c|c|c|c|}
\hline \multirow{2}{*}{$\begin{array}{l}\text { Tempo } \\
\text { (hora) }\end{array}$} & \multicolumn{2}{|c|}{$\begin{array}{c}\text { Pot. Ativa } \\
\text { dos Geradores (MW) }\end{array}$} & \multirow{2}{*}{$\begin{array}{c}\text { Potência Ativa } \\
\text { da Subestação } \\
\text { (MW) }\end{array}$} & \multicolumn{4}{|c|}{ Tensão da Rede (pu) } & \multirow{2}{*}{$\begin{array}{c}\text { Perdas de Energia } \\
\text { (MWh) }\end{array}$} & \multirow{2}{*}{$\begin{array}{c}\text { Valor Final } \\
\text { da } \\
\text { Funçao Objetivo }\end{array}$} \\
\hline & G1 & G2 & & mín & barra & máx & barra & & \\
\hline 1 & 6,667 & 5,960 & $-3,575$ & 0,9885 & 11 & 1,0093 & 12 & 0,11 & 0,0005027064 \\
\hline 2 & 5,236 & 3,791 & $-0,677$ & 0,9898 & 11 & 1,0111 & 12 & 0,07 & 0,0004071441 \\
\hline 3 & 4,799 & 6,308 & $-2,984$ & 0,9904 & 11 & 1,0057 & 12 & 0,07 & 0,0003536957 \\
\hline 4 & 4,120 & 2,585 & $-4,566$ & 0,9921 & 11 & 1,0075 & 12 & 0,10 & 0,0003414510 \\
\hline 5 & 5,174 & 6,499 & $-3,383$ & 0,9904 & 11 & 1,0057 & 12 & 0,08 & 0,0003536693 \\
\hline 6 & 6,668 & 7,409 & $-5,154$ & 0,9892 & 11 & 1,0103 & 12 & 0,11 & 0,0004829066 \\
\hline 7 & 4,559 & 6,739 & $-1,587$ & 0,9900 & 11 & 1,0104 & 12 & 0,10 & 0,0006802669 \\
\hline 8 & 10,901 & 10,522 & $-7,846$ & 0,9896 & 27 & 1,0105 & 12 & 0,27 & 0,0006396812 \\
\hline 9 & 12,034 & 13,872 & $-10,614$ & 0,9880 & 27 & 1,0096 & 12 & 0,37 & 0,0008721489 \\
\hline 10 & 10,548 & 13,872 & $-8,997$ & 0,9877 & 11 & 1,0132 & 12 & 0,32 & 0,0008987041 \\
\hline 11 & 10,854 & 13,872 & $-8,881$ & 0,9884 & 11 & 1,0139 & 12 & 0,32 & 0,0008730902 \\
\hline 12 & 10,322 & 13,872 & $-9,306$ & 0,9882 & 11 & 1,0137 & 12 & 0,32 & 0,0008457985 \\
\hline 13 & 10,201 & 13,243 & $-8,899$ & 0,9883 & 11 & 1,0139 & 12 & 0,30 & 0,0008021595 \\
\hline 14 & 10,923 & 13,872 & $-8,637$ & 0,9879 & 11 & 1,0133 & 12 & 0,33 & 0,0009360135 \\
\hline 15 & 11,101 & 13,872 & $-8,873$ & 0,9881 & 11 & 1,0137 & 12 & 0,33 & 0,0009154479 \\
\hline 16 & 11,797 & 13,872 & $-10,062$ & 0,9881 & 27 & 1,0094 & 12 & 0,36 & 0,0009082129 \\
\hline 17 & 11,316 & 13,872 & $-9,534$ & 0,9883 & 11 & 1,0138 & 12 & 0,34 & 0,0008735442 \\
\hline 18 & 12,441 & 13,698 & $-11,270$ & 0,9885 & 11 & 1,0137 & 12 & 0,40 & 0,0008603795 \\
\hline 19 & 10,910 & 13,872 & $-10,411$ & 0,9852 & 11 & 1,0158 & 12 & 0,37 & 0,0009892554 \\
\hline 20 & 12,816 & 13,835 & $-11,290$ & 0,9844 & 11 & 1,0143 & 18 & 0,45 & 0,0011514699 \\
\hline 21 & 12,013 & 13,020 & $-9,796$ & 0,9844 & 11 & 1,0142 & 12 & 0,40 & 0,0011943543 \\
\hline 22 & 10,860 & 13,086 & $-9,952$ & 0,9848 & 11 & 1,0151 & 12 & 0,37 & 0,0010195202 \\
\hline 23 & 10,603 & 13,084 & $-11,065$ & 0,9873 & 11 & 1,0151 & 18 & 0,36 & 0,0008759655 \\
\hline 24 & 7,696 & 8,184 & $-4,564$ & 0,9881 & 11 & 1,0137 & 12 & 0,18 & 0,0007418870 \\
\hline & & & & & & & & 6,43 & 0,0185194728 \\
\hline
\end{tabular}

Tabela A.10 - Resultados para a estratégia PQ Variável / min Perdas.

\begin{tabular}{|c|c|c|c|c|c|c|c|c|c|}
\hline \multirow{2}{*}{$\begin{array}{l}\text { Tempo } \\
\text { (hora) }\end{array}$} & \multicolumn{2}{|c|}{$\begin{array}{c}\text { Pot. Ativa } \\
\text { dos Geradores (MW) }\end{array}$} & \multirow{2}{*}{$\begin{array}{c}\text { Potência Ativa } \\
\text { da Subestação } \\
\text { (MW) }\end{array}$} & \multicolumn{4}{|c|}{ Tensão da Rede (pu) } & \multirow{2}{*}{$\begin{array}{c}\text { Perdas de Energia } \\
\text { (MWh) }\end{array}$} & \multirow{2}{*}{$\begin{array}{c}\text { Valor Final } \\
\text { da } \\
\text { Funçao Objetivo } \\
\end{array}$} \\
\hline & G1 & $\mathrm{G} 2$ & & mín & barra & máx & barra & & \\
\hline 1 & 3,865 & 4,439 & 0,712 & 1,00 & 1 & 1,0500 & 18 & 0,07 & 0,0725878740 \\
\hline 2 & 3,549 & 4,308 & 0,476 & 1,00 & 1 & 1,0485 & 12 & 0,06 & 0,0576114711 \\
\hline 3 & 3,436 & 4,190 & 0,475 & 1,00 & 1 & 1,0499 & 12 & 0,05 & 0,0525764298 \\
\hline 4 & 3,341 & 4,134 & 0,535 & 1,00 & 1 & 1,0500 & 12 & 0,05 & 0,0515097269 \\
\hline 5 & 3,515 & 4,225 & 0,523 & 1,00 & 1 & 1,0493 & 12 & 0,05 & 0,0533829124 \\
\hline 6 & 3,684 & 4,391 & 0,798 & 1,00 & 1 & 1,0500 & 12 & 0,06 & 0,0647523425 \\
\hline 7 & 4,279 & 4,817 & 0,595 & 1,00 & 1 & 1,0498 & 18 & 0,08 & 0,0841094919 \\
\hline 8 & 5,539 & 6,873 & 1,031 & 1,00 & 1 & 1,0492 & 12 & 0,13 & 0,1343093838 \\
\hline 9 & 6,077 & 7,819 & 1,194 & 1,00 & 1 & 1,0499 & 18 & 0,17 & 0,1656236273 \\
\hline 10 & 6,164 & 7,853 & 1,257 & 1,00 & 1 & 1,0497 & 12 & 0,17 & 0,1689376776 \\
\hline 11 & 6,247 & 8,205 & 1,246 & 1,00 & 1 & 1,0492 & 12 & 0,18 & 0,1776686910 \\
\hline 12 & 6,016 & 7,512 & 1,202 & 1,00 & 1 & 1,0464 & 12 & 0,16 & 0,1592008990 \\
\hline 13 & 5,986 & 7,168 & 1,243 & 1,00 & 1 & 1,0498 & 18 & 0,15 & 0,1513325032 \\
\hline 14 & 6,353 & 8,401 & 1,263 & 1,00 & 1 & 1,0499 & 12 & 0,19 & 0,1861155834 \\
\hline 15 & 6,044 & 8,389 & 1,518 & 1,00 & 1 & 1,0500 & 12 & 0,18 & 0,1828387474 \\
\hline 16 & 6,098 & 8,058 & 1,269 & 1,00 & 1 & 1,0500 & 12 & 0,17 & 0,1732255251 \\
\hline 17 & 6,207 & 8,051 & 1,227 & 1,00 & 1 & 1,0493 & 12 & 0,17 & 0,1748224145 \\
\hline 18 & 5,679 & 7,444 & 1,518 & 1,00 & 1 & 1,0500 & 12 & 0,17 & 0,1681539105 \\
\hline 19 & 5,995 & 7,336 & 0,857 & 1,00 & 1 & 1,0489 & 12 & 0,19 & 0,1870151684 \\
\hline 20 & 6,384 & 7,893 & 0,861 & 1,00 & 1 & 1,0500 & 12 & 0,22 & 0,2240525694 \\
\hline 21 & 6,462 & 7,678 & 0,924 & 1,00 & 1 & 1,0490 & 12 & 0,23 & 0,2254055539 \\
\hline 22 & 6,014 & 6,915 & 0,892 & 1,00 & 1 & 1,0485 & 18 & 0,19 & 0,1935985271 \\
\hline 23 & 5,402 & 6,219 & 0,798 & 1,00 & 1 & 1,0496 & 18 & 0,15 & 0,1537117949 \\
\hline 24 & 4,900 & 5,676 & 0,684 & 1,00 & 1 & 1,0490 & 18 & 0,13 & 0,1262611846 \\
\hline & & & & & & & & 3,37 & 3,3888040098 \\
\hline
\end{tabular}




\section{Anexo B}

\section{Dados do Sistema Elétrico}


Neste anexo estão os dados do sistema de distribuição de 42 barras utilizado no estudo (Figura 3.5). Os valores das potências ativas e reativas (cargas) estão apresentados nas Tabelas B.1 a B.6, enquanto que na Tabela B.7 são apresentados os dados dos ramos.

Tabela B.1 - Dados das barras do sistema de 42 barras durante o período de 1 às 4 horas.

\begin{tabular}{|c|c|c|c|c|c|c|c|c|}
\hline \multirow{2}{*}{$\begin{array}{c}\text { Número } \\
\text { da } \\
\text { barra }\end{array}$} & \multicolumn{2}{|c|}{ 01:00 } & \multicolumn{2}{|c|}{$02: 00$} & \multicolumn{2}{|c|}{ 03:00 } & \multicolumn{2}{|c|}{ 04:00 } \\
\hline & $\begin{array}{c}\text { Potência } \\
\text { ativa (MW) }\end{array}$ & $\begin{array}{c}\text { Potência } \\
\text { reativa (Mvar) }\end{array}$ & $\begin{array}{c}\text { Potência } \\
\text { ativa (MW) }\end{array}$ & $\begin{array}{c}\text { Potência } \\
\text { reativa (Mvar) }\end{array}$ & $\begin{array}{c}\text { Potência } \\
\text { ativa (MW) }\end{array}$ & $\begin{array}{c}\text { Potência } \\
\text { reativa (Mvar) }\end{array}$ & $\begin{array}{c}\text { Potência } \\
\text { ativa (MW) }\end{array}$ & \begin{tabular}{|c} 
Potência \\
reativa (Mvar)
\end{tabular} \\
\hline 1 & 0,0000 & 0,0000 & 0,0000 & 0,0000 & 0,0000 & 0,0000 & 0,0000 & 0,0000 \\
\hline 2 & 0,0000 & 0,0000 & 0,0000 & 0,0000 & 0,0000 & 0,0000 & 0,0000 & 0,0000 \\
\hline 3 & 0,0000 & 0,0000 & 0,0000 & 0,0000 & 0,0000 & 0,0000 & 0,0000 & 0,0000 \\
\hline 4 & 0,0000 & 0,0000 & 0,0000 & 0,0000 & 0,0000 & 0,0000 & 0,0000 & 0,0000 \\
\hline 5 & 0,0000 & 0,0000 & 0,0000 & 0,0000 & 0,0000 & 0,0000 & 0,0000 & 0,0000 \\
\hline 6 & 0,0000 & 0,0000 & 0,0000 & 0,0000 & 0,0000 & 0,0000 & 0,0000 & 0,0000 \\
\hline 7 & 0,0000 & 0,0000 & 0,0000 & 0,0000 & 0,0000 & 0,0000 & 0,0000 & 0,0000 \\
\hline 8 & 0,0000 & 0,0000 & 0,0000 & 0,0000 & 0,0000 & 0,0000 & 0,0000 & 0,0000 \\
\hline 9 & 0,6955 & 0,2293 & 0,6894 & 0,2273 & 0,6910 & 0,2278 & 0,6994 & 0,2306 \\
\hline 10 & 0,4162 & 0,1366 & 0,4127 & 0,1354 & 0,4225 & 0,1386 & 0,4197 & 0,1377 \\
\hline 11 & 0,0000 & 0,0000 & 0,0000 & 0,0000 & 0,0000 & 0,0000 & 0,0000 & 0,0000 \\
\hline 12 & 0,0571 & 0,0185 & 0,0615 & 0,0199 & 0,0620 & 0,0201 & 0,0583 & 0,0188 \\
\hline 13 & 0,0676 & 0,0225 & 0,0656 & 0,0219 & 0,0650 & 0,0217 & 0,0635 & 0,0212 \\
\hline 14 & 0,0373 & 0,0124 & 0,0265 & 0,0088 & 0,0220 & 0,0073 & 0,0209 & 0,0070 \\
\hline 15 & 0,0756 & 0,0252 & 0,0814 & 0,0271 & 0,0821 & 0,0274 & 0,0771 & 0,0257 \\
\hline 16 & 0,0000 & 0,0000 & 0,0000 & 0,0000 & 0,0000 & 0,0000 & 0,0000 & 0,0000 \\
\hline 17 & 0,0000 & 0,0000 & 0,0000 & 0,0000 & 0,0000 & 0,0000 & 0,0000 & 0,0000 \\
\hline 18 & 0,1691 & 0,0585 & 0,1677 & 0,0580 & 0,1716 & 0,0594 & 0,1705 & 0,0590 \\
\hline 19 & 1,6127 & 0,5274 & 1,5984 & 0,5227 & 1,6023 & 0,5240 & 1,6217 & 0,5303 \\
\hline 20 & 0,2545 & 0,0837 & 0,2470 & 0,0813 & 0,2447 & 0,0805 & 0,2389 & 0,0786 \\
\hline 21 & 0,0373 & 0,0124 & 0,0265 & 0,0088 & 0,0220 & 0,0073 & 0,0209 & 0,0070 \\
\hline 22 & 0,3318 & 0,1095 & 0,3220 & 0,1063 & 0,3190 & 0,1053 & 0,3115 & 0,1028 \\
\hline 23 & 0,9151 & 0,3023 & 0,6510 & 0,2150 & 0,5395 & 0,1782 & 0,5125 & 0,1693 \\
\hline 24 & 0,0000 & 0,0000 & 0,0000 & 0,0000 & 0,0000 & 0,0000 & 0,0000 & 0,0000 \\
\hline 25 & 0,0000 & 0,0000 & 0,0000 & 0,0000 & 0,0000 & 0,0000 & 0,0000 & 0,0000 \\
\hline 26 & 0,0064 & 0,0032 & 0,0063 & 0,0031 & 0,0062 & 0,0031 & 0,0060 & 0,0030 \\
\hline 27 & 1,2841 & 0,4204 & 1,2727 & 0,4166 & 1,2757 & 0,4176 & 1,2912 & 0,4227 \\
\hline 28 & 1,0341 & 0,3382 & 1,0254 & 0,3353 & 1,0496 & 0,3433 & 1,0427 & 0,3410 \\
\hline 29 & 0,4164 & 0,1360 & 0,4488 & 0,1466 & 0,4523 & 0,1477 & 0,4249 & 0,1388 \\
\hline 30 & 0,0097 & 0,0032 & 0,0094 & 0,0031 & 0,0093 & 0,0031 & 0,0091 & 0,0030 \\
\hline 31 & 0,0538 & 0,0166 & 0,0383 & 0,0118 & 0,0317 & 0,0098 & 0,0301 & 0,0093 \\
\hline 32 & 0,1997 & 0,0644 & 0,1938 & 0,0625 & 0,1920 & 0,0619 & 0,1875 & 0,0605 \\
\hline 33 & 0,0000 & 0,0000 & 0,0000 & 0,0000 & 0,0000 & 0,0000 & 0,0000 & 0,0000 \\
\hline 34 & 0,3395 & 0,1118 & 0,2415 & 0,0795 & 0,2002 & 0,0659 & 0,1902 & 0,0626 \\
\hline 35 & 0,1063 & 0,0354 & 0,1032 & 0,0344 & 0,1022 & 0,0341 & 0,0998 & 0,0333 \\
\hline 36 & 0,0000 & 0,0000 & 0,0000 & 0,0000 & 0,0000 & 0,0000 & 0,0000 & 0,0000 \\
\hline 37 & 0,8240 & 0,2691 & 0,5862 & 0,1915 & 0,4858 & 0,1587 & 0,4615 & 0,1507 \\
\hline 38 & 0,0000 & 0,0000 & 0,0000 & 0,0000 & 0,0000 & 0,0000 & 0,0000 & 0,0000 \\
\hline 39 & 0,0000 & 0,0000 & 0,0000 & 0,0000 & 0,0000 & 0,0000 & 0,0000 & 0,0000 \\
\hline 40 & 0,0000 & 0,0000 & 0,0000 & 0,0000 & 0,0000 & 0,0000 & 0,0000 & 0,0000 \\
\hline 41 & 0,0000 & 0,0000 & 0,0000 & 0,0000 & 0,0000 & 0,0000 & 0,0000 & 0,0000 \\
\hline 42 & 0,0000 & 0,0000 & 0,0000 & 0,0000 & 0,0000 & 0,0000 & 0,0000 & 0,0000 \\
\hline
\end{tabular}


Tabela B.2 - Dados das barras do sistema de 42 barras durante o período de 5 às 8 horas.

\begin{tabular}{|c|c|c|c|c|c|c|c|c|}
\hline \multirow{2}{*}{$\begin{array}{c}\text { Número } \\
\text { da } \\
\text { barra }\end{array}$} & \multicolumn{2}{|c|}{ 05:00 } & \multicolumn{2}{|c|}{$06: 00$} & \multicolumn{2}{|c|}{ 07:00 } & \multicolumn{2}{|c|}{ 08:00 } \\
\hline & \begin{tabular}{|} 
Potência \\
ativa (MW)
\end{tabular} & $\begin{array}{c}\text { Potência } \\
\text { reativa (Mvar) }\end{array}$ & $\begin{array}{c}\text { Potência } \\
\text { ativa (MW) }\end{array}$ & $\begin{array}{c}\text { Potência } \\
\text { reativa (Mvar) }\end{array}$ & $\begin{array}{c}\text { Potência } \\
\text { ativa (MW) }\end{array}$ & $\begin{array}{c}\text { Potência } \\
\text { reativa (Mvar) }\end{array}$ & $\begin{array}{c}\text { Potência } \\
\text { ativa (MW) }\end{array}$ & $\begin{array}{c}\text { Potência } \\
\text { reativa (Mvar) }\end{array}$ \\
\hline 1 & 0,0000 & 0,0000 & 0,0000 & 0,0000 & 0,0000 & 0,0000 & 0,0000 & 0,0000 \\
\hline 2 & 0,0000 & 0,0000 & 0,0000 & 0,0000 & 0,0000 & 0,0000 & 0,0000 & 0,0000 \\
\hline 3 & 0,0000 & 0,0000 & 0,0000 & 0,0000 & 0,0000 & 0,0000 & 0,0000 & 0,0000 \\
\hline 4 & 0,0000 & 0,0000 & 0,0000 & 0,0000 & 0,0000 & 0,0000 & 0,0000 & 0,0000 \\
\hline 5 & 0,0000 & 0,0000 & 0,0000 & 0,0000 & 0,0000 & 0,0000 & 0,0000 & 0,0000 \\
\hline 6 & 0,0000 & 0,0000 & 0,0000 & 0,0000 & 0,0000 & 0,0000 & 0,0000 & 0,0000 \\
\hline 7 & 0,0000 & 0,0000 & 0,0000 & 0,0000 & 0,0000 & 0,0000 & 0,0000 & 0,0000 \\
\hline 8 & 0,0000 & 0,0000 & 0,0000 & 0,0000 & 0,0000 & 0,0000 & 0,0000 & 0,0000 \\
\hline 9 & 0,7048 & 0,2323 & 0,7951 & 0,2621 & 0,8671 & 0,2859 & 0,8881 & 0,2928 \\
\hline 10 & 0,4083 & 0,1340 & 0,4094 & 0,1343 & 0,4052 & 0,1330 & 0,5103 & 0,1674 \\
\hline 11 & 0,0000 & 0,0000 & 0,0000 & 0,0000 & 0,0000 & 0,0000 & 0,0000 & 0,0000 \\
\hline 12 & 0,0672 & 0,0218 & 0,0541 & 0,0175 & 0,0388 & 0,0126 & 0,2084 & 0,0674 \\
\hline 13 & 0,0751 & 0,0250 & 0,0797 & 0,0266 & 0,0812 & 0,0271 & 0,1638 & 0,0546 \\
\hline 14 & 0,0211 & 0,0070 & 0,0243 & 0,0081 & 0,0339 & 0,0113 & 0,0400 & 0,0133 \\
\hline 15 & 0,0890 & 0,0297 & 0,0717 & 0,0239 & 0,0514 & 0,0171 & 0,2758 & 0,0919 \\
\hline 16 & 0,0000 & 0,0000 & 0,0000 & 0,0000 & 0,0000 & 0,0000 & 0,0000 & 0,0000 \\
\hline 17 & 0,0000 & 0,0000 & 0,0000 & 0,0000 & 0,0000 & 0,0000 & 0,0000 & 0,0000 \\
\hline 18 & 0,1659 & 0,0574 & 0,1663 & 0,0576 & 0,1646 & 0,0570 & 0,2073 & 0,0718 \\
\hline 19 & 1,6342 & 0,5344 & 1,8437 & 0,6029 & 2,0106 & 0,6575 & 2,0593 & 0,6734 \\
\hline 20 & 0,2825 & 0,0930 & 0,2998 & 0,0987 & 0,3055 & 0,1005 & 0,6163 & 0,2028 \\
\hline 21 & 0,0211 & 0,0070 & 0,0243 & 0,0081 & 0,0339 & 0,0113 & 0,0400 & 0,0133 \\
\hline 22 & 0,3683 & 0,1216 & 0,3908 & 0,1290 & 0,3983 & 0,1315 & 0,8035 & 0,2652 \\
\hline 23 & 0,5189 & 0,1714 & 0,5966 & 0,1971 & 0,8320 & 0,2748 & 0,9819 & 0,3243 \\
\hline 24 & 0,0000 & 0,0000 & 0,0000 & 0,0000 & 0,0000 & 0,0000 & 0,0000 & 0,0000 \\
\hline 25 & 0,0000 & 0,0000 & 0,0000 & 0,0000 & 0,0000 & 0,0000 & 0,0000 & 0,0000 \\
\hline 26 & 0,0072 & 0,0036 & 0,0076 & 0,0038 & 0,0077 & 0,0039 & 0,0156 & 0,0078 \\
\hline 27 & 1,3011 & 0,4260 & 1,4680 & 0,4806 & 1,6008 & 0,5241 & 1,6396 & 0,5368 \\
\hline 28 & 1,0143 & 0,3317 & 1,0170 & 0,3326 & 1,0067 & 0,3292 & 1,2678 & 0,4146 \\
\hline 29 & 0,4904 & 0,1602 & 0,3949 & 0,1290 & 0,2831 & 0,0925 & 1,5200 & 0,4964 \\
\hline 30 & 0,0107 & 0,0036 & 0,0114 & 0,0038 & 0,0116 & 0,0039 & 0,0234 & 0,0078 \\
\hline 31 & 0,0305 & 0,0094 & 0,0351 & 0,0108 & 0,0489 & 0,0151 & 0,0578 & 0,0178 \\
\hline 32 & 0,2217 & 0,0715 & 0,2353 & 0,0759 & 0,2397 & 0,0773 & 0,4836 & 0,1560 \\
\hline 33 & 0,0000 & 0,0000 & 0,0000 & 0,0000 & 0,0000 & 0,0000 & 0,0000 & 0,0000 \\
\hline 34 & 0,1925 & 0,0634 & 0,2214 & 0,0729 & 0,3087 & 0,1016 & 0,3643 & 0,1200 \\
\hline 35 & 0,1180 & 0,0393 & 0,1252 & 0,0417 & 0,1276 & 0,0425 & 0,2574 & 0,0858 \\
\hline 36 & 0,0000 & 0,0000 & 0,0000 & 0,0000 & 0,0000 & 0,0000 & 0,0000 & 0,0000 \\
\hline 37 & 0,4672 & 0,1526 & 0,5372 & 0,1755 & 0,7492 & 0,2447 & 0,8842 & 0,2888 \\
\hline 38 & 0,0000 & 0,0000 & 0,0000 & 0,0000 & 0,0000 & 0,0000 & 0,0000 & 0,0000 \\
\hline 39 & 0,0000 & 0,0000 & 0,0000 & 0,0000 & 0,0000 & 0,0000 & 0,0000 & 0,0000 \\
\hline 40 & 0,0000 & 0,0000 & 0,0000 & 0,0000 & 0,0000 & 0,0000 & 0,0000 & 0,0000 \\
\hline 41 & 0,0000 & 0,0000 & 0,0000 & 0,0000 & 0,0000 & 0,0000 & 0,0000 & 0,0000 \\
\hline 42 & 0,0000 & 0,0000 & 0,0000 & 0,0000 & 0,0000 & 0,0000 & 0,0000 & 0,0000 \\
\hline
\end{tabular}


Tabela B.3 - Dados das barras do sistema de 42 barras durante o período de 9 às 12 horas.

\begin{tabular}{|c|c|c|c|c|c|c|c|c|}
\hline \multirow{2}{*}{$\begin{array}{c}\text { Número } \\
\text { da } \\
\text { barra }\end{array}$} & \multicolumn{2}{|c|}{ 09:00 } & \multicolumn{2}{|c|}{$10: 00$} & \multicolumn{2}{|c|}{$11: 00$} & \multicolumn{2}{|c|}{$12: 00$} \\
\hline & $\begin{array}{l}\text { Potência } \\
\text { ativa (MW) }\end{array}$ & \begin{tabular}{|c|} 
Potência \\
reativa (Mvar)
\end{tabular} & $\begin{array}{c}\text { Potência } \\
\text { ativa (MW) }\end{array}$ & \begin{tabular}{|c|} 
Potência \\
reativa (Mvar)
\end{tabular} & $\begin{array}{c}\text { Potência } \\
\text { ativa (MW) }\end{array}$ & \begin{tabular}{|c|} 
Potência \\
reativa (Mvar)
\end{tabular} & $\begin{array}{c}\text { Potência } \\
\text { ativa (MW) }\end{array}$ & \begin{tabular}{|c} 
Potência \\
reativa (Mvar)
\end{tabular} \\
\hline 1 & 0,0000 & 0,0000 & 0,0000 & 0,0000 & 0,0000 & 0,0000 & 0,0000 & 0,0000 \\
\hline 2 & 0,0000 & 0,0000 & 0,0000 & 0,0000 & 0,0000 & 0,0000 & 0,0000 & 0,0000 \\
\hline 3 & 0,0000 & 0,0000 & 0,0000 & 0,0000 & 0,0000 & 0,0000 & 0,0000 & 0,0000 \\
\hline 4 & 0,0000 & 0,0000 & 0,0000 & 0,0000 & 0,0000 & 0,0000 & 0,0000 & 0,0000 \\
\hline 5 & 0,0000 & 0,0000 & 0,0000 & 0,0000 & 0,0000 & 0,0000 & 0,0000 & 0,0000 \\
\hline 6 & 0,0000 & 0,0000 & 0,0000 & 0,0000 & 0,0000 & 0,0000 & 0,0000 & 0,0000 \\
\hline 7 & 0,0000 & 0,0000 & 0,0000 & 0,0000 & 0,0000 & 0,0000 & 0,0000 & 0,0000 \\
\hline 8 & 0,0000 & 0,0000 & 0,0000 & 0,0000 & 0,0000 & 0,0000 & 0,0000 & 0,0000 \\
\hline 9 & 0,9045 & 0,2982 & 0,8899 & 0,2934 & 0,8735 & 0,2880 & 0,8860 & 0,2921 \\
\hline 10 & 0,5499 & 0,1804 & 0,5310 & 0,1742 & 0,6178 & 0,2027 & 0,5087 & 0,1669 \\
\hline 11 & 0,0000 & 0,0000 & 0,0000 & 0,0000 & 0,0000 & 0,0000 & 0,0000 & 0,0000 \\
\hline 12 & 0,2924 & 0,0946 & 0,2941 & 0,0951 & 0,3097 & 0,1002 & 0,2573 & 0,0832 \\
\hline 13 & 0,1920 & 0,0640 & 0,2042 & 0,0681 & 0,2003 & 0,0668 & 0,1957 & 0,0652 \\
\hline 14 & 0,0427 & 0,0142 & 0,0451 & 0,0150 & 0,0462 & 0,0154 & 0,0459 & 0,0153 \\
\hline 15 & 0,3870 & 0,1290 & 0,3892 & 0,1297 & 0,4099 & 0,1366 & 0,3405 & 0,1135 \\
\hline 16 & 0,0000 & 0,0000 & 0,0000 & 0,0000 & 0,0000 & 0,0000 & 0,0000 & 0,0000 \\
\hline 17 & 0,0000 & 0,0000 & 0,0000 & 0,0000 & 0,0000 & 0,0000 & 0,0000 & 0,0000 \\
\hline 18 & 0,2234 & 0,0773 & 0,2157 & 0,0747 & 0,2510 & 0,0869 & 0,2067 & 0,0715 \\
\hline 19 & 2,0972 & 0,6858 & 2,0634 & 0,6748 & 2,0253 & 0,6623 & 2,0543 & 0,6718 \\
\hline 20 & 0,7222 & 0,2377 & 0,7681 & 0,2528 & 0,7536 & 0,2480 & 0,7363 & 0,2423 \\
\hline 21 & 0,0427 & 0,0142 & 0,0451 & 0,0150 & 0,0462 & 0,0154 & 0,0459 & 0,0153 \\
\hline 22 & 0,9416 & 0,3108 & 1,0014 & 0,3306 & 0,9825 & 0,3243 & 0,9600 & 0,3169 \\
\hline 23 & 1,0494 & 0,3466 & 1,1063 & 0,3654 & 1,1345 & 0,3747 & 1,1268 & 0,3722 \\
\hline 24 & 0,0000 & 0,0000 & 0,0000 & 0,0000 & 0,0000 & 0,0000 & 0,0000 & 0,0000 \\
\hline 25 & 0,0000 & 0,0000 & 0,0000 & 0,0000 & 0,0000 & 0,0000 & 0,0000 & 0,0000 \\
\hline 26 & 0,0183 & 0,0091 & 0,0194 & 0,0097 & 0,0191 & 0,0095 & 0,0186 & 0,0093 \\
\hline 27 & 1,6698 & 0,5467 & 1,6429 & 0,5379 & 1,6126 & 0,5279 & 1,6357 & 0,5355 \\
\hline 28 & 1,3662 & 0,4468 & 1,3192 & 0,4314 & 1,5349 & 0,5020 & 1,2638 & 0,4133 \\
\hline 29 & 2,1331 & 0,6967 & 2,1451 & 0,7006 & 2,2592 & 0,7379 & 1,8768 & 0,6130 \\
\hline 30 & 0,0274 & 0,0091 & 0,0292 & 0,0097 & 0,0286 & 0,0095 & 0,0280 & 0,0093 \\
\hline 31 & 0,0617 & 0,0190 & 0,0651 & 0,0200 & 0,0667 & 0,0205 & 0,0663 & 0,0204 \\
\hline 32 & 0,5668 & 0,1828 & 0,6028 & 0,1945 & 0,5914 & 0,1908 & 0,5779 & 0,1864 \\
\hline 33 & 0,0000 & 0,0000 & 0,0000 & 0,0000 & 0,0000 & 0,0000 & 0,0000 & 0,0000 \\
\hline 34 & 0,3894 & 0,1282 & 0,4105 & 0,1352 & 0,4210 & 0,1386 & 0,4181 & 0,1377 \\
\hline 35 & 0,3017 & 0,1006 & 0,3208 & 0,1069 & 0,3148 & 0,1049 & 0,3076 & 0,1025 \\
\hline 36 & 0,0000 & 0,0000 & 0,0000 & 0,0000 & 0,0000 & 0,0000 & 0,0000 & 0,0000 \\
\hline 37 & 0,9449 & 0,3086 & 0,9962 & 0,3254 & 1,0216 & 0,3337 & 1,0146 & 0,3314 \\
\hline 38 & 0,0000 & 0,0000 & 0,0000 & 0,0000 & 0,0000 & 0,0000 & 0,0000 & 0,0000 \\
\hline 39 & 0,0000 & 0,0000 & 0,0000 & 0,0000 & 0,0000 & 0,0000 & 0,0000 & 0,0000 \\
\hline 40 & 0,0000 & 0,0000 & 0,0000 & 0,0000 & 0,0000 & 0,0000 & 0,0000 & 0,0000 \\
\hline 41 & 0,0000 & 0,0000 & 0,0000 & 0,0000 & 0,0000 & 0,0000 & 0,0000 & 0,0000 \\
\hline 42 & 0,0000 & 0,0000 & 0,0000 & 0,0000 & 0,0000 & 0,0000 & 0,0000 & 0,0000 \\
\hline
\end{tabular}


Tabela B.4 - Dados das barras do sistema de 42 barras durante o período de 13 às 16 horas.

\begin{tabular}{|c|c|c|c|c|c|c|c|c|}
\hline \multirow{2}{*}{$\begin{array}{c}\text { Número } \\
\text { da } \\
\text { barra }\end{array}$} & \multicolumn{2}{|c|}{$13: 00$} & \multicolumn{2}{|c|}{$14: 00$} & \multicolumn{2}{|c|}{$15: 00$} & \multicolumn{2}{|c|}{$16: 00$} \\
\hline & \begin{tabular}{|} 
Potência \\
ativa (MW)
\end{tabular} & $\begin{array}{c}\text { Potência } \\
\text { reativa (Mvar) }\end{array}$ & $\begin{array}{c}\text { Potência } \\
\text { ativa (MW) }\end{array}$ & $\begin{array}{c}\text { Potência } \\
\text { reativa (Mvar) }\end{array}$ & \begin{tabular}{|} 
Potência \\
ativa (MW)
\end{tabular} & $\begin{array}{c}\text { Potência } \\
\text { reativa (Mvar) }\end{array}$ & $\begin{array}{c}\text { Potência } \\
\text { ativa (MW) }\end{array}$ & $\begin{array}{c}\text { Potência } \\
\text { reativa (Mvar) }\end{array}$ \\
\hline 1 & 0,0000 & 0,0000 & 0,0000 & 0,0000 & 0,0000 & 0,0000 & 0,0000 & 0,0000 \\
\hline 2 & 0,0000 & 0,0000 & 0,0000 & 0,0000 & 0,0000 & 0,0000 & 0,0000 & 0,0000 \\
\hline 3 & 0,0000 & 0,0000 & 0,0000 & 0,0000 & 0,0000 & 0,0000 & 0,0000 & 0,0000 \\
\hline 4 & 0,0000 & 0,0000 & 0,0000 & 0,0000 & 0,0000 & 0,0000 & 0,0000 & 0,0000 \\
\hline 5 & 0,0000 & 0,0000 & 0,0000 & 0,0000 & 0,0000 & 0,0000 & 0,0000 & 0,0000 \\
\hline 6 & 0,0000 & 0,0000 & 0,0000 & 0,0000 & 0,0000 & 0,0000 & 0,0000 & 0,0000 \\
\hline 7 & 0,0000 & 0,0000 & 0,0000 & 0,0000 & 0,0000 & 0,0000 & 0,0000 & 0,0000 \\
\hline 8 & 0,0000 & 0,0000 & 0,0000 & 0,0000 & 0,0000 & 0,0000 & 0,0000 & 0,0000 \\
\hline 9 & 0,8928 & 0,2943 & 0,8956 & 0,2952 & 0,8926 & 0,2943 & 0,8896 & 0,2933 \\
\hline 10 & 0,5105 & 0,1675 & 0,6054 & 0,1986 & 0,6338 & 0,2080 & 0,5413 & 0,1776 \\
\hline 11 & 0,0000 & 0,0000 & 0,0000 & 0,0000 & 0,0000 & 0,0000 & 0,0000 & 0,0000 \\
\hline 12 & 0,2008 & 0,0650 & 0,3359 & 0,1087 & 0,3324 & 0,1075 & 0,3306 & 0,1069 \\
\hline 13 & 0,2036 & 0,0679 & 0,2020 & 0,0673 & 0,2005 & 0,0668 & 0,1963 & 0,0654 \\
\hline 14 & 0,0469 & 0,0156 & 0,0457 & 0,0152 & 0,0439 & 0,0146 & 0,0429 & 0,0143 \\
\hline 15 & 0,2658 & 0,0886 & 0,4446 & 0,1482 & 0,4399 & 0,1466 & 0,4375 & 0,1458 \\
\hline 16 & 0,0000 & 0,0000 & 0,0000 & 0,0000 & 0,0000 & 0,0000 & 0,0000 & 0,0000 \\
\hline 17 & 0,0000 & 0,0000 & 0,0000 & 0,0000 & 0,0000 & 0,0000 & 0,0000 & 0,0000 \\
\hline 18 & 0,2074 & 0,0718 & 0,2459 & 0,0851 & 0,2575 & 0,0891 & 0,2199 & 0,0761 \\
\hline 19 & 2,0700 & 0,6769 & 2,0766 & 0,6791 & 2,0697 & 0,6768 & 2,0626 & 0,6745 \\
\hline 20 & 0,7661 & 0,2521 & 0,7597 & 0,2500 & 0,7544 & 0,2483 & 0,7386 & 0,2431 \\
\hline 21 & 0,0469 & 0,0156 & 0,0457 & 0,0152 & 0,0439 & 0,0146 & 0,0429 & 0,0143 \\
\hline 22 & 0,9988 & 0,3297 & 0,9905 & 0,3270 & 0,9836 & 0,3247 & 0,9630 & 0,3179 \\
\hline 23 & 1,1521 & 0,3805 & 1,1218 & 0,3705 & 1,0789 & 0,3564 & 1,0527 & 0,3477 \\
\hline 24 & 0,0000 & 0,0000 & 0,0000 & 0,0000 & 0,0000 & 0,0000 & 0,0000 & 0,0000 \\
\hline 25 & 0,0000 & 0,0000 & 0,0000 & 0,0000 & 0,0000 & 0,0000 & 0,0000 & 0,0000 \\
\hline 26 & 0,0194 & 0,0097 & 0,0192 & 0,0096 & 0,0191 & 0,0095 & 0,0187 & 0,0093 \\
\hline 27 & 1,6482 & 0,5396 & 1,6534 & 0,5413 & 1,6479 & 0,5395 & 1,6423 & 0,5376 \\
\hline 28 & 1,2682 & 0,4147 & 1,5039 & 0,4918 & 1,5747 & 0,5150 & 1,3449 & 0,4398 \\
\hline 29 & 1,4649 & 0,4785 & 2,4501 & 0,8002 & 2,4245 & 0,7919 & 2,4111 & 0,7875 \\
\hline 30 & 0,0291 & 0,0097 & 0,0289 & 0,0096 & 0,0286 & 0,0095 & 0,0280 & 0,0093 \\
\hline 31 & 0,0678 & 0,0209 & 0,0660 & 0,0203 & 0,0635 & 0,0195 & 0,0619 & 0,0191 \\
\hline 32 & 0,6012 & 0,1939 & 0,5962 & 0,1923 & 0,5920 & 0,1910 & 0,5797 & 0,1870 \\
\hline 33 & 0,0000 & 0,0000 & 0,0000 & 0,0000 & 0,0000 & 0,0000 & 0,0000 & 0,0000 \\
\hline 34 & 0,4275 & 0,1407 & 0,4162 & 0,1370 & 0,4003 & 0,1318 & 0,3906 & 0,1286 \\
\hline 35 & 0,3200 & 0,1067 & 0,3174 & 0,1058 & 0,3151 & 0,1050 & 0,3085 & 0,1028 \\
\hline 36 & 0,0000 & 0,0000 & 0,0000 & 0,0000 & 0,0000 & 0,0000 & 0,0000 & 0,0000 \\
\hline 37 & 1,0374 & 0,3388 & 1,0101 & 0,3299 & 0,9715 & 0,3173 & 0,9479 & 0,3096 \\
\hline 38 & 0,0000 & 0,0000 & 0,0000 & 0,0000 & 0,0000 & 0,0000 & 0,0000 & 0,0000 \\
\hline 39 & 0,0000 & 0,0000 & 0,0000 & 0,0000 & 0,0000 & 0,0000 & 0,0000 & 0,0000 \\
\hline 40 & 0,0000 & 0,0000 & 0,0000 & 0,0000 & 0,0000 & 0,0000 & 0,0000 & 0,0000 \\
\hline 41 & 0,0000 & 0,0000 & 0,0000 & 0,0000 & 0,0000 & 0,0000 & 0,0000 & 0,0000 \\
\hline 42 & 0,0000 & 0,0000 & 0,0000 & 0,0000 & 0,0000 & 0,0000 & 0,0000 & 0,0000 \\
\hline
\end{tabular}


Tabela B.5 - Dados das barras do sistema de 42 barras durante o período de 17 às 20 horas.

\begin{tabular}{|c|c|c|c|c|c|c|c|c|}
\hline \multirow{2}{*}{$\begin{array}{c}\text { Número } \\
\text { da } \\
\text { barra }\end{array}$} & \multicolumn{2}{|c|}{$17: 00$} & \multicolumn{2}{|c|}{$18: 00$} & \multicolumn{2}{|c|}{$19: 00$} & \multicolumn{2}{|c|}{ 20:00 } \\
\hline & $\begin{array}{c}\text { Potência } \\
\text { ativa (MW) }\end{array}$ & $\begin{array}{c}\text { Potência } \\
\text { reativa (Mvar) }\end{array}$ & $\begin{array}{c}\text { Potência } \\
\text { ativa (MW) }\end{array}$ & $\begin{array}{c}\text { Potência } \\
\text { reativa (Mvar) }\end{array}$ & $\begin{array}{c}\text { Potência } \\
\text { ativa (MW) }\end{array}$ & $\begin{array}{c}\text { Potência } \\
\text { reativa (Mvar) }\end{array}$ & $\begin{array}{c}\text { Potência } \\
\text { ativa (MW) }\end{array}$ & $\begin{array}{c}\text { Potência } \\
\text { reativa (Mvar) }\end{array}$ \\
\hline 1 & 0,0000 & 0,0000 & 0,0000 & 0,0000 & 0,0000 & 0,0000 & 0,0000 & 0,0000 \\
\hline 2 & 0,0000 & 0,0000 & 0,0000 & 0,0000 & 0,0000 & 0,0000 & 0,0000 & 0,0000 \\
\hline 3 & 0,0000 & 0,0000 & 0,0000 & 0,0000 & 0,0000 & 0,0000 & 0,0000 & 0,0000 \\
\hline 4 & 0,0000 & 0,0000 & 0,0000 & 0,0000 & 0,0000 & 0,0000 & 0,0000 & 0,0000 \\
\hline 5 & 0,0000 & 0,0000 & 0,0000 & 0,0000 & 0,0000 & 0,0000 & 0,0000 & 0,0000 \\
\hline 6 & 0,0000 & 0,0000 & 0,0000 & 0,0000 & 0,0000 & 0,0000 & 0,0000 & 0,0000 \\
\hline 7 & 0,0000 & 0,0000 & 0,0000 & 0,0000 & 0,0000 & 0,0000 & 0,0000 & 0,0000 \\
\hline 8 & 0,0000 & 0,0000 & 0,0000 & 0,0000 & 0,0000 & 0,0000 & 0,0000 & 0,0000 \\
\hline 9 & 0,8880 & 0,2928 & 0,8765 & 0,2889 & 0,8563 & 0,2823 & 0,8579 & 0,2828 \\
\hline 10 & 0,5771 & 0,1894 & 0,4406 & 0,1446 & 0,4043 & 0,1327 & 0,4074 & 0,1337 \\
\hline 11 & 0,0000 & 0,0000 & 0,0000 & 0,0000 & 0,0000 & 0,0000 & 0,0000 & 0,0000 \\
\hline 12 & 0,3010 & 0,0974 & 0,2421 & 0,0783 & 0,1891 & 0,0612 & 0,2074 & 0,0671 \\
\hline 13 & 0,1970 & 0,0657 & 0,1818 & 0,0606 & 0,1273 & 0,0424 & 0,1241 & 0,0414 \\
\hline 14 & 0,0463 & 0,0154 & 0,0554 & 0,0185 & 0,0735 & 0,0245 & 0,0863 & 0,0288 \\
\hline 15 & 0,3984 & 0,1328 & 0,3204 & 0,1068 & 0,2503 & 0,0834 & 0,2746 & 0,0915 \\
\hline 16 & 0,0000 & 0,0000 & 0,0000 & 0,0000 & 0,0000 & 0,0000 & 0,0000 & 0,0000 \\
\hline 17 & 0,0000 & 0,0000 & 0,0000 & 0,0000 & 0,0000 & 0,0000 & 0,0000 & 0,0000 \\
\hline 18 & 0,2344 & 0,0812 & 0,1790 & 0,0620 & 0,1642 & 0,0569 & 0,1655 & 0,0573 \\
\hline 19 & 2,0591 & 0,6733 & 2,0322 & 0,6646 & 1,9856 & 0,6493 & 1,9891 & 0,6505 \\
\hline 20 & 0,7409 & 0,2439 & 0,6838 & 0,2251 & 0,4787 & 0,1576 & 0,4670 & 0,1537 \\
\hline 21 & 0,0463 & 0,0154 & 0,0554 & 0,0185 & 0,0735 & 0,0245 & 0,0863 & 0,0288 \\
\hline 22 & 0,9660 & 0,3189 & 0,8916 & 0,2943 & 0,6242 & 0,2060 & 0,6088 & 0,2010 \\
\hline 23 & 1,1366 & 0,3754 & 1,3604 & 0,4493 & 1,8036 & 0,5958 & 2,1194 & 0,7001 \\
\hline 24 & 0,0000 & 0,0000 & 0,0000 & 0,0000 & 0,0000 & 0,0000 & 0,0000 & 0,0000 \\
\hline 25 & 0,0000 & 0,0000 & 0,0000 & 0,0000 & 0,0000 & 0,0000 & 0,0000 & 0,0000 \\
\hline 26 & 0,0188 & 0,0094 & 0,0173 & 0,0087 & 0,0121 & 0,0061 & 0,0118 & 0,0059 \\
\hline 27 & 1,6395 & 0,5367 & 1,6181 & 0,5297 & 1,5809 & 0,5176 & 1,5838 & 0,5185 \\
\hline 28 & 1,4337 & 0,4689 & 1,0947 & 0,3580 & 1,0044 & 0,3285 & 1,0122 & 0,3310 \\
\hline 29 & 2,1958 & 0,7172 & 1,7658 & 0,5767 & 1,3792 & 0,4505 & 1,5132 & 0,4942 \\
\hline 30 & 0,0281 & 0,0094 & 0,0260 & 0,0087 & 0,0182 & 0,0061 & 0,0177 & 0,0059 \\
\hline 31 & 0,0669 & 0,0206 & 0,0800 & 0,0246 & 0,1061 & 0,0326 & 0,1247 & 0,0384 \\
\hline 32 & 0,5815 & 0,1876 & 0,5367 & 0,1731 & 0,3757 & 0,1212 & 0,3665 & 0,1182 \\
\hline 33 & 0,0000 & 0,0000 & 0,0000 & 0,0000 & 0,0000 & 0,0000 & 0,0000 & 0,0000 \\
\hline 34 & 0,4217 & 0,1389 & 0,5048 & 0,1662 & 0,6692 & 0,2204 & 0,7864 & 0,2589 \\
\hline 35 & 0,3095 & 0,1032 & 0,2856 & 0,0952 & 0,2000 & 0,0667 & 0,1951 & 0,0650 \\
\hline 36 & 0,0000 & 0,0000 & 0,0000 & 0,0000 & 0,0000 & 0,0000 & 0,0000 & 0,0000 \\
\hline 37 & 1,0235 & 0,3343 & 1,2250 & 0,4001 & 1,6241 & 0,5305 & 1,9084 & 0,6233 \\
\hline 38 & 0,0000 & 0,0000 & 0,0000 & 0,0000 & 0,0000 & 0,0000 & 0,0000 & 0,0000 \\
\hline 39 & 0,0000 & 0,0000 & 0,0000 & 0,0000 & 0,0000 & 0,0000 & 0,0000 & 0,0000 \\
\hline 40 & 0,0000 & 0,0000 & 0,0000 & 0,0000 & 0,0000 & 0,0000 & 0,0000 & 0,0000 \\
\hline 41 & 0,0000 & 0,0000 & 0,0000 & 0,0000 & 0,0000 & 0,0000 & 0,0000 & 0,0000 \\
\hline 42 & 0,0000 & 0,0000 & 0,0000 & 0,0000 & 0,0000 & 0,0000 & 0,0000 & 0,0000 \\
\hline
\end{tabular}


Tabela B.6 - Dados das barras do sistema de 42 barras durante o período de 21 às 24 horas.

\begin{tabular}{|c|c|c|c|c|c|c|c|c|}
\hline \multirow{2}{*}{$\begin{array}{c}\text { Número } \\
\text { da } \\
\text { barra }\end{array}$} & \multicolumn{2}{|c|}{$21: 00$} & \multicolumn{2}{|c|}{$22: 00$} & \multicolumn{2}{|c|}{$23: 00$} & \multicolumn{2}{|c|}{$24: 00: 00$} \\
\hline & \begin{tabular}{|} 
Potência \\
ativa (MW)
\end{tabular} & $\begin{array}{c}\text { Potência } \\
\text { reativa (Mvar) }\end{array}$ & $\begin{array}{c}\text { Potência } \\
\text { ativa (MW) }\end{array}$ & $\begin{array}{c}\text { Potência } \\
\text { reativa (Mvar) }\end{array}$ & \begin{tabular}{|} 
Potência \\
ativa (MW)
\end{tabular} & $\begin{array}{c}\text { Potência } \\
\text { reativa (Mvar) }\end{array}$ & $\begin{array}{c}\text { Potência } \\
\text { ativa (MW) }\end{array}$ & $\begin{array}{c}\text { Potência } \\
\text { reativa (Mvar) }\end{array}$ \\
\hline 1 & 0,0000 & 0,0000 & 0,0000 & 0,0000 & 0,0000 & 0,0000 & 0,0000 & 0,0000 \\
\hline 2 & 0,0000 & 0,0000 & 0,0000 & 0,0000 & 0,0000 & 0,0000 & 0,0000 & 0,0000 \\
\hline 3 & 0,0000 & 0,0000 & 0,0000 & 0,0000 & 0,0000 & 0,0000 & 0,0000 & 0,0000 \\
\hline 4 & 0,0000 & 0,0000 & 0,0000 & 0,0000 & 0,0000 & 0,0000 & 0,0000 & 0,0000 \\
\hline 5 & 0,0000 & 0,0000 & 0,0000 & 0,0000 & 0,0000 & 0,0000 & 0,0000 & 0,0000 \\
\hline 6 & 0,0000 & 0,0000 & 0,0000 & 0,0000 & 0,0000 & 0,0000 & 0,0000 & 0,0000 \\
\hline 7 & 0,0000 & 0,0000 & 0,0000 & 0,0000 & 0,0000 & 0,0000 & 0,0000 & 0,0000 \\
\hline 8 & 0,0000 & 0,0000 & 0,0000 & 0,0000 & 0,0000 & 0,0000 & 0,0000 & 0,0000 \\
\hline 9 & 0,8627 & 0,2844 & 0,7964 & 0,2625 & 0,7248 & 0,2390 & 0,7078 & 0,2333 \\
\hline 10 & 0,4076 & 0,1337 & 0,3962 & 0,1300 & 0,3932 & 0,1290 & 0,3890 & 0,1276 \\
\hline 11 & 0,0000 & 0,0000 & 0,0000 & 0,0000 & 0,0000 & 0,0000 & 0,0000 & 0,0000 \\
\hline 12 & 0,1558 & 0,0504 & 0,0949 & 0,0307 & 0,0728 & 0,0236 & 0,0611 & 0,0198 \\
\hline 13 & 0,1393 & 0,0464 & 0,1369 & 0,0456 & 0,1235 & 0,0412 & 0,1013 & 0,0338 \\
\hline 14 & 0,0893 & 0,0298 & 0,0859 & 0,0286 & 0,0761 & 0,0254 & 0,0661 & 0,0220 \\
\hline 15 & 0,2062 & 0,0687 & 0,1256 & 0,0419 & 0,0964 & 0,0321 & 0,0809 & 0,0270 \\
\hline 16 & 0,0000 & 0,0000 & 0,0000 & 0,0000 & 0,0000 & 0,0000 & 0,0000 & 0,0000 \\
\hline 17 & 0,0000 & 0,0000 & 0,0000 & 0,0000 & 0,0000 & 0,0000 & 0,0000 & 0,0000 \\
\hline 18 & 0,1656 & 0,0573 & 0,1610 & 0,0557 & 0,1597 & 0,0553 & 0,1580 & 0,0547 \\
\hline 19 & 2,0003 & 0,6541 & 1,8466 & 0,6038 & 1,6807 & 0,5496 & 1,6411 & 0,5367 \\
\hline 20 & 0,5242 & 0,1725 & 0,5152 & 0,1696 & 0,4646 & 0,1529 & 0,3812 & 0,1255 \\
\hline 21 & 0,0893 & 0,0298 & 0,0859 & 0,0286 & 0,0761 & 0,0254 & 0,0661 & 0,0220 \\
\hline 22 & 0,6834 & 0,2256 & 0,6717 & 0,2217 & 0,6057 & 0,2000 & 0,4970 & 0,1641 \\
\hline 23 & 2,1926 & 0,7243 & 2,1084 & 0,6964 & 1,8698 & 0,6176 & 1,6235 & 0,5363 \\
\hline 24 & 0,0000 & 0,0000 & 0,0000 & 0,0000 & 0,0000 & 0,0000 & 0,0000 & 0,0000 \\
\hline 25 & 0,0000 & 0,0000 & 0,0000 & 0,0000 & 0,0000 & 0,0000 & 0,0000 & 0,0000 \\
\hline 26 & 0,0133 & 0,0066 & 0,0130 & 0,0065 & 0,0118 & 0,0059 & 0,0097 & 0,0048 \\
\hline 27 & 1,5927 & 0,5214 & 1,4702 & 0,4813 & 1,3382 & 0,4381 & 1,3066 & 0,4278 \\
\hline 28 & 1,0125 & 0,3311 & 0,9843 & 0,3219 & 0,9769 & 0,3195 & 0,9665 & 0,3161 \\
\hline 29 & 1,1361 & 0,3711 & 0,6922 & 0,2261 & 0,5312 & 0,1735 & 0,4457 & 0,1456 \\
\hline 30 & 0,0199 & 0,0066 & 0,0196 & 0,0065 & 0,0176 & 0,0059 & 0,0145 & 0,0048 \\
\hline 31 & 0,1290 & 0,0397 & 0,1240 & 0,0382 & 0,1100 & 0,0338 & 0,0955 & 0,0294 \\
\hline 32 & 0,4114 & 0,1327 & 0,4043 & 0,1304 & 0,3646 & 0,1176 & 0,2992 & 0,0965 \\
\hline 33 & 0,0000 & 0,0000 & 0,0000 & 0,0000 & 0,0000 & 0,0000 & 0,0000 & 0,0000 \\
\hline 34 & 0,8136 & 0,2679 & 0,7823 & 0,2576 & 0,6938 & 0,2284 & 0,6024 & 0,1983 \\
\hline 35 & 0,2190 & 0,0730 & 0,2152 & 0,0717 & 0,1941 & 0,0647 & 0,1592 & 0,0531 \\
\hline 36 & 0,0000 & 0,0000 & 0,0000 & 0,0000 & 0,0000 & 0,0000 & 0,0000 & 0,0000 \\
\hline 37 & 1,9744 & 0,6449 & 1,8985 & 0,6201 & 1,6837 & 0,5499 & 1,4619 & 0,4775 \\
\hline 38 & 0,0000 & 0,0000 & 0,0000 & 0,0000 & 0,0000 & 0,0000 & 0,0000 & 0,0000 \\
\hline 39 & 0,0000 & 0,0000 & 0,0000 & 0,0000 & 0,0000 & 0,0000 & 0,0000 & 0,0000 \\
\hline 40 & 0,0000 & 0,0000 & 0,0000 & 0,0000 & 0,0000 & 0,0000 & 0,0000 & 0,0000 \\
\hline 41 & 0,0000 & 0,0000 & 0,0000 & 0,0000 & 0,0000 & 0,0000 & 0,0000 & 0,0000 \\
\hline 42 & 0,0000 & 0,0000 & 0,0000 & 0,0000 & 0,0000 & 0,0000 & 0,0000 & 0,0000 \\
\hline
\end{tabular}


Tabela B.7 - Dados dos ramos do sistema de 42 barras.

\begin{tabular}{|c|c|c|c|c|}
\hline \multirow{2}{*}{$\begin{array}{c}\text { Número } \\
\text { do ramo }\end{array}$} & \multicolumn{2}{|c|}{ Ramo } & $\begin{array}{c}\text { Resist. } \\
\text { (ohms) }\end{array}$ & $\begin{array}{c}\text { Reatân. } \\
\text { (ohms) }\end{array}$ \\
\hline 1 & 1 & 4 & 0,0000 & 14,8000 \\
\hline 2 & 1 & 5 & 0,0000 & 14,8000 \\
\hline 3 & 2 & 6 & 0,0000 & 5,7500 \\
\hline 4 & 3 & 7 & 0,0000 & 5,7500 \\
\hline 5 & 4 & 26 & 15,7380 & 28,5480 \\
\hline 6 & 4 & 30 & 16,2540 & 29,4840 \\
\hline 7 & 5 & 8 & 21,4140 & 32,4030 \\
\hline 8 & 5 & 9 & 80,4050 & 102,8300 \\
\hline 9 & 6 & 9 & 22,1690 & 32,7260 \\
\hline 10 & 6 & 10 & 25,6390 & 33,3970 \\
\hline 11 & 6 & 11 & 59,2420 & 88,8500 \\
\hline 12 & 6 & 14 & 39,3050 & 67,3830 \\
\hline 13 & 7 & 17 & 5,0640 & 6,0960 \\
\hline 14 & 7 & 19 & 37,7110 & 52,8000 \\
\hline 15 & 7 & 31 & 16,4580 & 42,0550 \\
\hline 16 & 7 & 32 & 62,1330 & 76,3540 \\
\hline 17 & 8 & 13 & 8,9680 & 15,3740 \\
\hline 18 & 8 & 40 & 21,4144 & 32,4028 \\
\hline 19 & 10 & 15 & 11,6050 & 13,9700 \\
\hline 20 & 10 & 22 & 27,4560 & 20,0080 \\
\hline 21 & 10 & 39 & 26,4020 & 34,7050 \\
\hline 22 & 11 & 12 & 0,0000 & 7,5000 \\
\hline 23 & 12 & 16 & 36,9430 & 55,5770 \\
\hline 24 & 13 & 20 & 16,6000 & 28,4580 \\
\hline 25 & 14 & 20 & 32,8180 & 56,2610 \\
\hline 26 & 15 & 21 & 31,5740 & 23,0090 \\
\hline 27 & 16 & 23 & 39,3050 & 67,3830 \\
\hline 28 & 17 & 18 & 0,0000 & 7,5000 \\
\hline 29 & 18 & 24 & 43,4570 & 60,4960 \\
\hline 30 & 19 & 25 & 6,8690 & 11,7760 \\
\hline 31 & 23 & 27 & 33,3900 & 57,2430 \\
\hline 32 & 24 & 28 & 6,8690 & 11,7760 \\
\hline 33 & 25 & 29 & 23,8500 & 40,8880 \\
\hline 34 & 25 & 41 & 68,4296 & 105,4627 \\
\hline 35 & 26 & 31 & 27,6860 & 49,8800 \\
\hline 36 & 28 & 33 & 8,7770 & 15,0470 \\
\hline 37 & 28 & 34 & 57,2400 & 98,1300 \\
\hline 38 & 29 & 35 & 68,8790 & 118,0830 \\
\hline 39 & 29 & 42 & 44,5796 & 64,5752 \\
\hline 40 & 30 & 36 & 24,4450 & 43,8860 \\
\hline 41 & 32 & 36 & 9,9430 & 17,2000 \\
\hline 43 & 33 & 37 & 35,4890 & 60,8410 \\
\hline & & 38 & 40,6992 & 73,3704 \\
\hline
\end{tabular}

